\title{
MÉTODO DE AMOSTRAGEM DO NÚMERO DE FRUTOS POR ÁRVORE EM CITROS
}

\author{
BEATRIZ MONTRÁGIO COSTA BALDIN MALOSSO \\ Engenheira Agrônoma
}

Orientador: Prof. Dr. ROBERTO SIMIONATO MORAES

Dissertação apresentada à Escola Superior de Agricultura "Luiz de Queiroz", Universidade de São Paulo, para obtenção do título de Mestre em Agronomia. Área de Concentração: Estatística e Experimentação Agronômica.

P I R A C I C A B A

Estado de São Paulo - Brasil

Maio - 1998 
WHINA

\begin{tabular}{|c|c|c|c|}
\hline Pág. & Linha & Onde se lê & Leia-se \\
\hline xxvii & 15 & circunferência & circunferência do galho \\
\hline xxviii & 15 & propõe-se & propôs-se \\
\hline xxviii & 19 & a área & à área \\
\hline 1 & 16 & danificar a árvore & danificar a produção da árvore \\
\hline 3 & 15 & entidade & entidades \\
\hline 5 & 04 & $\begin{array}{l}\text { deve ser baseada em estimativas } \\
\text { baseadas na contagem de frutos, } \\
\text { evitando-se observações baseadas }\end{array}$ & 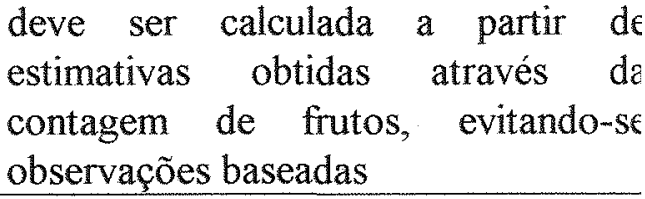 \\
\hline 5 & 15 & $\begin{array}{l}\text { persistem deficiências estruturais } \\
\text { que contribuem }\end{array}$ & $\begin{array}{l}\text { persistem práticas culturais, que visar } \\
\text { aumentar a vida de árvores doentes. } \\
\text { que contribuem }\end{array}$ \\
\hline 6 & 02 & tem & têm \\
\hline 6 & 15 & Realizou-se & Realizaram-se \\
\hline 6 & 14 & novembro & novembro do ano seguinte \\
\hline 6 & 21 & líquido & líquido das folhas \\
\hline 12 & 03 & outubro, utilizando & $\begin{array}{l}\text { outubro, para a laranjeira "Valência": } \\
\text { utilizando }\end{array}$ \\
\hline 15 & 09 & Coorg mandarim & tangerina 'Coorg' \\
\hline 17 & 14 & foi proposto & propõe-se \\
\hline 17 & 15 e 17 & Kinnow mandarim & tangerina 'Kinnow' \\
\hline 18 & 15 & das circunferências & $\begin{array}{l}\text { das circunferências dos troncos das } \\
\text { árvores amostradas; }\end{array}$ \\
\hline 18 & 16 & computaçà̃o & cálculo \\
\hline 18 & 20 & $\begin{array}{l}\text { computação do trabalho para } \\
\text { cálculos da copa. }\end{array}$ & cálculos para copa. \\
\hline 18 & 22 & $\begin{array}{l}\text { custos envolvidos para cada } \\
\text { esquema de amostragem (Tabela } \\
\text { 01). }\end{array}$ & $\begin{array}{l}\text { custos }\left(\mathrm{C}_{1}, \mathrm{C}_{2}, \ldots, \mathrm{C}_{6}\right) \text { descrito: } \\
\text { acima, envolvidos para os esquema: } \\
\text { de amostragem que levam en } \\
\text { consideração a probabilidad } \\
\text { equivalente ou aleatória (P.E.) dı } \\
\text { seleção e a probabilidade proporciona } \\
\text { à área da seção do corte transversa } \\
\text { (P.P.A.) (Tabela 01). }\end{array}$ \\
\hline 19 & $\begin{array}{l}\text { linha } 3 \text { da } \\
\text { Tabela } 01\end{array}$ & circunferência`2 & tronco \\
\hline 19 & 09 & proporcional a área & $\begin{array}{l}\text { proporcional à área da seção do cortı } \\
\text { transversal }\end{array}$ \\
\hline 19 & 12 & No começo da estação & No início da colheita \\
\hline 19 & 16 & apartir & partir \\
\hline 20 & 03 & Frutos que caem das & $\begin{array}{l}\text { Frutos que caem, durante o períodr } \\
\text { da estimativa da safra até a colheita } \\
\text { das }\end{array}$ \\
\hline 21 & 07 & utensilio & método \\
\hline 21 & 23 & apartir & a partir \\
\hline 22 & $\begin{array}{l}\text { Título da } \\
\text { Tabela } 02\end{array}$ & Arvores levantadas. & Árvores amostradas. \\
\hline
\end{tabular}




\section{ERRATA (continuação)}

\begin{tabular}{|c|c|c|c|}
\hline Pág. & Linha & Onde se lêt & Leia-se \\
\hline 22 & $\begin{array}{l}\text { linha } 2 \mathrm{da} \\
\text { Tabela } 02\end{array}$ & $N^{0}$ de frutos & $N^{\circ}$ real de frutos da árvore \\
\hline 23 & 23 & de cada galho & de todos os galhos \\
\hline 41 & $02,08,09$ e 26 & bifurcação & ramificação \\
\hline 41 & 21,22 e 23 & $1 / 3 \times 1 / 2 \times 1 / 2 \times 1 / 2=1 / 6$ & $1 / 3 \times 1 / 2=1 / 6$ \\
\hline 42 & 05 & Calcula-se & Calculam-se \\
\hline 42 & $\begin{array}{l}\text { Nos demostrati- } \\
\text { vos de cálculos }\end{array}$ & circunferência^2 & circunferência ${ }^{2}$ \\
\hline 42 & 10 & obtidas & calculadas \\
\hline 44 & Tabela 04 & $N^{\circ}$ de frutos & $N^{\circ}$ frutos dos galhos periféricos \\
\hline 45 & 04 & afim & a fim \\
\hline 45 & 06 & realizado & realizada \\
\hline 45 & 09 & estabeleceu-se & estabeleceram-se \\
\hline 47 & Última linha & $\begin{array}{l}\left({ }^{*}\right) \text { menor tamanho-limite } \\
\text { encontrado nas árvores, ou seja, } \\
\text { identifica a árvore toda }\end{array}$ & 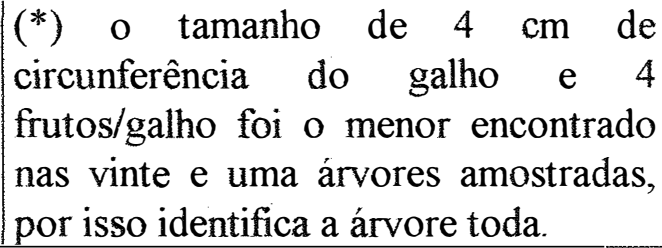 \\
\hline 50 & $\begin{array}{l}\text { Parágrafo após } \\
\text { a Tabela } 109\end{array}$ & $\begin{array}{l}\text { Essas variâncias e coeficientes de } \\
\text { variação }\end{array}$ & Esses coeficientes de variação \\
\hline 62 & 07 & Y calculado & \begin{tabular}{|llll} 
Y calculado pela equação & de \\
regressão linear
\end{tabular} \\
\hline 66 & 19 & contar-se & contarem-se \\
\hline 66 & 25 & conta-se & contam-se \\
\hline 67 & 01 & bifurcação & ramificação \\
\hline 70 & 05 & $\begin{array}{l}\text { A Tabela } 125 \text { apresenta os } \\
\text { valores estimados pelo modelo } \\
\text { para as três idades }\end{array}$ & $\begin{array}{l}\text { A Tabela } 125 \text { apresenta os valores } \\
\text { estimados pelo modelo } \\
y=-10,0291+0,0862 x_{1}+0,8003 x_{2}+6,0358 x_{3} \\
\text { para as três idades. }\end{array}$ \\
\hline 71 & 05 & probabilidade proporcional a área & PPA \\
\hline 71 & 12 & linear com & linear múltiplo com \\
\hline 72 & 10 & desoja & de soja \\
\hline
\end{tabular}

Pág. 43 - Fóruma 09

Onde se lê:

$$
\mathrm{V}(\hat{\mathrm{X}})=\sum_{\mathrm{i}=1}^{\mathrm{N}} \mathrm{P}_{\mathrm{i}}\left(\hat{\mathrm{X}}_{\mathrm{i}}-\mathrm{X}\right)^{2}
$$

Leia-se:

$$
\hat{\mathrm{V}}(\hat{\mathrm{X}})=\sum_{\mathrm{i}=1}^{\mathrm{N}} \mathrm{P}_{\mathrm{i}}\left(\hat{\mathrm{X}}_{\mathrm{i}}-\mathrm{X}\right)^{2}
$$


Dados Internacionais de Catalogação na Publicação (CIP) DIVISÃO DE BIBLIOTECA E DOCUMENTAÇĀO - Campus "Luiz de Queiroz"/USP

Malosso, Beatriz Montrágio Costa Baldin

Método de amostragem do número de frutos por árvore em citros / Beatriz

Montrágio Costa Baldin Malosso, 1998.

$180 \mathrm{p}$.

Dissertação (mestrado) - Escola Superior de Agricultura Luiz de Queiroz, 1998.

Bibliografia.

1. Amostragem 2. Análise de regressão 3. Citricultura 4. Fruto 5. Safra 1. Título

CDD 634.3 
iii.

A Deus, por me permitir chegar até aqui

\author{
Aos meus pais \\ Rubens e Raquel
}

A minha irmã e cunhado

Fernanda e José Geraldo

Ao meu marido Geraldo Ao meu filho Flávio Henrique 


\section{AGRADECIMENTOS}

Ao Prof. Dr. Roberto Simionato Moraes, pelo apoio e estímulo.

Ao corpo docente do Departamento de Matemática e Estatística - ESALQ/USP, pelos ensinamentos recebidos.

Ao Conselho Nacional de Desenvolvimento e Pesquisa $\mathrm{CNPq}$, pela bolsa de estudos.

A Sucocitrico CUTRALE S/A, pelos dados fornecidos a pesquisa, que possibilitaram a realização deste trabalho.

Aos amigos Luciane, Rosa, Solange, Rosni e Expedita, funcionários do Departamento de Matemática e Estatística, pelos serviços prestados e pelo convivio.

A Solange de Assis Paes Sabadin, pelo carinho e amizade recebidos.

Aos colegas do Curso de Pós-graduação, pelo companheirismo e amizade.

Aos amigos da Justiça Federal de $1^{\text {a }}$ Instância (Piracicaba/SP) pelo apoio, ajuda e incentivo ao término deste trabalho.

A Wolmar de Moura Appel, pelas sugestões recebidas.

A todos que, direta ou indiretamente, colaboraram para a realização deste trabalho. 


\section{SUMÁRIO}

Página

LISTA DE FIGURAS.

vi

LISTA DE TABELAS

xvii

RESUMO.

xxvii

SUMMARY

$\mathrm{XxX}$

1. INTRODUÇÃO ........................................................... 1

2. REVISÃO DE LITERATURA....................................... 3

2.1. Importância da previsão para citricultura............................. 3

2.1.1. No Estado de São Paulo................................................. 4

2.2. Previsão de safras citrícolas................................................ 5

2.3. Parâmetros básicos para previsão........................................ 8

2.3.1. Fator clima .......................................................... 9

2.3.2. Número de árvores produtivas.................................... 16

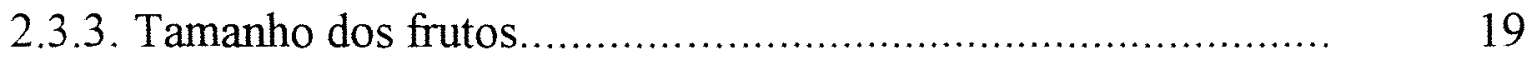

2.3.4. Queda............................................................... 20

2.3.5. Número de frutos por árvore .......................................... 20

3. MATERIAL E MÉTODOS ............................................ 22

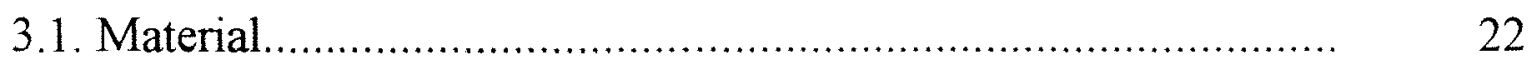

3.2. Métodos..................................................................... 40

4. RESULTADOS E DISCUSSÃO ........................................ 46

REFERÊNCIAS BIBLIOGRÁFICAS................................. 72

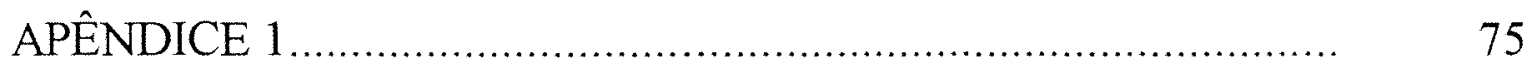

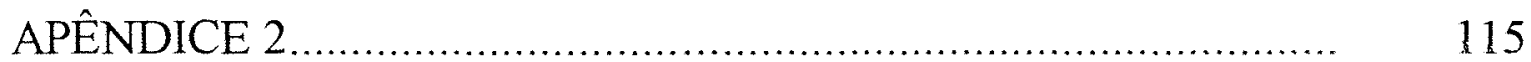




\section{LISTA DE FIGURAS}

Página

01 Árvore 01

24

02 Árvore 02

24

03 Árvore 03

25

04 Árvore 04

25

05 Árvore 05

26

06 Árvore 06

27

07 Árvore 07

28

08 Árvore 08

28

09 Árvore 09

29

10 Árvore 10

29

11 Árvore 11

30

12 Árvore 12

31

13 Árvore 13

32

14 Árvore 14

33

15 Árvore 15

33

16 Árvore 16

34

17 Árvore 17

35

18 Árvore 18

36

19 Árvore 19

37

20 Árvore 20

38

21 Árvore 21

39

22 Medida da circunferência e número de frutos dos principais 40 galhos da árvore 01 
23 Mínimo de $7 \mathrm{~cm}$ de circunferência e 10 frutos por galho, árvore 01

24 Mínimo de $10 \mathrm{~cm}$ de circunferência e 10 frutos por galho, árvore 01

25 Mínimo de $10 \mathrm{~cm}$ de circunferência e 20 frutos por galho, árvore 01 .

26 Mínimo de $15 \mathrm{~cm}$ de circunferência e 30 frutos por galho, árvore 01 .

27 Mínimo de $7 \mathrm{~cm}$ de circunferência e 10 frutos por galho, árvore 02

28 Mínimo de $10 \mathrm{~cm}$ de circunferência e 10 frutos por galho, árvore 02

29 Mínimo de $7 \mathrm{~cm}$ de circunferência e 10 frutos por galho, árvore 03

30 Mínimo de $10 \mathrm{~cm}$ de circunferência e 10 frutos por galho, árvore 03

31 Mínimo de $10 \mathrm{~cm}$ de circunferência e 20 frutos por galho, árvore 03

32 Mínimo de $7 \mathrm{~cm}$ de circunferência e 10 frutos por galho, árvore 04

33 Mínimo de $10 \mathrm{~cm}$ de circunferência e 20 frutos por galho, árvore 04 .

34 Mínimo de $15 \mathrm{~cm}$ de circunferência e 30 frutos por galho, árvore 04 
35 Mínimo de $20 \mathrm{~cm}$ de circunferência e 40 frutos por galho, árvore 04 .

36 Mínimo de $7 \mathrm{~cm}$ de circunferência e 10 frutos por galho, árvore 05 .

37 Mínimo de $10 \mathrm{~cm}$ de circunferência e 20 frutos por galho, árvore 05 .

38 Mínimo de $15 \mathrm{~cm}$ de circunferência e 30 frutos por galho, árvore 05 .

39 Mínimo de $20 \mathrm{~cm}$ de circunferência e 40 frutos por galho, árvore 05 .

40 Mínimo de $7 \mathrm{~cm}$ de circunferência e 10 frutos por galho,

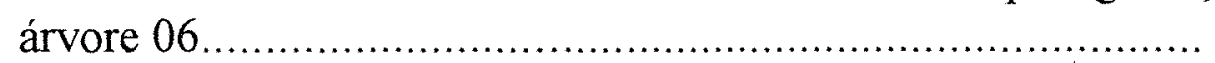

41 Mínimo de $10 \mathrm{~cm}$ de circunferência e 20 frutos por galho, árvore 06 .

42 Mínimo de $15 \mathrm{~cm}$ de circunferência e 30 frutos por galho, árvore 06 .

43 Mínimo de $20 \mathrm{~cm}$ de circunferência e 40 frutos por galho,

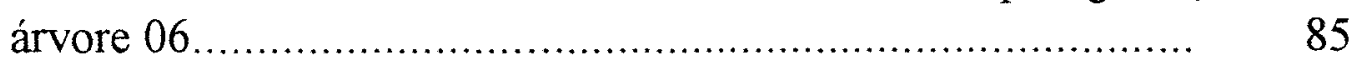

44 Mínimo de $7 \mathrm{~cm}$ de circunferência e 10 frutos por galho, árvore 07.

45 Mínimo de $10 \mathrm{~cm}$ de circunferência e 20 frutos por galho, árvore 07 
46 Mínimo de $15 \mathrm{~cm}$ de circunferência e 30 frutos por galho,

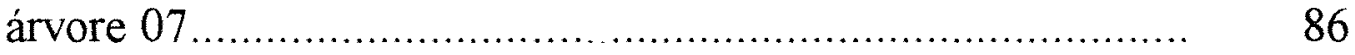

47 Mínimo de $20 \mathrm{~cm}$ de circunferência e 40 frutos por galho, árvore 07

48 Mínimo de $7 \mathrm{~cm}$ de circunferência e 10 frutos por galho, árvore 08

49 Mínimo de $10 \mathrm{~cm}$ de circunferência e 20 frutos por galho, árvore 08

50 Mínimo de $7 \mathrm{~cm}$ de circunferência e 10 frutos por galho, árvore 09

51 Mínimo de $10 \mathrm{~cm}$ de circunferência e 20 frutos por galho, árvore 09

52 Mínimo de $15 \mathrm{~cm}$ de circunferência e 30 frutos por galho, árvore 09

53 Mínimo de $7 \mathrm{~cm}$ de circunferência e 10 frutos por galho, árvore 10

54 Mínimo de $10 \mathrm{~cm}$ de circunferência e 20 frutos por galho, árvore 10

89

55 Mínimo de $15 \mathrm{~cm}$ de circunferência e 30 frutos por galho, árvore 10

56 Mínimo de $20 \mathrm{~cm}$ de circunferência e 40 frutos por galho, árvore 10 
57 Mínimo de $7 \mathrm{~cm}$ de circunferência e 10 frutos por galho, árvore 11

58 Mínimo de $10 \mathrm{~cm}$ de circunferência e 20 frutos por galho, árvore 11 .

59 Minimo de $15 \mathrm{~cm}$ de circunferência e 30 frutos por galho, árvore 11

60 Mínimo de $20 \mathrm{~cm}$ de circunferência e 40 frutos por galho, árvore 11

61 Mínimo de $25 \mathrm{~cm}$ de circunferência e 50 frutos por galho, árvore 11

62 Mínimo de $7 \mathrm{~cm}$ de circunferência e 10 frutos por galho, árvore 12

93

63 Mínimo de $10 \mathrm{~cm}$ de circunferência e 20 frutos por galho, árvore 12 .

64 Mínimo de $15 \mathrm{~cm}$ de circunferência e 30 frutos por galho, árvore 12

65 Mínimo de $20 \mathrm{~cm}$ de circunferência e 40 frutos por galho,

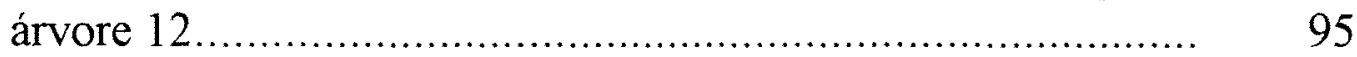

66 Mínimo de $25 \mathrm{~cm}$ de circunferência e 50 frutos por galho, árvore 12

67 Mínimo de $7 \mathrm{~cm}$ de circunferência e 10 frutos por galho, árvore 13 . 
68 Mínimo de $10 \mathrm{~cm}$ de circunferência e 20 frutos por galho, árvore 13.

69 Mínimo de $15 \mathrm{~cm}$ de circunferência e 30 frutos por galho, árvore 13

70 Minimo de $20 \mathrm{~cm}$ de circunferência e 40 frutos por galho,

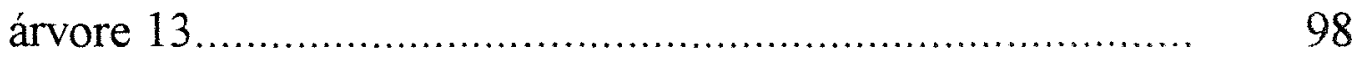

71 Mínimo de $7 \mathrm{~cm}$ de circunferência e 10 frutos por galho, árvore 14 .

72 Mínimo de $10 \mathrm{~cm}$ de circunferência e 10 frutos por galho, árvore 14

73 Mínimo de $10 \mathrm{~cm}$ de circunferência e 20 frutos por galho, árvore 14

74 Mínimo de $15 \mathrm{~cm}$ de circunferência e 30 frutos por galho, árvore 14 .

75 Mínimo de $7 \mathrm{~cm}$ de circunferência e 10 frutos por galho, árvore 15

76 Mínimo de $10 \mathrm{~cm}$ de circunferência e 10 frutos por galho, árvore 15

77 Mínimo de $7 \mathrm{~cm}$ de circunferência e 10 frutos por galho, árvore 16 .

78 Mínimo de $10 \mathrm{~cm}$ de circunferência e 10 frutos por galho, árvore 16 
79 Mínimo de $10 \mathrm{~cm}$ de circunferência e 20 frutos por galho, árvore 16 .

80 Mínimo de $15 \mathrm{~cm}$ de circunferência e 30 frutos por galho, árvore 16 .

81 Mínimo de $20 \mathrm{~cm}$ de circunferência e 40 frutos por galho, árvore 16 .

82 Mínimo de $7 \mathrm{~cm}$ de circunferência e 10 frutos por galho, árvore 17 .

83 Mínimo de $10 \mathrm{~cm}$ de circunferência e 20 frutos por galho, árvore 17

84 Mínimo de $15 \mathrm{~cm}$ de circunferência e 30 frutos por galho,

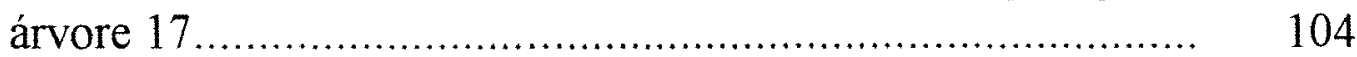

85 Mínimo de $20 \mathrm{~cm}$ de circunferência e 40 frutos por galho, árvore 17

86 Mínimo de $7 \mathrm{~cm}$ de circunferência e 10 frutos por galho, árvore 18

87 Mínimo de $10 \mathrm{~cm}$ de circunferência e 20 frutos por galho,

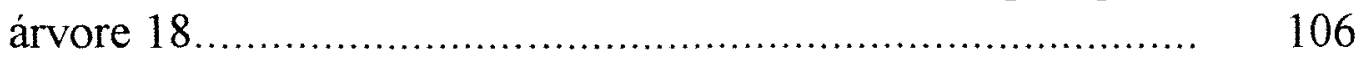

88 Mínimo de $15 \mathrm{~cm}$ de circunferência e 30 frutos por galho, árvore 18

89 Mínimo de $20 \mathrm{~cm}$ de circunferência e 40 frutos por galho, árvore 18 


\section{Página}

90 Mínimo de $7 \mathrm{~cm}$ de circunferência e 10 frutos por galho, árvore 19

91 Mínimo de $10 \mathrm{~cm}$ de circunferência e 20 frutos por galho, árvore 19

92 Mínimo de $15 \mathrm{~cm}$ de circunferência e 30 frutos por galho, árvore 19

93 Mínimo de $20 \mathrm{~cm}$ de circunferência e 40 frutos por galho, árvore 19

94 Mínimo de $25 \mathrm{~cm}$ de circunferência e 50 frutos por galho, árvore 19

95 Mínimo de $7 \mathrm{~cm}$ de circunferência e 10 frutos por galho, árvore 20

96 Mínimo de $10 \mathrm{~cm}$ de circunferência e 20 frutos por galho, árvore 20 .

97 Mínimo de $15 \mathrm{~cm}$ de circunferência e 30 frutos por galho, árvore 20

98 Mínimo de $20 \mathrm{~cm}$ de circunferência e 40 frutos por galho, árvore 20.

99 Mínimo de $25 \mathrm{~cm}$ de circunferência e 50 frutos por galho, árvore 20 .

100 Mínimo de $7 \mathrm{~cm}$ de circunferência e 10 frutos por galho, árvore 21

101 Mínimo de $10 \mathrm{~cm}$ de circunferência e 20 frutos por galho, árvore 21 
Página

102 Mínimo de $15 \mathrm{~cm}$ de circunferência e 30 frutos por galho, árvore 21

103 Mínimo de $20 \mathrm{~cm}$ de circunferência e 40 frutos por galho, árvore 21

104 Coeficiente de variação dos três métodos de seleção de galhos, em função do tamanho-limite, para a árvore 01 .........

105 Coeficiente de variação dos três métodos de seleção de galhos, em função do tamanho-limite, para a árvore $02 . . . \ldots . . .$.

106 Coeficiente de variação dos três métodos de seleção de galhos, em função do tamanho-limite, para a árvore $03 . . . . . . .$.

107 Coeficiente de variação dos três métodos de seleção de galhos, em função do tamanho-limite, para a árvore $04 . . . . . . . .$.

108 Coeficiente de variação dos três métodos de seleção de galhos, em função do tamanho-limite, para a árvore 05 .

109 Coeficiente de variação dos três métodos de seleção de galhos, em função do tamanho-limite, para a árvore 06

110 Coeficiente de variação dos três métodos de seleção de galhos, em função do tamanho-limite, para a árvore 07

111 Coeficiente de variação dos três métodos de seleção de galhos, em função do tamanho-limite, para a árvore 08 .

112 Coeficiente de variação dos três métodos de seleção de galhos, em função do tamanho-limite, para a árvore 09 .

113 Coeficiente de variação dos três métodos de seleção de galhos, em função do tamanho-limite, para a árvore 10 
114 Coeficiente de variação dos três métodos de seleção de galhos, em função do tamanho-limite, para a árvore 11 .

115 Coeficiente de variação dos três métodos de seleção de galhos, em função do tamanho-limite, para a árvore $12 \ldots \ldots \ldots . .$.

116 Coeficiente de variação dos três métodos de seleção de galhos, em função do tamanho-limite, para a árvore $13 . . . . . . .$.

117 Coeficiente de variação dos três métodos de seleção de galhos, em função do tamanho-limite, para a árvore 14

118 Coeficiente de variação dos três métodos de seleção de galhos, em função do tamanho-limite, para a árvore $15 . . . . . .$.

119 Coeficiente de variação dos três métodos de seleção de galhos, em função do tamanho-limite, para a árvore $16 . . . . . . .$.

120 Coeficiente de variação dos três métodos de seleção de galhos, em função do tamanho-limite, para a árvore 17.

121 Coeficiente de variação dos três métodos de seleção de galhos, em função do tamanho-limite, para a árvore $18 \ldots \ldots \ldots$.

122 Coeficiente de variação dos três métodos de seleção de galhos, em função do tamanho-limite, para a árvore $19 . \ldots \ldots \ldots$.

123 Coeficiente de variação dos três métodos de seleção de galhos, em função do tamanho-limite, para a árvore 20

124 Coeficiente de variação dos três métodos de seleção de galhos, em função do tamanho-limite, para a árvore 21 
xvi.

LISTA DE TABELAS

Página

01 Custos envolvidos nos esquemas de amostragem.............. 19

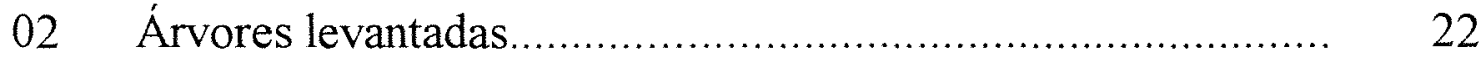

03 Medida das circunferências e cálculo das probabilidades proporcionais à área, para todos os galhos, árvore $01 \ldots \ldots \ldots \ldots$.

04 Valores das estimativas do número de frutos, variância e coeficiente de variação (\%), para os três métodos de seleção de galhos, árvore 01

05 Árvore 01

06 Mínimo de $7 \mathrm{~cm}$ de circunferência e 10 frutos por galho, árvore 01

07 Mínimo de $10 \mathrm{~cm}$ de circunferência e 10 frutos por galho, árvore 01

08 Mínimo de $10 \mathrm{~cm}$ de circunferência e 20 frutos por galho, árvore 01

09 Mínimo de $15 \mathrm{~cm}$ de circunferência e 30 frutos por galho, árvore 01

10 Árvore 02

11 Mínimo de $7 \mathrm{~cm}$ de circunferência e 10 frutos por galho, árvore 02 .

12 Mínimo de $10 \mathrm{~cm}$ de circunferência e 10 frutos por galho, árvore 02 . 
13 Árvore 03

14 Mínimo de $7 \mathrm{~cm}$ de circunferuncia e 10 frutos por galho, árvore 03 .

15 Mínimo de $10 \mathrm{~cm}$ de circunferência e 10 frutos por galho, árvore 03

16 Mínimo de $10 \mathrm{~cm}$ de circunferência e 20 frutos por galho, árvore 03 .

17 Árvore 04

18 Mínimo de $7 \mathrm{~cm}$ de circunferência e 10 frutos por galho, árvore 04

19 Mínimo de $10 \mathrm{~cm}$ de circunferência e 20 frutos por galho, árvore 04 .

20 Mínimo de $15 \mathrm{~cm}$ de circunferência e 30 frutos por galho, árvore 04.

21 Mínimo de $20 \mathrm{~cm}$ de circunferência e 40 frutos por galho, árvore 04 .

22 Árvore 05.

23 Mínimo de $7 \mathrm{~cm}$ de circunferência e 10 frutos por galho, árvore 05 .

24 Mínimo de $10 \mathrm{~cm}$ de circunferência e 20 frutos por galho, árvore 05 .

25 Mínimo de $15 \mathrm{~cm}$ de circunferência e 30 frutos por galho, árvore 05 . 
26 Mínimo de $20 \mathrm{~cm}$ de circunferência e 40 frutos por galho, árvore 05 .

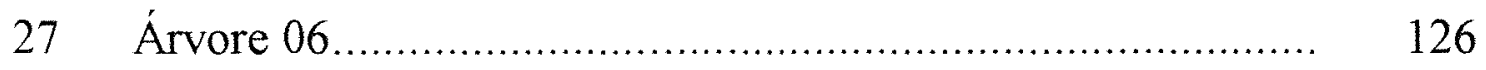

28 Mínimo de $7 \mathrm{~cm}$ de circunferência e 10 frutos por galho, árvore 06 .

29 Mínimo de $10 \mathrm{~cm}$ de circunferência e 20 frutos por galho, árvore 06 .

30 Mínimo de $15 \mathrm{~cm}$ de circunferência e 30 frutos por galho, árvore 06.

31 Mínimo de $20 \mathrm{~cm}$ de circunferência e 40 frutos por galho, árvore 06 .

32 Árvore 07

33 Mínimo de $7 \mathrm{~cm}$ de circunferência e 10 frutos por galho, árvore 07 .

34 Mínimo de $10 \mathrm{~cm}$ de circunferência e 20 frutos por galho, árvore 07 .

35 Mínimo de $15 \mathrm{~cm}$ de circunferência e 30 frutos por galho, árvore 07 .

36 Mínimo de $20 \mathrm{~cm}$ de circunferência e 40 frutos por galho, árvore 07 .

37 Árvore 08. 
38 Mínimo de $7 \mathrm{~cm}$ de circunferência e 10 frutos por galho, árvore 08

39 Mínimo de $10 \mathrm{~cm}$ de circunferência e 20 frutos por galho, árvore 08 .

40 Árvore 09

41 Mínimo de $7 \mathrm{~cm}$ de circunferência e 10 frutos por galho, árvore 09

42 Mínimo de $10 \mathrm{~cm}$ de circunferência e 20 frutos por galho, árvore 09

43 Mínimo de $15 \mathrm{~cm}$ de circunferência e 30 frutos por galho, árvore 09 .

44 Árvore 10

45 Mínimo de $7 \mathrm{~cm}$ de circunferência e 10 frutos por galho, árvore 10 .

46 Mínimo de $10 \mathrm{~cm}$ de circunferência e 20 frutos por galho, árvore 10

47 Mínimo de $15 \mathrm{~cm}$ de circunferência e 30 frutos por galho, árvore 10 .

48 Mínimo de $20 \mathrm{~cm}$ de circunferência e 40 frutos por galho, árvore 10 .

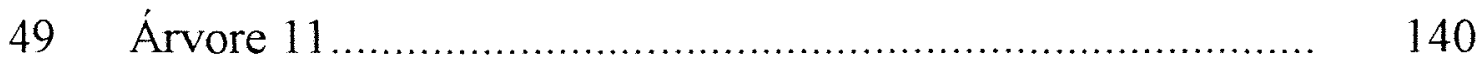

50 Mínimo de $7 \mathrm{~cm}$ de circunferência e 10 frutos por galho, árvore 11 
Página

51 Mínimo de $10 \mathrm{~cm}$ de circunferência e 20 frutos por galho, árvore 11

52 Mínimo de $15 \mathrm{~cm}$ de circunferência e 30 frutos por galho, árvore 11 .

53 Mínimo de $20 \mathrm{~cm}$ de circunferência e 40 frutos por galho, árvore 11

54 Mínimo de $25 \mathrm{~cm}$ de circunferência e 50 frutos por galho, árvore 11

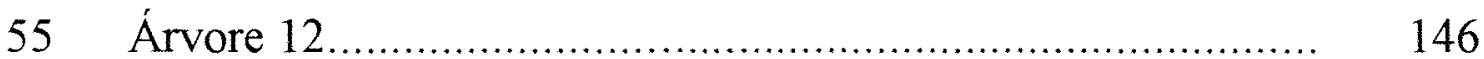

56 Mínimo de $7 \mathrm{~cm}$ de circunferência e 10 frutos por galho, árvore 12 .

57 Mínimo de $10 \mathrm{~cm}$ de circunferência e 20 frutos por galho, árvore 12

58 Mínimo de $15 \mathrm{~cm}$ de circunferência e 30 frutos por galho, árvore 12 .

59 Mínimo de $20 \mathrm{~cm}$ de circunferência e 40 frutos por galho, árvore 12

60 Mínimo de $25 \mathrm{~cm}$ de circunferência e 50 frutos por galho, árvore 12

61 Árvore 13

62 Mínimo de $7 \mathrm{~cm}$ de circunferência e 10 frutos por galho, árvore 13 
63 Mínimo de $10 \mathrm{~cm}$ de circunferência e 20 frutos por galho, árvore 13

64 Mínimo de $15 \mathrm{~cm}$ de circunferência e 30 frutos por galho, árvore 13

65 Mínimo de $20 \mathrm{~cm}$ de circunferência e 40 frutos por galho, árvore 13

66 Árvore 14

154

67 Mínimo de $7 \mathrm{~cm}$ de circunferência e 10 frutos por galho, árvore 14

68 Mínimo de $10 \mathrm{~cm}$ de circunferência e 10 frutos por galho, árvore 14

69 Mínimo de $10 \mathrm{~cm}$ de circunferência e 20 frutos por galho, árvore 14

70 Mínimo de $15 \mathrm{~cm}$ de circunferência e 30 frutos por galho, árvore 14

71 Árvore 15

72 Mínimo de $7 \mathrm{~cm}$ de circunferência e 10 frutos por galho, árvore 15

73 Mínimo de $10 \mathrm{~cm}$ de circunferência e 10 frutos por galho, árvore 15

74 Árvore 16

75 Mínimo de $7 \mathrm{~cm}$ de circunferência e 10 frutos por galho, árvore 16 
76 Mínimo de $10 \mathrm{~cm}$ de circunferência e 10 frutos por galho, árvore 16 .

77 Mínimo de $10 \mathrm{~cm}$ de circunferência e 20 frutos por galho,

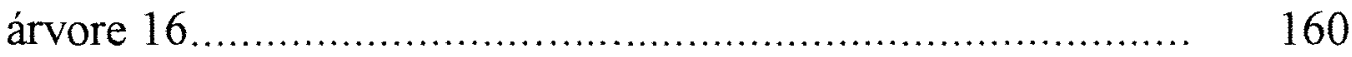

78 Mínimo de $15 \mathrm{~cm}$ de circunferência e 30 frutos por galho, árvore 16.

79 Mínimo de $20 \mathrm{~cm}$ de circunferência e 40 frutos por galho, árvore 16

160

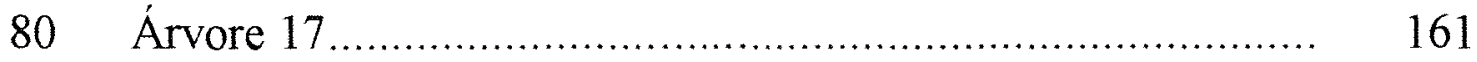

81 Mínimo de $7 \mathrm{~cm}$ de circunferência e 10 frutos por galho, árvore 17

82 Mínimo de $10 \mathrm{~cm}$ de circunferência e 20 frutos por galho, árvore 17

83 Mínimo de $15 \mathrm{~cm}$ de circunferência e 30 frutos por galho, árvore 17

84 Mínimo de $20 \mathrm{~cm}$ de circunferência e 40 frutos por galho, árvore 17

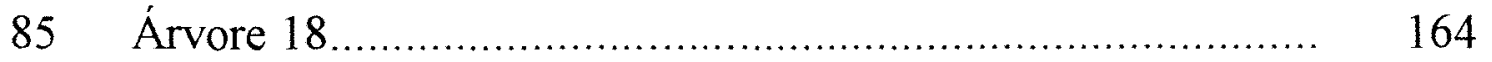

86 Mínimo de $7 \mathrm{~cm}$ de circunferência e 10 frutos por galho, árvore 18

87 Mínimo de $10 \mathrm{~cm}$ de circunferência e 20 frutos por galho, árvore 18 
xxiii.

Página

88 Mínimo de $15 \mathrm{~cm}$ de circunferência e 30 frutos por galho, árvore 18

89 Mínimo de $20 \mathrm{~cm}$ de circunferência e 40 frutos por galho, árvore 18

168

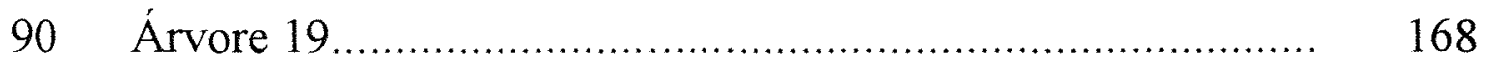

91 Mínimo de $7 \mathrm{~cm}$ de circunferência e 10 frutos por galho, árvore 19

92 Mínimo de $10 \mathrm{~cm}$ de circunferência e 20 frutos por galho, árvore 19

93 Mínimo de $15 \mathrm{~cm}$ de circunferência e 30 frutos por galho, árvore 19

94 Mínimo de $20 \mathrm{~cm}$ de circunferência e 40 frutos por galho, árvore 19

95 Mínimo de $25 \mathrm{~cm}$ de circunferência e 50 frutos por galho, árvore 19 .

172

96 Árvore 20

173

97 Mínimo de $7 \mathrm{~cm}$ de circunferência e 10 frutos por galho, árvore 20 .

98 Mínimo de $10 \mathrm{~cm}$ de circunferência e 20 frutos por galho, árvore 20 .

99 Mínimo de $15 \mathrm{~cm}$ de circunferência e 30 frutos por galho, árvore 20 . 
Página

100 Mínimo de $20 \mathrm{~cm}$ de circunferência e 40 frutos por galho, árvore 20

101 Mínimo de $25 \mathrm{~cm}$ de circunferência e 50 frutos por galho, árvore 20.

102 Árvore 21

103 Mínimo de $7 \mathrm{~cm}$ de circunferência e 10 frutos por galho, árvore 21

104 Mínimo de $10 \mathrm{~cm}$ de circunferência e 20 frutos por galho, árvore 21 .

105 Mínimo de $15 \mathrm{~cm}$ de circunferência e 30 frutos por galho, árvore 21

106 Mínimo de $20 \mathrm{~cm}$ de circunferência e 40 frutos por galho, árvore 21

107 Valores de variância e coeficiente de variação para as árvores da idade 1

108 Valores de variância e coeficiente de variação para as árvores da idade 2 .

109 Valores de variância e coeficiente de variação para as árvores da idade 3 .

110 Diferença obtida entre um tamanho-limite e o anterior para as árvores da idade 1

111 Diferença obtida entre um tamanho-limite e o anterior para as árvores da idade 2 
112 Diferença obtida entre um tamanho-limite e o anterior para as árvores da idade 3

113 Valores estimados dos coeficientes do modelo $\mathrm{y}=\mathrm{a}+\mathrm{bx}$ e do coeficiente de determinação $\mathrm{r}^{2}$, para as árvores da idade 1

114 Valores estimados dos coeficientes do modelo $\mathrm{y}=\mathrm{a}+\mathrm{bx}+\mathrm{cx}^{2}$ e do coeficiente de determinação $\mathrm{r}^{2}$, para as árvores da idade 1 .

115 Valores estimados dos coeficientes do modelo $\mathrm{y}=\mathrm{a}+\mathrm{bx}$ e do coeficiente de determinação $\mathrm{r}^{2}$, para as árvores da idade $2 . . . \ldots \ldots$.

116 Valores estimados dos coeficientes do modelo $\mathrm{y}=\mathrm{a}+\mathrm{bx}+\mathrm{cx}^{2}$ e do coeficiente de determinação $\mathrm{r}^{2}$, para as árvores da idade 2 .

117 Valores estimados dos coeficientes do modelo $\mathrm{y}=\mathrm{a}+\mathrm{bx}$ e do coeficiente de determinação $\mathrm{r}^{2}$, para as árvores da idade 3

118 Valores estimados dos coeficientes do modelo $\mathrm{y}=\mathrm{a}+\mathrm{bx}+\mathrm{cx}^{2}$ e do coeficiente de determinação $\mathrm{r}^{2}$, para as árvores da idade 3 .

119 Coeficiente de variação real e valor estimado pelo modelo linear, para as árvores da idade 1

120 Coeficiente de variação real e valor estimado pelo modelo linear, para as árvores da idade 2

121 Coeficiente de variação real e valor estimado pelo modelo linear, para as árvores da idade 3 .

122 Média do número real de frutos, valores estimados pelo método que utiliza a PPA e PPN e média da faixa etária das árvores 
xxvi.

Página

123 Análise de variância do modelo $\mathrm{y}=\mathrm{a}+\mathrm{bx}_{1}+\mathrm{cx}_{2}+\mathrm{dx}_{3} \ldots \ldots \ldots .69$

124 Testes e significância dos parâmetros estimados para o modelo. 69

125 Número real de frutos da árvore e o estimado pelo modelo.... 70 


\title{
MÉTODO DE AMOSTRAGEM DO NÚMERO DE FRUTOS POR ÁRVORE EM CITROS
}

\author{
Autora: Beatriz Montrágio Costa Baldin Malosso \\ Orientador: Prof. Dr. Roberto Simionato Moraes
}

\section{RESUMO}

A estimativa da safra citrícola é baseada em quatro fatores básicos: o censo das árvores, o número de frutos por árvore, o tamanho do fruto e a porcentagem de queda. O número de frutos por árvore, é um dos mais importantes para a determinação do tamanho da safra. Atualmente, essa determinação é feita através da derriça e contagem dos frutos, de árvores escolhidas por amostragem. Isso representa um custo, relativamente alto, devido a perda desses frutos e o tempo gasto nessa tarefa..

Estudou-se, então, uma nova metodologia que permite estimar, com eficiência, o número de frutos por árvore, sem derriçá-los. Foram levantados no campo, a circunferência e o número de frutos de todos os galhos, de vinte e uma árvores, das variedades Pera Rio, Natal e Valência, para as idades de 3 a 5 anos, chamada de categoria de idade 1 , de 6 a 10 anos, chamada categoria de idade 2, e acima de 10 anos, chamada de categoria de idade 3, de diversas regiões do Estado de São Paulo.

Três métodos de seleção de galhos foram estudados. $\mathrm{O}$ primeiro, baseado em probabilidades equivalentes (PE); o segundo, em 
xxviii.

probabilidades proporcionais ao número de galhos (PPN) e o terceiro, em probabilidades proporcionais à área (PPA) do corte transversal do galho. $\mathrm{O}$ número de frutos para cada árvore, foi estimado, dividindo-se o número de frutos contados no galho, pelo valor da probabilidade de seleção daquele galho. Obtiveram-se, também, valores da variância e coeficiente de variação, para os três métodos propostos.

Como o porte da maioria das árvores, com exceção as da categoria de idade 1, não permite a contagem de todos os seus galhos, estudou-se um ponto de parada, ou seja, um tamanho mínimo de galho que forneça a melhor estimativa, com maior eficiência. Obteve-se, então, uma tabela com os valores das estimativas do número de frutos da árvore, variância e coeficiente de variação, para todos os tamanhos-limites. Através do comportamento do coeficiente de variação, pôde-se determinar o melhor ponto de parada.

E, por fim, propõe-se uma combinação dos dois melhores métodos, através da análise de regressão múltipla, para verificar a provável melhora nas estimativas da produção da árvore.

Comparando-se os valores de variância, o método que utiliza a probabilidade proporcional a área, foi o que apresentou maior eficiência e as melhores estimativas; e o método que utiliza as probilidades equivalentes foi o que apresentou os piores resultados.

As maiores quedas nos coeficientes de variação foram obtidas no tamanho mínimo de $15 \mathrm{~cm}$ de circunferência do galho e 30 frutos por galho, para as categorias de idades 2 e 3 . No caso da categoria de idade 1 , 
xxix.

determinou-se que o melhor seria contar todos os frutos dos galhos, de uma de suas ramificações primárias.

A combinação dos métodos PPA e PPN, apresentou um bom ajuste através da regressão linear, com valor do coeficiente de determinação acima de 0,9000 . 


\title{
SAMPLING METHOD FOR THE NUMBER OF FRUITS PFR CITRUS TREE
}

\author{
Author: Beatriz Montrágio Costa Baldin Malosso \\ Adviser: Prof. Dr. Roberto Simionato Moraes
}

\section{SUMMARY}

The estimation of a citrus harvest is based on four basic factors: tree counting, the number of fruits per tree, fruit size and fall percentage. The number of fruits per tree is one of the major factors for determining harvest size. This determination is currently carried out by picking the fruits from trees chosen for sampling and counting them. Such task represents a relatively high cost due to fruit loss and to the time spent on it.

A new methodology was therefore studied which permits efficiently estimating the number of fruits per tree without picking them. The branch circumference and the number of fruits on all the branches of twenty one trees were gathered in the field. These trees were found in various regions of São Paulo State and belonged to the Pera Rio, Natal and Valência varieties. Those between 3 and 5 years of age were categorized as Age 
xxxi.

Category 1, those between 6 and 10 years of age were categorized as Age Category 2 and those above 10 years were categorized as Age Category 3.

Three branch selection methods were studied. The first was based on equivalent probabilities (PE); the second, on proportional probabilities to the number of branches (PPN) and the third, on proportional probabilities to the branch cross-section area (PPA). The square of the branch circumference was used as an area measurement. The number of fruits of each tree was estimated by dividing the number of fruits counted on the branch by the value of the selection probability of such branch. Variance values and the variance coefficient were also obtained for the three proposed methods.

As the size of most trees, except of those in Age Category 1, did not permit the counting of all their branches, a stop point was studied, that is to say, a minimum size of the branch that would supply the best estimation with the greatest efficiency. A table with the estimation values of the number of fruits on the tree, variance and variance coefficient for all limit sizes was then obtained. Through the behavior of the variance coefficient, it was possible to determine the best stop point.

Finally, a combination of the two best methods was proposed through the multiple regression analysis in order to verify the probable improvement in estimating the tree production.

By comparing the variance values, the method that utilizes the probability proportional to the area was the one which presented the greatest efficiency and the best estimations; and the method that utilizes the equivalent probabilities was the one which presented the worst results. 
xxxii.

The greatest drops in variance coefficients were obtained for the minimum size of $15 \mathrm{~cm}$ of branch circumference and 30 fruits per branch for Age Categories 2 and 3. In the case of Age Category 1, it was determined that it would be best to count all the fruits on the branches of the tree's main ramifications.

The combination of the PPA and PPN methods presented a good adjustment through linear regression with determination coefficient values above 0.9000 . 


\section{INTRODUÇÃO}

O conhecimento antecipado do tamanho da safra de citros é um fator extremamente importante para o país, pois é peça fundamental no planejamento comercial e industrial dos produtos citrícolas.

Para a estimativa da produção de citros, existem quatro fatores a serem considerados: o censo das árvores (número de árvores produtivas), número de frutos por árvore, tamanho dos frutos e porcentagem de queda.

A determinação do número de frutos por árvore é apenas um desses fatores, mas pode ser considerado um dos mais importantes. Atualmente, o número de frutos por árvore é obtido através da derriça e contagem dos frutos das árvores escolhidas por métodos de amostragem. Como a derriça é realizada antes do tempo correto para a colheita, esses frutos deixam de ter valor comercial.

Há uma perda economicamente significativa, o que justifica o empenho em se estudar um método de amostragem, que permita obter essa produtividade, sem danificar a árvore.

Uma metodologia, baseada em diferentes probabilidades de seleção de galhos, será estudada, visando verificar a eficiência, ou não, dos métodos propostos. Além disso, pretende-se determinar o tamanho mínimo do galho (circunferência, em centímetros, e número de frutos por galho), que 
viabilize a aplicação do método no campo e onde se obtenha a maior eficiência e a melhor estimativa da produção da árvore. Através de análise de regressão múltipla, pretende-se verificar também uma possivel melhora das estimativas, agrupando dois dos métodos que apresentarem melhores resultados. 


\section{REVISÃO DE LITERATURA}

\subsection{Importância da previsão para a citricultura}

O conhecimento antecipado do tamanho da safra, permite um planejamento estratégico de vendas internas e externas de frutas em natura, e produtos industrializados, como o suco de laranja, e outros.

Cases (1994) em seu trabalho, diz que a importância da previsão e estimativa da colheita é imprescindível na citricultura por diversas causas, entre elas:

- transparência de mercado: uma informação prévia sobre produções é necessária em todas as safras, pois serve de referência ao comerciante nas operações de compra antecipada e fixação dos preços;

- possibilita às cooperativas a planificação com antecedência suficiente da próxima safra, dada sua forma peculiar de atuar, e a obrigatoriedade de comercializar o total da colheita dos sócios;

- permitir as entidade asseguradoras planificar a próxima colheita e conhecer as expectativas da colheita por variedades;

- para poder planificar, com antecedência, medidas de política-econômica na administração. 
Além disso, Dyer \& Gillooly (1979), comentam que o retorno financeiro da exportação de frutas cítricas representa a principal parte da economia de muitos países. São frutas perecíveis, por isso é importante prever o número de frutos para atender exigências futuras, quanto ao transporte e estocagem.

\subsubsection{No Estado de São Paulo}

No caso da citricultura paulista, Pino \& Amaro (1986) reafirmam a importância das estimativas, pois são úteis, para as tomadas de decisão por parte de citricultores e da agroindústria citrícola, para elaboração de estratégias de vendas do setor de produção de insumos e para elaboração da política governamental para o setor.

Estatísticas sobre a citricultura paulista, em especial estimativas e previsões de safras, vêm sendo obtidas por diversas entidades, como a Secretaria de Agricultura e Abastecimento do Estado de São Paulo (SAAESP), desde o início da década de 40 (Pino et al., 1986; citado por Pino \& Amaro, 1986). Inicialmente, tais estatísticas eram obtidas por levantamentos subjetivos (nos quais agrônomos informavam sobre a produção de cada município). Posteriormente, passaram a ser levantadas também por amostragem.

Atualmente, a SAAESP, através do Instituto de Economia Agrícola (IEA) e da Coordenadoria de Assistência Técnica Integral (CATI), efetua cinco levantamentos por ano para elaborar as previsões e estimativas 
de safras dos principais produtos da agricultura paulista (Pino \& Amaro, 1986).

\subsection{Previsão de safras citrícolas}

Segundo Conner ${ }^{1}$ (1989), a previsão da safra anual deve ser baseada em estimativas baseadas na contagem de frutos, evitando-se observações baseadas em opiniões ou julgamentos.

Fucik (1984), diz que o sistema de previsão para o Texas é essencialmente subjetivo e que poderia ser expandido, à exemplo da experiência de outras áreas de produção citrícola. Melhoria da estimativa da produção tem sido realizada através de procedimentos mais sofisticados de amostragem.

Cases (1994) lembra que o citros é um cultivo perene de bastante longevidade e, apesar das várias técnicas culturais e novas variedades, persistem deficiências estruturais que contribuem para a existência de grande variabilidade das produções.

$\mathrm{O}$ interesse em uma previsão estatisticamente precisa, tem conduzido para o sistema atual baseado em dados objetivos da população de árvores, contagem de frutos na árvore sem derriçá-los e medidas de tamanho dos galhos da planta (Conner, 1989). Esse autor ainda comenta, que esse sistema de previsão serve como suporte industrial para a produção na Flórida,

\footnotetext{
${ }^{1}$ CONNER D. (Florida Departament of Agriculture and Consumer Services). Forecasting Florida's citrus production. United States Department of Agriculture, 1989.
} 
e as vantagens econômicas obtidas pela aplicação desse método são revertidas para as pesquisas, que tem por objetivo a melhoria da estimativa.

Deve ser notado que a previsão de safra é necessária ao planejamento da estratégia de mercado. A melhoria e sucesso da amostragem requer atualização periódica da população de árvores e eliminação de erros de contagem (Buch, 1975).

Peetz \& Amaro (1978), relatam que são realizados 5 levantamentos durante o ano agrícola. $\mathrm{O}$ primeiro em setembro, chamado intenção de plantio (que não inclui a laranja); o segundo em novembro, onde há florada dos citros (pode se estender de setembro a dezembro); o terceiro em fevereiro, época de formação e desenvolvimento dos frutos; o quarto em abril, época em que ocorre a maturação dos frutos (pode se estender de abril a maio); o quinto em junho, quando a colheita está em andamento e o levantamento final, realizado em novembro, onde obtém-se a estimativa da produção total para o ano agricola. Realizou-se estudos das relações entre o segundo, terceiro, quarto e quinto levantamentos de previsão de safra e a estimativa final de colheita, obtendo-se equações lineares, com bom ajuste.

Morinaga \& Ikeda (1991), apresentam um estudo abordando duas metodologias para estimativa da safra de laranjas, para duas variedades, no Japão. Uma associa a variação da concentração de açúcares do extrato líquido da planta, no decorrer do ciclo, com a produção. A outra se baseia na observação da copa da planta, na floração e frutificação, analisando dados de filmagem. Quanto a primeira metodologia, obteve-se uma correlação negativa entre o teor de açúcares e a produção, mas esta não foi estatisticamente significativa. 
Referindo-se a segunda metodologia, os autores explicam que para obter, com precisão, dados de floração e frutificação da copa da árvore e através da análise destes dados, obter a estimativa da produção, elaborou-se o sistema esquematizado abaixo.

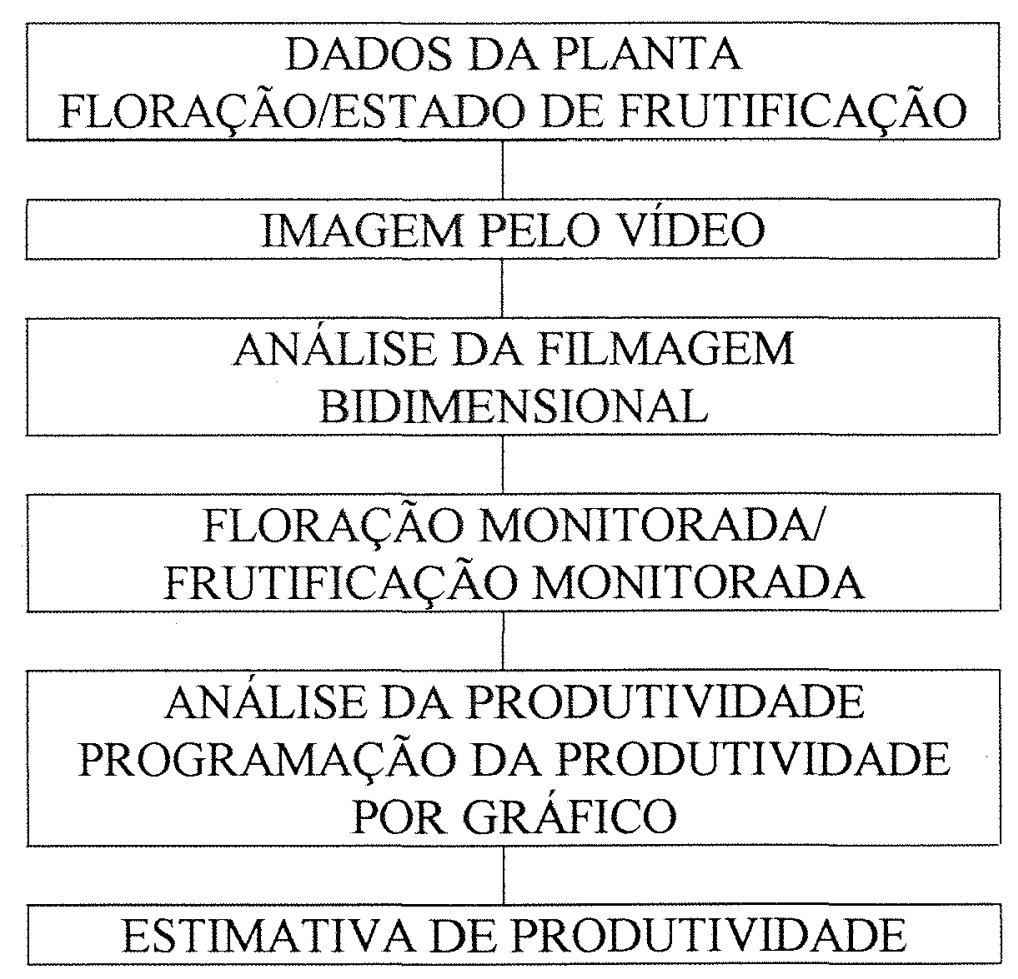

Através deste método, filmando a fase de floração (maio) e a fase de coloração (novembro), estudou-se uma relação entre a colheita e análise da filmagem. A filmagem foi feita instalando-se um balão de $2,5 \mathrm{~m}$ de diâmetro, com uma câmera de vídeo, a uma altura de $10 \mathrm{~m}$. Desta filmagem, usando um processo de focalização bidimensional, obtém-se a quantidade de floração ou número de frutos, através do monitoramento. 
A análise desses dados resultou em uma correlação positiva e estatisticamente significativa. Porém, para aumentar a precisão da estimativa da colheita se faz necessário resolver algumas dificuldades. Entre elas, resolver o problema da interferência da luminosidade (condições de céu limpo ou nublado) na filmagem e determinar uma forma de quantificar o número de frutos quando estes ainda estão verdes, pois a cor da folha e do fruto não apresentam diferença.

\subsection{Parâmetros básicos para previsão}

Conner (1989) e Stout (1963), apresentaram os quatro parâmetros básicos usados na previsão, que são:
(1) número de árvores produtivas;
(2) número de frutos por árvore;
(3) tamanho dos frutos;
(4) queda;

citando os dois primeiros como os de maior influência sobre a previsão.

Na Flórida, segundo Fucik (1984), esses parâmetros chegam a influenciar a estimativa da produção na seguinte proporção:

$45 \%$ - número de frutos por árvore;

$25 \%$ - tamanho dos frutos;

$20 \%$ - queda;

$10 \%$ - população de árvores. 
Um modelo de previsão foi proposto por Conner (1989),

Produção de Citros $=\mathrm{n}^{\circ}$ de árvores carregadas $\mathrm{x} \frac{\text { frutos } / \text { árvore } \mathrm{x} \% \text { de colheita }}{\text { número de frutos } / \text { caixa }}$ onde:

a) o número de árvores carregadas, corresponde as árvores em produção;

b) porcentagem de colheita $=(100-$ Porcentagem de Queda $) / 100$;

c) número de frutos/caixa $=40,8 /$ (peso médio dos frutos); sendo que 40,8 corresponde ao peso padrão de uma caixa.

\subsubsection{Fator clima}

Os quatro parâmetros citados acima são diretamente influenciados pelas variações climáticas.

Camargo (1984), citado por Ortolani et al. (1991) diz que as relações entre variáveis do clima e a produção agrícola são bastante complexas, pois os fatores ambientais podem afetar o crescimento e o desenvolvimento das plantas sobre diversas formas, nas diferentes fases do ciclo da cultura. Os estudos dessas interações, são desenvolvidos com o uso de modelos, que procuram quantificar os efeitos das variações do clima sobre o comportamento e produção vegetal. 
Pino \& Amaro (1986), apresentaram um esquema de fatores que influenciam na produção de citros:

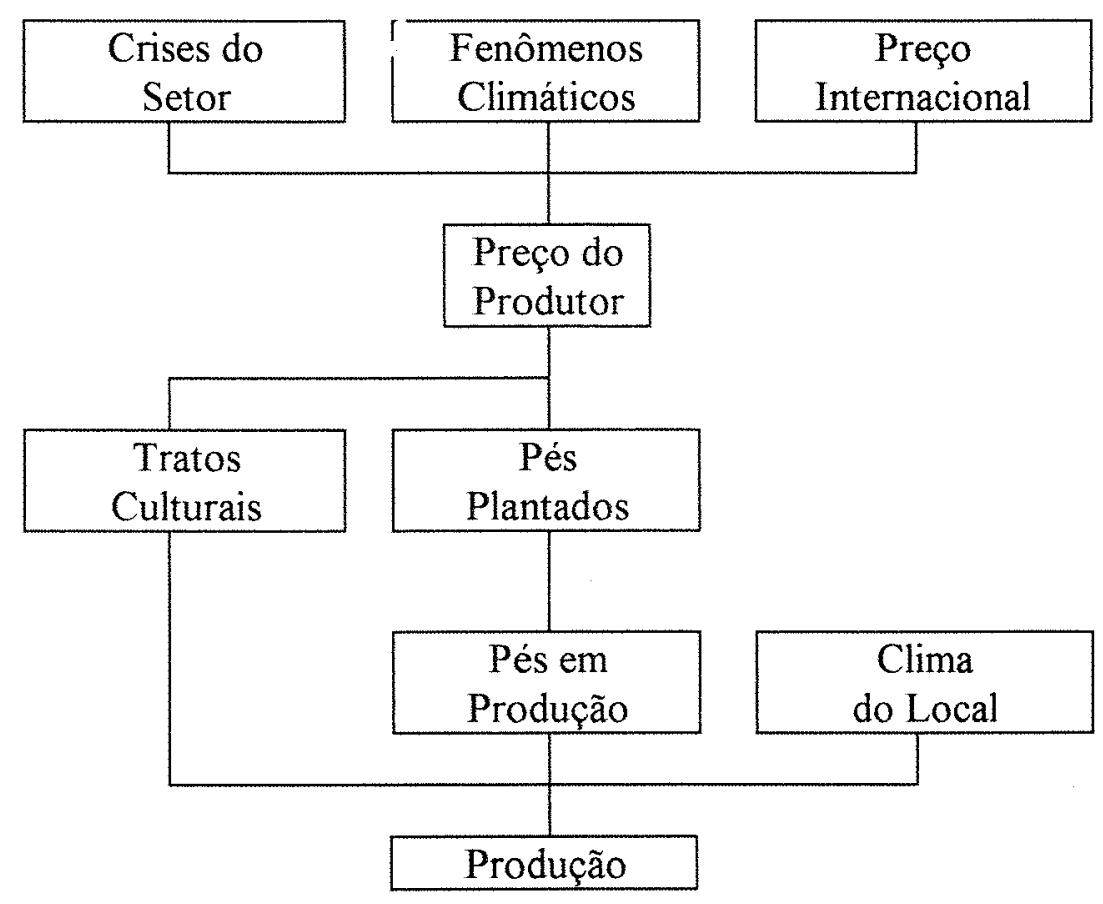

Aqui no Brasil, Tubelis \& Salibe (1989), há vários anos vêm estudando a possibilidade de fazer a previsão de safra de laranja a partir de dados climáticos. É um método que propicia previsões mais antecipadas e de menor custo. A previsão mais antecipada pode ser feita em setembro de cada ano, logo após a grande florada. A previsão pode ser feita também em meses subsequentes, com maior precisão.

O estudo do efeito do clima na produção vegetal tem sido feito por 3 tipos de modelos agroclimáticos: empirico-estatístico, fisico-estatístico e dinâmico (Robertson, 1983; citado por Rodriguez et al., 1991).

Ortolani et al. (1991), explicaram que o modelo empíricoestatístico é o mais simples, em que as variáveis metereológicas 
correspondem às condições de temperatura, chuva ou disponibilidade hídrica reinantes durante todo o ciclo da cultura ou parte dela. O fisico-estatístico procura descrever matematicamente os processos envolvidos durante o ciclo da cultura, através de análises parciais; enquanto o modelo dinâmico apresenta maior grau de detalhamento individual para cada processo envolvido, exigindo um grande número de informações metereológicas e fenológicas.

Tubelis \& Salibe (1989), enfatizaram que a previsão climatológica da safra de laranjeira Hamlin pode ser feita através da análise do regime pluviométrico da área. Influenciam também a idade do pomar e a variedade do porta-enxerto empregado.

A título de exemplo estão relacionados abaixo duas funções que permitem estimar a produtividade de laranja Hamlin, para previsão em setembro:

$$
\begin{gathered}
\mathrm{HA} / \mathrm{CR}=94,60+10,105 \mathrm{i}-0,2141 \mathrm{P} 1+0,514 \mathrm{P} 2-1,1283 \mathrm{P} 9 \\
\mathrm{HA} / \mathrm{CA}=58,48+18,679 \mathrm{i}+1,0020 \mathrm{P} 8-1,5710 \mathrm{P} 9
\end{gathered}
$$

onde:

$\mathrm{HA}=$ produção de laranja Hamlin ( $\mathrm{kg} / \mathrm{pé})$;

$\mathrm{CR}$ e $\mathrm{CA}=$ porta-enxertos de limoeiro cravo e laranja caipira, respectivamente;

$\mathrm{i}=$ idade (em anos) do pomar;

P1, P2, P8 e P9 = totais de chuvas (em mm) nos meses de janeiro, fevereiro, agosto e setembro, respectivamente. 
Um outro tipo de estudo é mostrado por Stout (1963), onde apresenta uma das equações usadas no desenvolvimento da previsão de outubro, utilizando tanto as informações do ano corrente, quanto as dos anos passados.

$$
\hat{P}_{t}=\frac{T_{t}}{T_{t-1}} \cdot \frac{C_{t}}{C_{t-1}} \cdot \frac{1-\hat{D}_{t}}{1-\hat{D}_{t-1}} \cdot \frac{\hat{N}_{t}}{\hat{N}_{t-1}} \cdot P_{t-1}
$$

onde: $\hat{\mathrm{P}}_{\mathrm{t}}=$ produção em caixas, no ano corrente $\mathrm{t}$

$\mathrm{T}_{\mathrm{t}}=$ número de árvores produtivas, no ano corrente $\mathrm{t}$

$\mathrm{C}_{\mathrm{t}}=\mathrm{n}^{\circ}$. de frutos/árvore por inspeção em Ago/Set, no ano corrente $\mathrm{t}$

$\hat{D}_{\mathrm{t}}=$ queda estimada da pré-colheita à colheita, no ano corrente $\mathrm{t}$

$\hat{\mathrm{N}}_{\mathrm{t}}=\mathrm{n}^{\mathrm{o}}$. estimado de frutos/caixa na colheita, no ano corrente $\mathrm{t}$

$\hat{\mathrm{P}}_{\mathrm{t}-1}=$ produção em caixas, no ano anterior $(\mathrm{t}-1)$

$\mathrm{T}_{\mathrm{t}-1}=$ número de árvores produtivas, no ano anterior ( $\left.\mathrm{t}-1\right)$

$\mathrm{C}_{\mathrm{t}-1}=\mathrm{n}^{\circ}$. de frutos/árvore por inspeção em Ago/Set, no ano anterior

$\hat{\mathrm{D}}_{\mathrm{t}-1}=$ queda estimada da pré-colheita à colheita, no ano anterior $(\mathrm{t}-1)$

$\hat{\mathrm{N}}_{\mathrm{t}-1}=\mathrm{n}^{\mathrm{o}}$. estimado de frutos/caixa na colheita, no ano anterior ( $\left.\mathrm{t}-1\right)$

Esse mesmo autor propõe um estudo para melhorar a previsão da pré-colheita. Um modelo de regressão linear múltipla foi usado na análise:

$$
\mathrm{Y}_{\mathrm{i}}=\alpha_{\mathrm{o}}+\sum \beta_{\mathrm{i}} \mathrm{X}_{\mathrm{i}}+\varepsilon_{\mathrm{i}}
$$

onde: $\quad Y_{i}=$ tamanho da fruta em $1^{\circ}$ de abril, em polegadas cúbicas

$$
\alpha_{0}=\text { intercepto }
$$




$$
\begin{aligned}
& X_{i}=\text { variáveis independentes } \\
& \beta_{i}=\text { coeficiente de regressão } \\
& \varepsilon_{\mathrm{i}}=\text { resíduo ou termo de erro }
\end{aligned}
$$

Duas diferentes equações, cada uma com cinco variáveis significativas ao nível de $5 \%$ de probabilidade, foram desenvolvidas para prever o tamanho da safra da variedade Valência em $1^{\circ}$ de outubro (Stout, 1963):

$$
\hat{Y}=28,81+0,070 X_{1}+0,100 X_{2}-0,055 X_{3}-0,260 X_{4}+1,926 X_{5}
$$

onde:

$$
\begin{aligned}
& \hat{\mathrm{Y}}=\begin{array}{l}
\text { previsão do tamanho da fruta em } 1^{\circ} \text { de abril (em polegadas } \\
\text { cúbicas); }
\end{array} \\
& \mathrm{X}_{1}=\text { tamanho da fruta elevado ao quadrado, em } 1^{\circ} \text { de outubro; } \\
& \mathrm{X}_{2}=\text { precipitação total de } 1^{\circ} \text { de julho a } 1^{\circ} \text { de outubro (em } \\
& \text { polegadas); } \\
& \mathrm{X}_{3}=\text { número de dias e precipitação com } 0,10 \text { ou mais } \\
& \quad \text { polegadas de } 1^{\circ} \text { de julho a } 1^{\circ} \text { de outubro; } \\
& \mathrm{X}_{4}=\text { temperatura média de agosto }\left({ }^{\circ} \mathrm{F}\right) ; \\
& \mathrm{X}_{5}=1 \text { se } 1,90<\mathrm{P}<2,35 \text {, caso contrário } \mathrm{X}_{5}=0 \text { onde } \\
& \mathrm{P}=\text { relação de crescimento da fruta, entre os meses de setembro } \\
& \quad \text { e outubro. }
\end{aligned}
$$$$
\hat{Y}=20,51+1,211 X_{1}+0,460 X_{2}+0,044 X_{3}-0,232 X_{4}+2,140 X_{5}
$$ 
onde:

$$
\begin{aligned}
& \begin{array}{r}
\hat{\mathrm{Y}}=\text { previsão do tamanho da fruta em } 1^{\circ} \text { de abril (em polegadas } \\
\text { cúbicas); }
\end{array} \\
& \mathrm{X}_{1}=\text { tamanho da fruta elevado ao quadrado, em } 1^{\circ} \text { de outubro; } \\
& \mathrm{X}_{2}=\text { precipitação total de } 1^{\circ} \text { de fevereiro a } 1^{\circ} \text { de outubro (em } \\
& \quad \text { polegadas); } \\
& \mathrm{X}_{3}=\text { número de dias de precipitação com } 0,10 \text { ou mais } \\
& \quad \text { polegadas de } 1^{\circ} \text { de julho a } 1^{\circ} \text { de outubro; } \\
& \mathrm{X}_{4}=\text { temperatura média de setembro }\left({ }^{\circ} \mathrm{F}\right) ; \\
& \mathrm{X}_{5}=1 \text { se } 1,90<\mathrm{P}<2,35, \text { caso contrário } \mathrm{X}_{5}=0 \text {, onde } \\
& \mathrm{P}=\text { relação de crescimento da fruta, entre os meses de setembro } \\
& \quad \text { e outubro. }
\end{aligned}
$$

Os coeficientes de correlação múltipla, 0,823 para a eq.(5) e 0,818 para a eq.(6), foram muito semelhantes. Igualmente, os erros padrões de $\hat{Y}$ foram similares, 1,40 para a eq.(5) e 1,42 para a eq.(6).

Com isso, o autor concluiu que as variáveis mais importantes para prever o tamanho da safra em outubro foram:

- tamanho da fruta em $1^{\circ}$ de outubro;

- precipitação anterior a $1^{\circ}$ de outubro;

- distribuição da precipitação durante 3 meses precedentes;

- temperatura média em agosto e setembro;

- taxa de crescimento de setembro a outubro.

Plessis (1983), apresenta um trabalho realizado na África do Sul, onde se concluiu que fatores climáticos foram os principais responsáveis pelas variações ano após ano na produção de laranja "navel" (Citrus sinensis 
(L.) Osb.) em três áreas de produção. Dois métodos foram testados para a previsão da safra. O primeiro método envolve o uso de "stepwise" na análise de regressão múltipla para relacionar uma produção maior a um número de estações com fatores climáticos. Entre 59 e $88 \%$ da variação sazonal na produção pode ser explicado por esta amostragem. O segundo método consiste na relação entre o número de dias quentes durante o período de florada (3 meses) e a produção. Nesse caso pode-se observar que altas temperaturas durante a florada pode ser muito prejudicial ao tamanho da safra de "Navel".

Mechlia \& Caroll (1989) dizem que o problema com modelos estatísticos é que quanto mais fatores climáticos são usados na equação de regressão, mais fortemente as características climáticas de uma dada área são enfatizadas. O produto final é um modelo com bom ajuste, mas de universalidade pequena. $\mathrm{O}$ objetivo é demonstrar a utilidade da previsão de safra e produzir um modelo abrangente. Estudou-se, então, um modelo no qual dados de clima, regularmente medidos, pudessem ser usados para dar informações sobre a performance da safra.

Shamasundaram (1984), propôs um trabalho buscando um método adequado e simples para estimar a produção de Coorg mandarim (Citrus reticulata Blanco), utilizando caracteres morfológicos da árvore e produção nos galhos. Caracteres como circunferência do tronco, altura da árvore, extensão norte-sul, leste-oeste da copa, volume, altura e raio da copa, área da superficie, número de galhos, circunferência do galho e sua produção foram correlacionados com a produção individual da árvore. Nenhum dos caracteres morfológicos apresentou correlação significativa com a produção. 
Já a produção dos quatro primeiros galhos obteve correlação positiva e significativa a nível de $1 \%$ de probabilidade com a produção da árvore.

\subsubsection{Número de árvores produtivas}

$\mathrm{Na}$ Flórida, para o recenseamento de árvores são utilizadas forografias aéreas. Fotos são tiradas a 15.000 pés, em filme preto e branco pancromático. As mesmas linhas de vôo são seguidas a cada recenseamento. As fotos são ampliadas e cada bloco de citros é identificado no solo e mapeado. Os resultados são registrados, corrigidos e adicionados a cada recenseamento (Conner, 1989). O censo é feito a cada dois anos e fornece um registro completo das árvores por idade, variedade e ano de plantio. Anualmente 2800 amostras de árvores são extraídas dos dados do censo de árvores, para serem representantes de sua população.

Para esse tipo de amostragem, Cochran (1953), diz que uma população de $\mathrm{N}$ unidades é primeiramente dividida em subpopulações de $\mathrm{N}_{1}$, $N_{2}, \ldots, N_{L}$ unidades, sendo que estas não se superpõem e de modo que:

$$
\mathrm{N}_{1}+\mathrm{N}_{2}+\ldots+\mathrm{N}_{\mathrm{L}}=\mathrm{N}
$$

As subpopulações são denominadas estratos. A seleção de amostras é realizada em cada estrato separadamente e suas grandezas são denominadas $\mathrm{n}_{1}, \mathrm{n}_{2}, \ldots, \mathrm{n}_{\mathrm{L}}$ respectivamente.

Com a subdivisão em estratos é possível, às vezes, obter subpopulações homogêneas de uma população heterogênea. Essa estratificação pode, portanto, aumentar a precisão das estimativas das características da população. 
Santos et al. (1987) apresentam em seu trabalho uma comparação entre a amostragem casual simples e a amostragem estratificada. Dada a crescente importância da citricultura paulista, os autores tiveram como objetivo discutir e calcular uma amostra de citricultores para o levantamento de dados estatísticos sobre o desenvolvimento da citricultura em todo Estado de São Paulo. A unidade amostral é o imóvel rural do produtor de citros (laranja, limão e tangerina). Justifica-se o uso de amostra estratificada para a citricultura por duas razões:

a) a citricultura é razoavelmente concentrada, com mais de $80 \%$ dos citricultores em apenas três das dez DIRA's (Divisões Regionais Agrícolas);

b) por se tratar de cultura perene, o cadastro é relativamente estável, não se alterando muito de um ano para outro.

Trabalho apresentado por Brar et al. (1993) foi proposto um método de amostragem onde uma única árvore de Kinnow mandarim, seria representativa de sua população na parcela. Os autores relatam que as árvores de Kinnow mandarim variam consideravelmente quanto a copa, altura da planta e circunferência do tronco, e na amostragem aleatória simples não aparece nos cálculos a possível importância do tamanho das árvores na parcela. A probabilidade proporcional ao tamanho da copa, da altura e da circunferência, leva esses aspectos em consideração (Sukhatme \& Sukhatme, 1976; citado por Brar, 1993).

Foi realizado experimento com 10 árvores de Kinnow mandarim, levando-se em conta dois métodos de amostragem, probabilidade equivalente ou aleatória e probabilidade proporcional a área, para três variáveis, 
circunferência do tronco, copa e altura. Comparando-se os valores das variâncias obtidas nos métodos de probabilidade equivalente e probabilidade proporcional a área, ficou evidente que o esquema de probabilidades equivalentes apresenta eficiência muita baixa. Além disso, a correlação entre copa, altura e circunferência, e a produção da árvore são da ordem de 0,8026 , 0,7838 e 0,9058 , respectivamente. Os resultados indicaram que a área da seção transversal pode ser usada como medida no cálculo para determinação de uma árvore representativa de sua população (Brar et al., 1993).

Ainda esses autores dizem que a utilização ou não de qualquer esquema de amostragem é determinado, observando-se três pontos:

(a) conveniência operacional;

(b) estimativas das variâncias;

(c) custos do processo.

Nesse trabalho, tem-se seis componentes de custos:

$\mathrm{C}_{1}=$ medidas das circunferências

$\mathrm{C}_{2}=$ computação das probabilidades;

$\mathrm{C}_{3}=$ enumeração dos frutos na árvore;

$\mathrm{C}_{4}=$ medidas da extensão N-S e L-O da copa;

$\mathrm{C}_{5}=$ altura medida;

$\mathrm{C}_{6}=$ computação do trabalho para cálculos da copa.

Para uma comparação rápida, apresentou-se uma tabela dos custos envolvidos para cada esquema de amostragem (Tabela 01). 
Tabela 01 - Custos envolvidos nos esquemas de amostragem.

\begin{tabular}{lccccccc}
\hline Esquema de amostragem & $\mathrm{C}_{1}$ & $\mathrm{C}_{2}$ & $\mathrm{C}_{3}$ & $\mathrm{C}_{4}$ & $\mathrm{C}_{5}$ & $\mathrm{C}_{6}$ & Total Custos \\
\hline P.E. & - & $\mathrm{X}$ & $\mathrm{X}$ & - & - & - & 2 \\
P.P.A. (circunferência`2) & $\mathrm{X}$ & $\mathrm{X}$ & $\mathrm{X}$ & - & - & - & 3 \\
P.P.A. (copa) & - & $\mathrm{X}$ & $\mathrm{X}$ & $\mathrm{X}$ & $\mathrm{X}$ & $\mathrm{X}$ & 5 \\
P.P.A. (altura) & - & $\mathrm{X}$ & $\mathrm{X}$ & - & $\mathrm{X}$ & - & 3 \\
\hline
\end{tabular}

Embora o esquema de probabilidade equivalente de seleção, tenha apresentado menor custo, comparativamente com outros esquema, prefere-se trabalhar com probabilidade proporcional a área (circunferência`2) por apresentar estimativas mais reais da produção da área (Brar, 1993).

\subsubsection{Tamanho dos frutos}

No começo da estação, segundo Buch (1976), as frutas de árvores-amostras são colhidos e classificados em "packinghouse" por tamanho.

Medidas do tamanho da fruta são conduzidas mensalmente a apartir de julho até a colheita, na Flórida. O tamanho da fruta é projetado para a colheita usando-se tabelas de crescimento, afinidades históricas de dados e outras afinidades para detectar anos de crescimentos similares. $O$ tamanho da fruta é convertido para número de frutos por caixa para registro de previsão em caixas. É importante lembrar que as condições climáticas afetam o tamanho da fruta (Conner, 1989). 


\subsubsection{Queda}

Para quantificar os frutos perdidos por queda, são necessárias observações mensais do número de frutos que caem das várias amostras de galhos. Estes galhos-amostras são etiquetados e os frutos são contados. Então em intervalos de meses, os mesmos galhos são recontados. Quedas de frutas cumulativas por estação e dados históricos de estações anteriores são usados para projetar a perda por queda no tempo de colheita (Conner, 1989).

\subsubsection{Número de frutos por árvore}

Segundo Fucik (1984), o número de frutos por árvore é considerado o fator mais importante na estimativa. Por esse motivo, a busca de processos mais eficientes de contagem de frutos se faz necessária, mesmo que isso represente um aumento nos custos.

$\mathrm{O}$ autor ressalta que contar todas as frutas numa árvore talvez ainda seja o melhor sistema para o Texas. Em árvores grandes o número $\mathrm{e}$ distribuição de frutos facilita a contagem. Em árvores novas, os frutos tendem a se agrupar dentro da copa. Esta contagem é mais dificil, mas mais precisa que a contagem de galhos.

Fucik (1984), diz ainda que aumentos na precisão da estimativa de produção de citros no Texas, tem se baseado em procedimentos mais sofisticados de amostragem. Do número de frutos contados num ramo representativo, ou dentro de um volume especifico de copa de árvore, uma estimativa do número de frutas por árvore é calculada. 
Jessen (1955), relatou que a contagem apurada de frutos é onerosa e dispende tempo de trabalho, especialmente se os frutos forem deixados na árvore, sem danificação. Se os frutos são derriçados antes da colheita, a fim de aumentar a precisão dos resultados, a remoção dos frutos pode interferir seriamente com outros aspectos da pesquisa.

Desenvolvido durante maio de 1950, a análise da contagem do galho (limb count) tem se tornado utensílio básico para estimar o número médio de frutos nas árvores de citros na Flórida (Conner, 1989). Um galho amostra é selecionado aleatoriamente, começando do tronco e movimentando-se em estágios sucessivos sobre a árvore. O procedimento utiliza a correlação entre tamanho do galho e a capacidade de frutificação desse galho. É um método mais eficiente, pois além de não danificar a árvore, permite que o tempo utilizado na derriça dos frutos seja utilizado para amostrar mais árvores, contando-se pequena parte delas.

Em seu trabalho, Jessen (1955), descreveu alguns possíveis esquemas de amostragem e compara alguns aspectos de sua eficácia. No caso, o objetivo é selecionar alguns galhos de uma árvore, de maneira que o número de frutos nesses galhos-amostras, seja suficiente para obter-se uma razoável precisão na estimativa do total de frutos da árvore. Para isso, o autor propõe o uso de uma metodologia, baseada em três probabilidades de seleção dos galhos: a probabilidade equivalente, a probabilidade propocional ao número de galhos e a probabilidade proporcional a área do galho. As estimativas, obtidas apartir dessas probabilidades, foram estudadas, buscando-se o método que apresentasse melhores resultados. Concluiu-se que o método que utiliza a probabilidade proporcional a área foi o melhor. 


\section{MATERIAL E MÉTODOS}

\subsection{Material}

O material utilizado nesse estudo foi fornecido pela SUCOCÍTRICO CUTRALE S/A (Araraquara) e é composto de 21 (vinte e uma) árvores especificadas na Tabela 02, onde foram feitas contagens de frutos galho a galho conforme esquematizado nas Figuras 01 a 21 .

Tabela 02 - Árvores levantadas.

\begin{tabular}{clclc}
\hline Número & Variedade & Idade $^{(*)}$ & \multicolumn{1}{c}{ Região } & $\mathbf{N}^{\mathbf{0}}$. de frutos \\
\hline 01 & Pera Rio & 1 & Colina & 150 \\
02 & Pera Rio & 1 & São José do Rio Preto & 148 \\
03 & Pera Rio & 1 & Porto Ferreira & 136 \\
04 & Pera Rio & 2 & São José do Rio Preto & 312 \\
05 & Pera Rio & 2 & Santa Rita & 562 \\
06 & Pera Rio & 3 & Bebedouro & 763 \\
07 & Pera Rio & 3 & Porto Ferreira & 312 \\
08 & Natal & 1 & Porto Ferreira & 113 \\
09 & Natal & 2 & Catanduva & 167 \\
10 & Natal & 2 & Bebedouro & 714 \\
11 & Natal & 3 & Catanduva & 1122 \\
12 & Natal & 3 & Conchal & 980
\end{tabular}


Tabela 02 - Árvores levantadas (continuação).

\begin{tabular}{clclc}
\hline Número & Variedade & Idade & \multicolumn{1}{c}{ Região } & $N^{\mathbf{0}}$. de frutos \\
\hline 13 & Natal & 3 & Colina & 930 \\
14 & Valência & 1 & Araraquara & 147 \\
15 & Valência & 1 & Porto Ferreira & 162 \\
16 & Valência & 1 & Severina & 436 \\
17 & Valência & 2 & São José do Rio Preto & 754 \\
18 & Valência & 2 & Porto Ferreira & 823 \\
19 & Valência & 3 & Conchal & 673 \\
20 & Valência & 3 & Catanduva & 502 \\
21 & Valência & 3 & Colina & 740 \\
(*) Idade 1, corresponde as árvores de 3 a 5 anos; Idade 2, as árvores de 6 a 10 anos e Idade 3, \\
as árvores com mais de 10 anos.
\end{tabular}

Observa-se, na Tabela 02, que algumas árvores apresentam número de frutos muito discrepantes em relação ao normal. É o caso das árvores números 16, que é uma árvore da variedade Valência da categoria de idade 1, apresentando um número de frutos muito acima da média normal. Já, as árvores 09 e 07, de categoria de idade 2 e 3 respectivamente, apresentam um número de frutos bem abaixo da média das variedades correspondentes, nessas idades. Nesses casos pode ter ocorrido algum erro de anotação ou problemas de doença.

No campo foram levantados o número de frutos $\mathrm{e}$ a circunferência de cada galho, para as vinte e uma árvores. Pode-se observar, nas figuras a seguir, a medida da circunferência (em centímetros) e logo em seguida $o n^{\circ}$ de frutos (entre parênteses). 


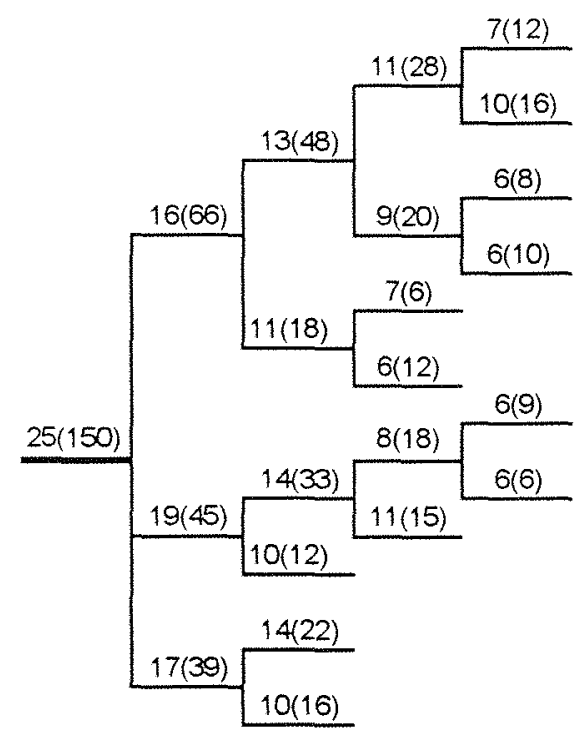

Figura 01 - Árvore 01.

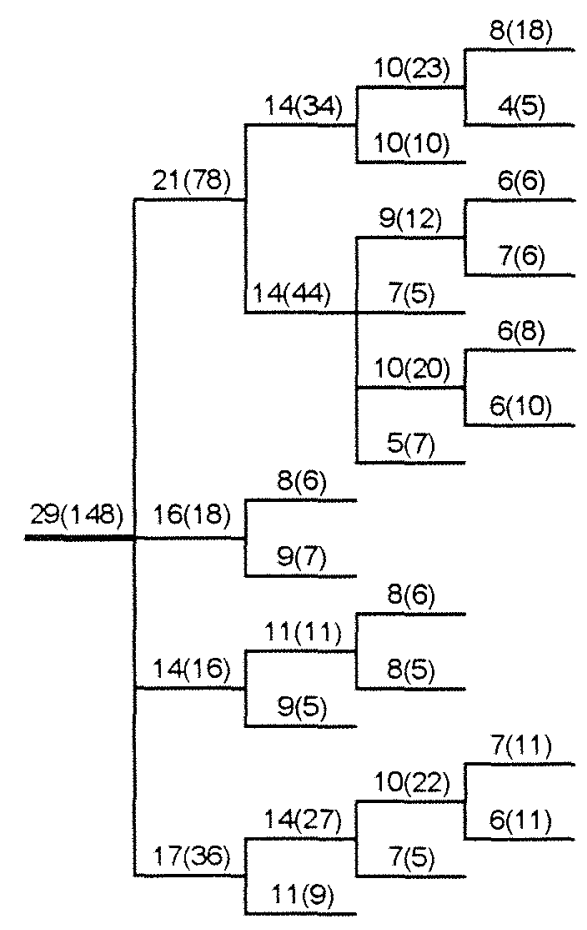

Figura 02 - Árvore 02. 


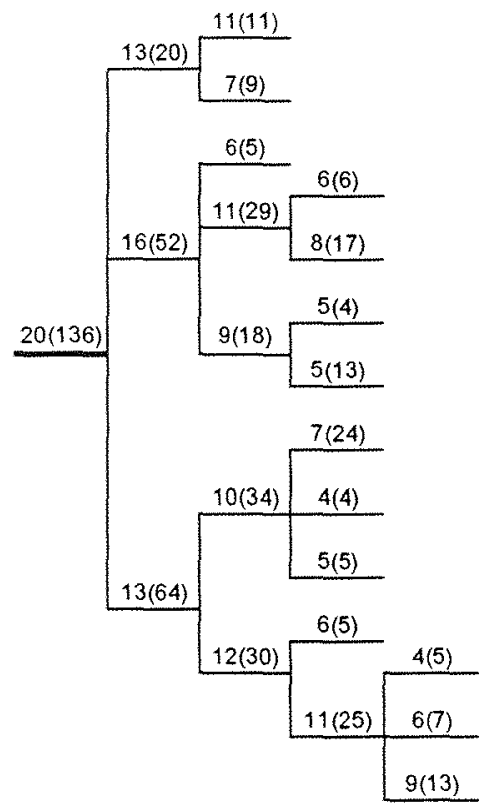

Figura 03 - Árvore 03.

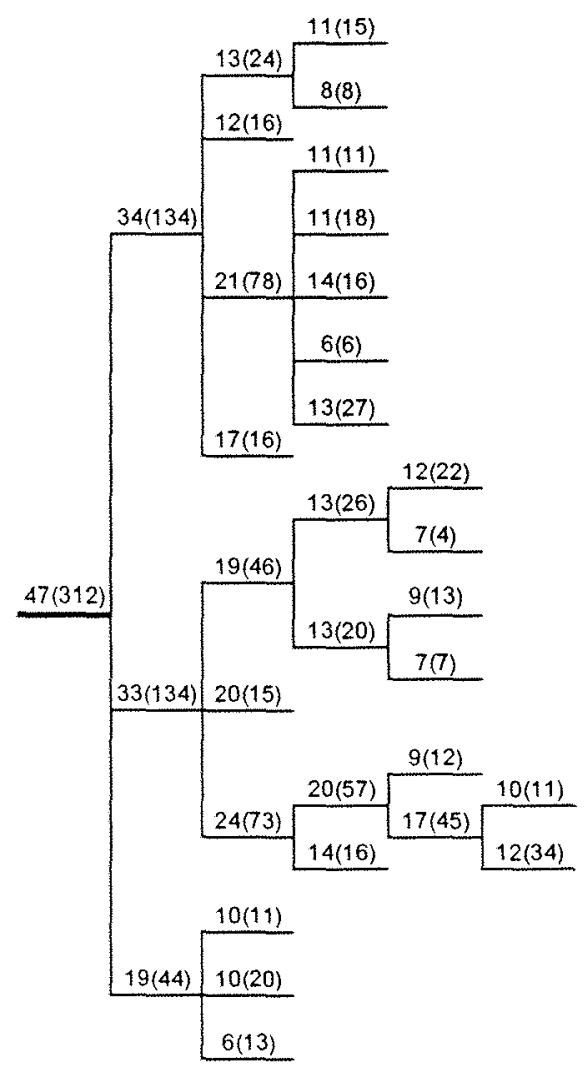

Figura 04-Árvore 04. 
26.

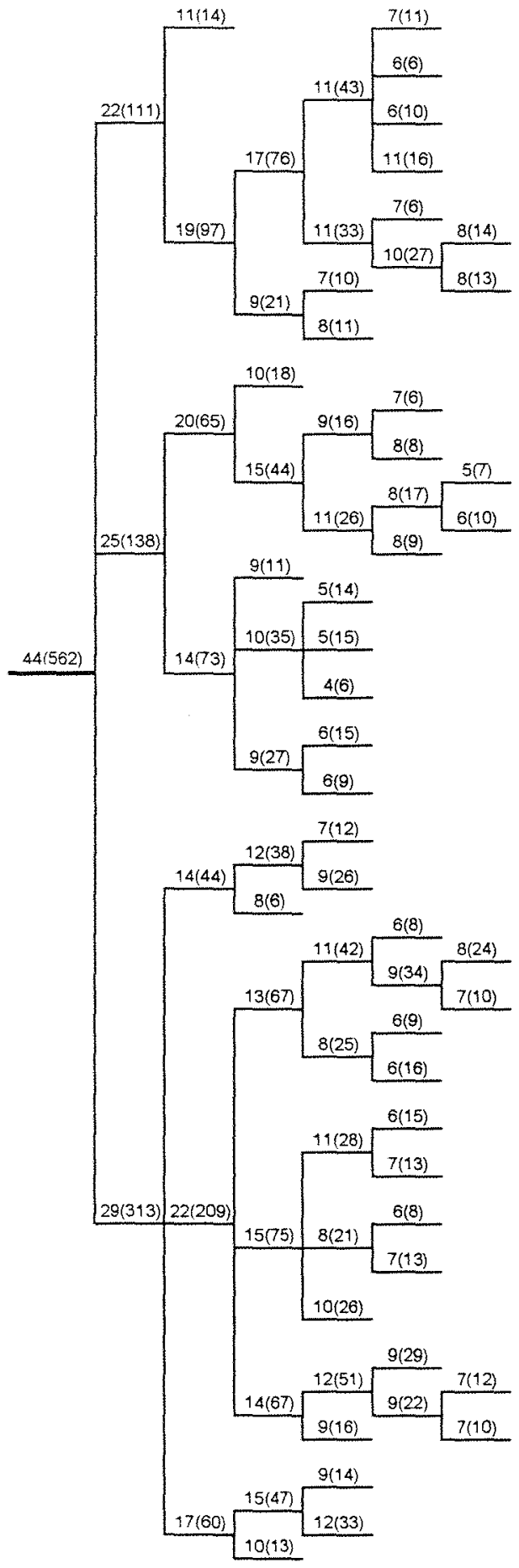

Figura 05 - Árvore 05. 
27.

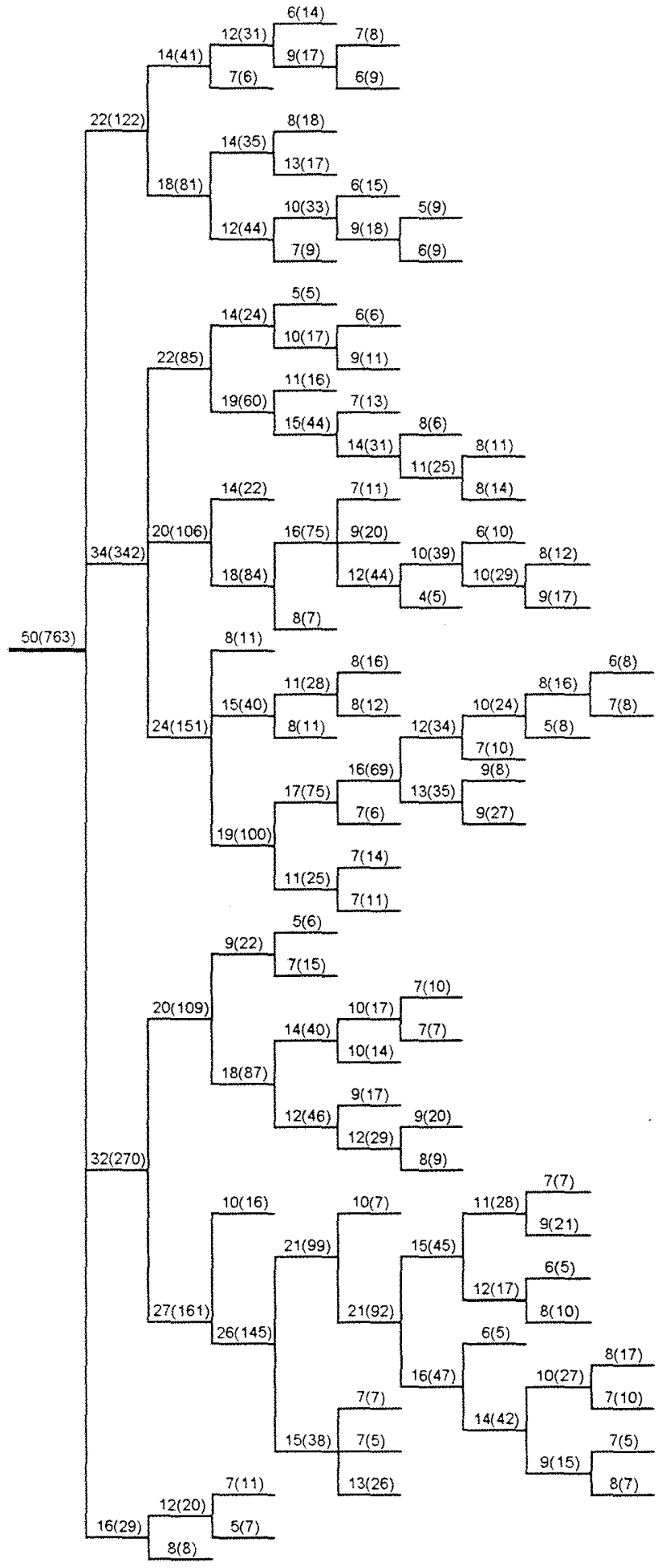

Figura 06 - Árvore 06. 


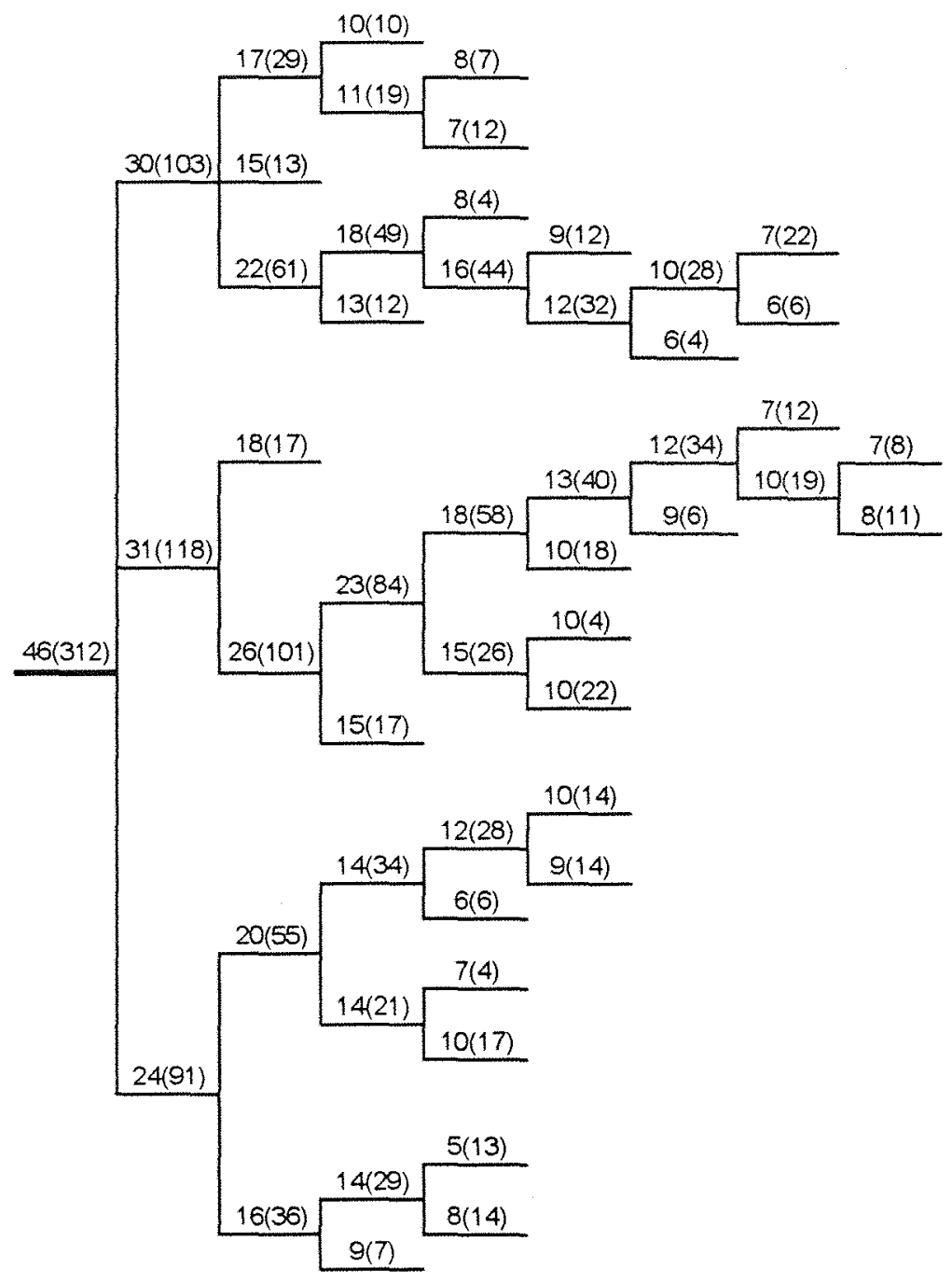

Figura 07 - Árvore 07.

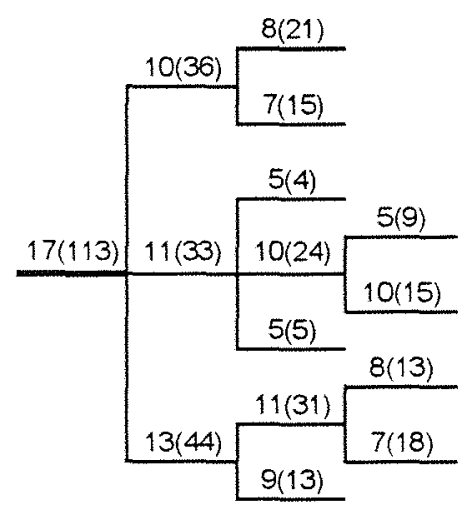

Figura 08 - Árvore 08. 


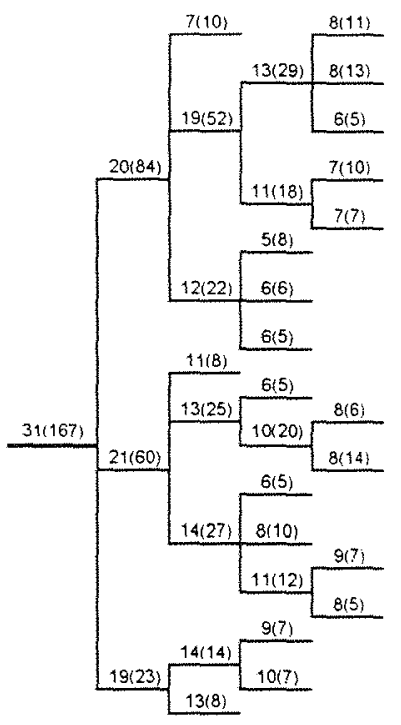

Figura 09-Árvore 09.

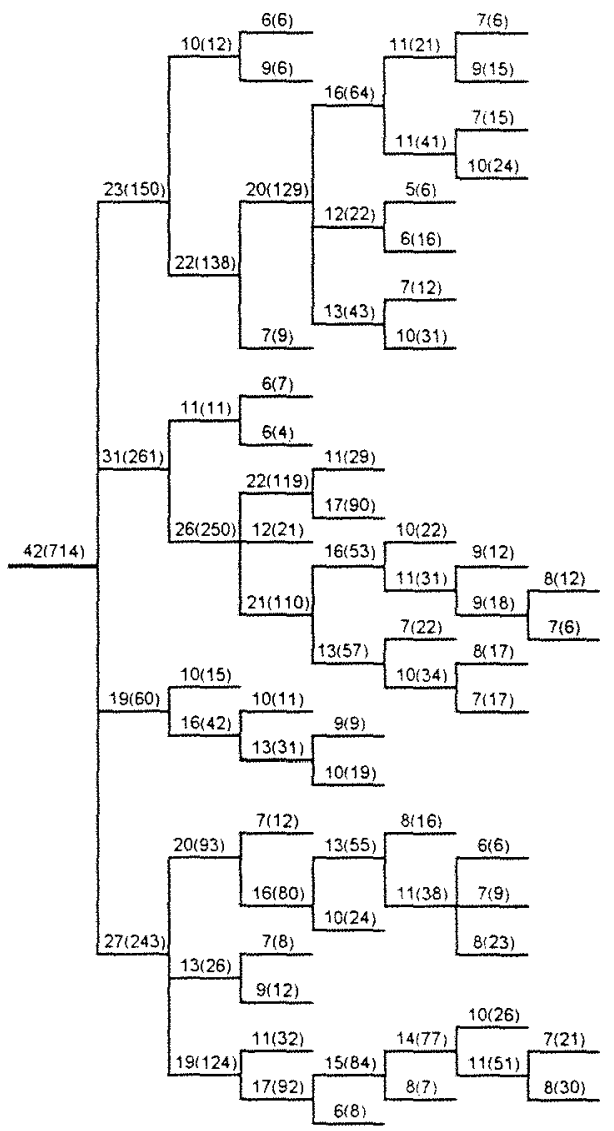

Figura 10 - Árvore 10. 


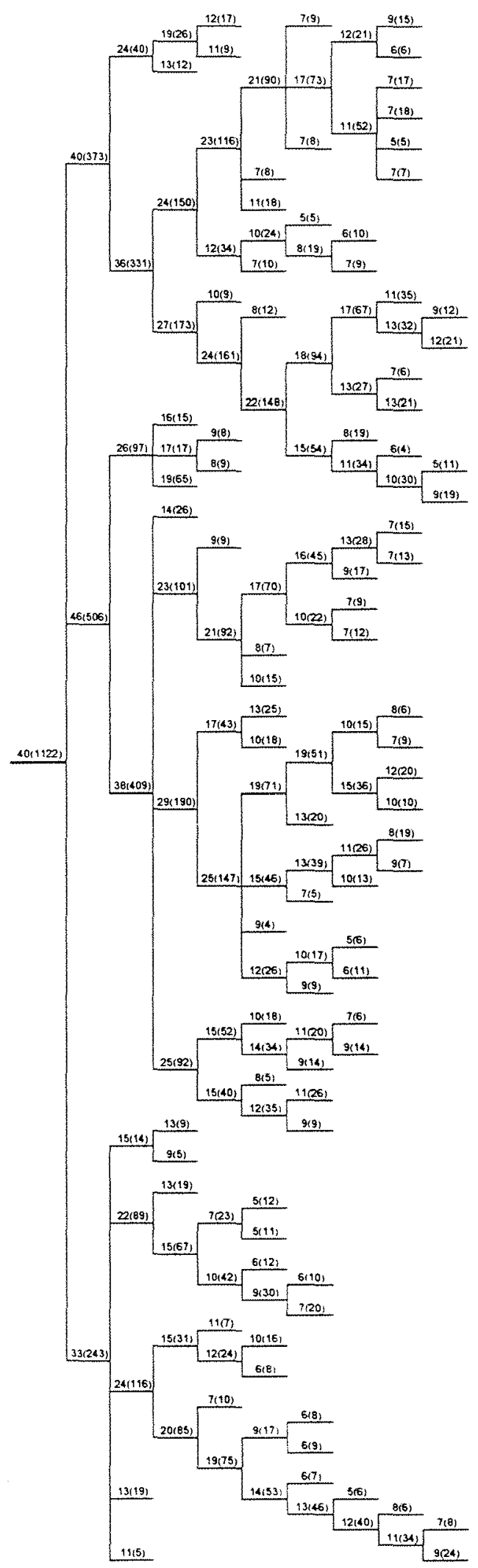

Figura 11 - Árvore 11. 


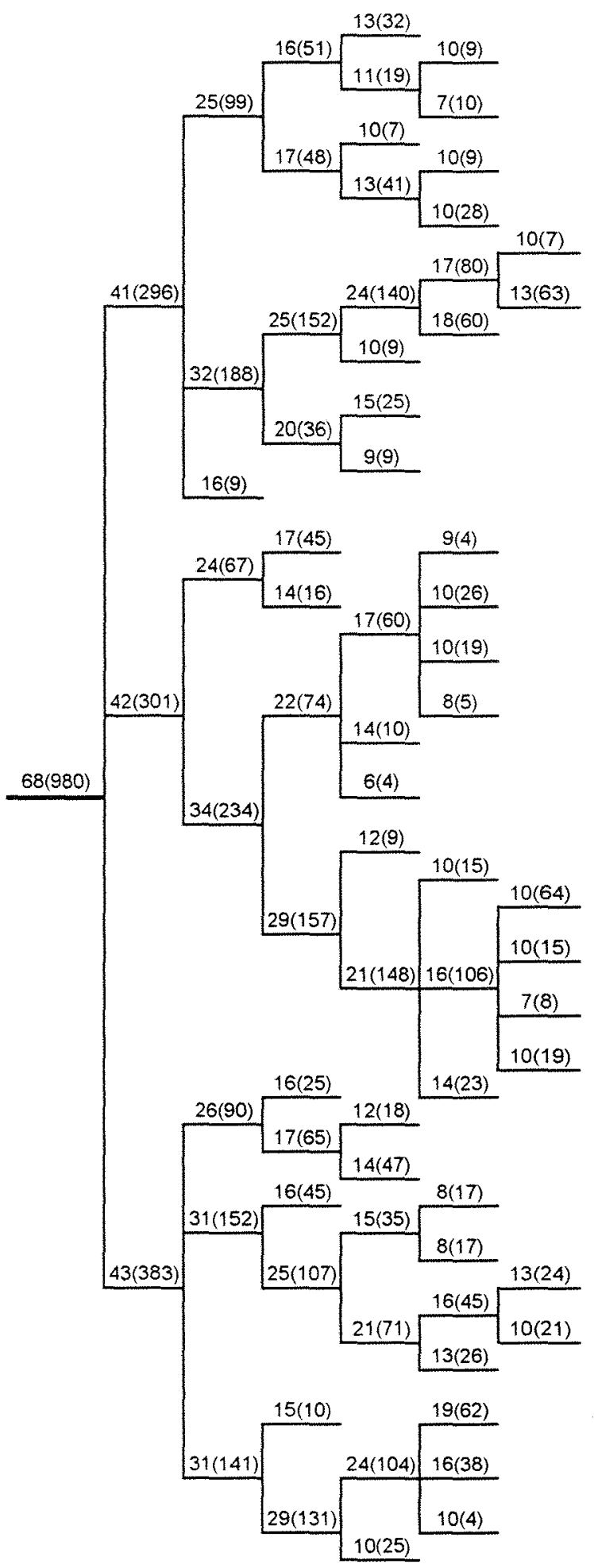

Figura 12 - Árvore 12. 


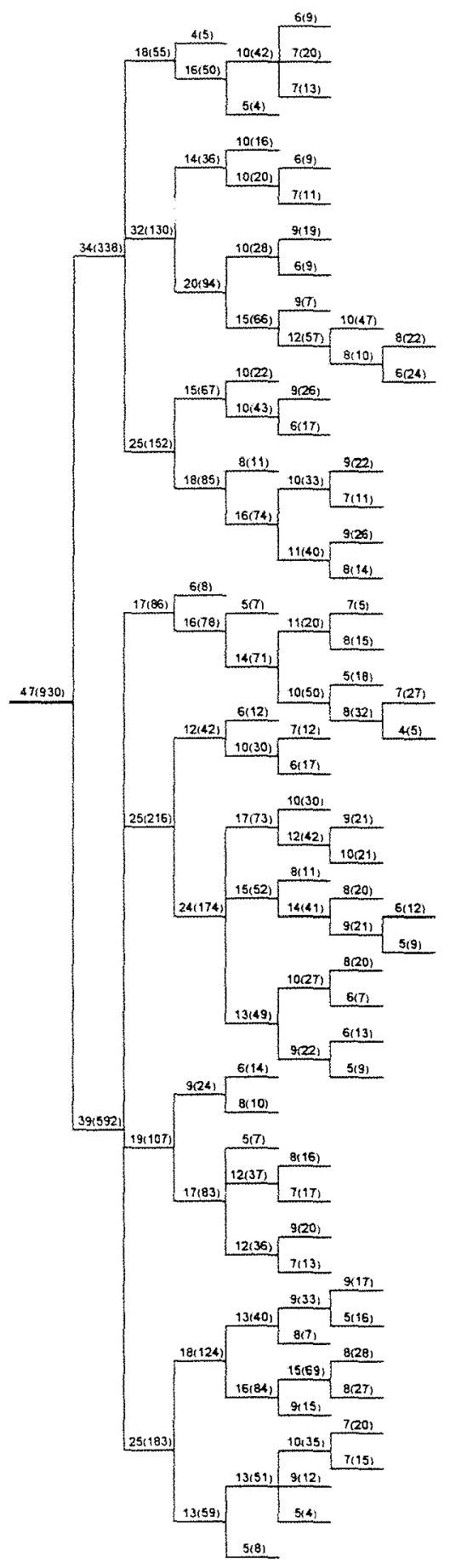

Figura 13 - Árvore 13. 


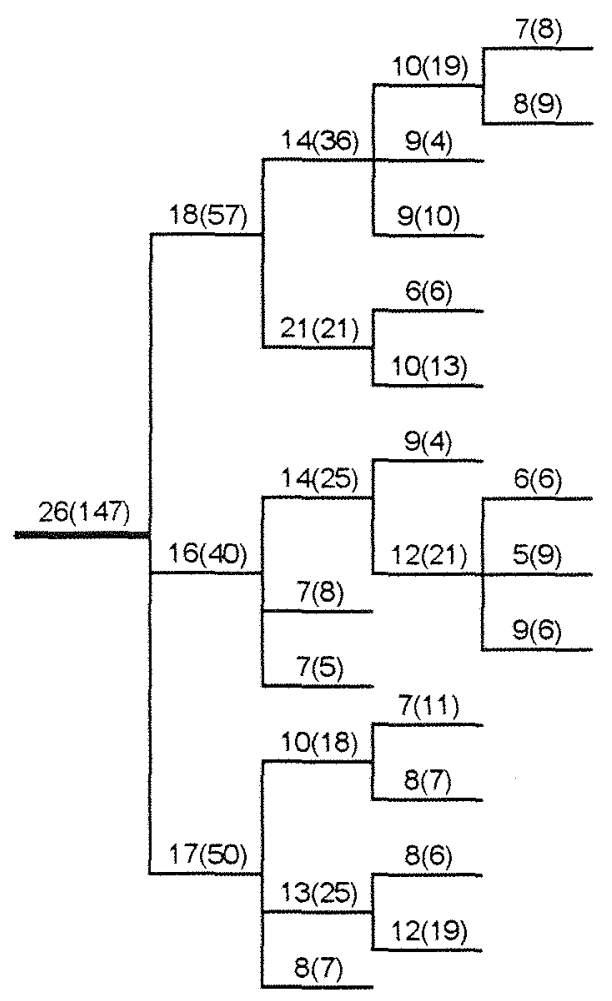

Figura 14 - Árvore 14.

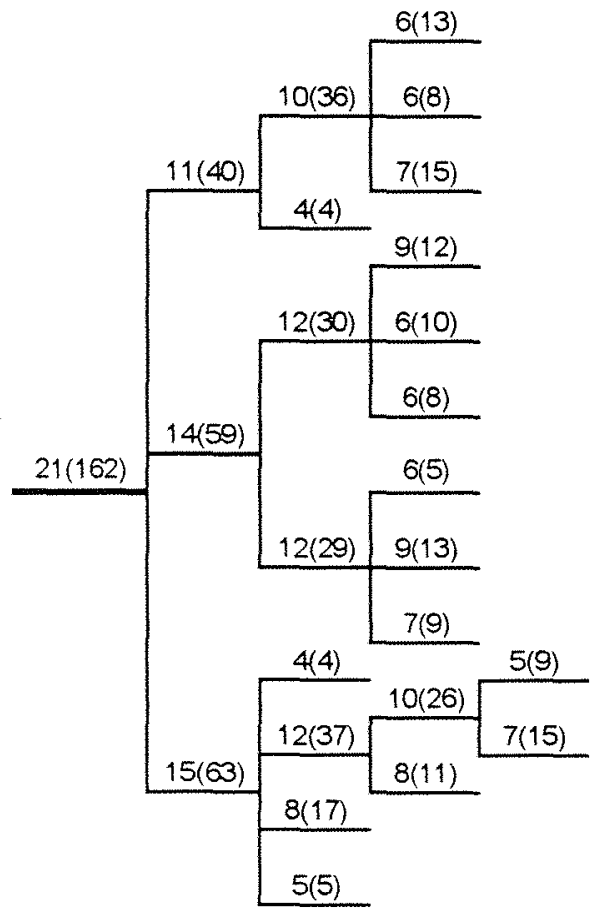

Figura 15 - Árvore 15. 


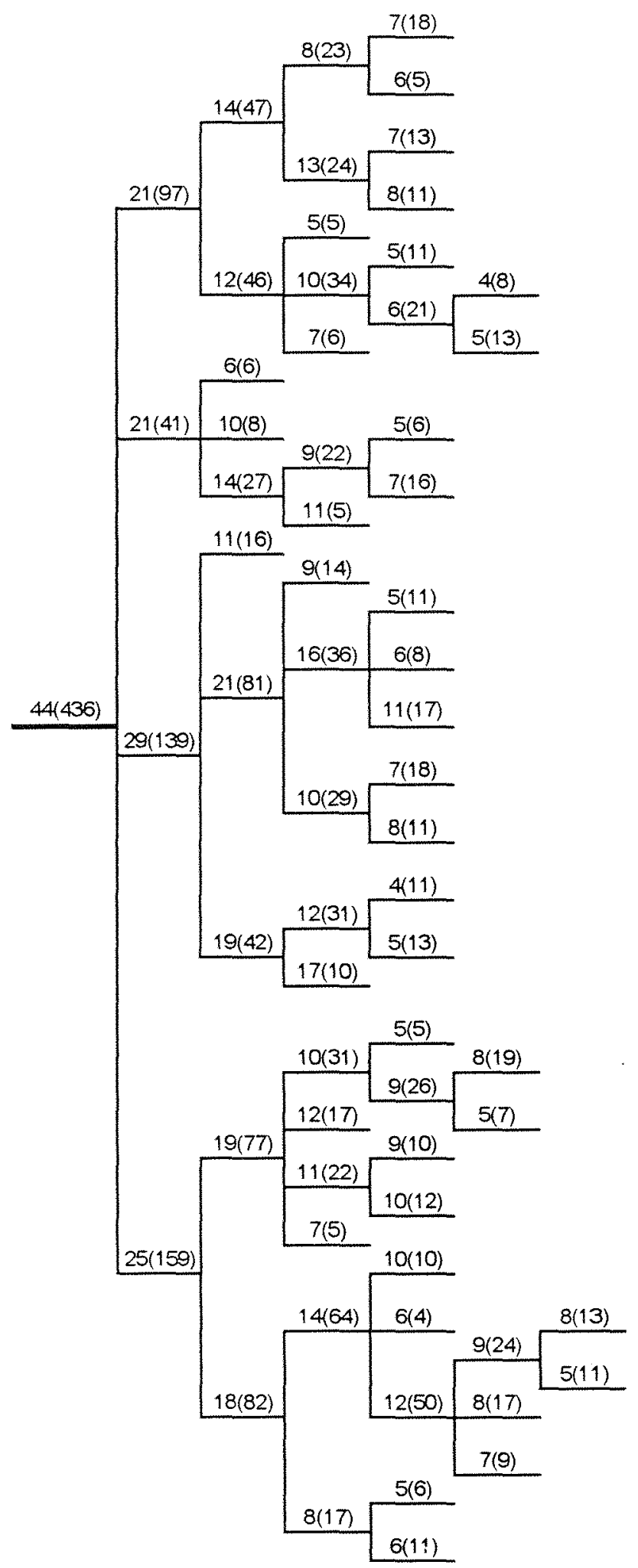

Figura 16 - Árvore 16. 
35.

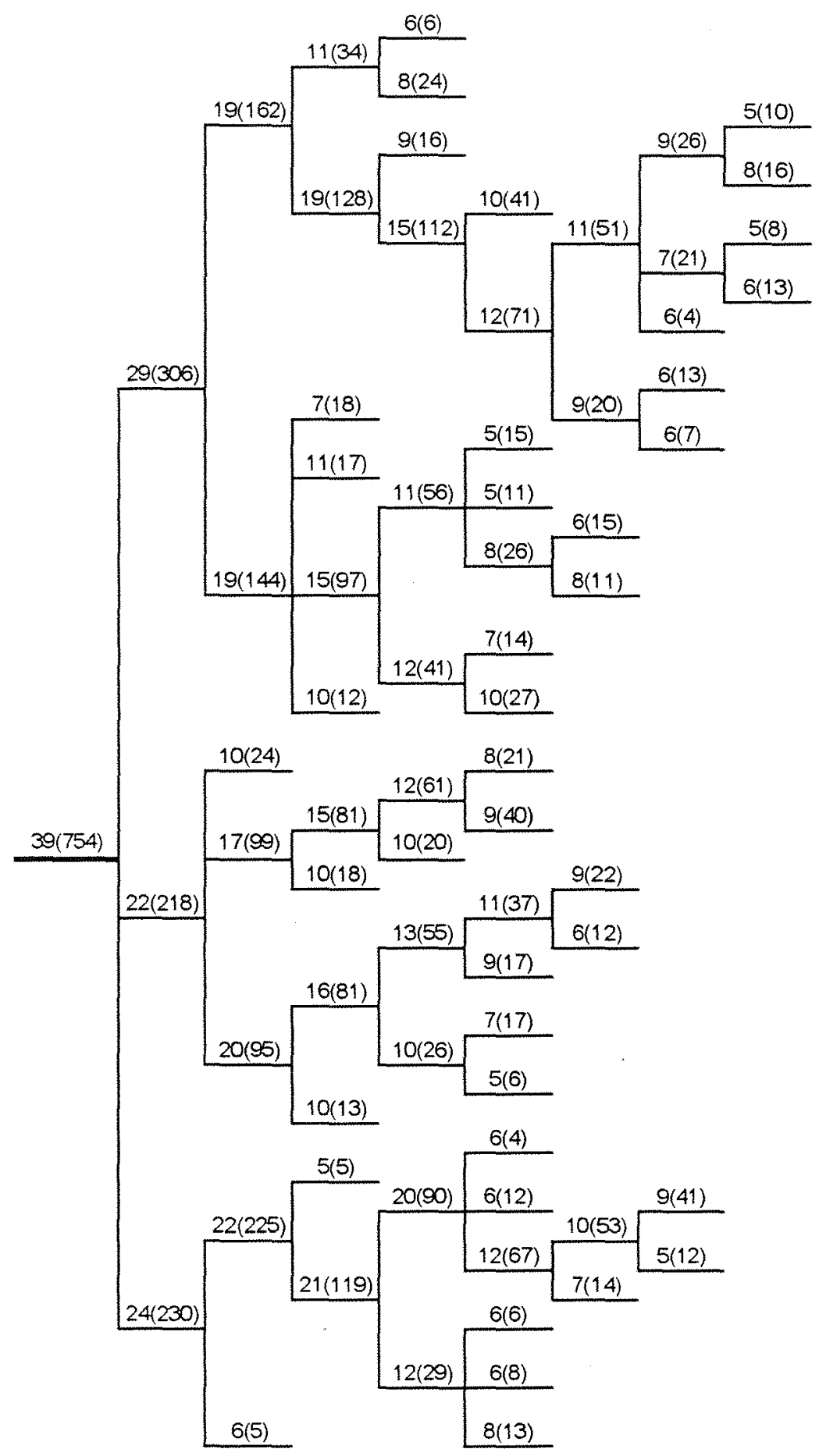

Figura 17 - Árvore 17. 


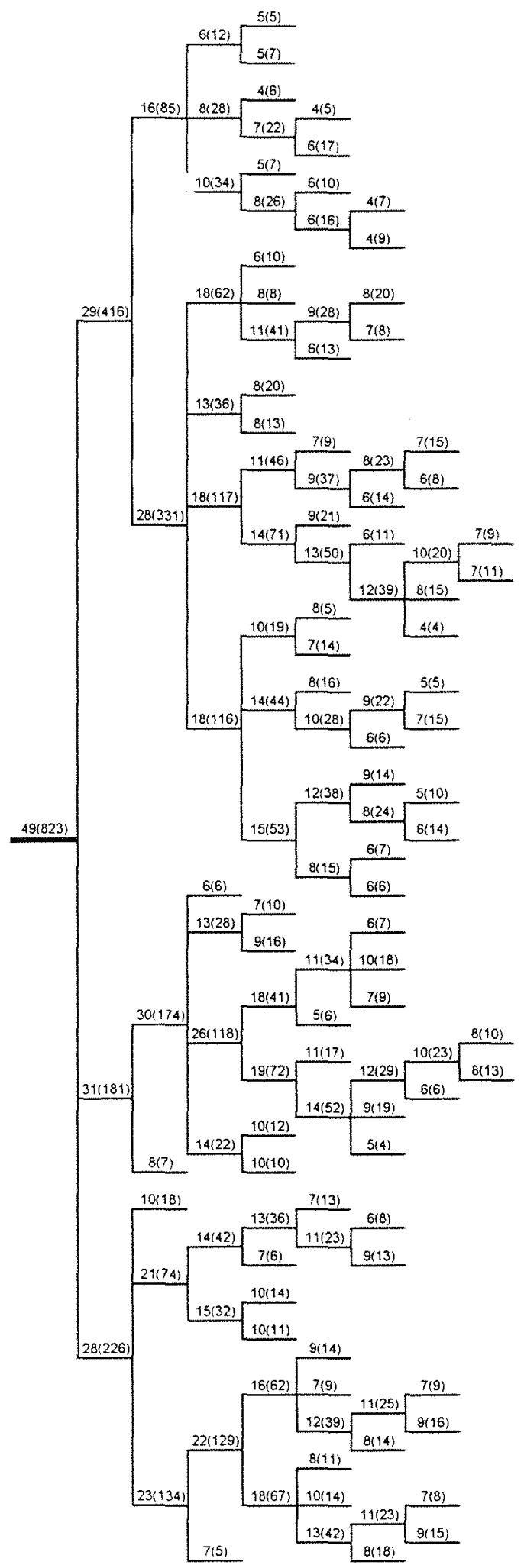

Figura 18 - Árvore 18. 


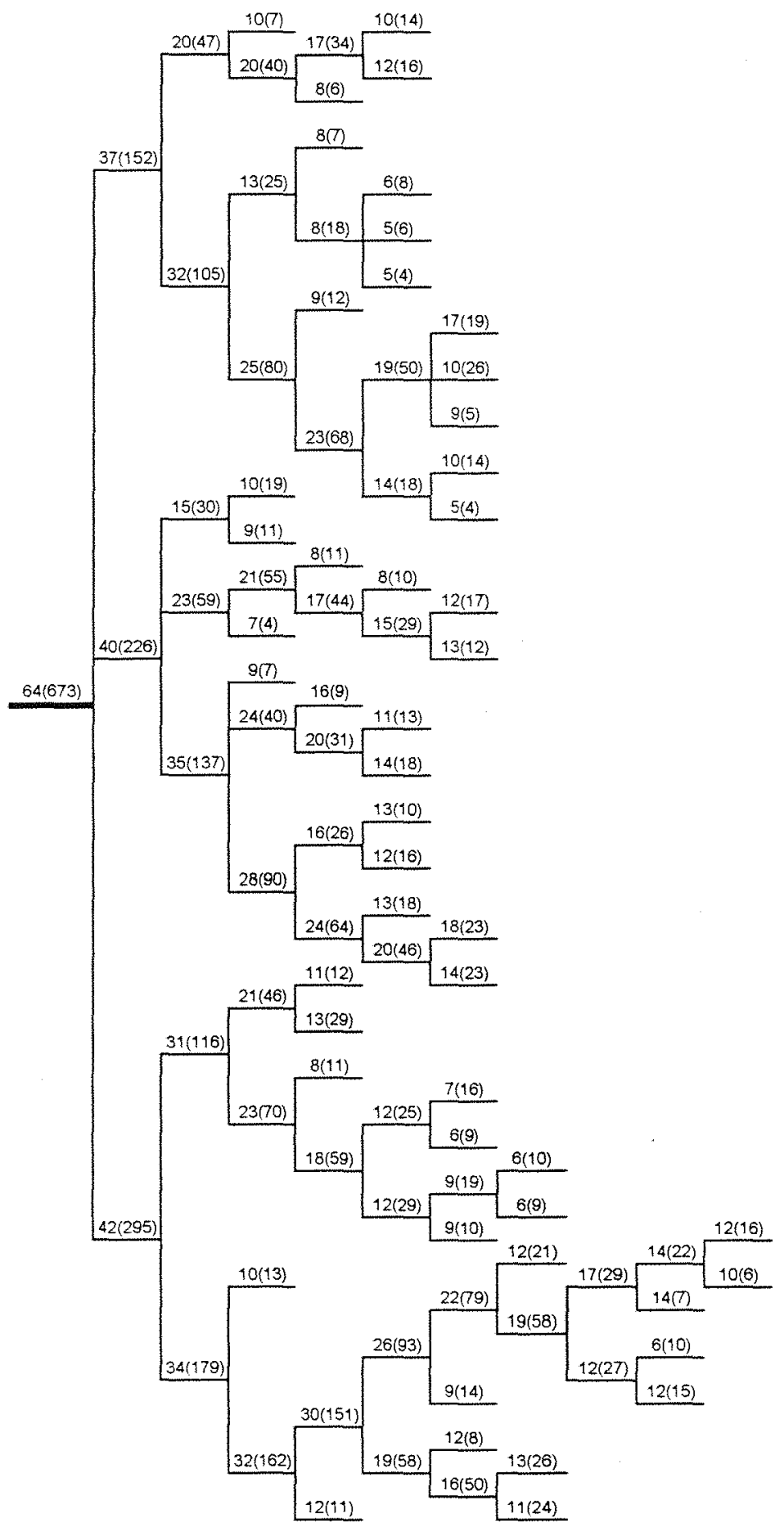

Figura 19 - Árvore 19. 
38.

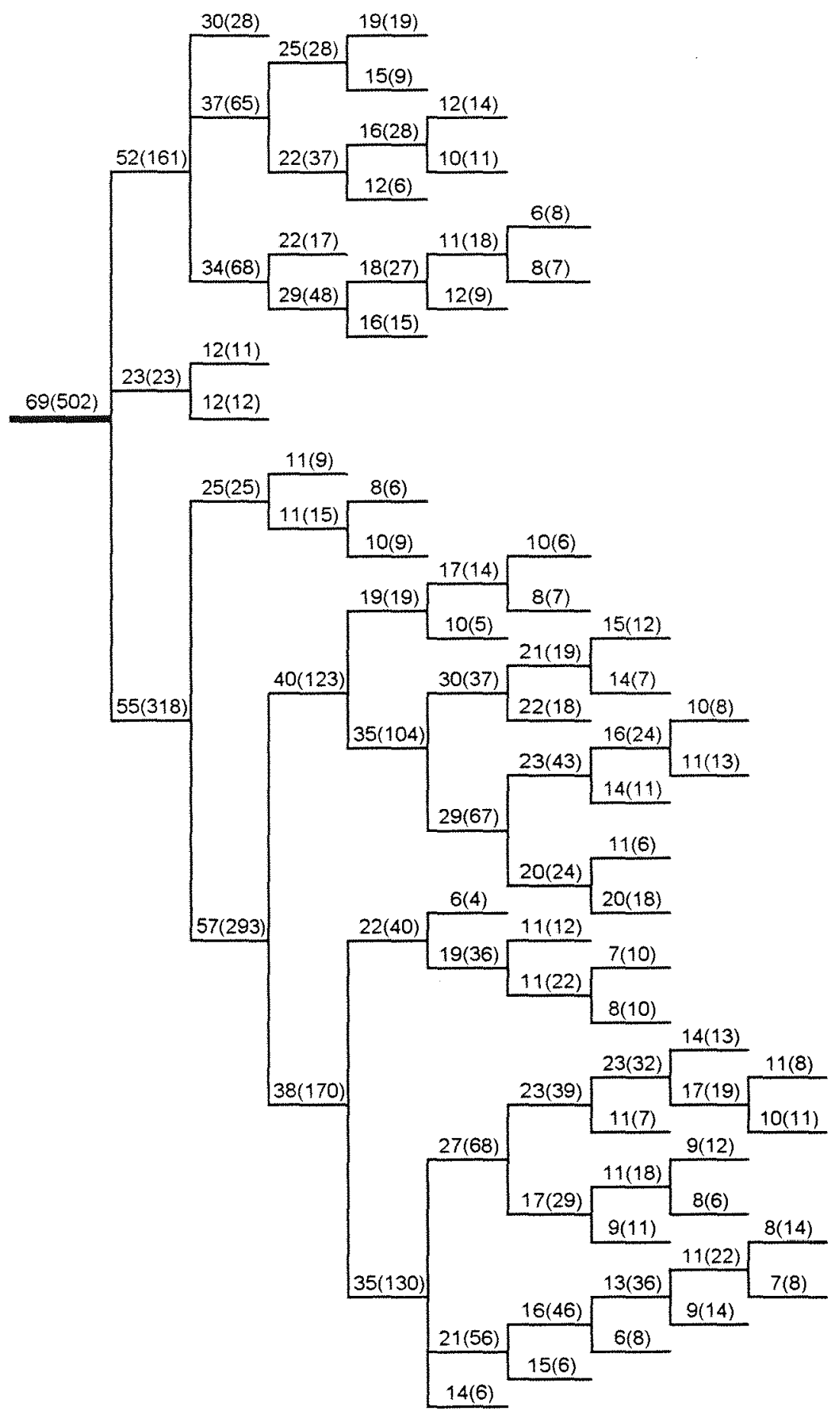

Figura 20 - Árvore 20. 


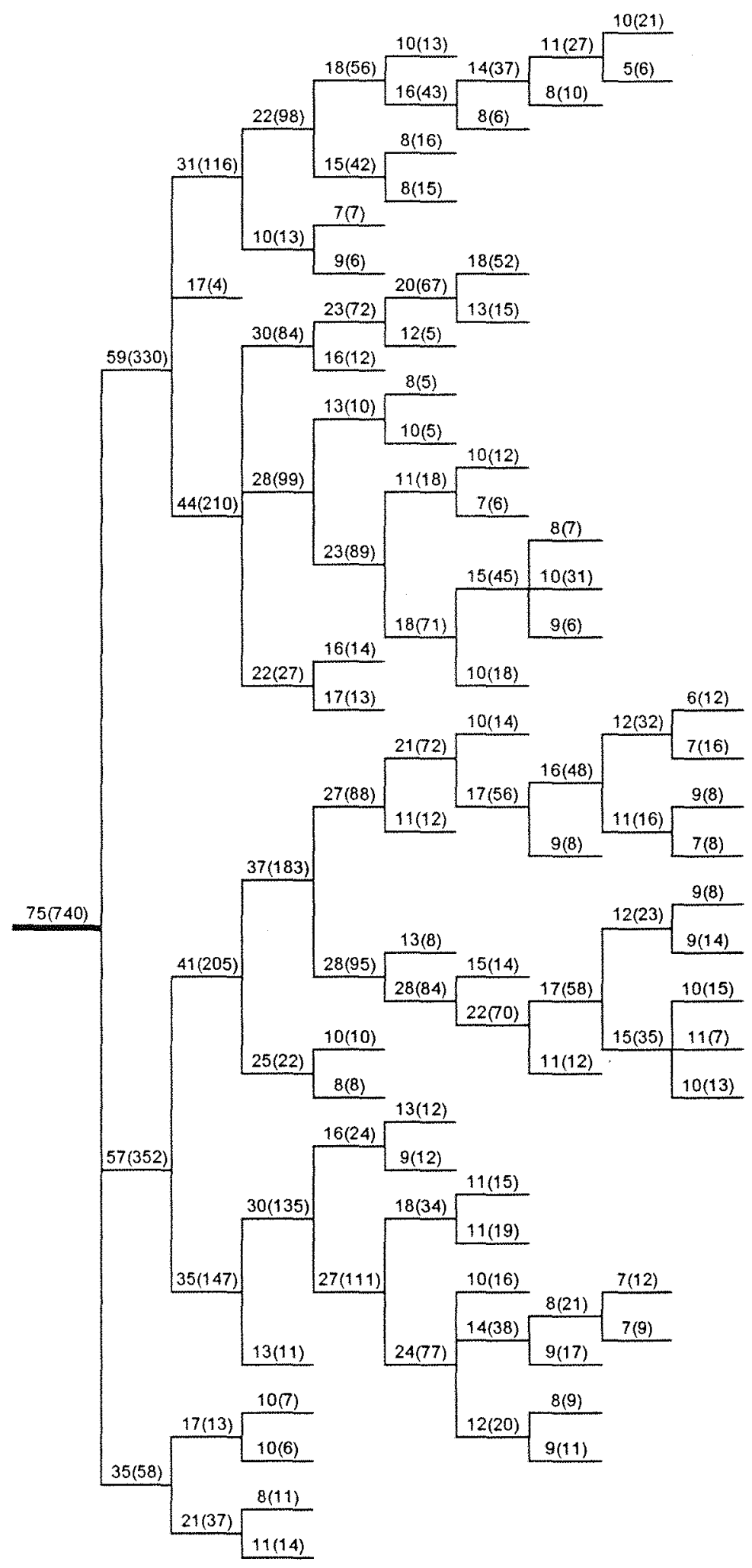

Figura 21 - Árvore 21. 


\subsection{Métodos}

Inicialmente, três métodos de amostragem de galhos propostos por Jessen (1955) foram empregados no estudo.

Esses métodos baseiam-se em diferentes probabilidades de seleção de galhos. No primeiro método a probabilidade de escolha dos galhos é igual em toda a copa da árvore ( $\mathrm{PE}=$ probabilidades equivalentes); no segundo, a probabilidade é proporcional ao número de galhos das bifurcações ( $\mathrm{PPN}=$ probabilidade proporcional ao número de galhos) e no terceiro método a probabilidade é proporcional à área do galho (PPA).

Para ilustrar, foi considerado o esquema da árvore $n^{\circ}$. 01, que pode ser melhor observado abaixo:

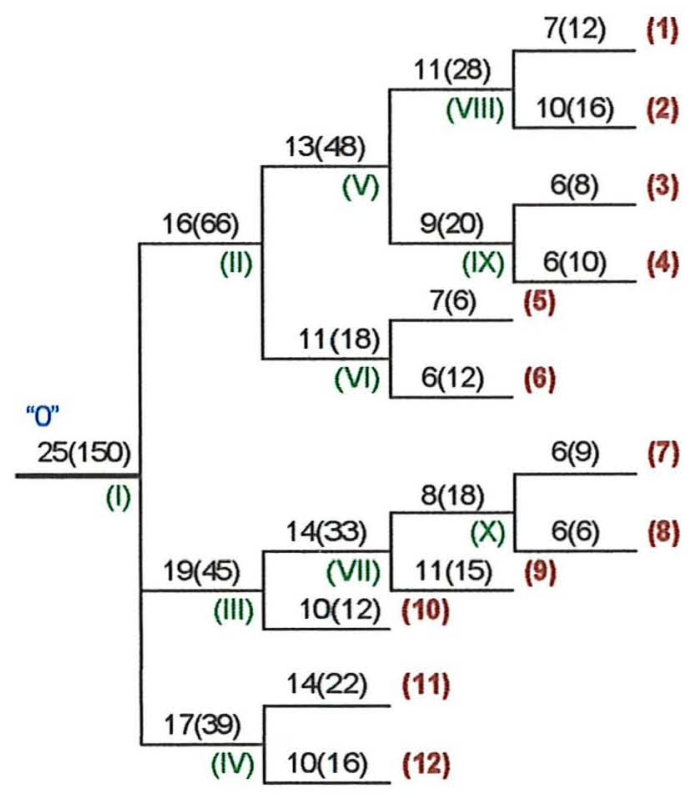

Figura 22 - Medida da circunferência e número de frutos dos principais galhos da árvore 01 . 
O tronco " 0 " se divide em três galhos com circunferências $16 \mathrm{~cm}$, $19 \mathrm{~cm}$ e $17 \mathrm{~cm}$ na bifurcação I. O galho de $16 \mathrm{~cm}$, por sua vez, se divide em dois menores de 13 e $11 \mathrm{~cm}$ na bifurcação II. E assim por diante, até totalizar a árvore. Os galhos considerados para a árvore $\mathrm{n}^{\circ}$. 01 são os de números $1 \mathrm{a} 12$.

As probabilidades dos três métodos no exemplo ficam:

$\mathrm{PE}=1 / 12$ (já que nesse caso existem 12 galhos, cada um terá a probabilidade de 1/12);

PPN $=$ existem três galhos na $1^{\mathrm{a}}$. Bifurcação, portanto a probabilidade de cada um é 1/3. Aplicando o mesmo princípio a cada bifurcação subsequente obtém-se a probabilidade final multiplicando-se as probabilidades parciais, como é mostrado a seguir.

$$
\begin{aligned}
& \text { galho }(1) \Rightarrow 1 / 3 \times 1 / 2 \times 1 / 2 \times 1 / 2=1 / 24 \\
& \text { galho }(2) \Rightarrow 1 / 3 \times 1 / 2 \times 1 / 2 \times 1 / 2=1 / 24 \\
& \text { galho }(3) \Rightarrow 1 / 3 \times 1 / 2 \times 1 / 2 \times 1 / 2=1 / 24 \\
& \text { galho }(4) \Rightarrow 1 / 3 \times 1 / 2 \times 1 / 2 \times 1 / 2=1 / 24 \\
& \text { galho }(5) \Rightarrow 1 / 3 \times 1 / 2 \times 1 / 2=1 / 12 \\
& \text { galho }(6) \Rightarrow 1 / 3 \times 1 / 2 \times 1 / 2=1 / 12 \\
& \text { galho }(7) \Rightarrow 1 / 3 \times 1 / 2 \times 1 / 2 \times 1 / 2=1 / 24 \\
& \text { galho }(8) \Rightarrow 1 / 3 \times 1 / 2 \times 1 / 2 \times 1 / 2=1 / 24 \\
& \text { galho }(9) \Rightarrow 1 / 3 \times 1 / 2 \times 1 / 2=1 / 12 \\
& \text { galho }(10) \Rightarrow 1 / 3 \times 1 / 2 \times 1 / 2 \times 1 / 2=1 / 6 \\
& \text { galho }(11) \Rightarrow 1 / 3 \times 1 / 2 \times 1 / 2 \times 1 / 2=1 / 6 \\
& \text { galho }(12) \Rightarrow 1 / 3 \times 1 / 2 \times 1 / 2 \times 1 / 2=1 / 6
\end{aligned}
$$

PPA = foi utilizado neste caso, o quadrado da circunferência como uma medida da área do corte transversal do galho. Tomando-se inicialmente a bifurcação I, tem-se: 


\begin{tabular}{lcccc}
\hline Circunferência & 16 & 19 & 17 & \\
Circunferência`2 $^{\wedge}$ & 256 & 361 & 289 & 906 \\
$\begin{array}{l}\text { Fração do total } \\
\text { ou probabilidade }\end{array}$ & 0,2825 & 0,3985 & 0,3190 & 1,0000 \\
\hline
\end{tabular}

Calcula-se, agora as probabilidades para a bifurcação II, assim:

\begin{tabular}{lccc}
\hline Circunferência & 13 & 11 & \\
Circunferência`2 & 169 & 121 & 290 \\
Fração do total ou probabilidade & 0,5828 & 0,4172 & 1,0000 \\
\hline P.P.A. & 0,1647 & 0,1179 & \\
\hline
\end{tabular}

sendo que as P.P.A. obtidas para os galhos de circunferências 13 e $16 \mathrm{~cm}$, foram obtidas, multiplicando-se os seus valores da fração do total pelo valor de probabilidade do galho 16 , ao qual estão ligados.

Para a bifurcação III, as P.P.A. são obtidas de maneira análoga, assim:

\begin{tabular}{lccc}
\hline Circunferência & 14 & 10 & \\
Circunferência`2 & 196 & 100 & 296 \\
Fração do total ou probabilidade & 0,6622 & 0,3378 & 1,0000 \\
\hline P.P.A. & 0,2638 & 0,1346 & \\
\hline
\end{tabular}

Utilizando o mesmo princípio, obtém-se as probabilidades proporcionais à área para os doze galhos principais, observadas na Tabela 03 . 
Tabela 03 - Medida das circunferências e cálculo das probabilidades proporcionais à area para todos os galhos da árvore 01 .

\begin{tabular}{|c|c|c|c|c|c|c|}
\hline Circunferência dos galhos & \multicolumn{2}{|c|}{16} & \multicolumn{2}{|c|}{19} & \multicolumn{2}{|c|}{17} \\
\hline P.P.A. & \multicolumn{2}{|c|}{0,2825} & \multicolumn{2}{|c|}{0,3985} & \multicolumn{2}{|c|}{0,3190} \\
\hline $\begin{array}{l}\text { Circunferência dos galhos } \\
\text { da } 2^{\mathrm{a}}, 3^{\mathrm{a}} \text { e } 4^{\mathrm{a}} \text { Bifurcação }\end{array}$ & 13 & 11 & 14 & 10 & 14 & 10 \\
\hline P.P.A. & 0,1647 & 0,1179 & 0,2638 & 0,1346 & 0,2112 & 0,1078 \\
\hline $\begin{array}{l}\text { Circunferência dos galhos } \\
\text { da } 5^{\mathrm{a}}, 6^{\mathrm{a}} \text { e } 7^{\mathrm{a}} \text { Bifurcação }\end{array}$ & 11 & 9 & 7 & 6 & 8 & 11 \\
\hline P.P.A. & 0,0986 & 0,0660 & 0,0680 & 0,0499 & 0,0913 & 0,1726 \\
\hline $\begin{array}{l}\text { Circunferência dos galhos } \\
\text { da } 8^{\mathrm{a}}, 9^{\mathrm{a}} \text { e } 10^{\mathrm{a}} \text { Bifurcação }\end{array}$ & 7 & 10 & 6 & 6 & 6 & 6 \\
\hline P.P.A. & 0,0324 & 0,0662 & 0,0330 & 0,0330 & 0,0456 & 0,0456 \\
\hline
\end{tabular}

Para avaliar os efeitos nas árvores, de um procedimento de seleção de amostras de galhos, pode-se comparar as variabilidades da estimativa do total obtido, desde que a estimativa seja feita pela fórmula:

$$
\hat{X}=\frac{x}{P}
$$

onde:

$\hat{X}$ é o número estimado de frutos na árvore;

x é o número de frutos num galho-amostra;

P é a probabilidade de seleção do galho-amostra.

Como uma medida de precisão da estimativa, pode-se usar o desvio padrão de $\mathrm{X}$ ou sua variância para cada amostra, dado pela fórmula:

$$
V(\hat{X})=\sum_{i=1}^{N} P_{i}\left(\hat{X}_{i}-X\right)^{2}
$$


$\hat{X}$ é o número estimado de frutos na árvore;

$\mathrm{X}$ é o número real de frutos;

$P_{i}$ é a probabilidade de seleção do galho-amostra.

As variâncias e coeficientes de variação (C.V.) da árvore 01, correspondentes para os três métodos de seleção de galhos são apresentadas na Tabela 04, para os doze galhos-amostras.

Tabela 04 - Valores das estimativas do número de frutos, variância e coeficiente de variação, para os três métodos de seleção de galhos, árvore 01 .

\begin{tabular}{|c|c|c|c|c|c|c|c|}
\hline $\mathrm{N}^{\circ}$ do galho & $\begin{array}{l}\mathrm{N}^{\circ} \mathrm{de} \\
\text { frutos }\end{array}$ & $P E$ & PPN & PPA & $\begin{array}{l}\text { Estimativa do } \\
\mathrm{n}^{\circ} \text { de frutos } \\
\text { (PE) }\end{array}$ & $\begin{array}{c}\text { Estimativa do } \\
\mathrm{n}^{\circ} \text { de frutos } \\
\text { (PPN) }\end{array}$ & $\begin{array}{c}\text { Estimativa do } \\
\mathrm{n}^{\circ} \text { de frutos } \\
\text { (PPA) }\end{array}$ \\
\hline 1 & 12 & $1 / 12$ & $1 / 24$ & 0,0324 & 144 & 288 & 370 \\
\hline 2 & 16 & $1 / 12$ & $1 / 24$ & 0,0662 & 192 & 384 & 242 \\
\hline 3 & 8 & $1 / 12$ & $1 / 24$ & 0,0330 & 96 & 192 & 242 \\
\hline 4 & 10 & $1 / 12$ & $1 / 24$ & 0,0330 & 120 & 240 & 303 \\
\hline 5 & 6 & $1 / 12$ & $1 / 12$ & 0,0680 & 72 & 72 & 88 \\
\hline 6 & 12 & $1 / 12$ & $1 / 12$ & 0,0499 & 144 & 144 & 240 \\
\hline 7 & 9 & $1 / 12$ & $1 / 24$ & 0,0456 & 108 & 216 & 197 \\
\hline 8 & 6 & $1 / 12$ & $1 / 24$ & 0,0456 & 72 & 144 & 131 \\
\hline 9 & 15 & $1 / 12$ & $1 / 12$ & 0,1726 & 180 & 180 & 87 \\
\hline 10 & 12 & $1 / 12$ & $1 / 6$ & 0,1346 & 144 & 72 & 89 \\
\hline 11 & 22 & $1 / 12$ & $1 / 6$ & 0,2112 & 264 & 132 & 104 \\
\hline 12 & 16 & $1 / 12$ & $1 / 6$ & 0,1078 & 192 & 96 & 148 \\
\hline TOTAIS & 144 & 1 & 1 & 1,0000 & & & \\
\hline VARIÂNCIA & & & & & 2940,0000 & 5808,0000 & 5591,8603 \\
\hline MÉDIA & & & & & 144,00 & 180,00 & 186,90 \\
\hline C.V. $(\%)$ & & & & & 37,65 & 42,34 & 40,01 \\
\hline
\end{tabular}

No caso da laranja, existem frutos que nascem em pequenos galhos diretamente conectados com galhos relativamente grandes. Entretanto, o galho é geralmente tão pequeno em diâmetro que é dificil medir seu tamanho 
acuradamente. Nesse caso, é aconselhável contar as frutas desses galhos juntamente com as do galho maior ao qual está ligado (Jessen, 1955).

Com o objetivo de se determinar qual o tamanho mínimo de um galho (circunferência mínima ou número de frutos/galho mínimo), afim de eliminar a contagem de galhos muito pequenos, agrupando os seus frutos aos do galho ao qual está conectado, foi realizado uma série de simulações com as árvores disponíveis nesse trabalho.

Considerando-se que as árvores na categoria de idade 1 são de porte pequeno, estabeleceu-se os seguintes tamanhos mínimos:

$\left.1^{\circ}\right)$ Circunferência: $7 \mathrm{~cm}-\mathrm{N}^{\circ}$.de frutos/galho: 10

$2^{\circ}$ ) Circunferência: $10 \mathrm{~cm}-\mathrm{N}^{\circ}$.de frutos/galho: 10

$\left.3^{\circ}\right)$ Circunferência: $10 \mathrm{~cm}-\mathrm{N}^{\circ}$.de frutos/galho: 20

$\left.4^{\circ}\right)$ Circunferência: $15 \mathrm{~cm}-\mathrm{N}^{\circ}$.de frutos/galho: 30

Para as categorias de idades 2 e 3 consideraram-se os tamanhos:

$\left.1^{\circ}\right)$ Circunferência: $7 \mathrm{~cm}-\mathrm{N}^{\circ}$.de frutos/galho: 10

$\left.2^{\circ}\right)$ Circunferência: $10 \mathrm{~cm}-\mathrm{N}^{\circ}$.de frutos/galho: 20

$\left.3^{\circ}\right)$ Circunferência: $15 \mathrm{~cm}-\mathrm{N}^{\circ}$.de frutos/galho: 30

$\left.4^{\circ}\right)$ Circunferência: $20 \mathrm{~cm}-\mathrm{N}^{\circ}$.de frutos/galho: 40

$5^{\circ}$ ) Circunferência: $25 \mathrm{~cm}-\mathrm{N}^{\circ}$.de frutos/galho: 50

As figuras representativas para essas condições, podem ser observadas no Apêndice 1.

Os três métodos foram avaliados para as árvores, considerando todos os tamanhos-limites. 


\section{RESULTADOS E DISCUSSÃO}

Como visto, até agora, os objetivos desse trabalho são:

- verificar a eficiência dos três métodos de seleção de galhos, propostos na metodologia;

- determinar o "ponto de parada", ou seja, um tamanho mínimo de galho que forneça a melhor estimativa com maior eficiência, para o método que se mostrar mais eficiente;

- estudar uma possível combinação dos dois melhores métodos,através da análise de regressão múltipla, averiguando uma provável melhora nas estimativas da produção da árvore.

Inicialmente, a eficiência dos três métodos de seleção de galhos, foi determinada através da comparação dos valores de variância e coeficiente de variação, para todas as árvores, que podem ser observados nas Tabelas de 5 a 106, no Apêndice 2.

Para uma melhor visualização, as tabelas 107,108 e 109 apresentam um resumo desses resultados. Observa-se, então, que as menores variâncias são encontradas no método que utiliza a probabilidade proporcional à área (PPA), principalmente para as categorias de idades 2 e 3 , e as maiores variâncias, no método que utiliza a probabilidade equivalente ao número de galhos $(\mathrm{PE})$. 
Tabela 107 - Valores de variância e coeficiente de variação para as árvores da idade 1.

\begin{tabular}{|c|c|c|c|c|c|c|c|}
\hline Árvore & $\begin{array}{c}\text { Tamanho } \\
\text { limite }\end{array}$ & $\begin{array}{l}\text { Variância } \\
\text { (PE) }\end{array}$ & $\begin{array}{l}\text { Variância } \\
\text { (PPN) }\end{array}$ & $\begin{array}{c}\text { Variância } \\
\text { (PPA) }\end{array}$ & $\begin{array}{c}\mathrm{CV}(\%) \\
(\mathrm{PE})\end{array}$ & $\begin{array}{l}\mathrm{CV}(\%) \\
(\mathrm{PPN})\end{array}$ & $\begin{array}{l}\mathrm{CV}(\%) \\
\text { (PPA) }\end{array}$ \\
\hline \multirow[t]{5}{*}{01} & $(4-4)^{(*)}$ & 2940,0000 & 5808,0000 & 5591,8603 & 37,65 & 42,34 & 40,01 \\
\hline & $(7-10)$ & 813,0000 & 6036,0000 & 5502,9153 & 19,14 & 40,75 & 39,43 \\
\hline & (10-1 & 5406,0000 & 5406,0000 & 4569 & 49,35 & 49,35 & 43,71 \\
\hline & & 2196,0000 & 3906,0000 & 4090,6444 & 31,24 & 38,58 & 37,66 \\
\hline & & 1206,0000 & 1206,0000 & 2766,5453 & 23,15 & 23,15 & 33,66 \\
\hline \multirow[t]{5}{*}{02} & & 3458,5817 & 21352,0000 & 6208 & 42,16 & 60,11 & 45,69 \\
\hline & $(7-1)$ & 2688,0000 & 13544,0000 & 440 & 35,27 & 56,22 & 41,65 \\
\hline & (1) & 5038,0000 & 11448,0000 & 3853 & 48,28 & 55,34 & 40,64 \\
\hline & $(10-20)$ & 64,0000 & 64,0000 & 544,1830 & 5,41 & 5,41 & 15,25 \\
\hline & (1 & - & - & - & - & - & - \\
\hline \multirow[t]{5}{*}{03} & $(4-4)$ & 6388,0000 & 14451,0000 & 7103,8868 & 51,32 & 73,02 & 64,34 \\
\hline & $(7-10)$ & 1184,0000 & 3920,0000 & 453 & 25,30 & 41,41 & 43,38 \\
\hline & $(10-10)$ & 2144,0000 & 3152,0000 & 4458,0 & 34,05 & 37,43 & 40,39 \\
\hline & $(10-20)$ & 3104,0000 & 3104,0000 & 3580,6 & 40,97 & 40,97 & 43,16 \\
\hline & $(15-30)$ & & - & - & - & - & - \\
\hline \multirow[t]{5}{*}{08} & $(4-4)$ & 2306,0000 & 4034,0000 & 1402,7129 & 42,50 & 48,48 & 31,07 \\
\hline & $(7-10)$ & 2466,0000 & 1316,0000 & & 43,95 & 27,61 & 24,75 \\
\hline & $(10-10)$ & 194,0000 & 194,0000 & 263,0 & 12,33 & 12,33 & 13,97 \\
\hline & $(10-20)$ & - & - & - & - & - & - \\
\hline & $(15-30)$ & - & - & - & - & - & - \\
\hline \multirow[t]{5}{*}{14} & $(4-4)$ & 3817,0000 & 10803, & 8657 & 44,77 & 54,33 & 50,02 \\
\hline & $(7-10)$ & 49,0000 & 1491,0000 & 344 & 37,71 & 24,59 & 32,37 \\
\hline & $(10-10)$ & 1663,0000 & 1341,0000 & 3427,1 & 28,32 & 24,61 & 36,43 \\
\hline & $(10-20)$ & 1793,0000 & 753,0000 & 3422,6660 & 29,41 & 18,48 & 35,72 \\
\hline & $(15-30)$ & 438,0000 & 438,0000 & 53,6899 & 14,24 & 14,24 & 5,01 \\
\hline \multirow[t]{5}{*}{15} & $(4-4)$ & 3679,7500 & 14934,0000 & 838,2708 & 37,91 & 56,48 & 17,71 \\
\hline & & 1770,0000 & 2178,0000 & 507,4 & 26,63 & 26,67 & 14,63 \\
\hline & $(10-10)$ & 2995,0000 & 321,0000 & 46,7755 & 33,78 & 10,81 & 4,16 \\
\hline & $(10-20)$ & - & - & - & - & - & - \\
\hline & & - & - & - & - & - & - \\
\hline \multirow[t]{6}{*}{16} & $(4-4)$ & 26691,7436 & 229451,5000 & 75995,9808 & 39,27 & 59,59 & 48,96 \\
\hline & & 41067,8095 & 113119,0000 & & & & 45,38 \\
\hline & $(10-10)$ & 30419,2308 & 75002,0000 & 39292,5324 & 42,44 & 51,96 & 42,64 \\
\hline & $(10-20)$ & 16809,2222 & 39722,0000 & & 31,32 & 40,80 & 34,33 \\
\hline & $(15-30)$ & 15847,3333 & 44296,0000 & 23663,8524 & 28,87 & 43,01 & 34,23 \\
\hline & $(20-40)$ & 32096,0000 & 32096,0000 & 16652,6042 & 41,09 & 41,09 & 30,01 \\
\hline
\end{tabular}

$\left(^{*}\right)$ menor tamanho-limite encontrado nas árvores, ou seja, identifica a árvore toda. 
Tabela 108 - Valores de variância e coeficiente de variação para as árvores da idade 2.

\begin{tabular}{|c|c|c|c|c|c|c|c|}
\hline Árvore & $\begin{array}{c}\text { Tamanho } \\
\text { limite }\end{array}$ & $\begin{array}{c}\text { Variância } \\
(\mathrm{PE})\end{array}$ & $\begin{array}{c}\text { Variância } \\
\text { (PPN) }\end{array}$ & $\begin{array}{c}\text { Variância } \\
\text { (PPA) }\end{array}$ & $\begin{array}{l}\mathrm{CV}(\%) \\
(\mathrm{PE})\end{array}$ & $\begin{array}{l}\mathrm{CV}(\%) \\
(\mathrm{PPN})\end{array}$ & $\begin{array}{l}\mathrm{CV}(\%) \\
(\mathrm{PPA})\end{array}$ \\
\hline \multirow[t]{5}{*}{04} & $(4-4)$ & 20397,0000 & 140139,0000 & 24257,8221 & 45,92 & 66,83 & 42,83 \\
\hline & $(7-10)$ & 13600,0000 & 125685,0000 & 22780,4758 & 37,38 & 59,07 & 43,35 \\
\hline & $(10-20)$ & 40080,0000 & 55563,0000 & 9289,8654 & 64,17 & 58,69 & 29,50 \\
\hline & $(15-30)$ & 18424,0000 & 16632,0000 & 967,1936 & 43,50 & 38,55 & 9,70 \\
\hline & $(20-40)$ & 16200,0000 & 16200,0000 & 79,4192 & 40,79 & 40,79 & 2,84 \\
\hline \multirow[t]{5}{*}{05} & -4) & 69196,0000 & 435124,0000 & 99756,6883 & 47,65 & 59,45 & 47,27 \\
\hline & $(7-10)$ & 61052,0000 & 350259,0000 & 86741,3497 & 44,84 & 58,50 & 46,21 \\
\hline & $(10-20)$ & 52068,0000 & 241329,0000 & 64010,1848 & 41,64 & 47,18 & 37,94 \\
\hline & $(15-30)$ & 80052,0000 & 183905,0000 & 52575,9980 & 50,34 & 65,35 & 41,94 \\
\hline & $(20-40)$ & 72158,0000 & 72158,0000 & 20371,2826 & 47,80 & 47,80 & 26,70 \\
\hline \multirow[t]{5}{*}{09} & $(4-6)$ & 2871,0000 & 20409,0 & 6924,0658 & 34,13 & 57,93 & 44,80 \\
\hline & $(7-10)$ & 3841,0000 & 13438,0000 & 5988,5649 & 38,26 & 46,43 & 37,93 \\
\hline & $(10-20)$ & 5486,0000 & 10574,0000 & 5242,7194 & 44,35 & 55,11 & 40,21 \\
\hline & $(15-30)$ & 1,0000 & 1,0000 & 83,7661 & 0,60 & 0,60 & 5,47 \\
\hline & $(20-40)$ & - & - & - & - & - & - \\
\hline \multirow[t]{5}{*}{10} & $(4-4)$ & 327933,0000 & 1543808,0000 & 122428,7849 & 82,63 & 58,93 & 47,59 \\
\hline & $(7-10$ & 177756,0000 & 847252,0000 & 74705,5055 & 62,18 & 59,46 & 37,02 \\
\hline & $(10-20)$ & 119400,0000 & 669584,0000 & 65256,2974 & 52,20 & 63,19 & 37,37 \\
\hline & $(15-30)$ & 27666,0000 & 97184,0000 & 20732,0199 & 23,66 & 39,10 & 20,40 \\
\hline & $(20-40)$ & 88436,0000 & 36771,0000 & 25356,9470 & 42,30 & 26,83 & 23,4 \\
\hline \multirow[t]{5}{*}{17} & $(4-4)$ & 148772,4958 & 1244966,1823 & 149355,4100 & 61,52 & 53,51 & 51,00 \\
\hline & $(7-10)$ & 99659,8333 & 633215,6667 & 149220,9474 & 51,08 & 56,32 & 50,93 \\
\hline & $(10-20)$ & 85363,9836 & 182988,0156 & 65760,3150 & 50,12 & 57,39 & 41,02 \\
\hline & $(15-30)$ & 51026,8000 & 9067,3333 & 21081,4506 & 29,96 & 12,42 & 18,44 \\
\hline & $(20-40)$ & 4698,6667 & 4698,6667 & 2668,9545 & 9,09 & 9,09 & 6,72 \\
\hline \multirow[t]{5}{*}{18} & $(4-4)$ & 66660,3380 & 1661055,1343 & 229335,7267 & 32,97 & 46,18 & 46,39 \\
\hline & $(7-10)$ & 123868,0000 & 680035,0000 & 201580,5072 & 47,11 & 53,74 & 48,26 \\
\hline & $(10-20)$ & 85421,0000 & 497649,0000 & 184093,6680 & 37,37 & 57,09 & 46,43 \\
\hline & $(15-30)$ & 79157,0000 & 284796,0000 & 121690,7173 & 34,39 & 46,86 & 35,59 \\
\hline & $(20-40)$ & 251619,0000 & 98642,0000 & 112970,4302 & 60,95 & 39,92 & 41,44 \\
\hline
\end{tabular}


Tabela 109 - Valores de variância e coeficiente de variação para as árvores da idade 3 .

\begin{tabular}{|c|c|c|c|c|c|c|c|}
\hline Árvore & $\begin{array}{c}\text { Tamanho } \\
\text { limite }\end{array}$ & $\begin{array}{l}\text { Variância } \\
\text { (PE) }\end{array}$ & $\begin{array}{l}\text { Variância } \\
\text { (PPN) }\end{array}$ & $\begin{array}{l}\text { Variância } \\
\text { (PPA) }\end{array}$ & $\begin{array}{l}\mathrm{CV}(\%) \\
(\mathrm{PE})\end{array}$ & $\begin{array}{l}\mathrm{CV}(\%) \\
(\mathrm{PPN})\end{array}$ & $\begin{array}{l}\mathrm{CV}(\%) \\
\text { (PPA) }\end{array}$ \\
\hline \multirow[t]{6}{*}{06} & $(4-4)$ & 65205,5781 & 2379359,0000 & 143351,3646 & 35,49 & 43,89 & 45,14 \\
\hline & $(7-10)$ & 112126,0000 & 721259,0000 & 62906,2700 & 48,32 & 48,70 & 32,60 \\
\hline & $(10-20)$ & 80033,0000 & 405461,0000 & 63401,5169 & 40,41 & 52,86 & 34,33 \\
\hline & & 80936,0000 & 137240,0000 & 26496,5167 & 40,47 & 41,06 & 23,42 \\
\hline & & 25773,0000 & 104907,0000 & 13608,6928 & 21,87 & 38,38 & 15,61 \\
\hline & $(25-5$ & 27225,0000 & 27225,0000 & 14165,3753 & 21,63 & 21,63 & 15,75 \\
\hline \multirow[t]{6}{*}{07} & $(4-4)$ & 20232,0000 & 265515,0000 & 35172,2518 & 46,48 & 53,18 & 49,74 \\
\hline & $(7-10)$ & 13600,0000 & 77529,0000 & 12588,5696 & 39,94 & 53,36 & 35,08 \\
\hline & $(10-20)$ & 34732,0000 & 25446,0000 & 8266,0997 & 59,73 & & 28,49 \\
\hline & $(15-30)$ & 21306,0000 & 3264,0000 & 1874,0426 & 46,78 & 18,82 & 13,21 \\
\hline & $(20-40)$ & 1098,0000 & 1098,0000 & 1728,7934 & 10,62 & 10,62 & 12,95 \\
\hline & $(25-50)$ & 11236,0000 & 11236,0000 & 9182,3791 & 33,97 & 33,97 & 31,03 \\
\hline \multirow[t]{6}{*}{11} & & 368689 & 486391 & 315046 & 56,59 & 38,65 & 42,26 \\
\hline & $(7-10)$ & 227013 & 2525526,0000 & 2305 & 45,42 & 44,09 & 38,83 \\
\hline & $(10-20)$ & 314670,0000 & 1860303,0000 & 294067,8172 & 50,72 & 48,41 & 37,68 \\
\hline & $5-30)$ & 233682,0000 & 944154,0000 & 173891,0324 & 45,48 & 52,49 & 36,85 \\
\hline & $(20-40)$ & 152616,0000 & 732486,0000 & 139735,6164 & 35,13 & 56,98 & 33,28 \\
\hline & $(25-50)$ & 323816,0000 & 699540,0000 & 136659,5762 & 50,72 & 56,99 & 33,95 \\
\hline \multirow[t]{6}{*}{12} & $(4-4)$ & 5139 & 268532 & 448699 & 76,43 & 75,91 & 65,22 \\
\hline & $(7-10)$ & & 93217 & 2623 & 54,90 & & 49,23 \\
\hline & $(10-20)$ & 250356,0000 & 573570,0000 & 175433,5019 & 54,98 & 54,35 & 41,25 \\
\hline & $5-30)$ & 220731,0000 & 305301,0000 & 592 & 49,20 & 48 & 24,94 \\
\hline & $(20-40)$ & 119952,0000 & 185339,0000 & 28126,5848 & 35,45 & 41,02 & 17,41 \\
\hline & $(25-50)$ & 181376,0000 & 62828,0000 & 11614,5578 & 43,46 & 24,55 & 10,81 \\
\hline \multirow[t]{6}{*}{13} & $(4-4)$ & 119719,6721 & 1046477,0000 & 163659,4738 & 38,70 & 60,27 & 40,98 \\
\hline & & 141275,0000 & 575542,0000 & 94943 & 43,65 & 48,39 & 33,46 \\
\hline & $(10-20)$ & 89095,0000 & 422238,0000 & 75060,1 & 34,27 & 49 , & 29,66 \\
\hline & $(15-30)$ & 151979,5000 & 128998,0000 & 43349,6245 & 41,96 & 37,46 & 21,56 \\
\hline & & 58467,0000 & 58467,0000 & 7372,6894 & 26,03 & 26,03 & 9,28 \\
\hline & & & & $x^{3}+2$ & s & - & - \\
\hline \multirow[t]{6}{*}{19} & $(4-4)$ & 80017,5200 & 1397691,9167 & 93390,9327 & 43,52 & 49,34 & 42,15 \\
\hline & & 49264,8788 & 990644,8 & 64999,3 & 35,23 & & 36,75 \\
\hline & $(10-20)$ & 76092,1176 & 94239,8 & 16951,3336 & 46,83 & 37,89 & 20,92 \\
\hline & $(15-30)$ & 50168,1000 & 92021,8333 & 11529,3875 & 34,73 & 41,09 & 16,10 \\
\hline & & 32251,5556 & 38264,8333 & 16813,4939 & 27,84 & 27,97 & 19,57 \\
\hline & $(25-50)$ & 24722,7500 & 26896,6667 & 8715,2250 & 23,36 & 22,59 & 13,53 \\
\hline
\end{tabular}


Tabela 109 - Valores de variância e coeficiente de variação para as árvores da idade 3. (continuação).

\begin{tabular}{|c|c|c|c|c|c|c|c|}
\hline Árvore & $\begin{array}{c}\text { Tamanho } \\
\text { limite }\end{array}$ & $\begin{array}{l}\text { Variância } \\
\text { (PE) }\end{array}$ & $\begin{array}{c}\text { Variância } \\
\text { (PPN) }\end{array}$ & $\begin{array}{c}\text { Variância } \\
\text { (PPA) }\end{array}$ & $\begin{array}{c}\mathrm{CV}(\%) \\
(\mathrm{PE})\end{array}$ & $\begin{array}{l}\mathrm{CV}(\%) \\
(\mathrm{PPN})\end{array}$ & $\begin{array}{l}\mathrm{CV}(\%) \\
(\mathrm{PPA}) \\
\end{array}$ \\
\hline \multirow[t]{6}{*}{20} & $(4-4)$ & 28629,2727 & 1084143,5556 & 91976,7227 & 36,70 & 39,39 & 44,99 \\
\hline & $(7-10)$ & 25107,8400 & 430933,5556 & 33946,7312 & 36,88 & 47,35 & 32,96 \\
\hline & $(10-20)$ & 29702,0769 & 451810,5556 & 54197,2352 & 35,68 & 51,95 & 41,57 \\
\hline & $(15-30)$ & 17992,5556 & 51221,3333 & 28229,0799 & 30,84 & 38,53 & 33,55 \\
\hline & $(20-40)$ & 26485,3333 & 53859,0000 & 21675,0444 & 35,85 & 39,38 & 27,53 \\
\hline & $(25-50)$ & 21171,0000 & 21171,0000 & 16362,2790 & 32,05 & 32,05 & 28,43 \\
\hline \multirow[t]{6}{*}{21} & $(4-4)$ & 170311,0000 & 2949190,0000 & 214610,5828 & 60,60 & 47,33 & 53,97 \\
\hline & $(7-10)$ & 112628,0000 & 1312998,0000 & 132131,7188 & 51,47 & 56,60 & 47,80 \\
\hline & $(10-20)$ & 134240,0000 & 417040,0000 & 69332,5197 & 55,01 & 60,49 & 38,44 \\
\hline & $(15-30)$ & 67840,0000 & 242488,0000 & 35085,5026 & 39,46 & 56,88 & 28,49 \\
\hline & $(20-40)$ & 38478,0000 & 187518,0000 & 35030,4274 & 27,32 & 46,69 & 25,85 \\
\hline & $(25-50)$ & & & & & & \\
\hline
\end{tabular}

Essas variâncias e coeficientes de variação menores, para o método PPA, observados nas tabelas acima, podem ser visualizados nas figuras 104 a 124. 


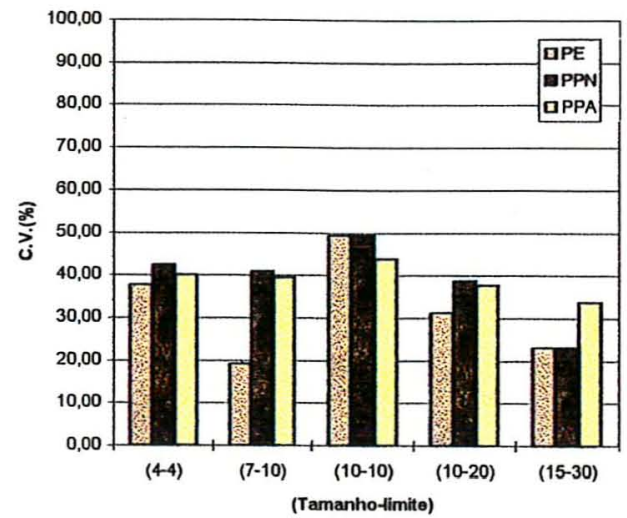

Figura 104 - Coeficiente de variação dos três métodos de seleção, em função do tamanho-limite, para a árvore 01 .

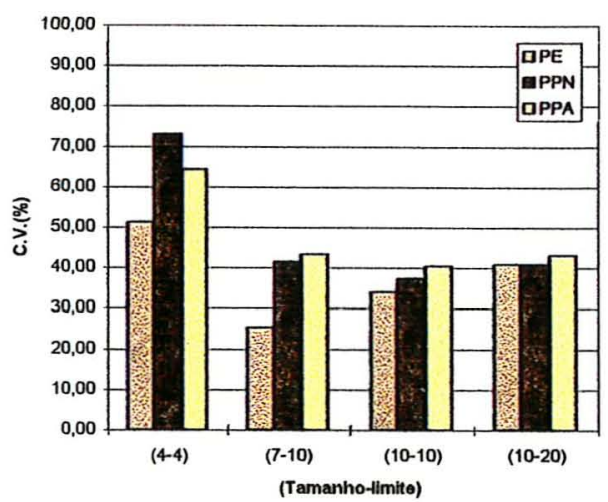

Figura 106 - Coeficiente de variação dos três métodos de seleção, em função do tamanho-limite, para a árvore 03 .

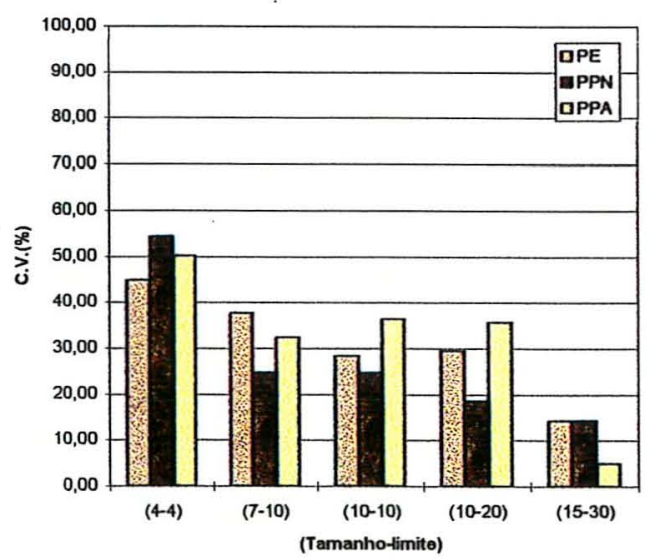

Figura 108 - Coeficiente de variação dos três métodos de seleção, em função do tamanho-limite, para a árvore 05.

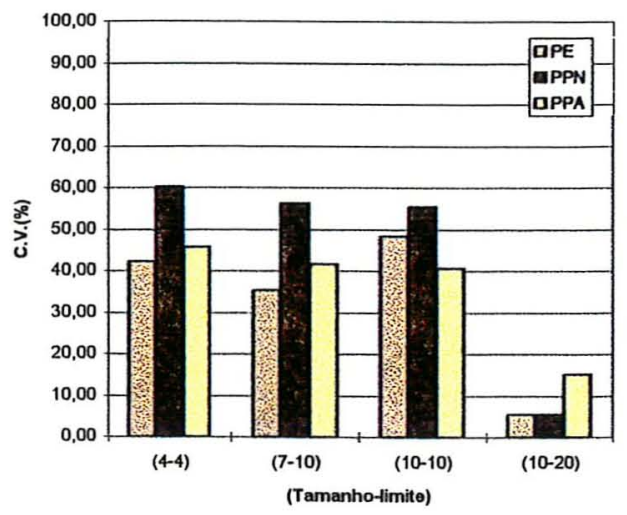

Figura 105 - Coeficiente de variação dos três métodos de seleção, em função do tamanho-limite, para a árvore 02.

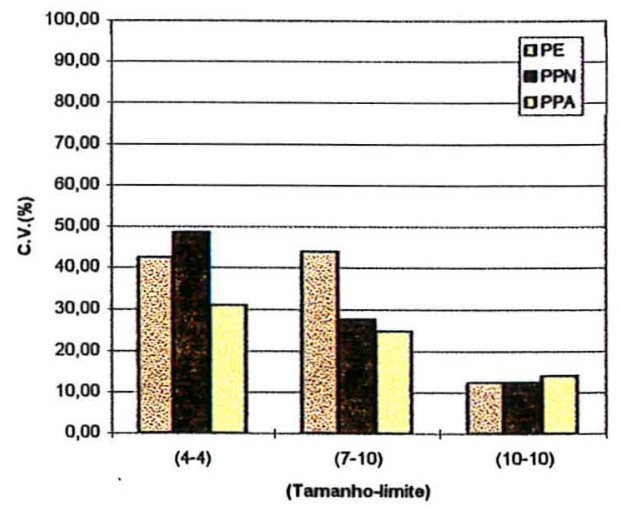

Figura 107 - Coeficiente de variação dos três métodos de seleção, em função do tamanho-limite, para a árvore 04.

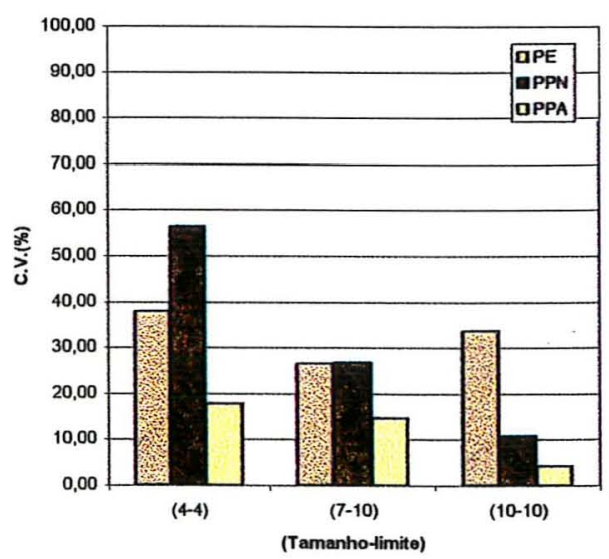

Figura 109 - Coeficiente de variação dos três métodos de seleção, em função do tamanho-limite, para a árvore 06. 


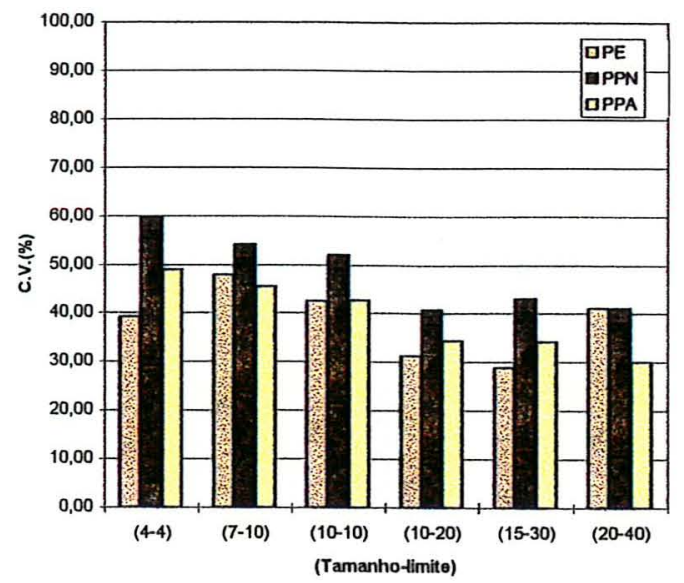

Figura 110 - Coeficiente de variação dos três métodos de seleção, em função do tamanho-limite, para a árvore 07.

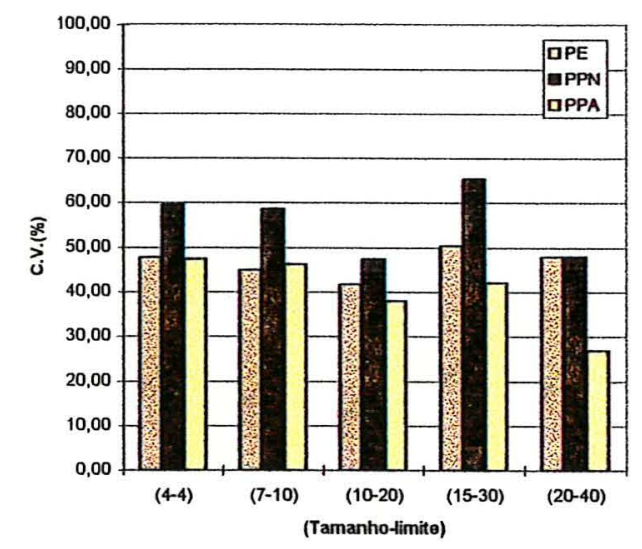

Figura 112 - Coeficiente de variação dos três métodos de seleção, em função do tamanho-limite, para a árvore 09.

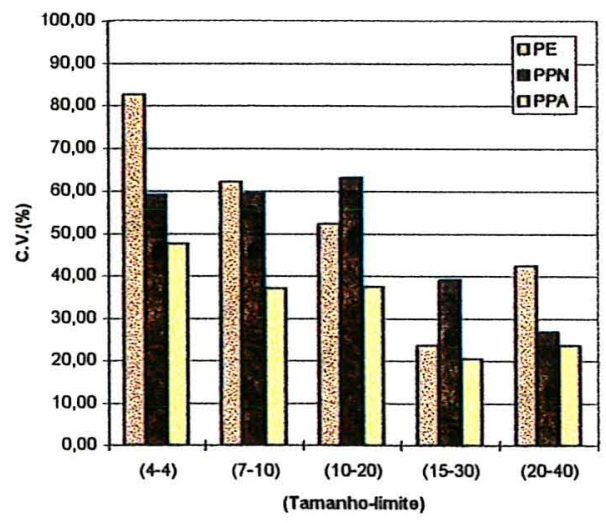

Figura 114 - Coeficiente de variação dos três métodos de seleção, em função do tamanho-limite, para a árvore 11.

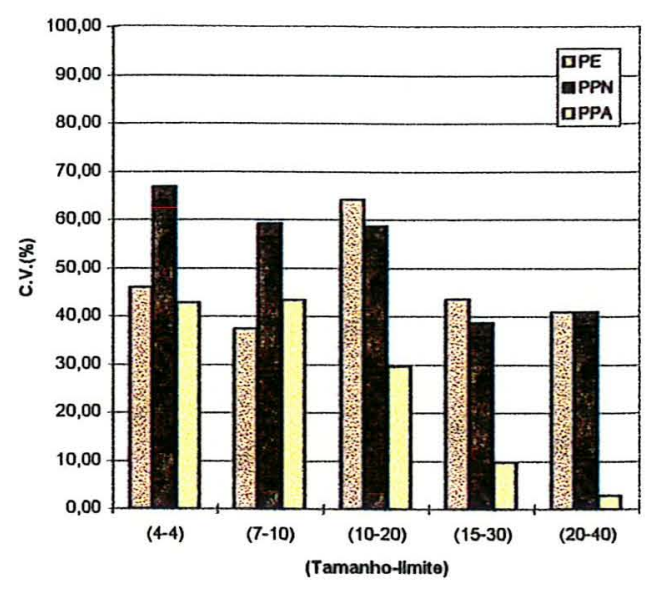

Figura 111 - Coeficiente de variação dos três métodos de seleção, em função do tamanho-limite, para a árvore 08.

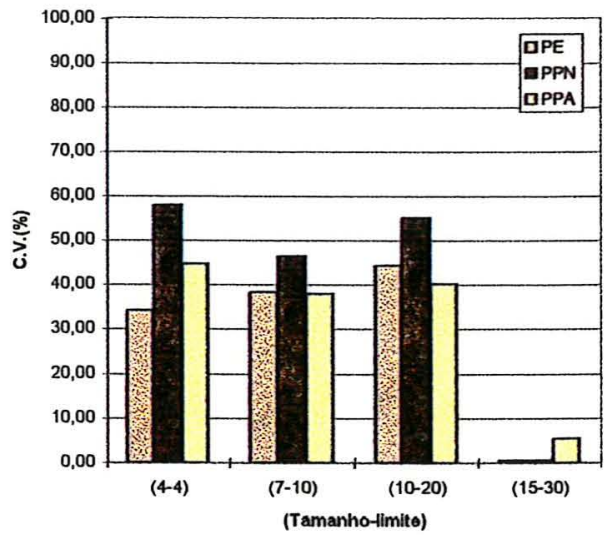

Figura 113 - Coeficiente de variação dos três métodos de seleção, em função do tamanho-limite, para a árvore 10.

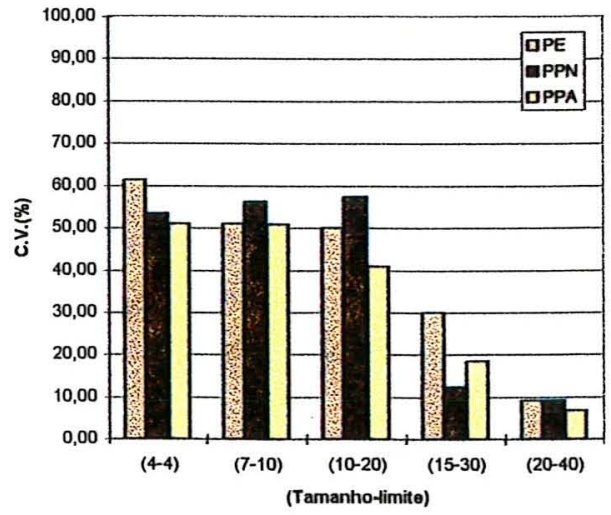

Figura 115 - Coeficiente de variação dos três métodos de seleção, em função do tamanho-limite, para a árvore 12. 


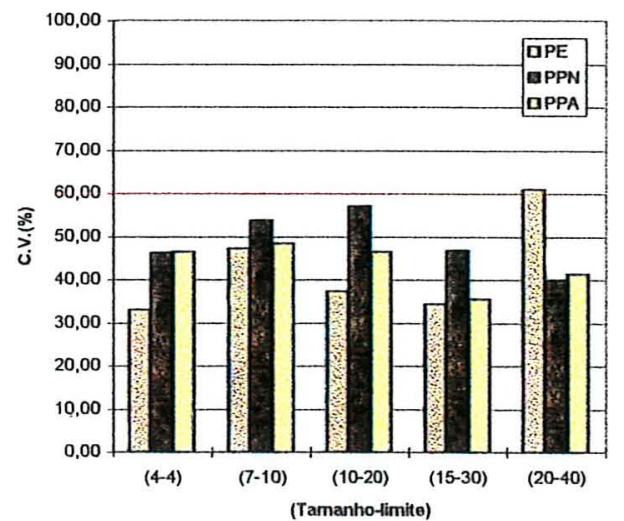

Figura 116 - Coeficiente de variação dos três métodos de seleção, em função do tamanho-limite, para a árvore 13.

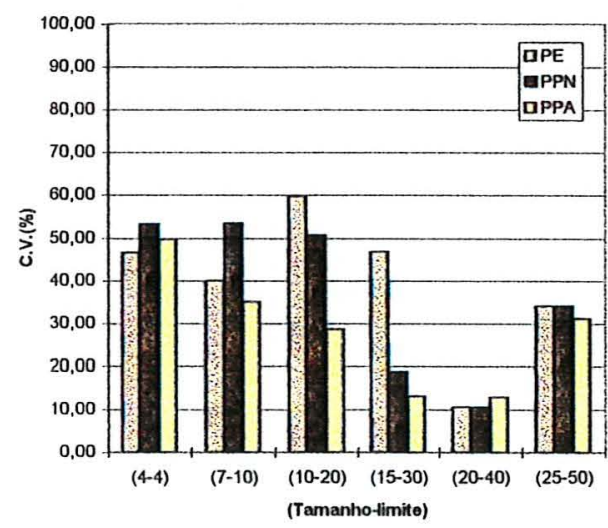

Figura 118 - Coeficiente de variação dos três métodos de seleção, em função do tamanho-limite, para a árvore 15.

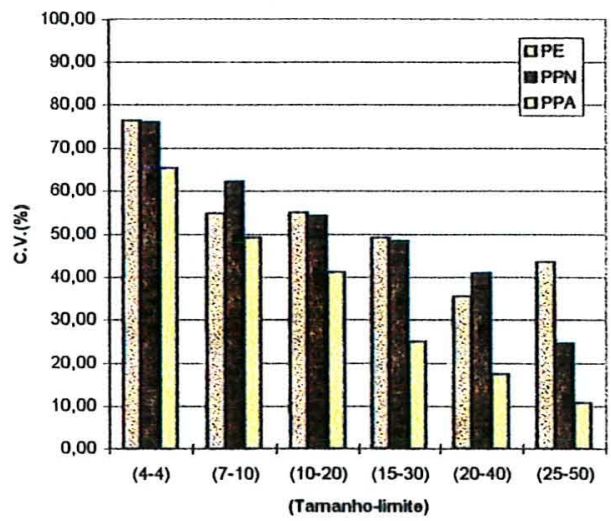

Figura 120 - Coeficiente de variação dos três métodos de seleção, em função do tamanho-limite, para a árvore 17.

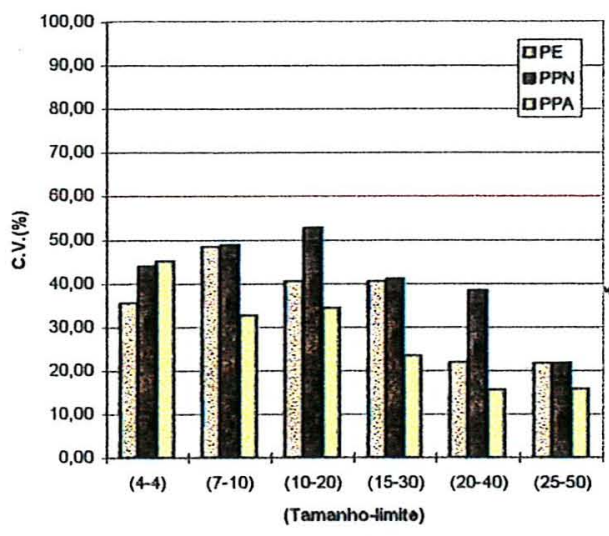

Figura 117 - Coeficiente de variação dos três métodos de selę̧ão, em função do tamanho-limite, para a árvore 14.

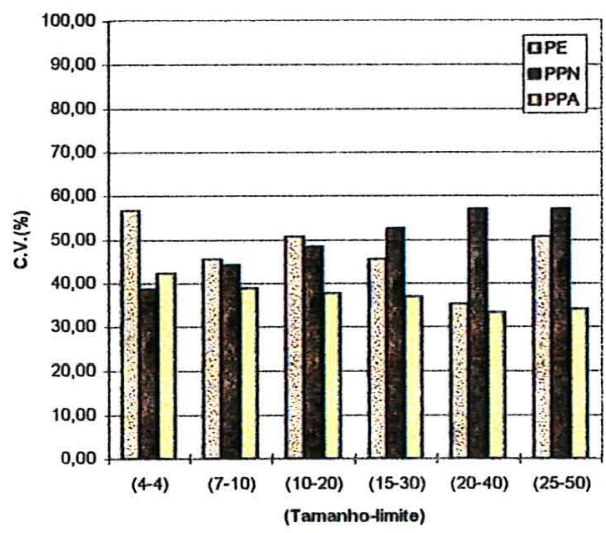

Figura 119 - Coeficiente de variação dos três métodos de seleção, em função do tamanho-limite, para a árvore 16 .

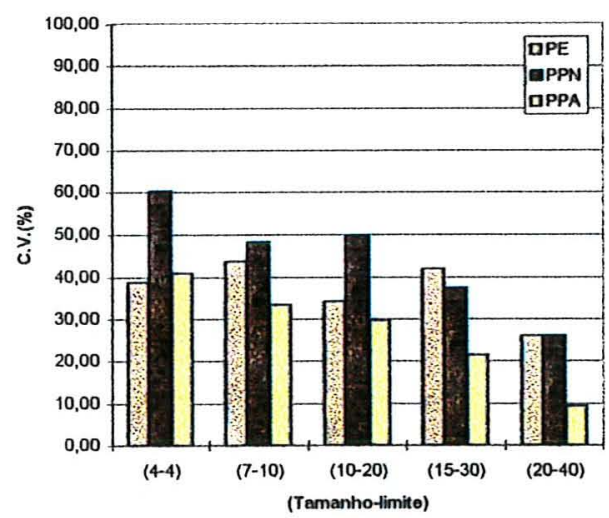

Figura 121 - Coeficiente de variação dos três métodos de seleção, em função do tamanho-limite, para a árvore 18. 


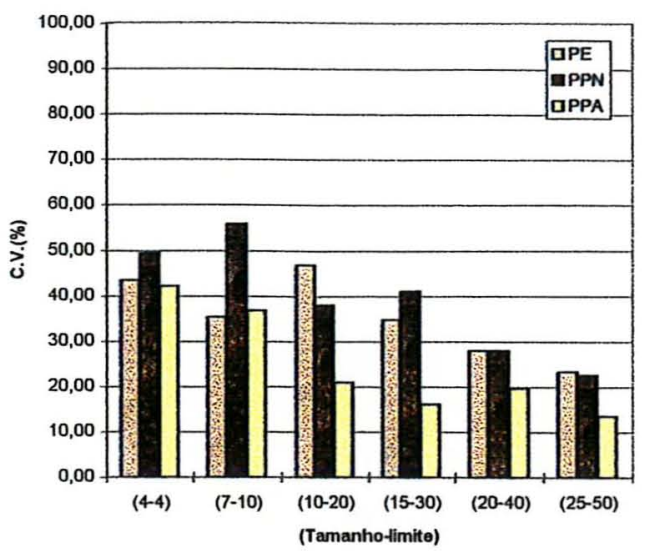

Figura 122 - Coeficiente de variação dos três métodos de seleção, em função do tamanho-limite, para a árvore 19.

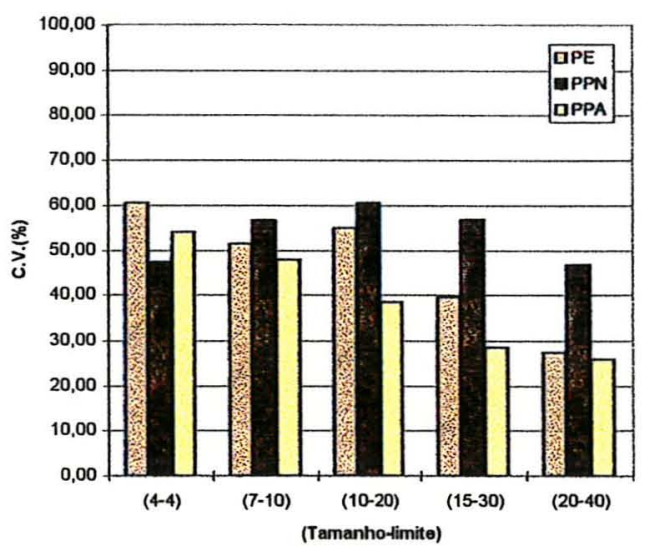

Figura 124 - Coeficiente de variação dos três métodos de seleção, em função do tamanho-limite, para a árvore 21.

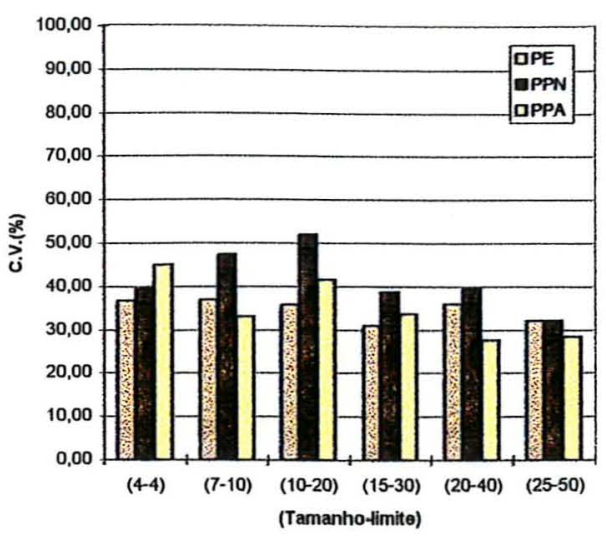

Figura 123 - Coeficiente de variação dos três métodos de seleção, em função do tamanho-limite, para a árvore 20.

Existe, aparentemente, uma tendência de comportamento dos coeficientes de variação, de acordo com o tamanho-limite, para os casos dos métodos que utilizam PPN e PPA. O método que utiliza a PE não apresentou nenhuma tendência. Como o método da PPA obteve as melhores estimativas do número total de frutos da árvore e os menores valores de variância, ele foi adotado para um estudo mais detalhado. 
Uma vez determinado o método mais eficiente, o próximo passo será determinar um tamanho-limite para o galho a ser amostrado. Para isso, estudou-se o comportamento do coeficiente de variação, entre um tamanho e outro, verificando se existe alguma tendência, nas três idades. As Tabelas 110, 111 e 112 , mostram os resultados.

Tabela 110 - Diferença obtida entre um tamanho-limite e o anterior para as árvores da idade 1 .

\begin{tabular}{cccc}
\hline Árvore & $\begin{array}{c}\text { Tamanho- } \\
\text { limite }\end{array}$ & C.V.(\%) & Diferença \\
\hline 01 & $(4-4)$ & 40,01 & - \\
& $(7-10)$ & 39,43 & $-0,58$ \\
& $(10-10)$ & 43,71 & 4,28 \\
& $(10-20)$ & 37,66 & $-6,05$ \\
& $(15-30)$ & 33,66 & $-4,00$ \\
02 & $(4-4)$ & 45,69 & - \\
& $(7-10)$ & 41,65 & $-4,04$ \\
& $(10-10)$ & 40,64 & $-1,01$ \\
& $(10-20)$ & 15,25 & $-25,39$ \\
& $(15-30)$ & - & - \\
03 & & & - \\
& $(4-4)$ & 64,34 & - \\
& $(7-10)$ & 43,38 & $-20,97$ \\
& $(10-10)$ & 40,39 & $-2,98$ \\
& $(10-20)$ & 43,16 & 2,77 \\
08 & $(15-30)$ & - & - \\
& $(4-4)$ & 31,07 & - \\
& $(7-10)$ & 24,75 & $-6,32$ \\
& $(10-10)$ & 13,97 & $-10,78$ \\
& $(10-20)$ & - & - \\
& $(15-30)$ & - & - \\
& & &
\end{tabular}


Tabela 110 - Diferença obtida entre um tamanho-limite e o anterior para as árvores da idade 1 (continuação).

\begin{tabular}{cccc}
\hline Árvore & $\begin{array}{c}\text { Tamanho- } \\
\text { limite }\end{array}$ & C.V.(\%) & Diferença \\
\hline 14 & $(4-4)$ & 50,02 & - \\
& $(7-10)$ & 32,37 & $-17,65$ \\
& $(10-10)$ & 36,43 & 4,06 \\
& $(10-20)$ & 35,72 & $-0,71$ \\
& $(15-30)$ & 5,01 & $-30,71$ \\
15 & $(4-4)$ & 17,71 & - \\
& $(7-10)$ & 14,63 & $-3,09$ \\
& $(10-10)$ & 4,16 & $-10,46$ \\
& $(10-20)$ & - & - \\
& $(15-30)$ & - & - \\
& & & \\
& $(4-4)$ & 48,96 & - \\
& $(7-10)$ & 45,38 & $-3,58$ \\
& $(10-10)$ & 42,64 & $-2,74$ \\
& $(10-20)$ & 34,33 & $-8,31$ \\
& $(15-30)$ & 34,23 & $-0,10$ \\
& $(20-40)$ & 30,01 & $-4,22$ \\
\hline
\end{tabular}


Tabela 111 - Diferença obtida entre um tamanho-limite e o anterior para as árvores da idade 2.

\begin{tabular}{|c|c|c|c|}
\hline Árvore & $\begin{array}{l}\text { Tamanho- } \\
\text { limite }\end{array}$ & C.V. $(\%)$ & Diferença \\
\hline \multirow[t]{5}{*}{04} & $(4-4)$ & 42,83 & - \\
\hline & $(7-10)$ & 43,35 & 0,52 \\
\hline & $(10-20)$ & 29,50 & $-13,85$ \\
\hline & $(15-30)$ & 9,70 & $-19,80$ \\
\hline & $(20-40)$ & 2,84 & $-6,85$ \\
\hline \multirow[t]{5}{*}{05} & $(4-4)$ & 47,27 & - \\
\hline & $(7-10)$ & 46,21 & $-1,05$ \\
\hline & $(10-20)$ & 37,94 & $-8,27$ \\
\hline & $(15-30)$ & 41,94 & 4,00 \\
\hline & $(20-40)$ & 26,70 & $-15,24$ \\
\hline \multirow[t]{5}{*}{09} & $(4-4)$ & 44,80 & - \\
\hline & $(7-10)$ & 37,93 & $-6,87$ \\
\hline & $(10-20)$ & 40,21 & 2,28 \\
\hline & $(15-30)$ & 5,47 & $-34,74$ \\
\hline & $(20-40)$ & - & - \\
\hline \multirow[t]{5}{*}{10} & $(4-4)$ & 47,59 & - \\
\hline & $(7-10)$ & 37,02 & $-10,57$ \\
\hline & $(10-20)$ & 37,37 & 0,34 \\
\hline & $(15-30)$ & 20,40 & $-16,97$ \\
\hline & $(20-40)$ & 23,49 & 3,09 \\
\hline \multirow[t]{5}{*}{17} & $(4-4)$ & 51,00 & - \\
\hline & $(7-10)$ & 50,93 & $-0,06$ \\
\hline & $(10-20)$ & 41,02 & $-9,91$ \\
\hline & $(15-30)$ & 18,44 & $-22,58$ \\
\hline & $(20-40)$ & 6,72 & $-11,72$ \\
\hline \multirow[t]{5}{*}{18} & $(4-4)$ & 46,39 & - \\
\hline & $(7-10)$ & 48,26 & 1,87 \\
\hline & $(10-20)$ & 46,43 & $-1,84$ \\
\hline & $(15-30)$ & 35,59 & $-10,84$ \\
\hline & $(20-40)$ & 41,44 & 5,85 \\
\hline
\end{tabular}


Tabela 112 - Diferença obtida entre um tamanho-limite e o anterior para as árvores da idade 3 .

\begin{tabular}{|c|c|c|c|}
\hline Árvore & $\begin{array}{l}\text { Tamanho- } \\
\text { limite }\end{array}$ & C.V. $(\%)$ & Diferença \\
\hline \multirow[t]{6}{*}{06} & $(4-4)$ & 45,14 & - \\
\hline & $(7-10)$ & 32,60 & $-12,55$ \\
\hline & $(10-20)$ & 34,33 & 1,74 \\
\hline & $(15-30)$ & 23,42 & $-10,91$ \\
\hline & $(20-40)$ & 15,61 & $-7,82$ \\
\hline & $(25-50)$ & 15,75 & 0,14 \\
\hline \multirow[t]{6}{*}{07} & $(4-4)$ & 49,74 & - \\
\hline & $(7-10)$ & 35,08 & $-14,66$ \\
\hline & $(10-20)$ & 28,49 & $-6,59$ \\
\hline & $(15-30)$ & 13,21 & $-15,29$ \\
\hline & $(20-40)$ & 12,95 & $-0,25$ \\
\hline & $(25-50)$ & 31,03 & 18,07 \\
\hline \multirow[t]{6}{*}{11} & $(4-4)$ & 42,26 & - \\
\hline & $(7-10)$ & 38,83 & $-3,43$ \\
\hline & $(10-20)$ & 37,68 & $-1,15$ \\
\hline & $(15-30)$ & 36,85 & $-0,83$ \\
\hline & $(20-40)$ & 33,28 & $-3,57$ \\
\hline & $(25-50)$ & 33,95 & 0,67 \\
\hline \multirow[t]{6}{*}{12} & $(4-4)$ & 65,22 & - \\
\hline & $(7-10)$ & 49,23 & $-15,98$ \\
\hline & $(10-20)$ & 41,25 & $-7,98$ \\
\hline & $(15-30)$ & 24,94 & $-16,31$ \\
\hline & $(20-40)$ & 17,41 & $-7,53$ \\
\hline & $(25-50)$ & 10,81 & $-6,60$ \\
\hline \multirow[t]{6}{*}{13} & $(4-4)$ & 40,98 & - \\
\hline & $(7-10)$ & 33,46 & $-7,52$ \\
\hline & $(10-20)$ & 29,66 & $-3,80$ \\
\hline & $(15-30)$ & 21,56 & $-8,10$ \\
\hline & $(20-40)$ & 9,28 & $-12,28$ \\
\hline & $(25-50)$ & - & - \\
\hline \multirow[t]{6}{*}{19} & $(4-4)$ & 42,15 & - \\
\hline & $(7-10)$ & 36,75 & $-5,40$ \\
\hline & $(10-20)$ & 20,92 & $-15,83$ \\
\hline & $(15-30)$ & 16,10 & $-4,82$ \\
\hline & $(20-40)$ & 19,57 & 3,47 \\
\hline & $(25-50)$ & 13,53 & $-6,03$ \\
\hline
\end{tabular}


Tabela 112 - Diferença obtida entre um tamanho-limite e o anterior para as árvores da idade 3 (continuação).

\begin{tabular}{cccc}
\hline Arvore & $\begin{array}{c}\text { Tamanho- } \\
\text { limite }\end{array}$ & C.V.(\%) & Diferença \\
\hline 20 & $(4-4)$ & 44,99 & \\
& $(7-10)$ & 32,96 & $-12,03$ \\
& $(10-20)$ & 41,57 & 8,61 \\
& $(15-30)$ & 33,55 & $-8,02$ \\
& $(20-40)$ & 27,53 & $-6,02$ \\
& $(25-50)$ & 28,43 & 0,90 \\
21 & $(4-4)$ & 53,97 & - \\
& $(7-10)$ & 47,80 & $-6,17$ \\
& $(10-20)$ & 38,44 & $-9,36$ \\
& $(15-30)$ & 28,49 & $-9,95$ \\
& $(20-40)$ & 25,85 & $-2,65$ \\
& $(25-50)$ & - & - \\
\hline
\end{tabular}

Verificando-se a diferença dos coeficientes de variação entre um tamanho-limite e outro, nota-se nas categorias de idade 2 e 3 , que a maior queda ocorre no tamanho mínimo de $15 \mathrm{~cm}$ de circunferência e 30 frutos/galho. Para a primeira idade isso não foi observado.

O comportamento dos coeficientes de variação em função dos tamanhos-limites em questão, foi então estudado, utilizando-se o ajuste de modelos de regressão linear e quadrático. O modelo linear é dado por:

$$
y=a+b x
$$

e o modelo quadrático, por:

$$
y=a+b x+c x^{2}
$$

onde: $y=$ coeficiente de variação estimado;

$\mathrm{x}=$ circunferência mínima estudada. 
As Tabelas de 113 a 118, mostram as equações ajustadas para os dois modelos, bem como os respectivos valores de $\mathrm{r}^{2}$.

Tabela 113 - Valores estimados dos coeficientes do modelo $\mathrm{y}=\mathrm{a}+\mathrm{bx}$ e do coeficiente de determinaçao $\mathrm{r}^{2}$, para as árvores da idade 1 .

\begin{tabular}{cccc}
\hline Árvore & Coeficiente "b" & Coeficiente "a" & $\mathbf{r}^{\mathbf{2}}$ \\
\hline 01 & $-0,5161$ & 43,6416 & 0,3318 \\
02 & $-3,1042$ & 59,8676 & 0,4127 \\
03 & $-3,4677$ & 74,6936 & 0,8051 \\
08 & $-2,8497$ & 43,2118 & 0,9778 \\
14 & $-3,6611$ & 65,5906 & 0,8238 \\
15 & $-2,2583$ & 27,9744 & 0,9101 \\
16 & $-1,1842$ & 52,2814 & 0,8268 \\
\hline
\end{tabular}

Tabela 114 - Valores estimados dos coeficientes do modelo $y=a+b x+c x^{2} e$ do coeficiente de determinação ${ }^{2}$, para as árvores da idade 1 .

\begin{tabular}{ccccc}
\hline Árvore & Coeficiente "c" & Coeficiente "b" & Coeficiente "a" & $\mathbf{r}^{\mathbf{2}}$ \\
\hline 01 & $-0,1221$ & 1,8134 & 34,1802 & 0,6000 \\
02 & $-0,5372$ & 4,5634 & 36,0345 & 0,4421 \\
03 & 1,0762 & $-18,8278$ & 122,4370 & 0,9896 \\
08 & - & - & - & - \\
14 & $-0,2524$ & 1,1518 & 46,0429 & 0,8803 \\
15 & - & - & - & - \\
16 & 0,0481 & $-2,3549$ & 58,0254 & 0,8609 \\
\hline
\end{tabular}

Tabela 115 - Valores estimados dos coeficientes do modelo $\mathrm{y}=\mathrm{a}+\mathrm{bx}$ e do coeficiente de determinação ${ }^{2}$, para as árvores da idade 2 .

\begin{tabular}{cccc}
\hline Árvore & Coeficiente "b" & Coeficiente "a" & $\mathbf{r}^{\mathbf{2}}$ \\
\hline 04 & $-2,85017$ & 57,5675 & 0,94595 \\
05 & $-1,13985$ & 52,7796 & 0,76587 \\
09 & $-3,43763$ & 63,0419 & 0,80358 \\
10 & $-1,58924$ & 50,9746 & 0,82710 \\
17 & $-3,07822$ & 68,0984 & 0,95773 \\
18 & $-0,56828$ & 49,9869 & 0,49428 \\
\hline
\end{tabular}


Tabela 116 - Valores estimados dos coeficientes do modelo $\mathrm{y}=\mathrm{a}+\mathrm{bx}+\mathrm{cx}^{2} \mathrm{e}$ do coeficiente de determinação $\mathrm{r}^{2}$, para as árvores da idade 2 .

\begin{tabular}{ccccc}
\hline Árvore & Coeficiente "c" & Coeficiente "b" & Coeficiente "a" & $\mathbf{r}^{\mathbf{2}}$ \\
\hline 04 & 0,0093 & $-3,0749$ & 58,6150 & 0,9462 \\
05 & $-0,0568$ & 0,2335 & 46,3779 & 0,8056 \\
09 & $-0,4329$ & 4,9050 & 30,1633 & 0,9469 \\
10 & 0,1011 & $-4,0328$ & 62,3655 & 0,8970 \\
17 & $-0,0593$ & $-1,6441$ & 61,4133 & 0,9652 \\
18 & 0,0318 & $-1,3357$ & 53,5643 & 0,5265 \\
\hline
\end{tabular}

Tabela 117 - Valores estimados dos coeficientes do modelo $\mathrm{y}=\mathrm{a}+\mathrm{bx}$ e do coeficiente de determinação $\mathrm{r}^{2}$, para as árvores da idade 3 .

\begin{tabular}{cccc}
\hline Árvore & Coeficiente "b" & Coeficiente "a" & $\mathbf{r}^{\mathbf{2}}$ \\
\hline 06 & $-1,3785$ & 46,4172 & 0,8992 \\
07 & $-1,0558$ & 42,6693 & 0,3671 \\
11 & $-0,3850$ & 42,3406 & 0,8735 \\
12 & $-2,5167$ & 68,7850 & 0,9469 \\
13 & $-1,8894$ & 48,1490 & 0,9886 \\
19 & $-1,2613$ & 41,8639 & 0,7426 \\
20 & $-0,7187$ & 44,5393 & 0,6690 \\
21 & $-1,8413$ & 59,5310 & 0,9430 \\
\hline
\end{tabular}

Tabela 118 - Valores estimados dos coeficientes do modelo $y=a+b x+c x^{2} e$ do coeficiente de determinação $\mathrm{r}^{2}$, para as árvores da idade 3 .

\begin{tabular}{ccccc}
\hline Árvore & Coeficiente "c" & Coeficiente "b" & Coeficiente "a" & $\mathbf{r}^{\mathbf{2}}$ \\
\hline 06 & 0,0537 & $-2,9325$ & 54,7328 & 0,9455 \\
07 & 0,2310 & $-7,7415$ & 78,4458 & 0,9642 \\
11 & 0,0177 & $-0,8985$ & 45,0883 & 0,9365 \\
12 & 0,0981 & $-5,3556$ & 83,9763 & 0,9958 \\
13 & 0,0187 & $-1,4352$ & 46,0379 & 0,9906 \\
19 & 0,0978 & $-4,0906$ & 57,0041 & 0,8942 \\
20 & 0,0191 & $-1,2717$ & 47,4988 & 0,6851 \\
21 & 0,0894 & $-4,0019$ & 69,6025 & 0,9894 \\
\hline
\end{tabular}


O modelo linear apresentou o melhor ajuste, com valores de $\mathrm{r}^{2}$ superiores a 0,6600. Apenas as árvores $n^{\circ} \mathrm{s} .01,02,07$ e 18, mostraram valores menores. $\mathrm{O}$ ajuste do termo quadrático não caracterizou aumento significativo nos valores de $\mathrm{r}^{2}$, além de não ser possível seu ajuste no caso de algumas árvores de pequeno porte, geralmente as árvores da categoria de idade 1.

A comparação entre a estimativa do coeficiente de variação ( $Y$ estimado) e o coeficiente de variação real (Y calculado), pode ser observada nas Tabelas 119,120 e 121.

Tabela 119 - Coeficiente de variação real e valor estimado pelo modelo linear, para as árvores da idade 1 .

\begin{tabular}{cccc}
\hline Árvore & $\begin{array}{c}\text { Tamanho- } \\
\text { limite }\end{array}$ & $\begin{array}{c}\text { C.V.(\%) } \\
\text { estimado }\end{array}$ & $\begin{array}{c}\text { C.V.(\%) } \\
\text { calculado }\end{array}$ \\
\hline 01 & $(4-4)$ & 41,5772 & 40,0094 \\
& $(7-10)$ & 40,0290 & 39,4323 \\
& $(10-10)$ & 38,4807 & 43,7086 \\
& $(10-20)$ & 38,4807 & 37,6569 \\
02 & $(15-30)$ & 35,9002 & 33,6607 \\
& $(4-4)$ & 47,4507 & 45,6925 \\
& $(7-10)$ & 38,1379 & 41,6543 \\
& $(10-10)$ & 28,8252 & 40,6419 \\
& $(10-20)$ & 28,8252 & 15,2503 \\
03 & $(15-30)$ & 13,3040 & - \\
& $(4-4)$ & 60,8228 & 64,3448 \\
& $(7-10)$ & 50,4197 & 43,3755 \\
& $(10-10)$ & 40,0166 & 40,3920 \\
& $(10-20)$ & 40,0166 & 43,1632 \\
& $(15-30)$ & 22,6781 & - \\
& $(4-4)$ & 31,8132 & 31,0687 \\
& $(7-10)$ & 23,2642 & 24,7532 \\
& $(10-10)$ & 14,7152 & 13,9707 \\
& $(10-20)$ & - & - \\
& $(15-30)$ & - & -
\end{tabular}


Tabela 119 - Coeficiente de variação real e valor estimado pelo modelo linear, para as árvores da idade 1 (continuação).

\begin{tabular}{cccc}
\hline Árvore & $\begin{array}{c}\text { Tamanho- } \\
\text { limite }\end{array}$ & $\begin{array}{c}\text { C.V. }(\%) \\
\text { estimado }\end{array}$ & $\begin{array}{c}\text { C.V. } \%) \\
\text { calculado }\end{array}$ \\
\hline 14 & $(4-4)$ & 50,9464 & 50,0195 \\
& $(7-10)$ & 39,9632 & 32,3710 \\
& $(10-10)$ & 28,9801 & 36,4270 \\
& $(10-20)$ & 28,9801 & 35,7198 \\
& $(15-30)$ & 10,6748 & 5,0072 \\
15 & $(4-4)$ & 18,9412 & 17,7120 \\
& $(7-10)$ & 12,1663 & 14,6253 \\
& $(10-10)$ & 5,3614 & 4,1624 \\
& $(10-20)$ & - & - \\
& $(15-30)$ & - & - \\
& $(4-4)$ & 47,5446 & 48,9558 \\
& $(7-10)$ & 43,9920 & 45,3805 \\
& $(10-10)$ & 40,4394 & 42,6359 \\
& $(10-20)$ & 40,4394 & 34,3277 \\
& $(15-30)$ & 34,5184 & 34,2261 \\
& $(20-40)$ & 28,5974 & 30,0077 \\
\hline
\end{tabular}


Tabela 120 - Coeficiente de variação real e valor estimado pelo modelo linear, para as árvores da idade 2 .

\begin{tabular}{|c|c|c|c|}
\hline Árvore & $\begin{array}{c}\text { Tamanho- } \\
\text { limite }\end{array}$ & $\begin{array}{l}\text { C.V. }(\%) \\
\text { estimado }\end{array}$ & $\begin{array}{l}\text { C.V. }(\%) \\
\text { calculado }\end{array}$ \\
\hline \multirow[t]{5}{*}{04} & - & 46,1668 & 42,8339 \\
\hline & $(7-10)$ & 37,6163 & 43,3505 \\
\hline & $(10-20)$ & 29,0657 & 29,5025 \\
\hline & $(15-30)$ & 14,8148 & 9,6977 \\
\hline & $(20-40)$ & 0,5640 & 2,8430 \\
\hline \multirow[t]{5}{*}{05} & - & 48,2202 & 47,2653 \\
\hline & $(7-10)$ & 44,8007 & 46,2120 \\
\hline & $(10-20)$ & 41,3811 & 37,9442 \\
\hline & $(15-30)$ & 35,6818 & 41,9419 \\
\hline & $(20-40)$ & 29,9825 & 26,7029 \\
\hline \multirow[t]{5}{*}{09} & - & 49,2915 & 44,8045 \\
\hline & $(7-10)$ & 38,9786 & 37,9330 \\
\hline & $(10-20)$ & 28,6657 & 40,2098 \\
\hline & $(15-30)$ & 11,4775 & 5,4658 \\
\hline & $(20-40)$ & - & - \\
\hline \multirow[t]{5}{*}{10} & & 44,6177 & 47,5912 \\
\hline & $(7-10)$ & 39,8499 & 37,0240 \\
\hline & $(10-20)$ & 35,0822 & 37,3665 \\
\hline & $(15-30)$ & 27,1359 & 20,3995 \\
\hline & $(20-40)$ & 19,1897 & 23,4942 \\
\hline \multirow[t]{5}{*}{17} & - & 55,7856 & 50,9964 \\
\hline & $(7-10)$ & 46,5509 & 50,9342 \\
\hline & $(10-20)$ & 37,3163 & 41,0233 \\
\hline & $(15-30)$ & 21,9252 & 18,4401 \\
\hline & $(20-40)$ & 6,5341 & 6,7181 \\
\hline \multirow[t]{5}{*}{18} & - & 47,7138 & 46,3927 \\
\hline & $(7-10)$ & 46,0090 & 48,2626 \\
\hline & $(10-20)$ & 44,3041 & 46,4256 \\
\hline & $(15-30)$ & 41,4627 & 35,5882 \\
\hline & $(20-40)$ & 38,6213 & 41,4419 \\
\hline
\end{tabular}


Tabela 121 - Coeficiente de variação real e valor estimado pelo modelo linear, para as árvores da idade 3 .

\begin{tabular}{|c|c|c|c|}
\hline Árvore & $\begin{array}{c}\text { Tamanho- } \\
\text { limite }\end{array}$ & $\begin{array}{l}\text { C.V. }(\%) \\
\text { estimado }\end{array}$ & $\begin{array}{l}\text { C.V. }(\%) \\
\text { calculado }\end{array}$ \\
\hline \multirow[t]{6}{*}{06} & - & 40,9032 & 45,1407 \\
\hline & $(7-10)$ & 36,7676 & 32,5952 \\
\hline & $(10-20)$ & 32,6321 & 34,3308 \\
\hline & $(15-30)$ & 25,7396 & 23,4238 \\
\hline & $(20-40)$ & 18,8471 & 15,6059 \\
\hline & $(25-50)$ & 11,9545 & 15,7478 \\
\hline \multirow[t]{6}{*}{07} & - & 38,4459 & 49,7352 \\
\hline & $(7-10)$ & 35,2783 & 35,0802 \\
\hline & $(10-20)$ & 32,1108 & 28,4948 \\
\hline & $(15-30)$ & 26,8315 & 13,2050 \\
\hline & $(20-40)$ & 21,5523 & 12,9509 \\
\hline & $(25-50)$ & 16,2730 & 31,0256 \\
\hline \multirow[t]{6}{*}{11} & - & 40,8005 & 42,2608 \\
\hline & $(7-10)$ & 39,6454 & 38,8346 \\
\hline & $(10-20)$ & 38,4904 & 37,6797 \\
\hline & $(15-30)$ & 36,5652 & 36,8544 \\
\hline & $(20-40)$ & 34,6401 & 33,2795 \\
\hline & $(25-50)$ & 32,7150 & 33,9476 \\
\hline \multirow[t]{6}{*}{12} & - & 58,7181 & 65,2178 \\
\hline & $(7-10)$ & 51,1680 & 49,2336 \\
\hline & $(10-20)$ & 43,6178 & 41,2500 \\
\hline & $(15-30)$ & 31,0342 & 24,9404 \\
\hline & $(20-40)$ & 18,4507 & 17,4069 \\
\hline & $(25-50)$ & 5,8671 & 10,8072 \\
\hline \multirow[t]{6}{*}{13} & - & 40,5911 & 40,9758 \\
\hline & $(7-10)$ & 34,9232 & 33,4643 \\
\hline & $(10-20)$ & 29,2550 & 29,6598 \\
\hline & $(15-30)$ & 19,8080 & 21,5624 \\
\hline & $(20-40)$ & 10,3610 & 9,2765 \\
\hline & $(25-50)$ & - & - \\
\hline \multirow[t]{6}{*}{19} & - & 36,8186 & 42,1486 \\
\hline & $(7-10)$ & 33,0347 & 36,7470 \\
\hline & $(10-20)$ & 29,2507 & 20,9205 \\
\hline & $(15-30)$ & 22,9442 & 16,0994 \\
\hline & $(20-40)$ & 16,6376 & 19,5679 \\
\hline & $(25-50)$ & 10,3311 & 13,5336 \\
\hline
\end{tabular}


Tabela 121 - Coeficiente de variação real e valor estimado pelo modelo linear, para as árvores da idade 3 (continuação).

\begin{tabular}{cccc}
\hline Árvore & $\begin{array}{c}\text { Tamanho- } \\
\text { limite }\end{array}$ & $\begin{array}{c}\text { C.V.(\%) } \\
\text { estimado }\end{array}$ & $\begin{array}{c}\text { C.V.(\%) } \\
\text { calculado }\end{array}$ \\
\hline 20 & - & 41,6645 & 44,9944 \\
& $(7-10)$ & 39,5084 & 32,9621 \\
& $(10-20)$ & 37,3523 & 41,5681 \\
& $(15-30)$ & 33,7588 & 33,5457 \\
& $(20-40)$ & 30,1653 & 27,5254 \\
& $(25-50)$ & 26,5719 & 28,4256 \\
21 & - & 52,1658 & 53,9697 \\
& $(7-10)$ & 46,6419 & 47,7997 \\
& $(10-20)$ & 41,1181 & 38,4373 \\
& $(15-30)$ & 31,9116 & 28,4907 \\
& $(20-40)$ & 22,7052 & 25,8453 \\
& $(25-50)$ & 13,4987 & - \\
\hline
\end{tabular}

Na categoria de idade 1 as árvores, por serem de menor porte e apresentarem menor número de frutos, possibilitam a contagem de um maior número de galhos. É possível, então, contar-se todos os frutos de um dos ramos primários da árvore. Nas categorias de idades 2 e 3, o porte da árvore é geralmente grande, não sendo viável a contagem de muitos galhos para a estimativa do número de frutos.

Pelos resultados acima tem-se que o tamanho-limite ideal, para a segunda e terceira idades, é o de $15 \mathrm{~cm}$ de circunferência e 30 frutos/galho e para a idade 1 não há uma tamanho definido, conta-se todos os galhos de uma das ramificações primárias da árvore.

Na prática, utilizando o tamanho-limite para uma árvore da categoria de idade 3, por exemplo, o "amostrador" no campo diante dessa árvore, sorteia um dos ramos principais e mede sua circunferência. Em seguida, 
faz-se novo sorteio entre os galhos da $2^{\mathrm{a}}$ bifurcação e mede-se sua circunferência, contando os frutos e assim por diante até encontrar um galho com circunferência, por volta, de $15 \mathrm{~cm}$ e/ou cerc $\exists$ de 30 frutos/galho. Encontrando o ponto de parada a estimativa seria dada pelo número de frutos contados dividido pela probabilidade proporcional a área daquele galho.

Uma vez determinado o tamanho mínimo do galho, foi realizado um estudo, envolvendo as estimativas do número de frutos da árvore, pelos métodos PPA e PPN, através da análise de regressão linear múltipla, buscando verificar se existe melhora nos valores estimados. Visando a obtenção de um modelo que englobe as três categorias de idades, convencionou-se adotar a média da faixa etária como uma variável do modelo a ser estudado.

A Tabela 122, apresenta os valores das estimativas pelos métodos PPN e PPA e os respectivos desvios em relação ao real, a média do número real de frutos, e a idade, considerando o tamanho-limite de cada árvore. 
Tabela 122 - Média do número real de frutos, valores estimados pelo método que utiliza a PPA e PPN e média da faixa etária das árvores.

\begin{tabular}{|c|c|c|c|c|c|c|}
\hline $\begin{array}{c}\text { Árvor } \\
\mathrm{e} \\
\end{array}$ & Idade & $\begin{array}{c}\text { Média do } n^{0} \text {. real } \\
\text { de frutos } \\
\end{array}$ & $\begin{array}{l}\text { Estimativa do } \mathrm{n}^{\circ} \\
\text { de frutos (PPA) }\end{array}$ & Desvi (PPA) & $\begin{array}{l}\text { Estimativa do } \mathrm{n}^{\circ} \text {. } \\
\text { de frutos (PPN) }\end{array}$ & Desvio (PPN) \\
\hline 01 & 4,0 & 150,00 & 156,26 & 6,26 & 150,00 & 0,00 \\
\hline 02 & 4,0 & 148,00 & 152,97 & 4,97 & 193,33 & 45,33 \\
\hline 03 & 4,0 & 136,00 & 138,63 & 2,63 & 136,00 & 0,00 \\
\hline 08 & 4,0 & 113,00 & 116,10 & 3,10 & 113,00 & 0,00 \\
\hline 14 & 4,0 & 147,00 & 146,34 & $-0,66$ & 147,00 & 0,00 \\
\hline 15 & 4,0 & 162,00 & 165,75 & 3,75 & 164,31 & 2,31 \\
\hline 16 & 4,0 & 436,00 & 489,33 & 53,33 & 449,45 & 13,45 \\
\hline 04 & 7,5 & 312,00 & 320,69 & 8,69 & 334,50 & 22,50 \\
\hline 05 & 7,5 & 562,00 & 546,70 & $-15,30$ & 656,25 & 94,25 \\
\hline 09 & 7,5 & 167,00 & 167,45 & 0,45 & 167,00 & 0,00 \\
\hline 10 & 7,5 & 714,00 & 705,83 & $-8,17$ & 797,33 & 83,33 \\
\hline 17 & 7,5 & 754,00 & 787,39 & 33,39 & 766,80 & 12,80 \\
\hline 18 & 7,5 & 823,00 & 980,22 & 157,22 & 1138,88 & 315,88 \\
\hline 06 & 15,0 & 763,00 & 694,92 & $-68,08$ & 902,33 & 139,33 \\
\hline 07 & 15,0 & 312,00 & 327,83 & 15,83 & 303,60 & $-8,40$ \\
\hline 11 & 15,0 & 1122,00 & 1131,48 & 9,48 & 1851,00 & 729,00 \\
\hline 12 & 15,0 & 980,00 & 975,86 & $-4,14$ & 1143,00 & 163,00 \\
\hline 13 & 15,0 & 930,00 & 958,75 & 28,75 & 965,59 & 35,59 \\
\hline 19 & 15,0 & 673,00 & 666,95 & $-6,05$ & 738,30 & 65,30 \\
\hline 20 & 15,0 & 502,00 & 500,85 & $-1,15$ & 587,33 & 85,33 \\
\hline 21 & 15,0 & 740,00 & 657,45 & $-82,55$ & 865,80 & 125,80 \\
\hline Média & & 506,95 & 513,70 & 6,75 & 598,61 & 91,66 \\
\hline \multicolumn{2}{|c|}{ Variância } & & & 2091,0028 & & 36232,4630 \\
\hline
\end{tabular}

O modelo de regressão linear múltipla adotado foi:

$$
\mathrm{y}=\mathrm{a}+\mathrm{bx}_{1}+\mathrm{cx}_{2}+\mathrm{dx} \mathrm{x}_{3}
$$

onde: $\quad \mathrm{y}=$ produção estimada da árvore,

$\mathrm{x}_{1}=$ estimativa do número de frutos pelo método PPN,

$\mathrm{x}_{2}=$ estimativa do número de frutos pelo método PPA.

$\mathrm{x}_{3}=$ média da faixa etária da árvore. 
A Tabela 123, apresenta o quadro da análise de variância para o modelo adotado, e a Tabela 124, os testes e a significância dos parâmetros estimados pelo modelo, obtidos pelo programa SAS,

Tabela 123 - Análise de variância do modelo $y=a+b x_{1}+c x_{2}+d x_{3}$.

\begin{tabular}{lcrrrr}
\hline & G.L. & $\begin{array}{c}\text { Soma de } \\
\text { Quadrados }\end{array}$ & $\begin{array}{c}\text { Quadrado } \\
\text { Médio }\end{array}$ & Valor F & Prob>F \\
\hline Modelo & 3 & 2105150,5138 & 701716,8379 & 488,892 & 0.0001 \\
Resíduo & 17 & 24400,43854 & 1435,3199 & & \\
\hline Total & 20 & 2129550,9524 & & & \\
\hline
\end{tabular}

Pelos resultados acima, tem-se que o modelo é significativo ao nível de $0,1 \%$ de probabilidade, com o valor do coeficiente de determinação ajustado de 0,9885 .

Tabela 124 - Testes e significância dos parâmetros estimados para o modelo.

\begin{tabular}{lccccc}
\hline Variáveis & G.L. & $\begin{array}{c}\text { Estimativa do } \\
\text { Parâmetro }\end{array}$ & Erro Padrão & $\begin{array}{c}\text { Teste t para } \\
\text { Ho: parâmetro=0 }\end{array}$ & Prob $>|\mathbf{t}|$ \\
\hline Intercepto & 1 & $-10,0291$ & 19,0304 & $-0,527$ & 0,6050 \\
$\mathbf{x}_{\mathbf{1}}$ & 1 & 0,0862 & 0,0667 & 1,291 & 0,2141 \\
$\mathbf{x}_{2}$ & 1 & 0,8003 & 0,0918 & 8,714 & 0,0001 \\
$\mathbf{x}_{3}$ & 1 & 6,0358 & 2,3332 & 2,587 & 0,0192 \\
\hline
\end{tabular}

Nota-se que a variável que representa as estimativas pelo método que utiliza a PPN, e o intercepto, não foram significativos. Já a variável que representa as estimativas pelo método que utiliza a PPA e a média da faixa 
etária, foram altamente significativas, confirmando que o método da PPA é o que melhor se ajusta.

Apesar disso, verifica-se que existe uma melhora nas estimativas, uma diminuição da média e das variâncias dos desvios, com o uso do modelo que envolve os dois métodos. A Tabela 125 apresenta os valores estimados pelo modelo para as três idades.

Tabela 125 - Número real de frutos da árvore e o estimado pelo modelo.

\begin{tabular}{cccc}
\hline Árvore & $\begin{array}{c}\mathbf{N}^{0} \text { de frutos } \\
\text { real }\end{array}$ & $\begin{array}{c}\mathbf{N}^{0} \text { de frutos } \\
\text { estimado }\end{array}$ & Desvio \\
\hline 1 & 150,00 & 152,10 & 2,10 \\
2 & 148,00 & 153,20 & 5,20 \\
3 & 136,00 & 136,78 & 0,78 \\
8 & 113,00 & 116,77 & 3,77 \\
14 & 147,00 & 143,90 & $-3,10$ \\
15 & 162,00 & 160,93 & $-1,07$ \\
16 & 436,00 & 444,47 & 8,47 \\
4 & 312,00 & 320,72 & 8,72 \\
5 & 562,00 & 529,33 & $-32,67$ \\
9 & 167,00 & 183,65 & 16,65 \\
10 & 714,00 & 668,84 & $-45,16$ \\
17 & 754,00 & 731,49 & $-22,51$ \\
18 & 823,00 & 917,88 & 94,88 \\
6 & 763,00 & 714,43 & $-48,57$ \\
7 & 312,00 & 369,04 & 57,04 \\
11 & 1122,00 & 1145,59 & 23,59 \\
12 & 980,00 & 960,02 & $-19,98$ \\
13 & 930,00 & 931,03 & 1,03 \\
19 & 673,00 & 677,91 & 4,91 \\
20 & 502,00 & 531,97 & 29,97 \\
21 & 740,00 & 681,30 & $-58,70$ \\
\hline Média & 506,95 & 508,16 & 1,21 \\
\hline Variância & & & 1201,7284 \\
\hline
\end{tabular}




\section{CONCLUSÕES}

Pelos resultados acima, pode-se concluir que:

- dos três métodos estudados, o que apresentou a maior eficiência, com as melhores estimativas do número de frutos da árvore, foi o que utiliza a probabilidade proporcional a área, concordando com os resultados obtidos por Jessen (1955);

- considerando o método que utiliza a PPA, o tamanho mínimo do galho próximo de $15 \mathrm{~cm}$ de circunferência $\mathrm{e}$ aproximadamente 30 frutos/galho, foi o que melhor se adaptou;

- a combinação dos métodos que utilizam a PPA e PPN, apresentou ajuste linear com alto valor do coeficiente de determinação, e melhora nos valores estimados, bem como diminuição dos valores das variâncias dos desvios. 


\section{REFERÊNCIAS BIBLIOGRÁFICAS}

BRAR, W.S.; MANN, S.S.; MANN, M.S. Single tree sampling scheme for estimating plot yield Kinnow mandarin. Punjab Horticultural Journal, v.30, n.1-4, p.33-37, 1993.

BUCH, J. Statistical crop forecasting in Israel. Citrograph, p.297-298, June, 1975.

BUCH, J. By-products of crop forecasting in Israel. Citrograph, p.339-341, July, 1976.

CAMARGO, M.P.B. Exigências bioclimáticas e estimativa de produtividade para quatro cultivares desoja no Estado de São Paulo. Piracicaba, 1984. 96 p. Dissertação (Mestrado) - Escola Superior de Agricultura "Luiz de Queiroz", Universidade de São Paulo.

CASES, B. Crop forecasting for citrus. Comparison between several methods. Investigation Agraria, Economia, v.9, n.3, p.411-446, 1994. 
COCHRAN, J.E. Sampling techiques. New York: John Wiley, 1953. 555p.

DYER, T.G.J.; GILOOLY, J.F. On the provision of one year ahead forecasts for Valencia orange production in the Eastern Transvaal. Agroplantae, v.11, n.1, p.27-28, 1979.

FUCIK, J.E. Forecasting Texas citrus production. Journal of the Rio Grande Valley Horticultural Society, v.37, p.75-81, 1984.

JESSEN, R.J. Determining the fruit count on a tree by randomized branch sampling. Biometrics, p.99-109, Mar., 1955.

MORINAGA, K.; IKEDA, J. The use of information on the structure of citrus trees in forecasting yields. Agriculture and Horticulture, v.66, n.6, p.723$726,1991$.

ORTOLANI, A.A.; PEDRO JUNIOR, M.J.; ALFONSI, R.R. Agroclimatologia e o cultivo de citros. In: RODRIGUEZ, O.; VIEGAS, F.; PEDRO JUNIOR, M.J.; AMARO, A. A. Cirtricultura brasileira. Campinas: Fundação Cargill, 1991. v.1, p.153-195.

PEETZ, M.S.; AMARO, A. A. Aplicação de equações de regressão à previsão de safra de laranja no Estado de São Paulo. Informações Econômicas, v.8, n.3, p.1-8, 1978. 
PINO, F. A.; AMARO, A. A. Previsão de safras de citros: algumas possibilidades no Estado de São Paulo. Laranja, v.2, n.7, p.403-422, 1986.

PLESSIS, S.F. du. Crop forecasting for navels in South Africa. Proceedings of the Florida State Horticultural Society, v.96, p.40-43, 1984.

SANTOS, V.L.F. dos; PINO, F.A.; AMARO, A.A.; SEVER, F.A.A. Dimensionamento de amostra para levantamento da citricultura Paulista. Pesquisa Agropecuária Brasileira, v.22, n.1, p.15-21, jan., 1987.

SHAMASUNDARAM, K.S. Forecasting yield in Coorg mandarin (Citmus reticulata Blanco). South Indian Horticulture, v.32, n.3, p.125-126, 1984.

STOUT, R.G. Some relevant factors in forecasting harvest size of Valencia oranges. Proceedings of the Florida State Horticultural Society, p.57-63, 1963.

TUBELIS, A. Previsão de colheita de citros em função das chuvas. Laranja, v. 2, n. 7, p. $453-462,1986$.

TUBELIS, A.; SALIBE, A. A. Estimativa de safra de laranja Hamlin em cinco porta-enxertos. Laranja, v.2, n.10, p.531-543, 1989. 
75.

APÊNDICE 1

ESQUEMA DAS ÁRVORES COM DIFERENTES

TAMANHOS MINIMOS 


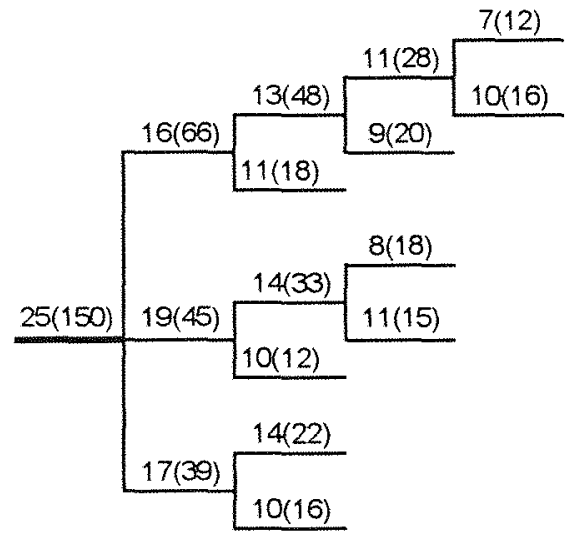

Figura 23 - Mínimo de $7 \mathrm{~cm}$ de circunferência e 10 frutos por galho, árvore 01 .

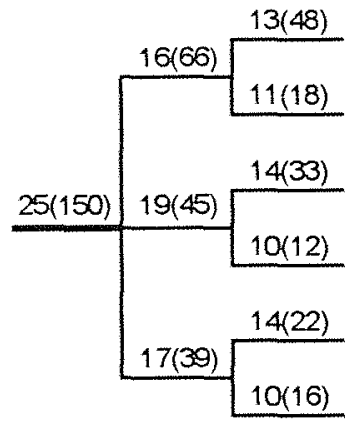

Figura 24 - Mínimo de $10 \mathrm{~cm}$ de circunferência e 10 frutos por galho, árvore 01 .

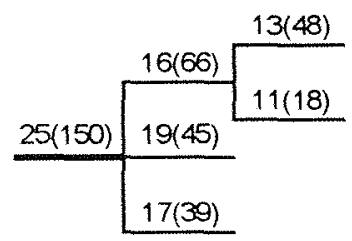

Figura 25 - Mínimo de $10 \mathrm{~cm}$ de circunferência e 20 frutos por galho, árvore 01 . 


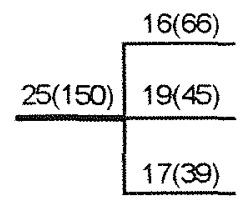

Figura 26 - Mínimo de $15 \mathrm{~cm}$ de circunferência e 30 frutos por galho, árvore 01 .

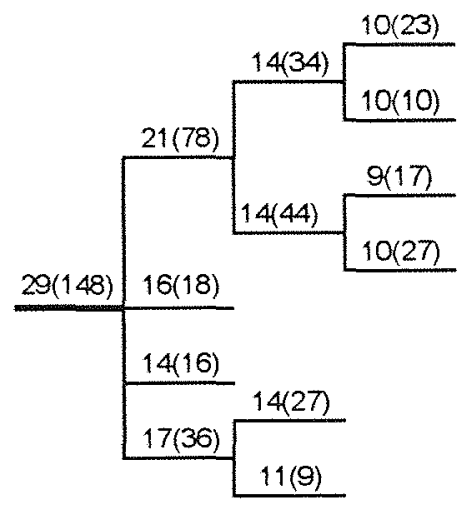

Figura 27 - Mínimo de $7 \mathrm{~cm}$ de circunferência e 10 frutos por galho, árvore 02 .

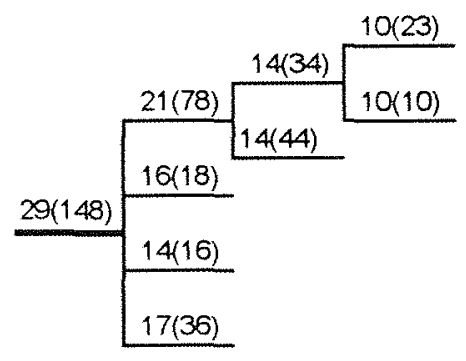

Figura 28 - Minimo de $10 \mathrm{~cm}$ de circunferência e 10 frutos por galho, árvore 02 . 


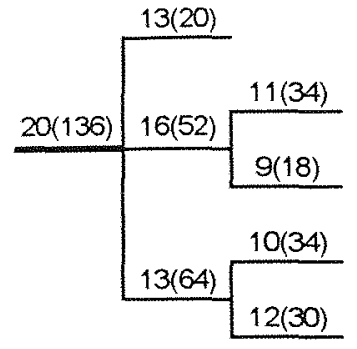

Figura 29 - Minimo de $7 \mathrm{~cm}$ de circunferência e 10 frutos por galho, árvore 03 .

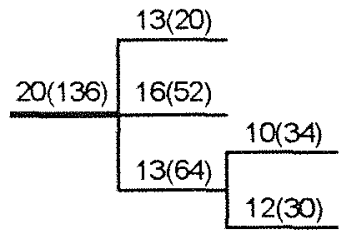

Figura 30 - Mínimo de $10 \mathrm{~cm}$ de circunferência e 10 frutos por galho, árvore 03

\begin{tabular}{c|c}
\multicolumn{1}{c}{} & $13(20)$ \\
\cline { 2 - 2 } $20(136)$ & $16(52)$ \\
\hline & $13(64)$ \\
\hline
\end{tabular}

Figura 31 - Mínimo de $10 \mathrm{~cm}$ de circunferência e 20 frutos por galho, árvore 03 . 
79.

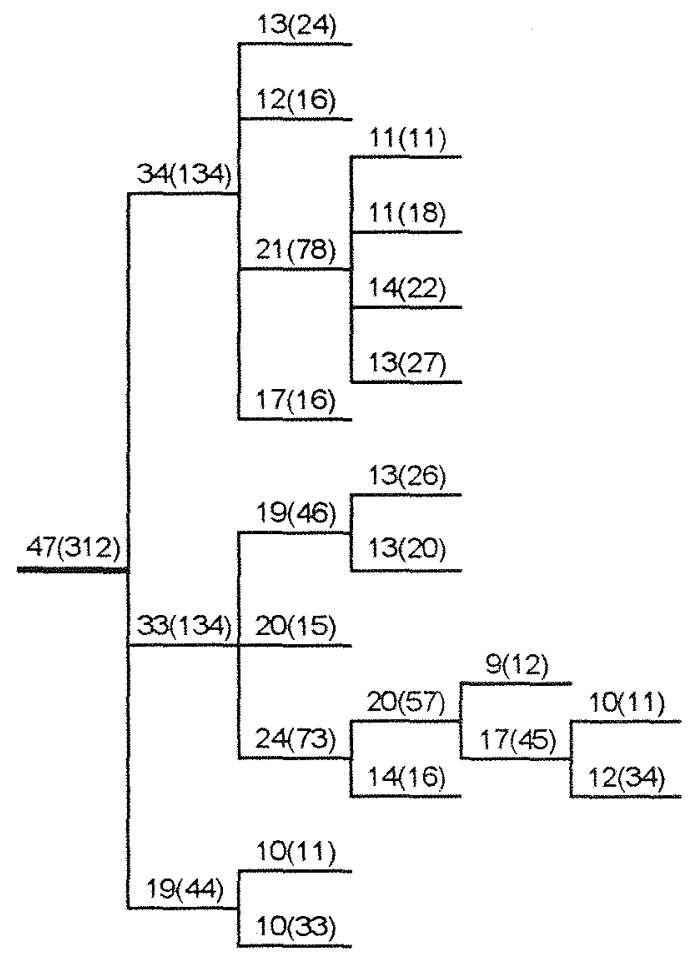

Figura 32 - Minimo de $7 \mathrm{~cm}$ de circunferência e 10 frutos por galho, árvore 04 .

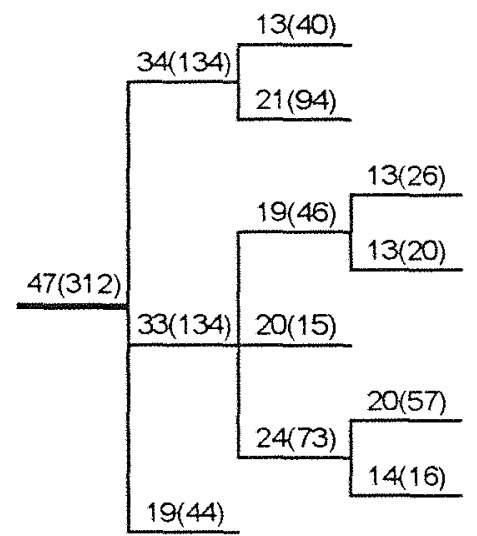

Figura 33 - Mínimo de $10 \mathrm{~cm}$ de circunferência e 20 frutos por galho, árvore 04 . 


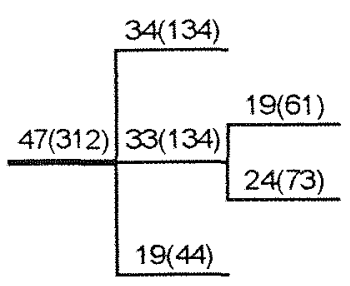

Figura 34 - Mínimo de $15 \mathrm{~cm}$ de circunferência e 30 frutos por galho, árvore 04 .

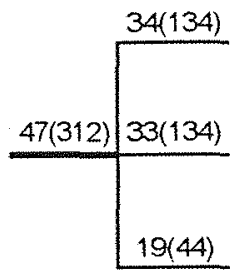

Figura 35 - Mínimo de $20 \mathrm{~cm}$ de circunferência e 40 frutos por galho, árvore 04. 


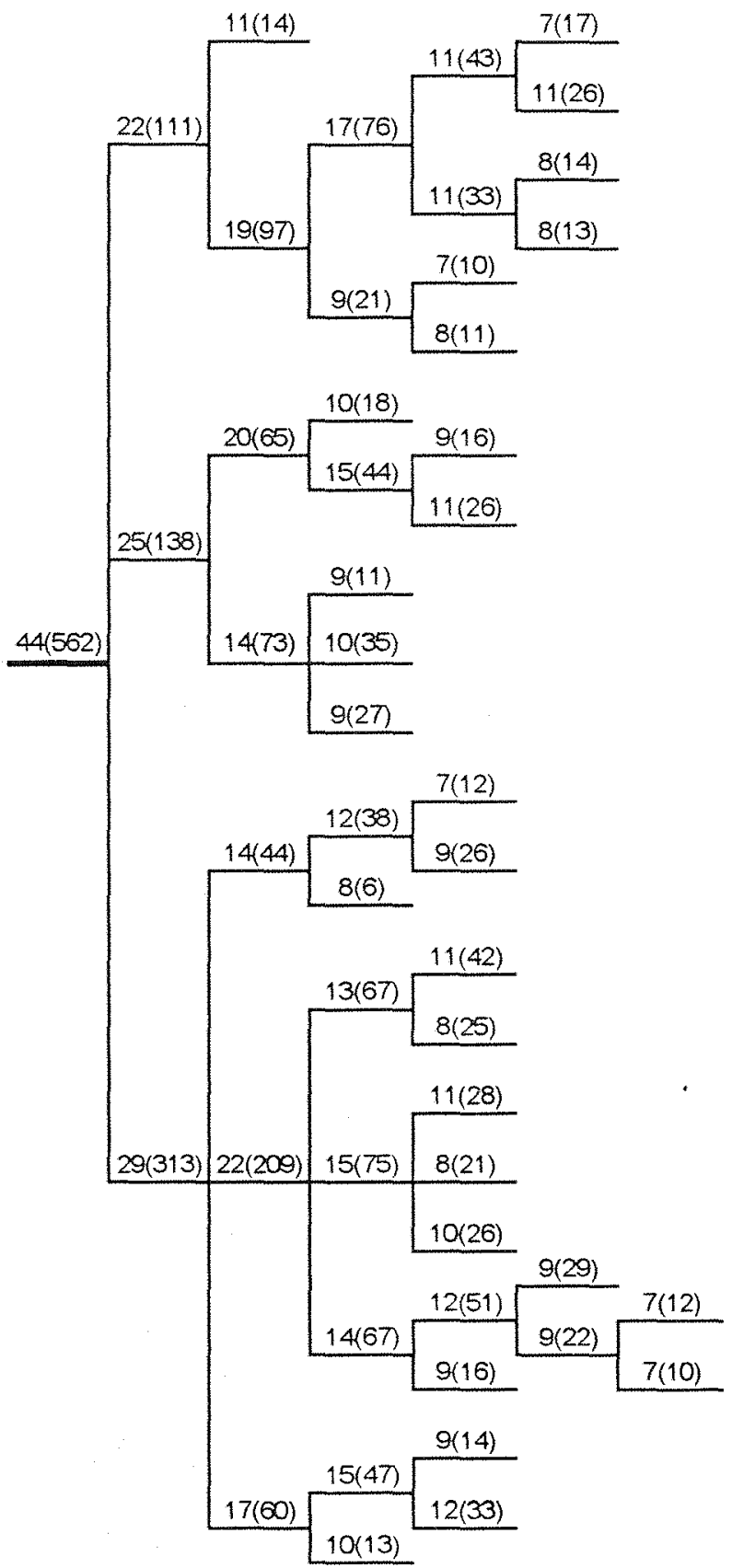

Figura 36 - Mínimo de $7 \mathrm{~cm}$ de circunferência e 10 frutos por galho, árvore 05 . 


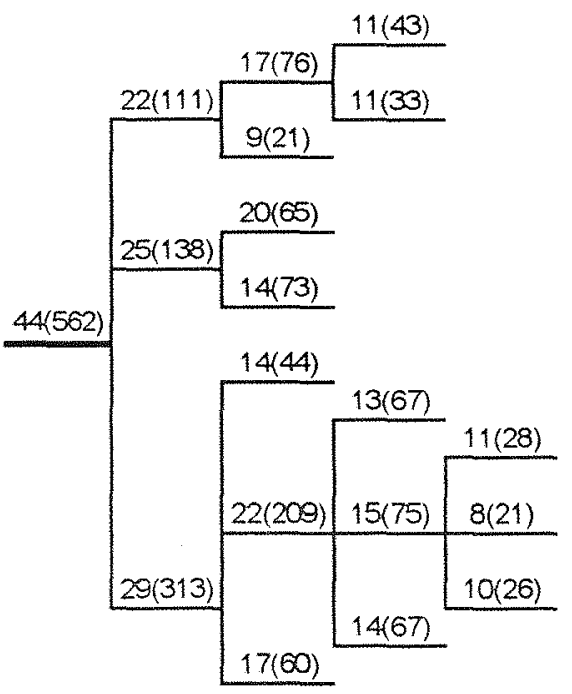

Figura 37 - Minimo de $10 \mathrm{~cm}$ de circunferência e 20 trutos por galho, arvore 05 .

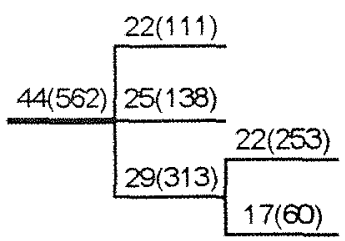

Figura 38 - Minimo de $15 \mathrm{~cm}$ de circunterência e 30 trutos por galho, árvore 05 .

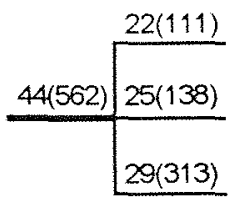

Figura 39 - Minimo de $20 \mathrm{~cm}$ de circunferência e 40 frutos por galho, árvore 05 . 


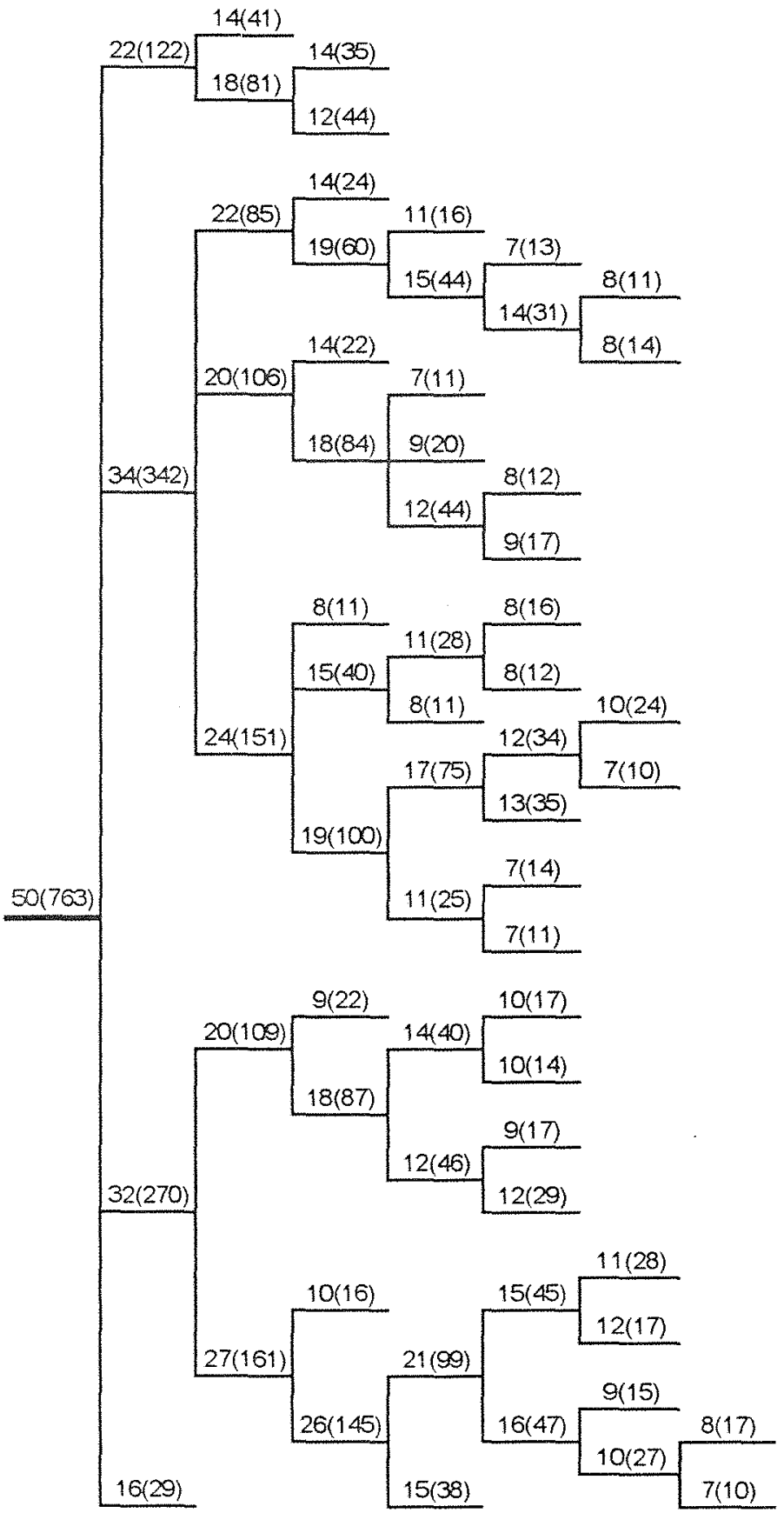

Figura 40 - Mínimo de $7 \mathrm{~cm}$ de circunferência e 10 frutos por galho, árvore 06 . 


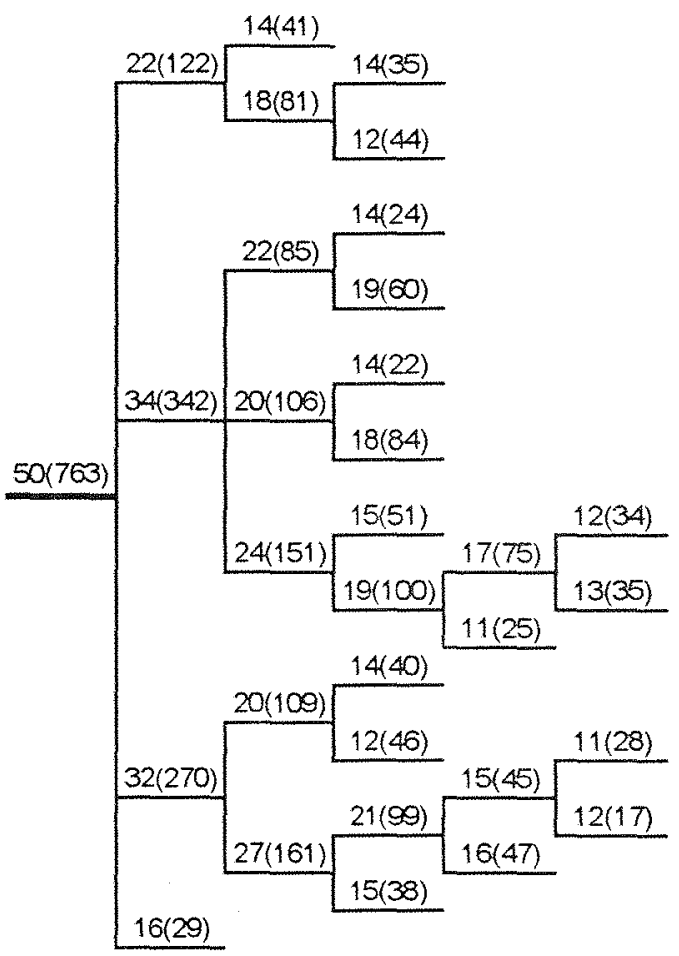

Figura 41 - Mínimo de $10 \mathrm{~cm}$ de circunferência e 20 frutos por galho, arvore 06.

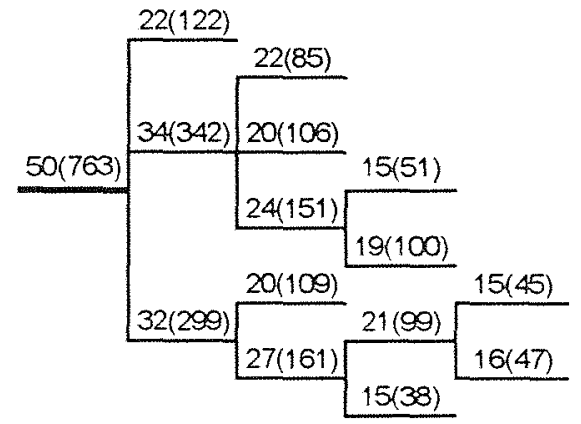

Figura 42 - Mínimo de $15 \mathrm{~cm}$ de circunferência e 30 frutos por galho, árvore 06 . 


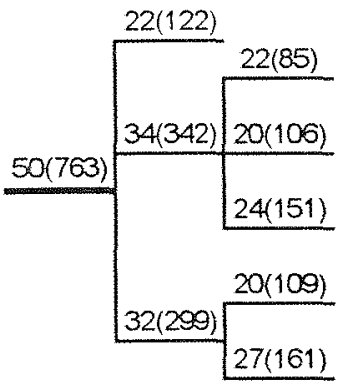

Figura 43 - Mínimo de $20 \mathrm{~cm}$ de circunferência e 40 frutos por galho, árvore 06 .

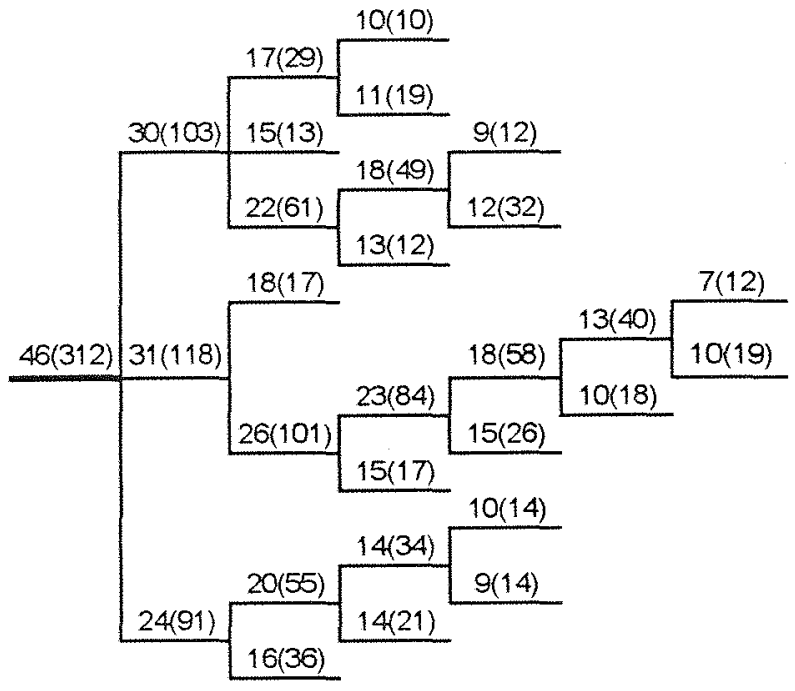

Figura 44 - Mínimo de $7 \mathrm{~cm}$ de circunferência e 10 frutos por galho, árvore 07 .

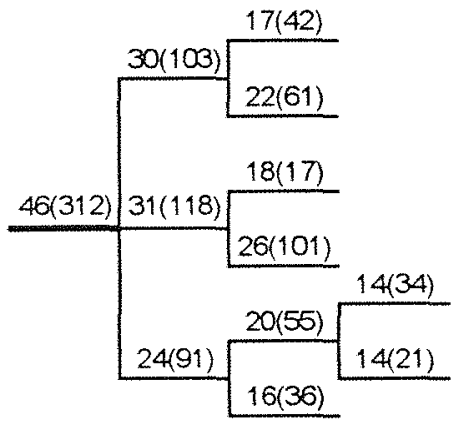

Figura 45 - Mínimo de $10 \mathrm{~cm}$ de circunferência e 20 frutos por galho, árvore 07 . 


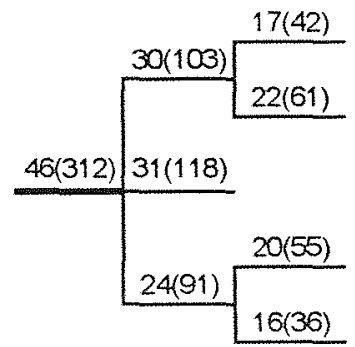

Figura 46 - Mínimo de $15 \mathrm{~cm}$ de circunferência e 30 frutos por galho, árvore 07 .

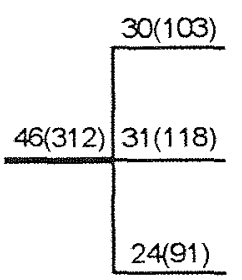

Figura 47 - Mínimo de $20 \mathrm{~cm}$ de circunferência e 40 frutos por galho, árvore 07 .

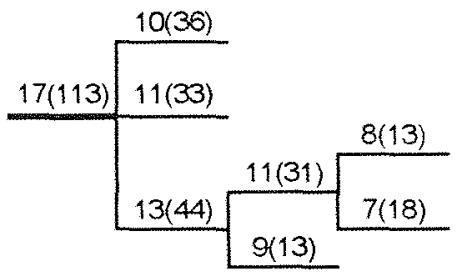

Figura 48 - Mínimo de $7 \mathrm{~cm}$ de circunferência e 10 frutos por galho, árvore 08 .

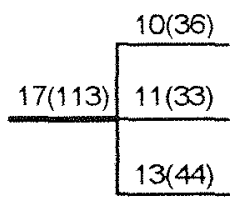

Figura 49 - Mínimo de $10 \mathrm{~cm}$ de circunferência e 10 frutos por galho, árvore 08 . 


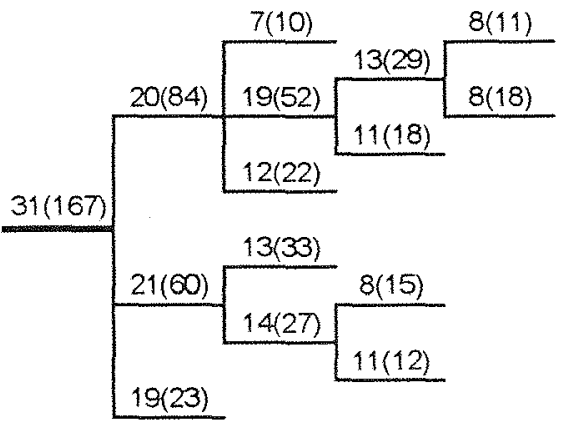

Figura 50 - Mínimo de $7 \mathrm{~cm}$ de circunferência e 10 frutos por galho, árvore 09 .

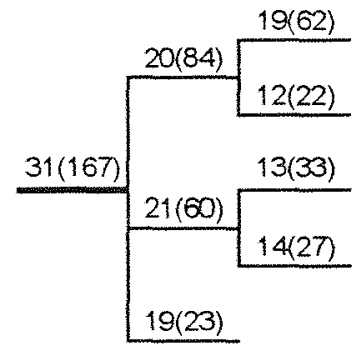

Figura 51 - Mínimo de $10 \mathrm{~cm}$ de circunferência e 20 frutos por galho, árvore 09.

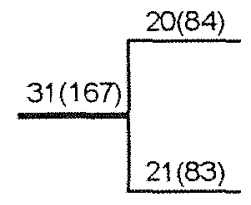

Figura 52 - Mínimo de $15 \mathrm{~cm}$ de circunferência e 30 frutos por galho, árvore 09 . 
88.

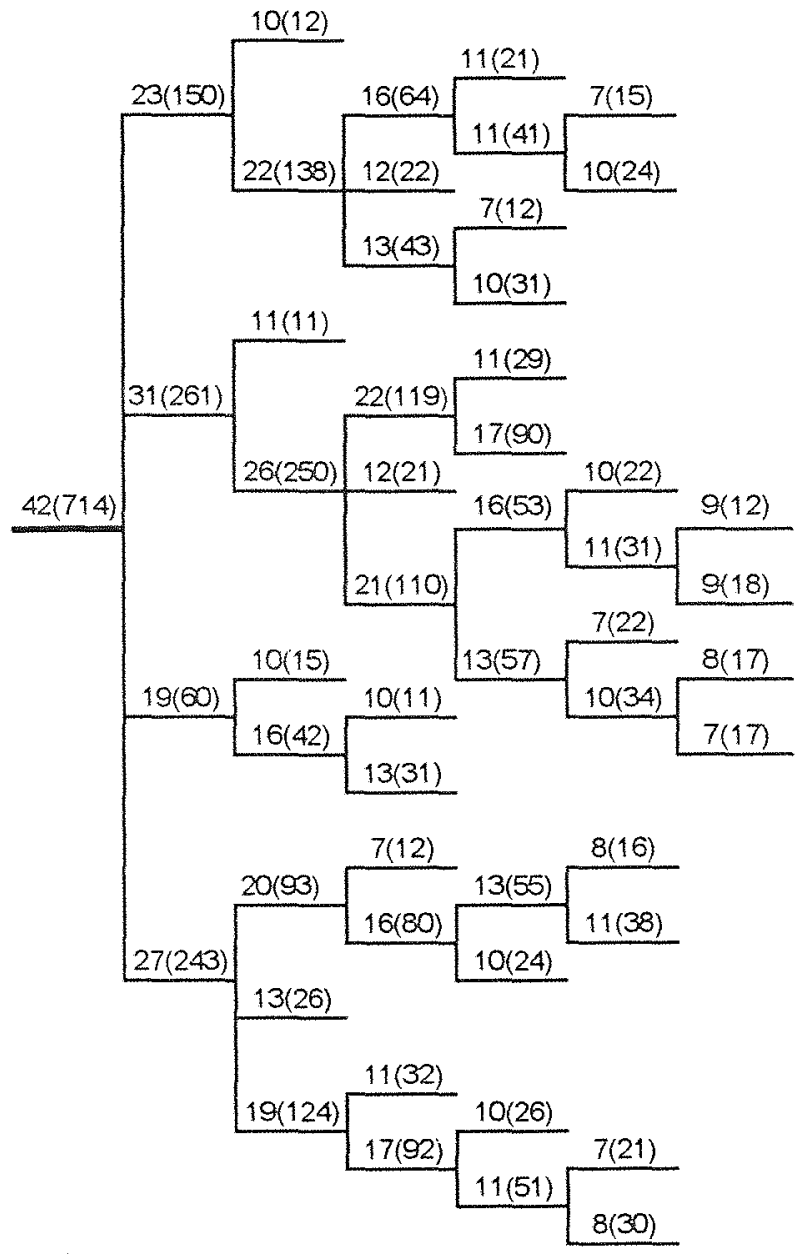

Figura 53 - Mínimo de $7 \mathrm{~cm}$ de circunferência e 10 frutos por galho, árvore 10 . 


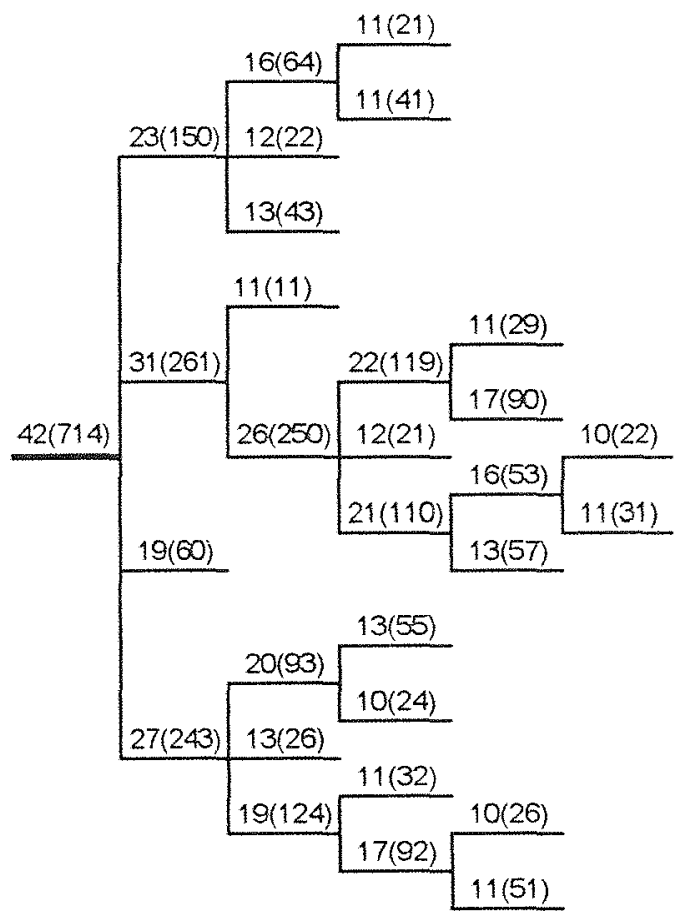

Figura 54 - Mínimo de $10 \mathrm{~cm}$ de circunferência e 20 frutos por galho, árvore 10 .

\begin{tabular}{|c|c|c|}
\hline \multirow[b]{3}{*}{$42(714)$} & $23(150)$ & $22(119)$ \\
\hline & $31(261)$ & \multirow{2}{*}{$21(131)$} \\
\hline & \multirow[b]{2}{*}{$19(60)$} & \\
\hline & & \multirow[b]{2}{*}{$20(119)$} \\
\hline & & \\
\hline & & $19(124)$ \\
\hline
\end{tabular}

Figura 55 - Mínimo de $15 \mathrm{~cm}$ de circunferência e 30 frutos por galho, árvore 10 .

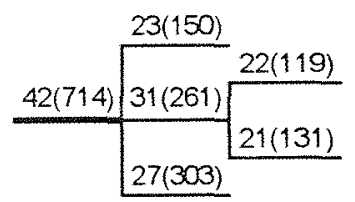

Figura 56 - Mínimo de $20 \mathrm{~cm}$ de circunferência e 40 frutos por galho, árvore 10 . 
90.

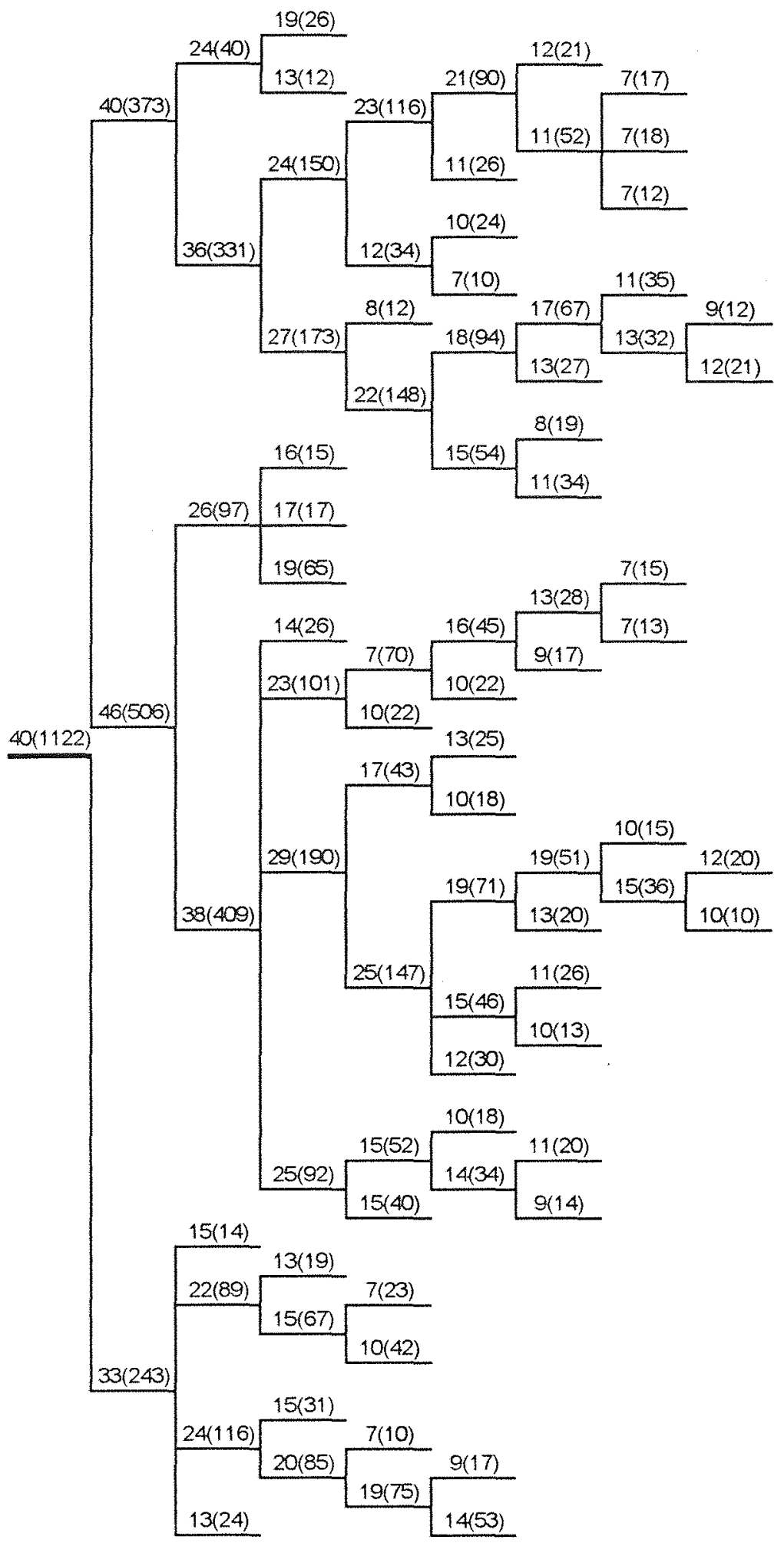

Figura 57 - Mínimo de $7 \mathrm{~cm}$ de circunferência e 10 frutos por galho, árvore 11 . 
91.

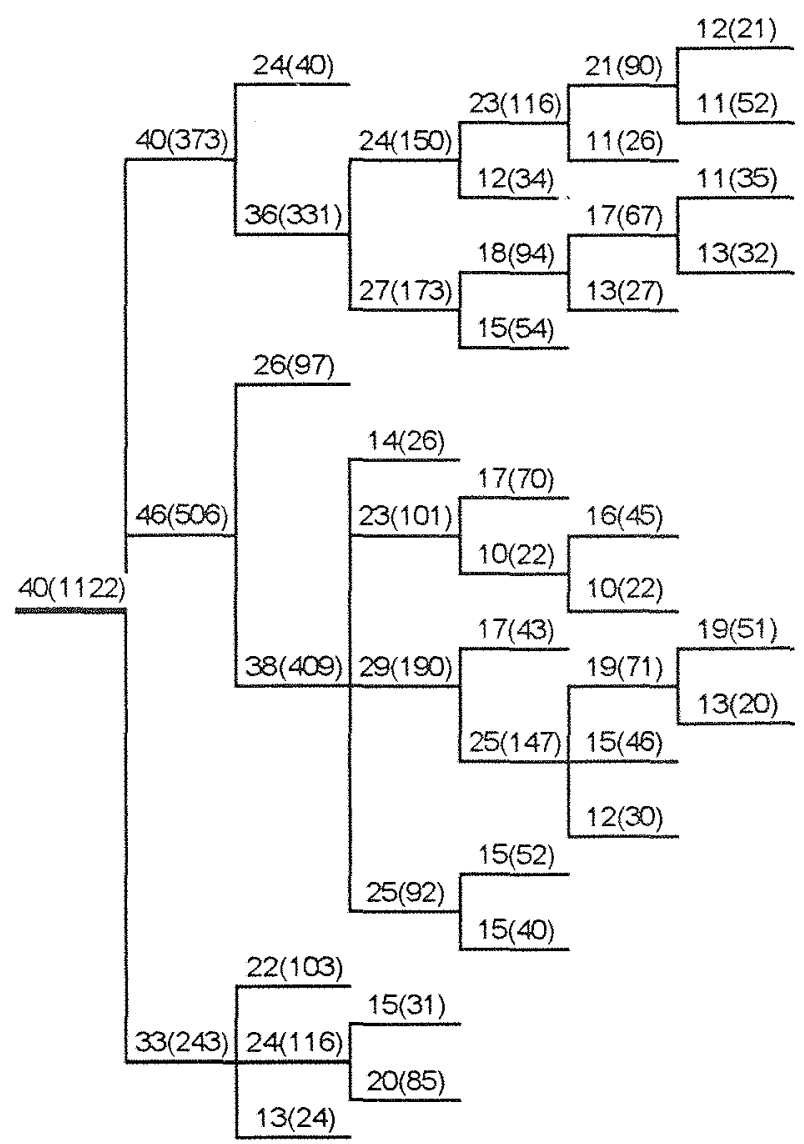

Figura 58 - Mínimo de $10 \mathrm{~cm}$ de circunferência e 20 frutos por galho, árvore 11 .

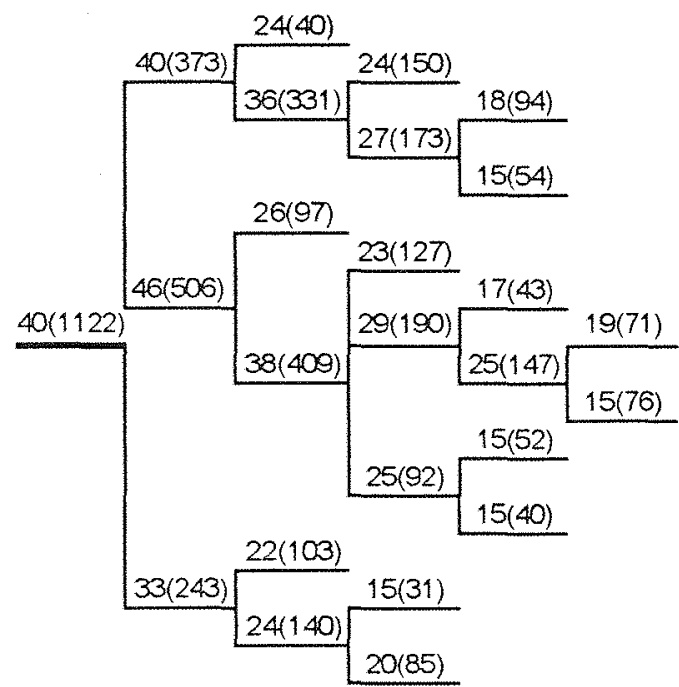


Figura 59 - Mínimo de $15 \mathrm{~cm}$ de circunferência e 30 frutos por galho, árvore 11 .

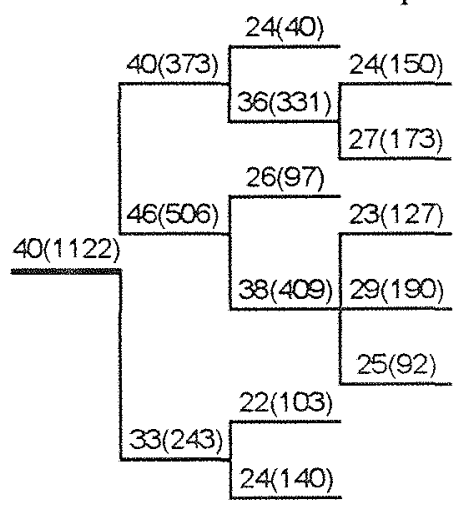

Figura 60 - Mínimo de $20 \mathrm{~cm}$ de circunferência e 40 frutos por galho, árvore 11 .

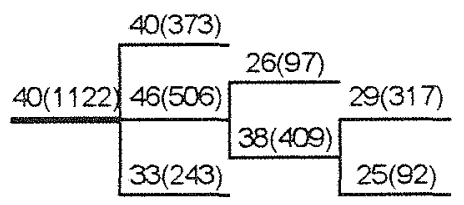

Figura 61 - Minimo de $25 \mathrm{~cm}$ de circunferência e 50 frutos por galho, árvore 11 . 
93.

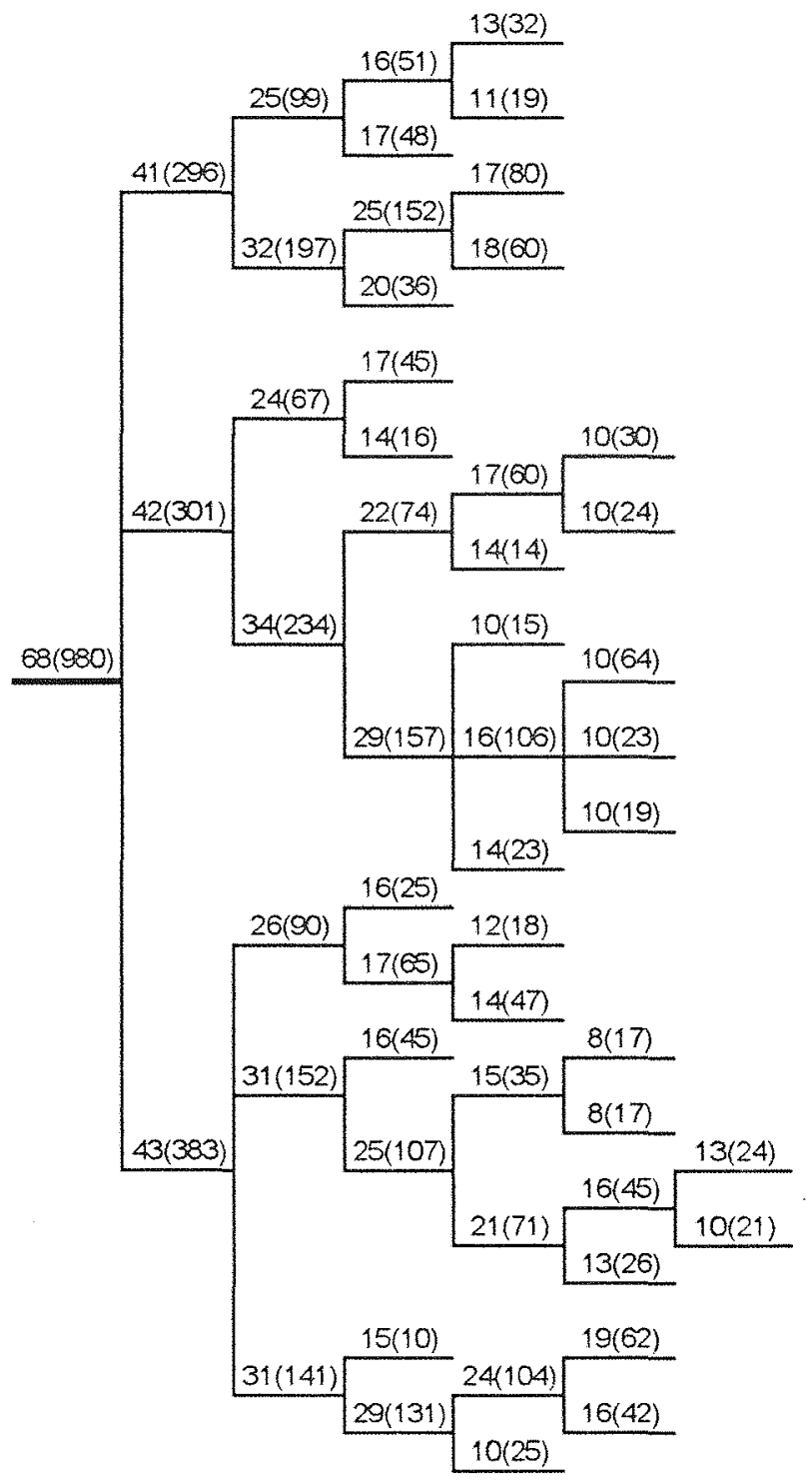

Figura 62 - Mínimo de $7 \mathrm{~cm}$ de circunferência e 10 frutos por galho, árvore 12 . 


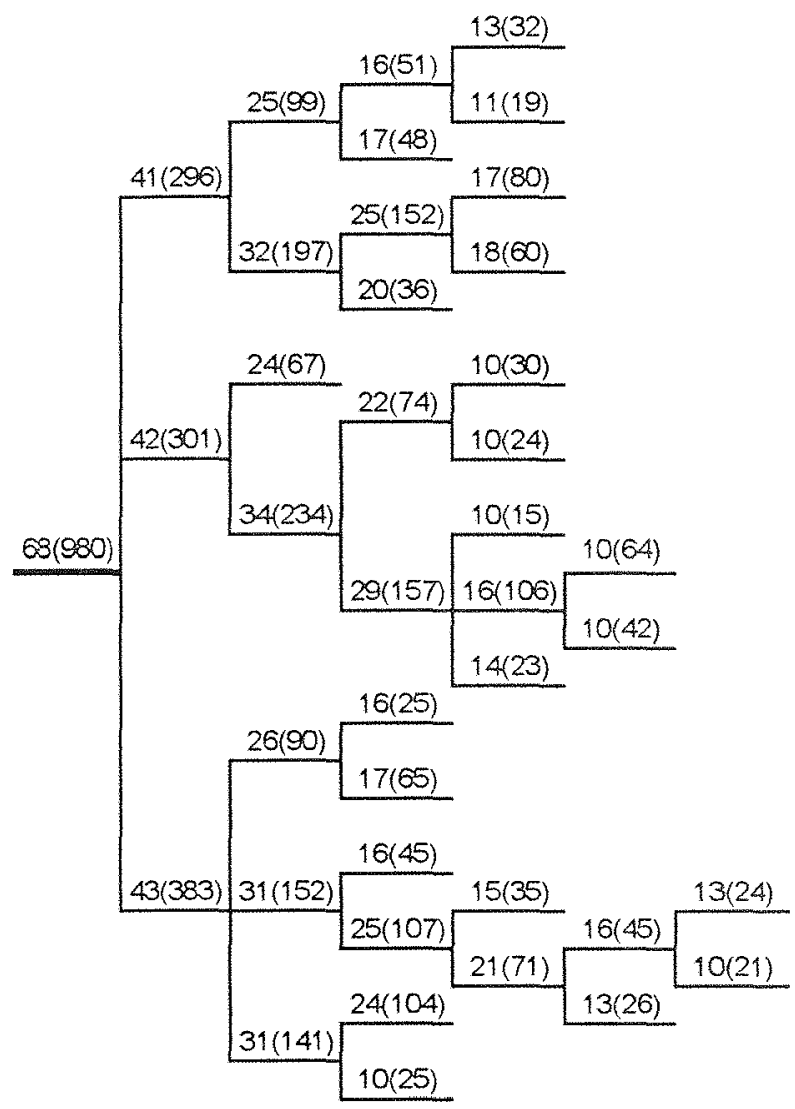

Figura 63 - Mínimo de $10 \mathrm{~cm}$ de circunferência e 20 frutos por galho, árvore 12 .

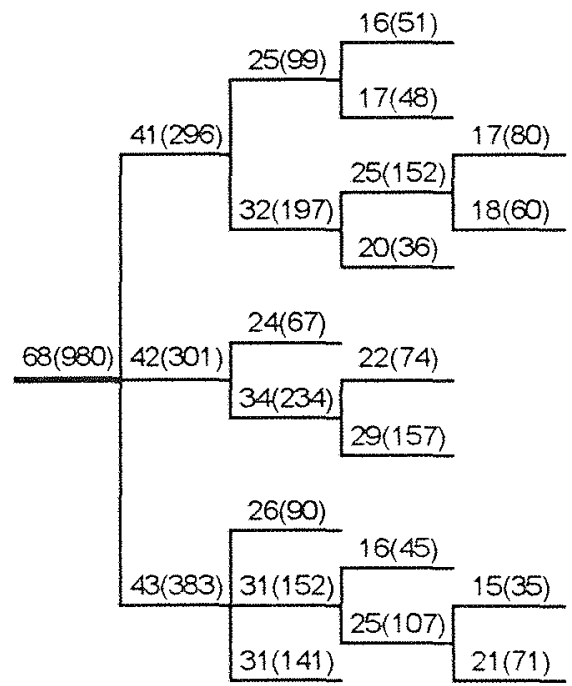

Figura 64 - Mínimo de $15 \mathrm{~cm}$ de circunferência e 30 frutos por galho, árvore 12 . 


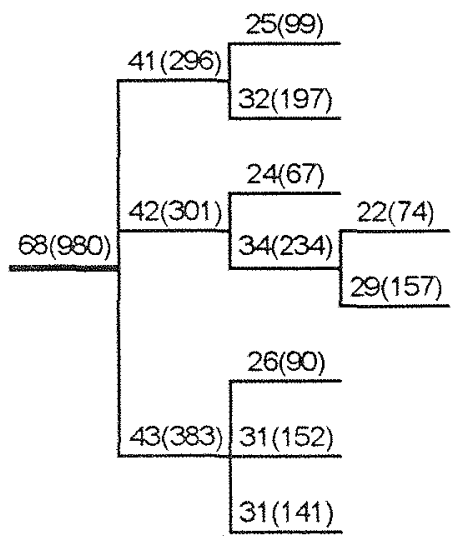

Figura 65 - Mínimo de $20 \mathrm{~cm}$ de circunferência e 40 frutos por galho, árvore 12 .

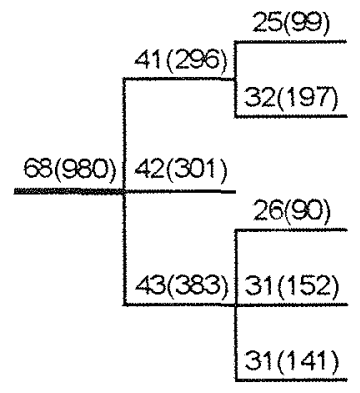

Figura 66 - Mínimo de $25 \mathrm{~cm}$ de circunferência e 50 frutos por galho, árvore 12 . 
96.

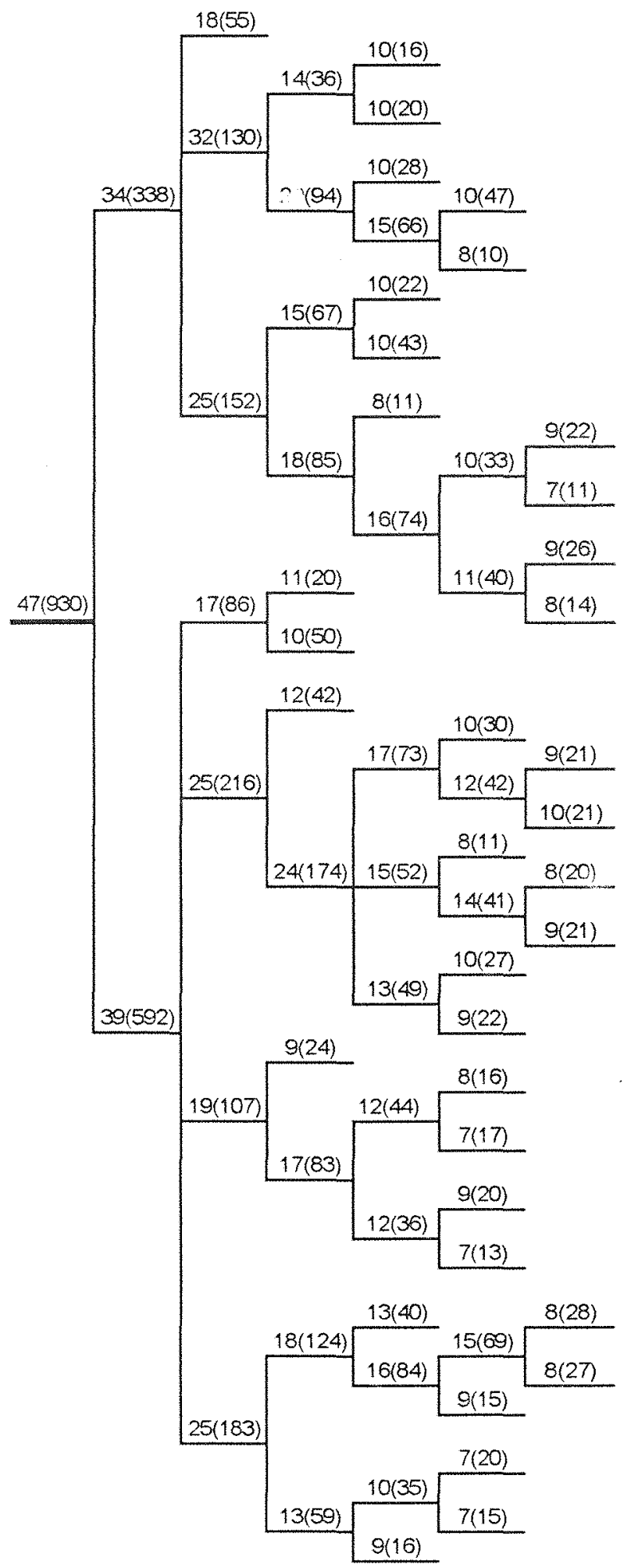

Figura 67 - Mínimo de $7 \mathrm{~cm}$ de circunferência e 10 frutos por galho, árvore 13 . 


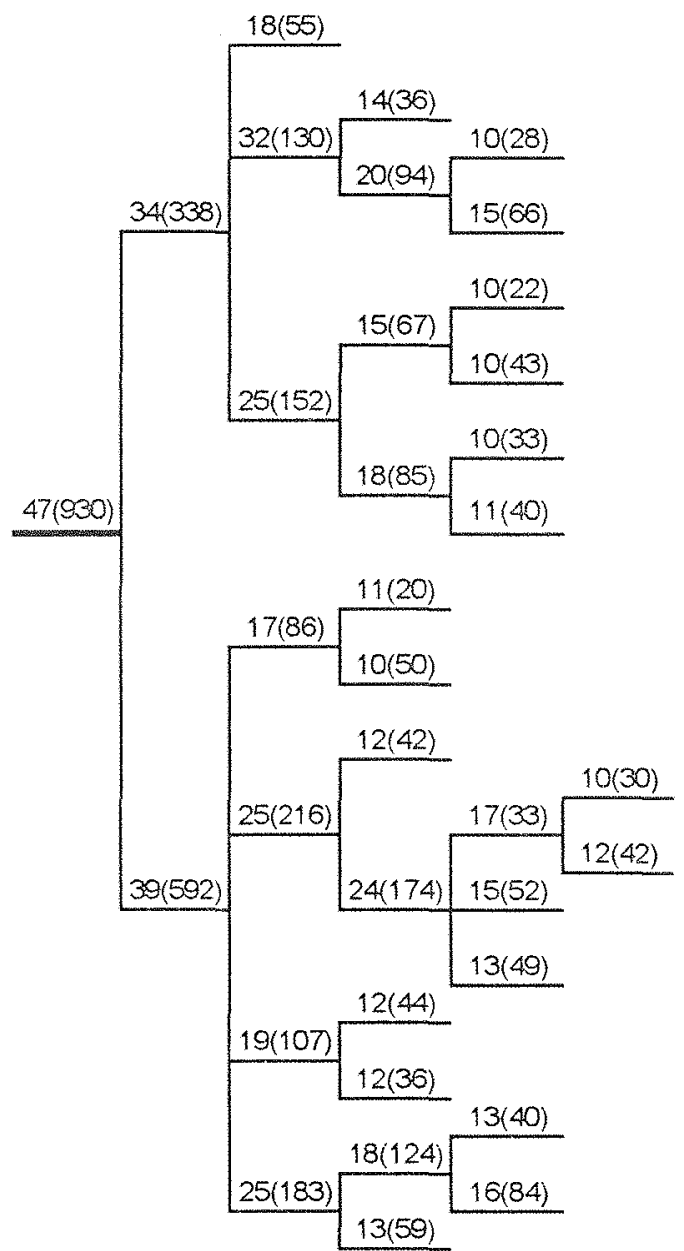

Figura 68 - Mínimo de $10 \mathrm{~cm}$ de circunferência e 20 frutos por galho, árvore 13 .

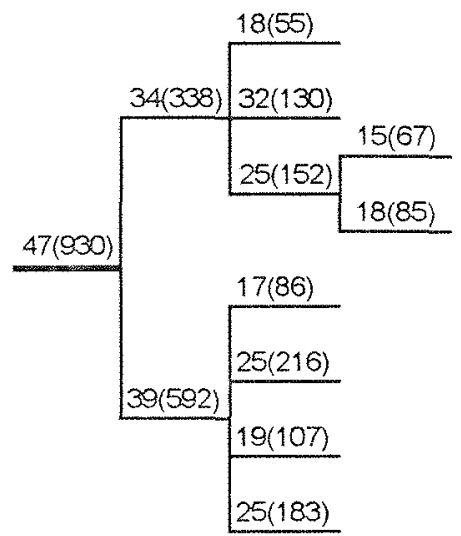

Figura 69 - Minimo de $15 \mathrm{~cm}$ de circunferência e 30 frutos por galho, árvore 13 . 
98.

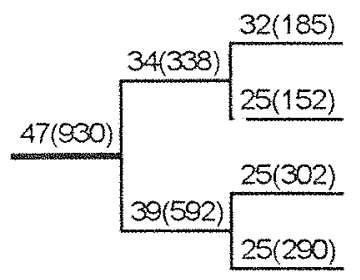

Figura 70 - Mínimo de $20 \mathrm{~cm}$ de circunferência e 40 frutos por galho, árvore 13 .

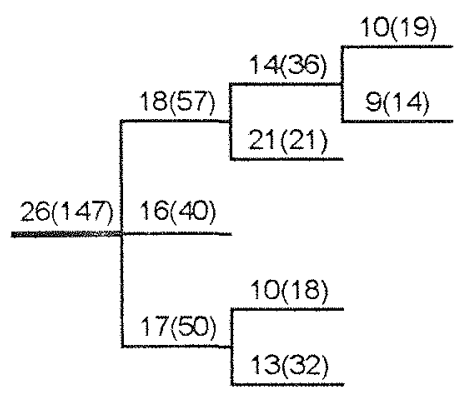

Figura 71 - Mínimo de $7 \mathrm{~cm}$ de circunferência e 10 frutos por galho, árvore 14 .

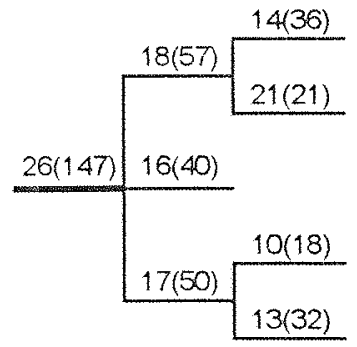

Figura 72 - Mínimo de $10 \mathrm{~cm}$ de circunferência e 10 frutos por galho, árvore 14 .

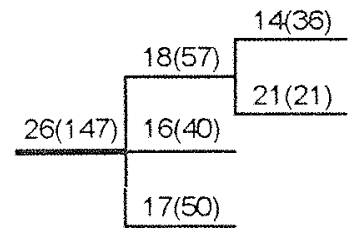

Figura 73 - Mínimo de $10 \mathrm{~cm}$ de circunferência e 20 frutos por galho, árvore 14 . 
99.

\begin{tabular}{c|c}
\multicolumn{1}{c}{$18(57)$} \\
\cline { 2 - 2 } & $16(40)$ \\
\hline $17(50)$ \\
\hline
\end{tabular}

Figura 74 - Mínimo de $15 \mathrm{~cm}$ de circunferência e 30 frutos por galho, árvore 14 .

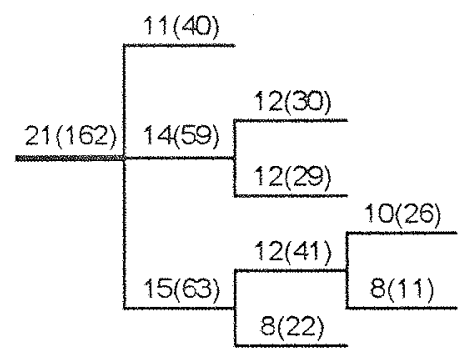

Figura 75 - Mínimo de $7 \mathrm{~cm}$ de circunferência e 10 frutos por galho, árvore 15 .

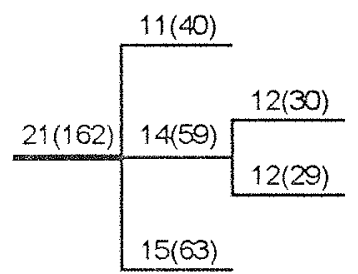

Figura 76 - Mínimo de $10 \mathrm{~cm}$ de circunferência e 10 frutos por galho, árvore 15 . 
100.

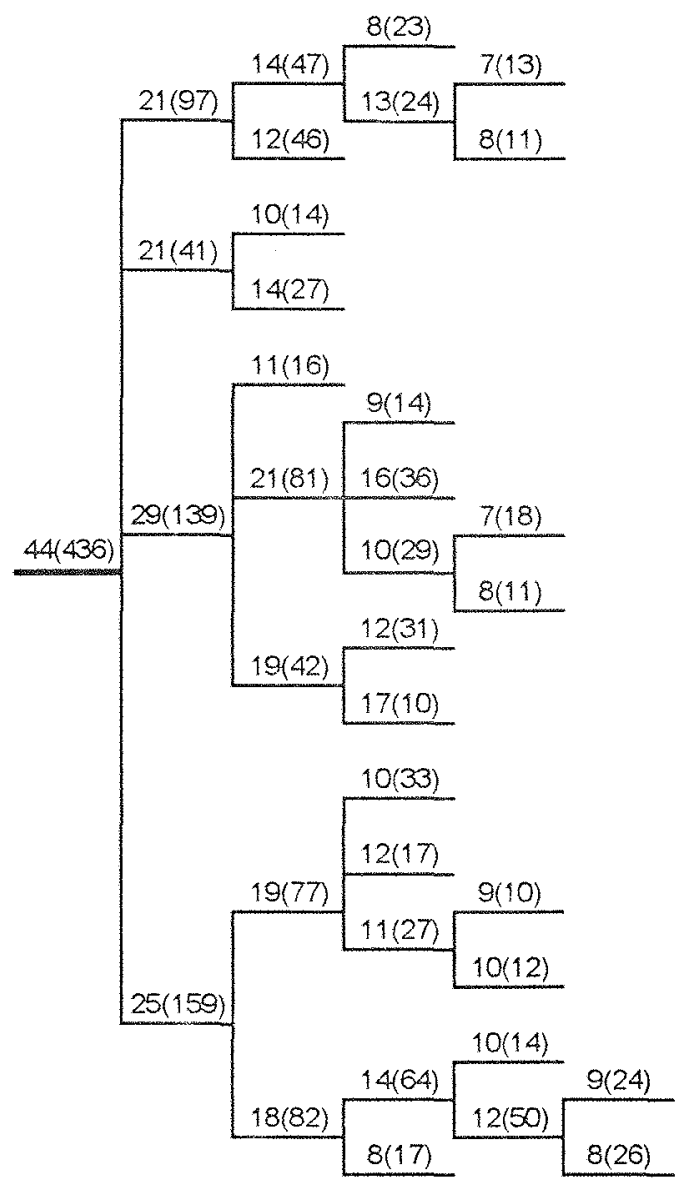

Figura 77 - Mínimo de $7 \mathrm{~cm}$ de circunferência e 10 frutos por galho, árvore 16 . 


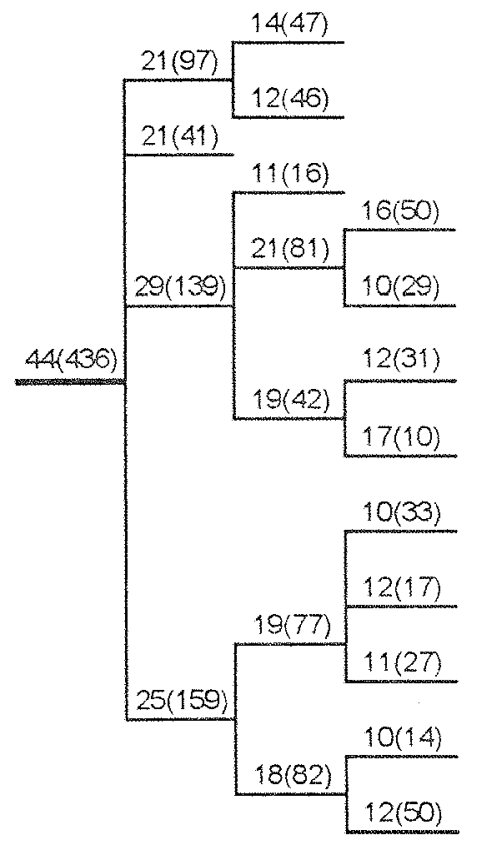

Figura 78 - Mínimo de $10 \mathrm{~cm}$ de circunferência e 10 frutos por galho, árvore 16 .

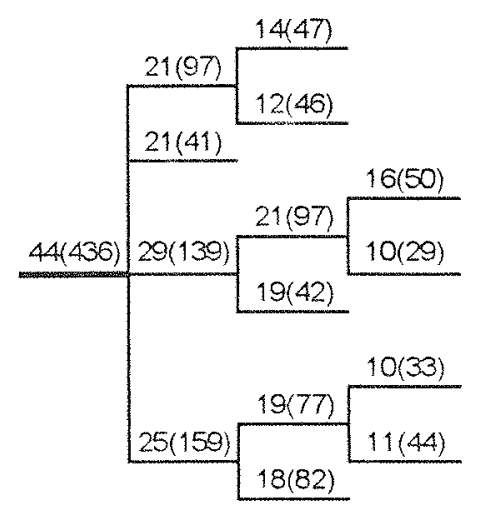

Figura 79 - Mínimo de $10 \mathrm{~cm}$ de circunferência e 20 frutos por galho, árvore 16 . 


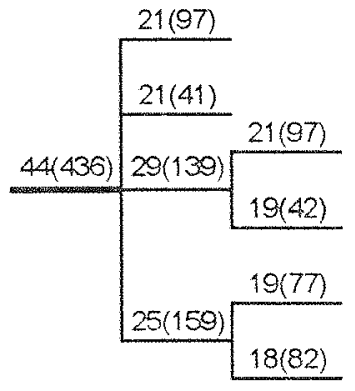

Figura 80 - Mínimo de $15 \mathrm{~cm}$ de circunferência e 30 frutos por galho, árvore 16 .

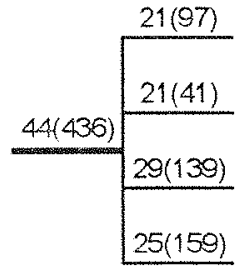

Figura 81 - Mínimo de $20 \mathrm{~cm}$ de circunferência e 40 frutos por galho, árvore 16 . 


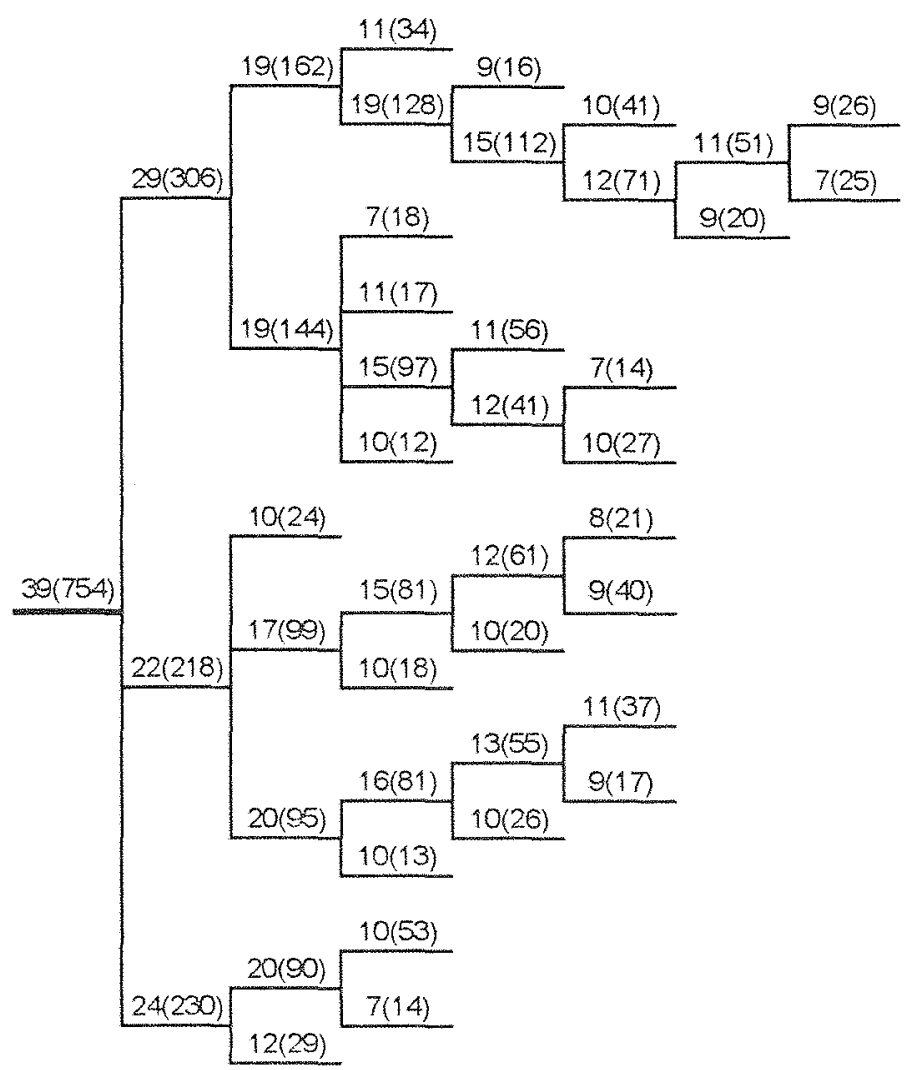

Figura 82 - Mínimo de $7 \mathrm{~cm}$ de circunferência e 10 frutos por galho, árvore 17 .

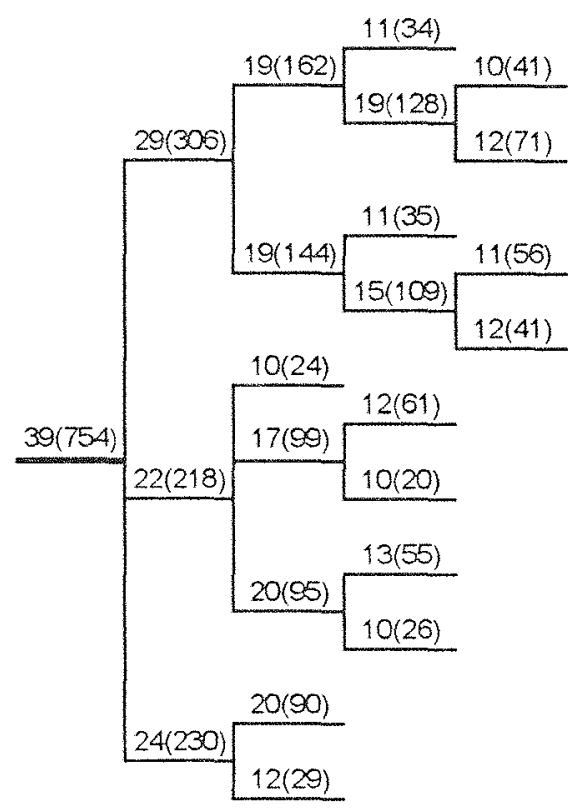

Figura 83 - Minimo de $10 \mathrm{~cm}$ de circunferência e 20 frutos por galho, árvore 17 . 
104.

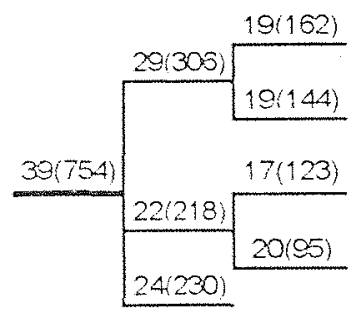

Figura 84 - Minimo de $15 \mathrm{~cm}$ de circunferência e 30 frutos por alho, árvore 17

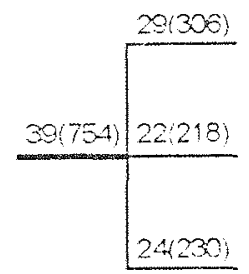

Figura 85 - Minimo de $20 \mathrm{~cm}$ de circunferencia e 40 frutos por galho, arvore 17 . 


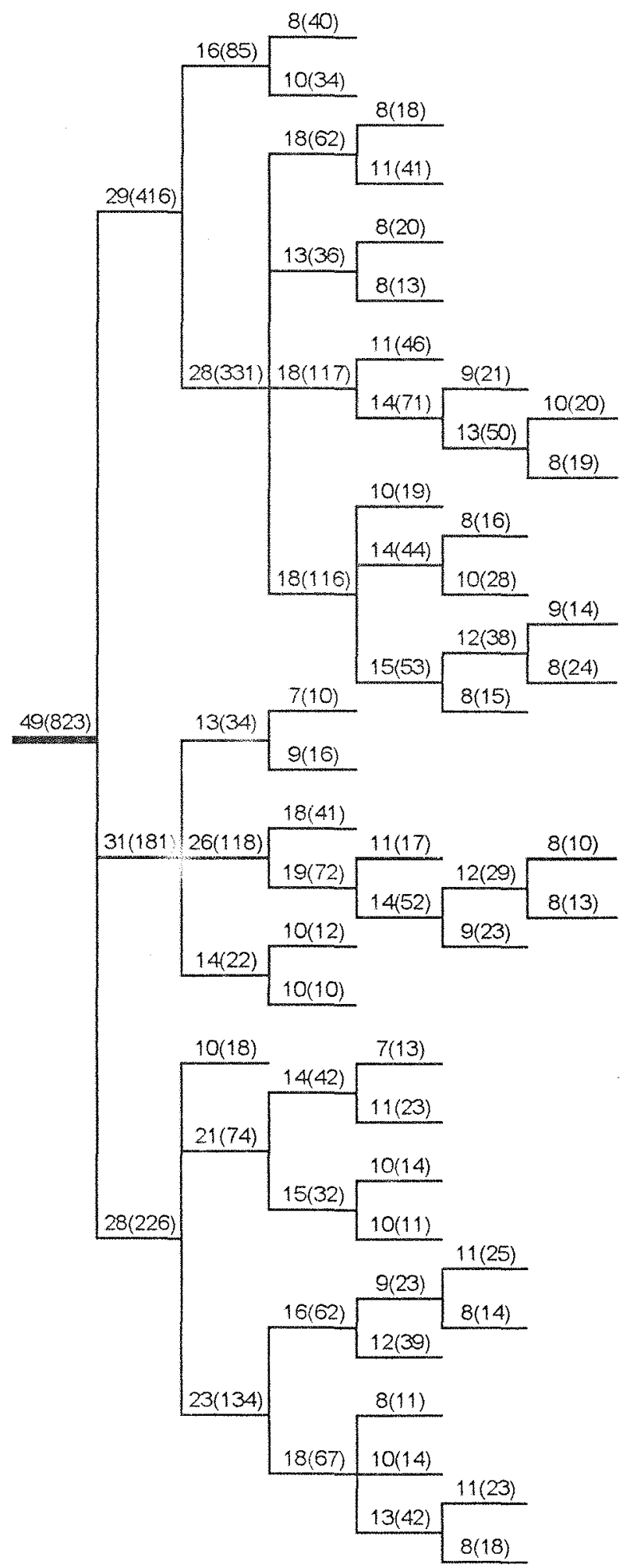

Figura 86 - Mínimo de $7 \mathrm{~cm}$ de circunferência e 10 frutos por galho, árvore 18 . 


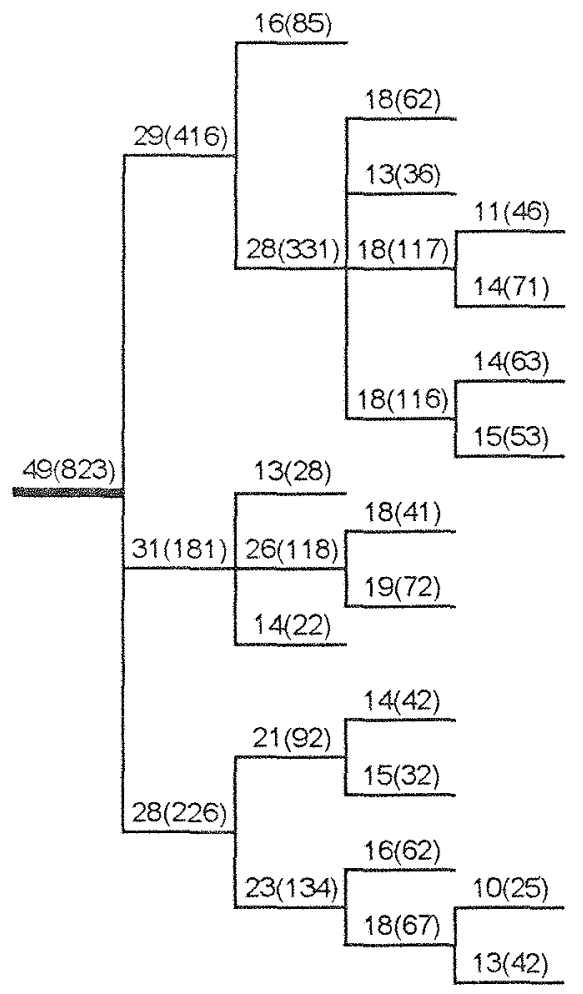

Figura 87 - Mínimo de $10 \mathrm{~cm}$ de circunferência e 20 frutos por galho, árvore 18 .

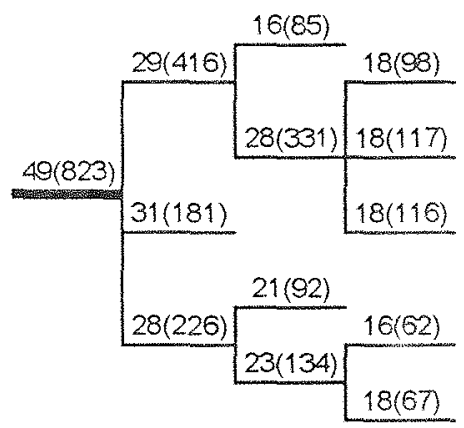

Figura 88 - Mínimo de $15 \mathrm{~cm}$ de circunferência e 30 frutos por galho, árvore 18 .

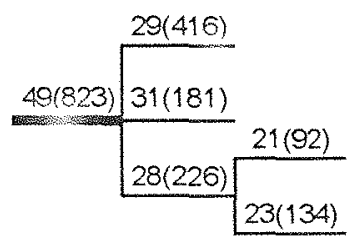

Figura 89 - Mínimo de $20 \mathrm{~cm}$ de circunferência e 40 frutos por galho, árvore 18 . 


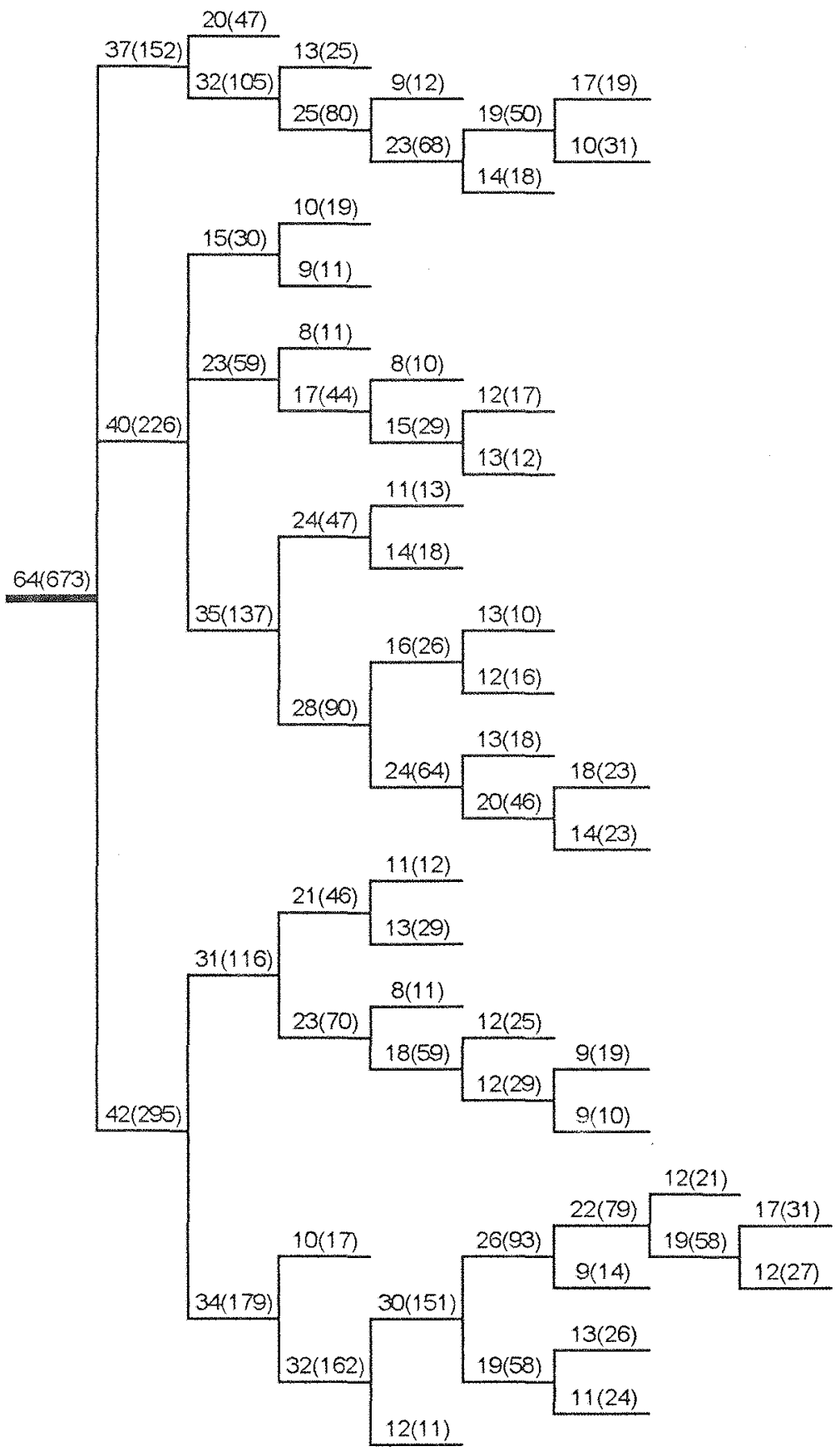

Figura 90 - Mínimo de $7 \mathrm{~cm}$ de circunferência e 10 frutos por galho, árvore 19 . 


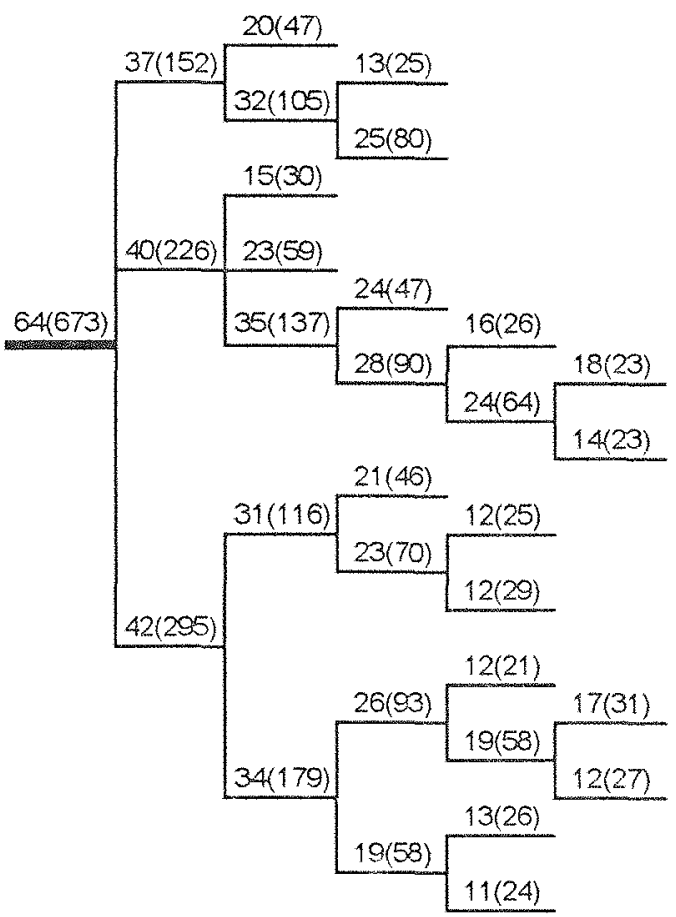

Figura 91 - Mínimo de $10 \mathrm{~cm}$ de circunferência e 20 frutos por alho, árvore 19.

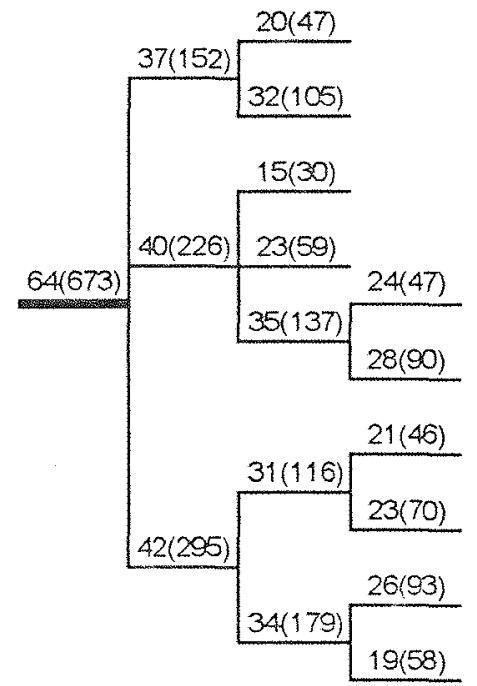

Figura 92 - Mínimo de $15 \mathrm{~cm}$ de circunferência e 30 frutos por galho, árvore 19 . 


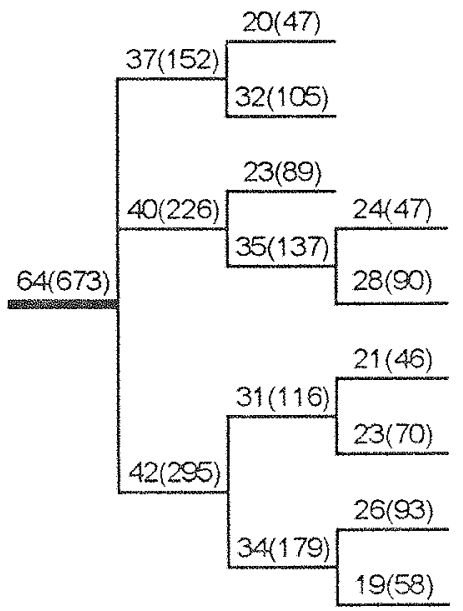

Figura 93 - Mínimo de $20 \mathrm{~cm}$ de circunferência e 40 frutos por galho, árvore 19.

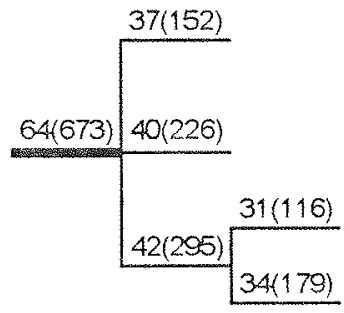

Figura 94 - Mínimo de $25 \mathrm{~cm}$ de circunferência e 50 frutos por galho, árvore 19 . 


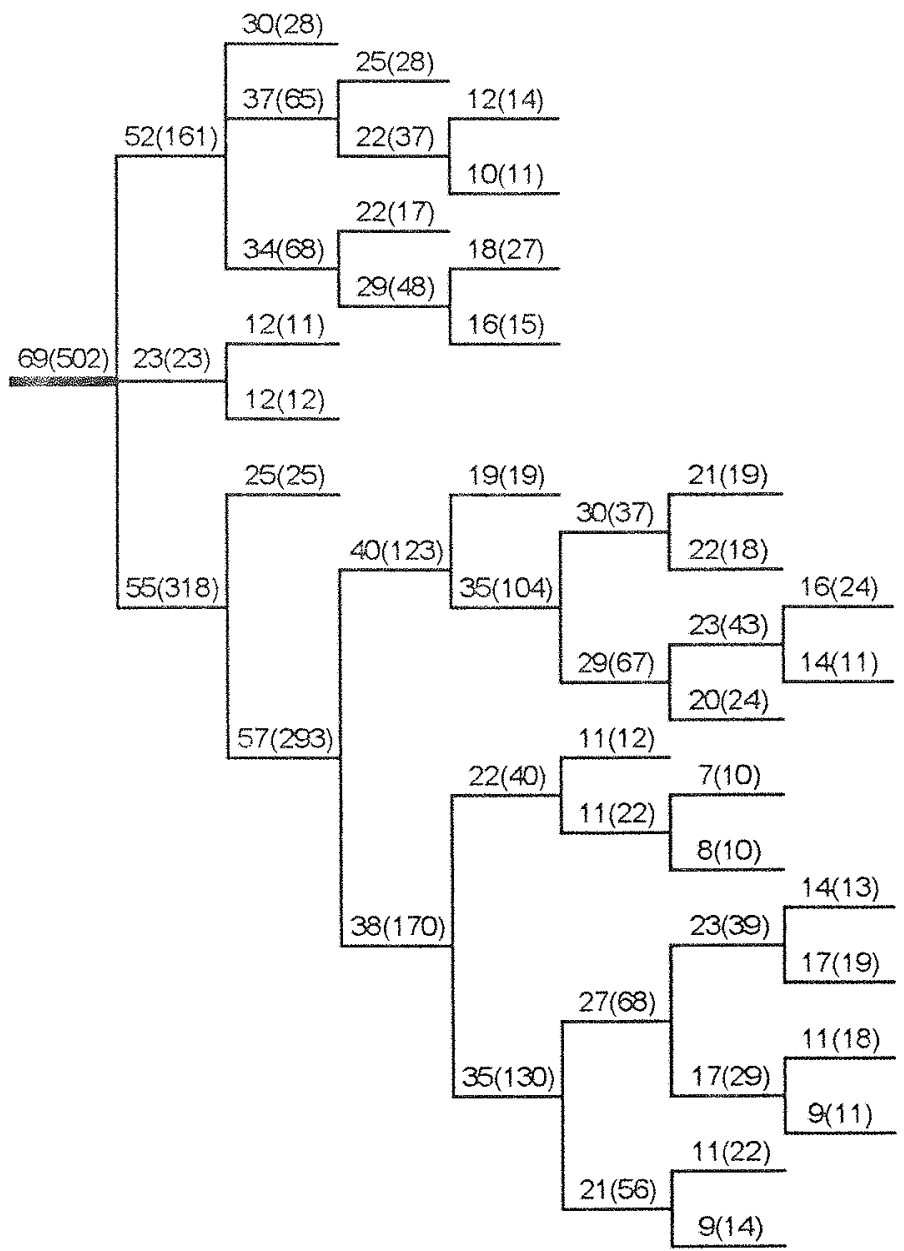

Figura 95 - Mínimo de $7 \mathrm{~cm}$ de circunferência e 10 frutos por galho, árvore 20 . 


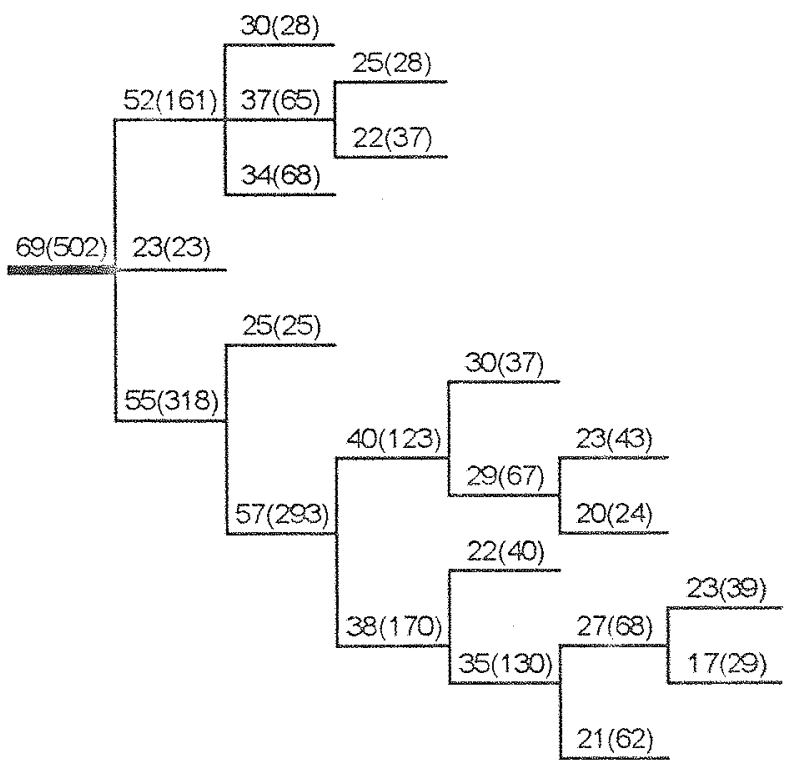

Figura 96 - Mínimo de $10 \mathrm{~cm}$ de circunferência e 20 frutos por galho, árvore 20 .

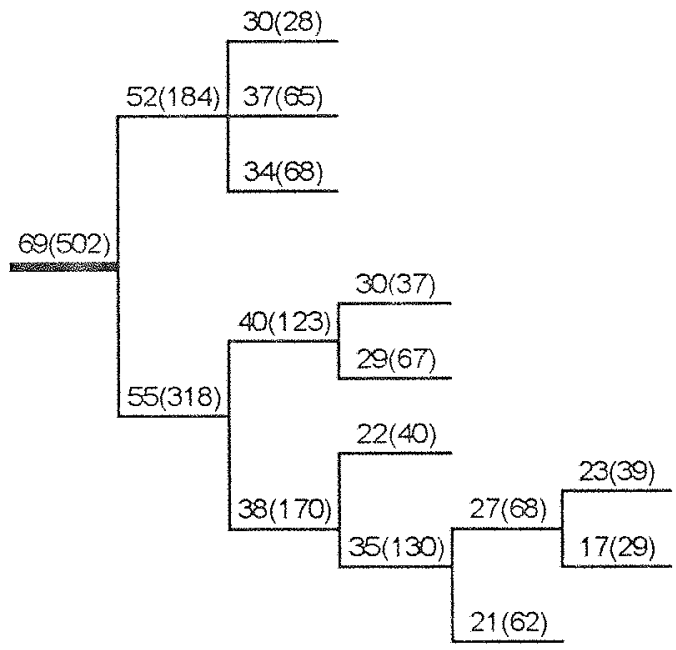

Figura 97 - Mínimo de $15 \mathrm{~cm}$ de circunferência e 30 frutos por galho, árvore 20. 


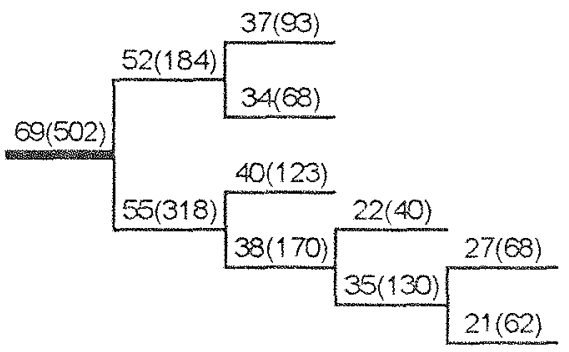

Figura 98 - Mínimo de $20 \mathrm{~cm}$ de circunferência e 40 frutos por galho, árvore 20 .

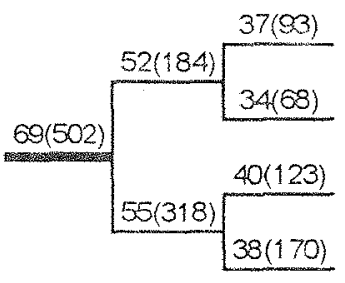

Figura 99 - Mínimo de $25 \mathrm{~cm}$ de circunferencia e 50 frutos por galho, árvore 20 . 
113.

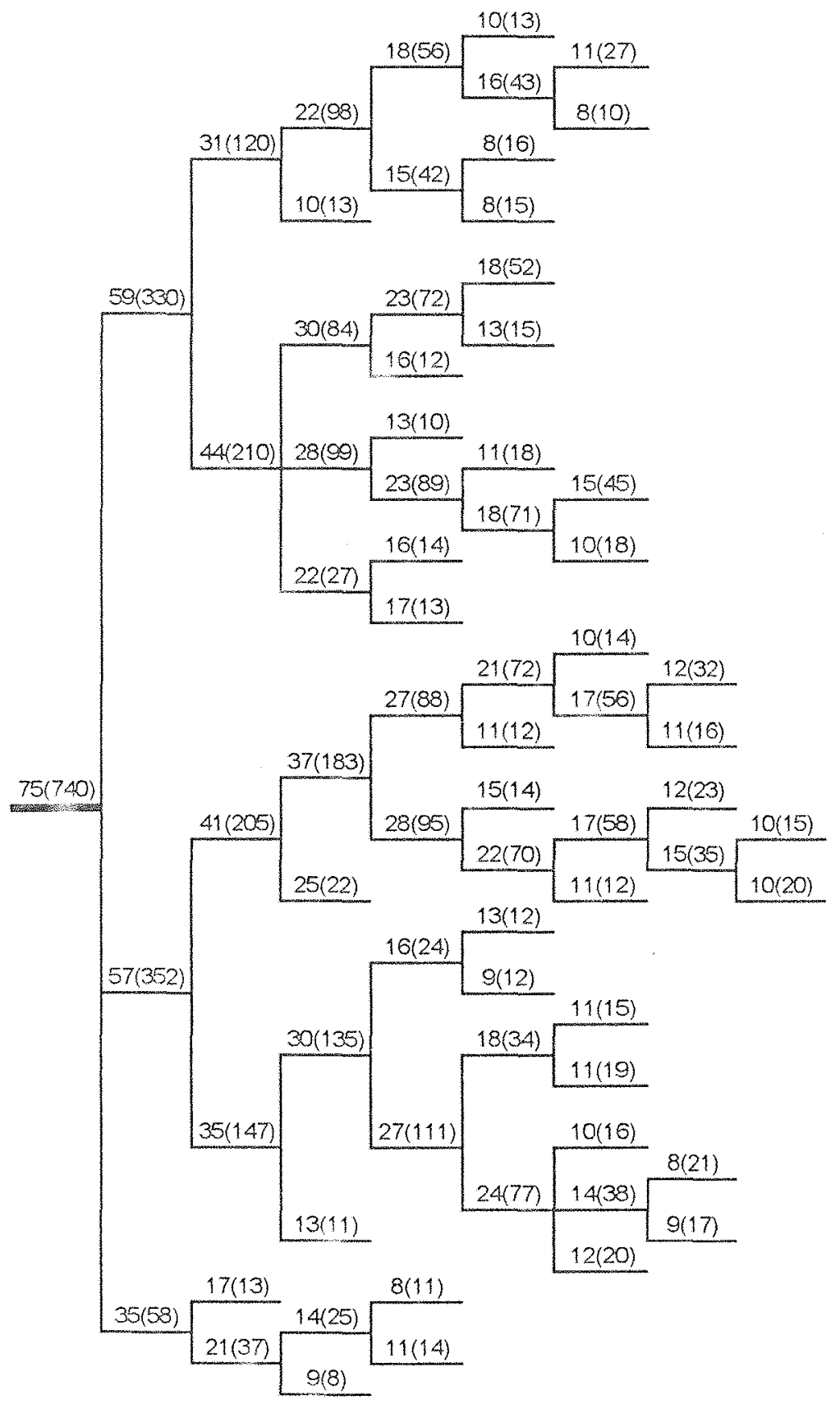

Figura $100 \cdot$ Minimo de $7 \mathrm{~cm}$ de circunferência e 10 frutos por galho, árvore 21 . 


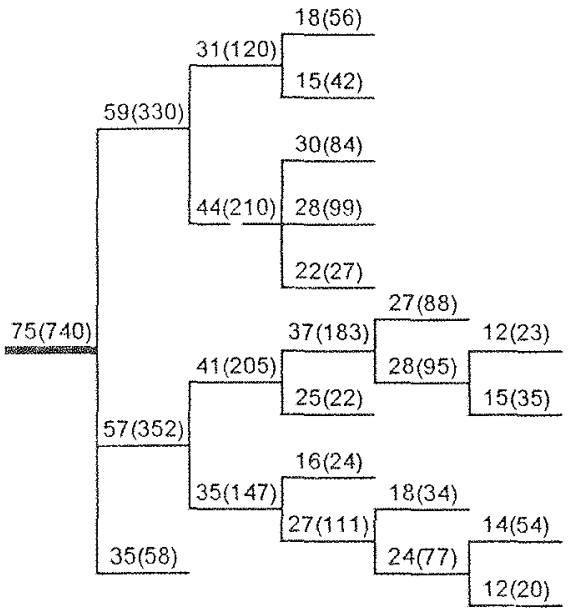

Figura 101 Mínimo de $10 \mathrm{~cm}$ de circunferencia e 20 frutos por galho, árvore 21 .

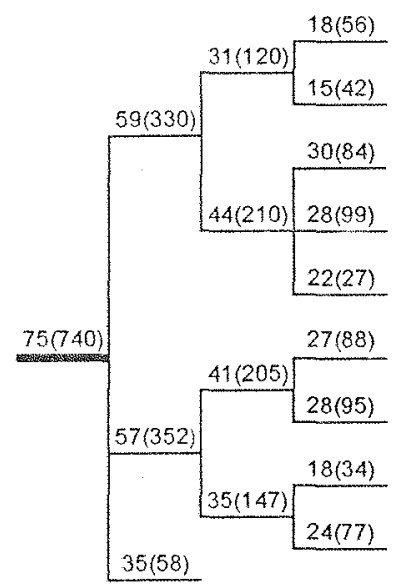

Figura 102 Mínimo de $15 \mathrm{~cm}$ de circunferência e 30 frutos por galho, árvore 21 .

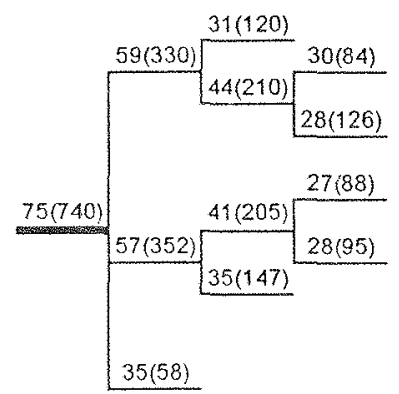

Figura 103 Minimo de $20 \mathrm{~cm}$ de circunferência e 40 frutos por galho. árvore 21. 
APENDICE 2

VALORES DAS PROBABILIDADES, ESTIMATIVA DO NÚMERO DE FRUTOS, VARIÂNCIA E COEFICIENTE DE VARIAÇÃO PARA OS TRÊS MÉTODOS DE SELEÇÃO. 
Tabela 05 - Árvore 01.

\begin{tabular}{|c|c|c|c|c|c|c|c|}
\hline $\begin{array}{l}\text { Número } \\
\text { do } \\
\text { galho }\end{array}$ & $\begin{array}{c}\text { Número } \\
\text { de } \\
\text { frutos }\end{array}$ & PE & PPN & PPA & $\begin{array}{l}\text { Estimativa } \\
\text { do } n^{\circ} \text { de } \\
\text { frutos (PE) }\end{array}$ & $\begin{array}{l}\text { Estimativa } \\
\text { do } n^{\circ} \text { de } \\
\text { frutos (PPN) }\end{array}$ & $\begin{array}{l}\text { Estimativa } \\
\text { do } n^{\circ} \text { de } \\
\text { frutos (PPA) }\end{array}$ \\
\hline 1 & 12 & $1 / 12$ & $1 / 24$ & 0.0324 & 144 & 288 & 370 \\
\hline 2 & 16 & $1 / 12$ & $1 / 24$ & 0,0662 & 192 & 384 & $2+2$ \\
\hline 3 & 8 & $1 / 12$ & $1 / 24$ & 0,0330 & 96 & 192 & $2+2$ \\
\hline 4 & 10 & $1 / 12$ & $1 / 24$ & 0.0330 & 120 & 240 & 303 \\
\hline 5 & 6 & $1 / 12$ & $1 / 12$ & 0.0680 & 72 & 72 & 88 \\
\hline 6 & 12 & $1 / 12$ & $1 / 12$ & 0.0499 & 144 & 144 & 240 \\
\hline 7 & 9 & $1 / 12$ & $1 / 24$ & 0,0456 & 108 & 216 & 197 \\
\hline 8 & 6 & $1 / 12$ & $1 / 24$ & 0.0456 & 72 & 144 & 131 \\
\hline 9 & 15 & $1 / 12$ & $1 / 12$ & 0,1726 & 180 & 180 & 87 \\
\hline 10 & 12 & $1 / 12$ & $1 / 6$ & 0.1346 & 144 & 72 & 89 \\
\hline 11 & 22 & $1 / 12$ & $1 / 6$ & 0,2112 & 264 & 132 & 104 \\
\hline 12 & 16 & $1 / 12$ & $1 / 6$ & 0.1078 & 192 & 96 & 148 \\
\hline TOTAIS & 144 & 1 & 1 & 1.0000 & & & \\
\hline \multicolumn{5}{|c|}{ VARIANC A } & 2940,0000 & 5808.0000 & 5591.8603 \\
\hline \multicolumn{5}{|l|}{ MEDIA } & 144.00 & 180.00 & 186.90 \\
\hline \multicolumn{3}{|l|}{ C.V. $(\%)$} & & & 37.65 & 42.34 & 40.01 \\
\hline
\end{tabular}

Tabela 06 - Minimo de $7 \mathrm{~cm}$ de circunferência e 10 frutos/galho, árvore 01.

\begin{tabular}{|c|c|c|c|c|c|c|c|}
\hline $\begin{array}{l}\text { Número } \\
\text { do } \\
\text { galho }\end{array}$ & $\begin{array}{l}\text { Número } \\
\text { de } \\
\text { frutos }\end{array}$ & $\mathrm{PE}$ & PPN & PPA & $\begin{array}{l}\text { Estimativa } \\
\text { do } n^{\circ} \text { de } \\
\text { frutos (PE) }\end{array}$ & $\begin{array}{l}\text { Estimativa } \\
\text { do } n^{\circ} \text { de } \\
\text { frutos (PPN) }\end{array}$ & $\begin{array}{l}\text { Estimativa } \\
\text { do } n^{\circ} \text { de } \\
\text { frutos (PPA) }\end{array}$ \\
\hline 1 & 48 & $1 / 6$ & $1 / 6$ & 0.1647 & 288 & 288 & 292 \\
\hline 2 & 16 & $1 / 9$ & $1 / 24$ & 0.0662 & 144 & 384 & 242 \\
\hline 3 & 20 & $1 / 9$ & $1 / 12$ & 0.0660 & 180 & 240 & 303 \\
\hline 4 & 18 & $1 / 9$ & $1 / 6$ & 0.1179 & 162 & 108 & 153 \\
\hline 5 & 18 & $1 / 9$ & $1 / 12$ & 0,0913 & 162 & 216 & 197 \\
\hline 6 & 15 & $1 / 9$ & $1 / 12$ & 0.1726 & 135 & 180 & 87 \\
\hline 7 & 12 & $1 / 9$ & $1 / 6$ & 0.1346 & 108 & 72 & 89 \\
\hline 8 & 22 & $1 / 9$ & $1 / 6$ & 0.2112 & 198 & 132 & 104 \\
\hline 9 & 16 & $1 / 9$ & $1 / 6$ & 0.1078 & 144 & 96 & 148 \\
\hline TOTAIS & $1+9$ & 1 & 1 & 1.0000 & & & \\
\hline VARIANCIA & & & & & 813,0000 & 6036.0000 & 5502.9153 \\
\hline MEDIA & & & & & 149.00 & 190.67 & 188.12 \\
\hline C.V. $(\%)$ & & & & & 19.14 & 40.75 & $39 .+3$ \\
\hline
\end{tabular}


Tabela 07 - Mínimo de $10 \mathrm{~cm}$ de circunferência e 10 frutos/galho, árvore 01 .

\begin{tabular}{|c|c|c|c|c|c|c|c|}
\hline $\begin{array}{l}\text { Número } \\
\text { do } \\
\text { gallye }\end{array}$ & $\begin{array}{c}\text { Número } \\
\text { de } \\
\text { frutos }\end{array}$ & $\mathrm{PE}$ & PPN & PPA & $\begin{array}{l}\text { Estimativa } \\
\text { do } n^{\circ} \text { de } \\
\text { frutos (PE) }\end{array}$ & $\begin{array}{c}\text { Estimativa } \\
\text { do } n^{\circ} \text { de } \\
\text { fn tos (PPN) }\end{array}$ & $\begin{array}{c}\text { Estimativa } \\
\text { do } n^{\circ} \text { de } \\
\text { frutos (PPA) }\end{array}$ \\
\hline 1 & 48 & $1 / 6$ & $1 / 6$ & 0.1647 & 288 & 288 & 292 \\
\hline 2 & 18 & $1 / 6$ & $1 / 6$ & 0.1179 & 108 & 108 & 153 \\
\hline 3 & 33 & $1 / 6$ & $1 / 6$ & 0.2638 & 198 & 198 & 125 \\
\hline 4 & 12 & $1 / 6$ & $1 / 6$ & 0.1346 & 72 & 72 & 89 \\
\hline 5 & 22 & $1 / 6$ & $1 / 6$ & 0.2112 & 132 & 132 & 104 \\
\hline 6 & 16 & $1 / 6$ & $1 / 6$ & 0,1078 & 96 & 96 & 148 \\
\hline TOTAIS & 159 & 1 & 1 & 1.0000 & & & \\
\hline \multicolumn{5}{|c|}{ VARIANCIA } & 5406.0000 & 5406,0000 & 4404,469 \\
\hline \multicolumn{5}{|l|}{ MEDIA } & 149.00 & 149.00 & 85184 \\
\hline C.V. $(\%)$ & & & & & 49.35 & 49.35 & 4.71 \\
\hline
\end{tabular}

Tabela 08 - Minimo de $10 \mathrm{~cm}$ de circunferência e 20 frutos/gallho, árvore 01 .

\begin{tabular}{|c|c|c|c|c|c|c|c|}
\hline $\begin{array}{l}\text { Número } \\
\text { do } \\
\text { galho }\end{array}$ & $\begin{array}{l}\text { Número } \\
\text { de } \\
\text { frutos }\end{array}$ & $\mathrm{PE}$ & PPN & PPA & $\begin{array}{l}\text { Estimativa } \\
\text { do } n^{0} \text { de } \\
\text { frutos (PE) }\end{array}$ & $\begin{array}{l}\text { Estimativa } \\
\text { do } n^{\circ} \text { de } \\
\text { frutos (PPN) }\end{array}$ & $\begin{array}{l}\text { Estimuativa } \\
\text { do no de } \\
\text { frutas (PPA) }\end{array}$ \\
\hline 1 & 48 & $1 / 4$ & $1 / 6$ & 0,1647 & 192 & 288 & 292 \\
\hline 2 & 18 & $1 / 4$ & $1 / 6$ & 0.1179 & 72 & 108 & 153 \\
\hline 3 & 45 & $1 / 4$ & $1 / 3$ & 0,3985 & 180 & 135 & 113 \\
\hline 4 & 39 & $1 / 4$ & $1 / 3$ & 0,3190 & 156 & 117 & 122 \\
\hline TOTAIS & 150 & 1 & 1 & 1.0000 & & & \\
\hline VARIANCIA & & & & & 2196.0000 & 3906.0000 & 4090.6444 \\
\hline MEDIA & & & & & 150,00 & 162,00 & 169.84 \\
\hline C.V. $(\%)$ & & & & & 31.24 & 38.58 & 37.66 \\
\hline
\end{tabular}

Tabela 09 - Mínimo de $15 \mathrm{~cm}$ de circunferência e 30 frutos/galho, árvore 01.

\begin{tabular}{|c|c|c|c|c|c|c|c|}
\hline $\begin{array}{l}\text { Núnero } \\
\text { do } \\
\text { galho }\end{array}$ & $\begin{array}{l}\text { Número } \\
\text { de } \\
\text { frutos }\end{array}$ & PE & PPN & PPA & $\begin{array}{l}\text { Estimativa } \\
\text { do } n^{\circ} \text { de } \\
\text { frutos (PE) }\end{array}$ & $\begin{array}{l}\text { Estimativa } \\
\text { do } n^{\circ} \text { de } \\
\text { frutos (PPN) }\end{array}$ & $\begin{array}{l}\text { Estimativa } \\
\text { do } 1^{\circ} \text { de } \\
\text { frutos (PPA) }\end{array}$ \\
\hline 1 & 66 & $1 / 3$ & $1 / 3$ & 0.2826 & 198 & 198 & 234 \\
\hline 2 & 45 & $1 / 3$ & $1 / 3$ & 0.3985 & 135 & 135 & 113 \\
\hline 3 & 39 & $1 / 3$ & $1 / 3$ & 0.3190 & 117 & 117 & 122 \\
\hline TOTAIS & 150 & 1 & 1 & 1.0000 & & & \\
\hline VARIANCIA & & & & & 1206.0000 & 1206.0000 & 2766.5453 \\
\hline MEDIA & & & & & 150.00 & 150,00 & 156.26 \\
\hline C.V. $(0 / 0)$ & & & & & 23.15 & 23.15 & 33.66 \\
\hline
\end{tabular}


Tabela 10 - Árore 02.

\begin{tabular}{|c|c|c|c|c|c|c|c|}
\hline $\begin{array}{c}\text { Número } \\
\text { do } \\
\text { galho }\end{array}$ & $\begin{array}{l}\text { Numero } \\
\text { de } \\
\text { frutos }\end{array}$ & PE & PPN & PPA & $\begin{array}{l}\text { Estimativa } \\
\text { do } n^{\circ} \mathrm{de} \\
\text { frutos (PE) }\end{array}$ & $\begin{array}{l}\text { Estimativa } \\
\text { do } n^{\circ} \text { de } \\
\text { frutos (PPN) }\end{array}$ & $\begin{array}{l}\text { Estimativa } \\
\text { do } n^{\circ} \text { de } \\
\text { frutos (PPA) }\end{array}$ \\
\hline 1 & 18 & 1.18 & $1 / 32$ & 0.0746 & 324 & 576 & $2+1$ \\
\hline 2 & 5 & $1 / 18$ & $1 / 32$ & 0.0187 & 90 & 160 & 268 \\
\hline 3 & 10 & $1 / 18$ & $1 / 16$ & 0,0933 & 180 & 160 & 107 \\
\hline 4 & 6 & $1 / 18$ & $1 / 64$ & 0,0251 & 108 & 384 & 239 \\
\hline 5 & 6 & $1 / 18$ & $1 / 64$ & 0.0342 & 108 & 384 & 176 \\
\hline 6 & 5 & $1 / 18$ & $1 / 32$ & 0,0358 & 90 & 160 & 139 \\
\hline 7 & 8 & $1 / 18$ & $1 / 64$ & 0.0366 & 144 & 512 & 219 \\
\hline 8 & 10 & $1 / 18$ & $1 / 64$ & 0.0366 & 180 & 640 & 273 \\
\hline 9 & 7 & $1 / 18$ & $1 / 32$ & 0.0183 & 126 & 224 & 383 \\
\hline 10 & 6 & $1 / 18$ & $1 / 8$ & 0.0956 & 108 & 48 & 63 \\
\hline 11 & 7 & $1 / 18$ & $1 / 8$ & 0.1210 & 126 & 56 & 58 \\
\hline 12 & 6 & $1 / 18$ & $1 / 16$ & 0,0497 & 108 & 96 & 121 \\
\hline 13 & 5 & $1 / 18$ & $1 / 16$ & 0.0497 & 90 & 80 & 101 \\
\hline 14 & 5 & $1 / 18$ & $1 / 8$ & 0.0665 & 90 & 40 & 75 \\
\hline 15 & 11 & $1 / 18$ & $1 / 32$ & 0.0585 & 198 & 352 & 188 \\
\hline 16 & 11 & $1 / 18$ & $1 / 32$ & 0.0430 & 198 & 352 & 256 \\
\hline 17 & 5 & $1 / 18$ & $1 / 16$ & 0.0497 & 90 & 80 & 101 \\
\hline 18 & 9 & $1 / 17$ & $1 / 8$ & 0.0933 & 153 & 72 & 96 \\
\hline TOTAIS & $1+0$ & 1 & 1 & 1.0000 & & & \\
\hline \multicolumn{5}{|c|}{ VARIANCIA } & 3458,5817 & 21352.0000 & 62080427 \\
\hline \multicolumn{5}{|c|}{ MEDIA } & 139.50 & 243.11 & 172,44 \\
\hline \multicolumn{5}{|l|}{ C.V. $(\%)$} & 42.16 & 60,11 & 45.69 \\
\hline
\end{tabular}

Tabela 11 - Mínimo de $7 \mathrm{~cm}$ de circunferência e 10 frutos/galho, árvore 02.

\begin{tabular}{|c|c|c|c|c|c|c|c|}
\hline $\begin{array}{l}\text { Número } \\
\text { do } \\
\text { galho }\end{array}$ & $\begin{array}{c}\text { Número } \\
\text { de } \\
\text { frutos }\end{array}$ & PE & PPN & PPA & $\begin{array}{l}\text { Estimativa } \\
\text { do } n^{\circ} \text { de } \\
\text { frutos (PE) }\end{array}$ & $\begin{array}{l}\text { Estimativa } \\
\text { do } n^{\circ} \text { de } \\
\text { frutos (PPN) }\end{array}$ & $\begin{array}{l}\text { Estimativa } \\
\text { do } n^{\circ} \text { de } \\
\text { frutos (PPA) }\end{array}$ \\
\hline 1 & 23 & $1 / 8$ & $1 / 16$ & 0.0933 & 184 & 368 & 247 \\
\hline 2 & 10 & $1 / 8$ & $1 / 16$ & 0.0933 & 80 & 160 & 107 \\
\hline 3 & 17 & $1 / 8$ & $1 / 16$ & 0.0835 & 136 & 272 & 204 \\
\hline 4 & 27 & $1 / 8$ & $1 / 16$ & 0.1031 & 216 & 432 & 262 \\
\hline 5 & 18 & $1 / 8$ & $1 / 4$ & 0.2166 & 144 & 72 & 83 \\
\hline 6 & 16 & $1 / 8$ & $1 / 4$ & 0.1658 & 128 & 64 & 96 \\
\hline 7 & 27 & $1 / 8$ & $1 / 8$ & 0.1512 & 216 & 216 & 179 \\
\hline 8 & 9 & $1 / 8$ & $1 / 8$ & 0.0933 & 72 & 72 & 96 \\
\hline TOTAIS & $1+17$ & 1 & 1 & 1.0000 & & & \\
\hline \multicolumn{4}{|c|}{ VARIANCIA } & & 2688.0000 & $1354+, 0000$ & $4+00.5158$ \\
\hline \multicolumn{4}{|c|}{ MEDIA } & & 147.00 & 207.00 & 159.25 \\
\hline \multicolumn{4}{|l|}{ C.V. $(\%)$} & & 35.27 & 56.22 & 41.65 \\
\hline
\end{tabular}


Tabela 12 - Mínimo de $10 \mathrm{~cm}$ de circunferência e 10 frutos/galho, árvore 02 .

\begin{tabular}{|c|c|c|c|c|c|c|c|}
\hline $\begin{array}{l}\text { Número } \\
\text { do } \\
\text { galho }\end{array}$ & $\begin{array}{c}\text { Numero } \\
\text { de } \\
\text { frutos }\end{array}$ & $P E$ & PPN & PPA & $\begin{array}{l}\text { Estimativa } \\
\text { do } n^{\circ} \text { de } \\
\text { frutos (PE) }\end{array}$ & $\begin{array}{l}\text { Estimativa } \\
\text { do } n^{\circ} \text { de } \\
\text { frutos (PPN) }\end{array}$ & $\begin{array}{l}\text { Estimativa } \\
\text { do } n^{\circ} \text { de } \\
\text { frutos (PPA) }\end{array}$ \\
\hline 1 & 23 & $1 / 6$ & $1 / 6$ & 0.0933 & 138 & 368 & 247 \\
\hline 2 & 10 & $1 / 6$ & $1 / 16$ & 0.0933 & 60 & 160 & 107 \\
\hline 3 & 4 & $1 / 6$ & $1 / 8$ & 0.1865 & 264 & 352 & 236 \\
\hline 4 & 18 & $1 / 6$ & $1 / 4$ & 0.2166 & 108 & 72 & 83 \\
\hline 5 & 16 & $1 / 6$ & $1 / 4$ & 0,1658 & 96 & 64 & 96 \\
\hline 6 & 36 & $1 / 6$ & $1 / 4$ & 0.2445 & 216 & 144 & 147 \\
\hline TOTAIS & 147 & 1 & 1 & 1.0000 & & & \\
\hline \multicolumn{5}{|c|}{ VARIANCIA } & 5038.0000 & 11448,0000 & 3853,9789 \\
\hline \multicolumn{5}{|c|}{ MEDIA } & 147.00 & 193,33 & 152,75 \\
\hline \multicolumn{5}{|l|}{ C.V. $(\%)$} & 48.28 & 55.34 & 40.64 \\
\hline
\end{tabular}

Tabela 13 - Árvore 03 ,

\begin{tabular}{|c|c|c|c|c|c|c|c|}
\hline $\begin{array}{l}\text { Número } \\
\text { do } \\
\text { galho }\end{array}$ & $\begin{array}{c}\text { Número } \\
\text { de } \\
\text { frutos }\end{array}$ & $\mathrm{PE}$ & PPN & PPA & $\begin{array}{l}\text { Estimativa } \\
\text { do } n^{\circ} \text { de } \\
\text { frutos (PE) }\end{array}$ & $\begin{array}{l}\text { Estimativa } \\
\text { do } n^{\circ} \text { de } \\
\text { frutos (PPN) }\end{array}$ & $\begin{array}{l}\text { Estimativa } \\
\text { do } n^{\circ} \text { de } \\
\text { frutos (PPA) }\end{array}$ \\
\hline 1 & 11 & $1 / 14$ & $1 / 6$ & 0,2025 & 154 & 66 & 54 \\
\hline 2 & 9 & $1 / 14$ & $1 / 6$ & 0,0820 & 126 & 54 & 110 \\
\hline 3 & 5 & $1 / 14$ & $1 / 9$ & 0.0652 & 70 & 45 & 77 \\
\hline 4 & 6 & $1 / 14$ & $1 / 18$ & 0.0789 & 84 & 108 & 76 \\
\hline 5 & 17 & $1 / 14$ & $1 / 18$ & 0.1402 & 238 & 306 & 121 \\
\hline 6 & 4 & $1 / 14$ & $1 / 18$ & 0.0733 & 56 & 72 & 55 \\
\hline 7 & 13 & $1 / 14$ & $1 / 18$ & 0,0733 & 182 & 234 & 177 \\
\hline 8 & 24 & $1 / 14$ & $1 / 18$ & 0,0635 & 336 & +32 & 378 \\
\hline 9 & 4 & $1 / 14$ & $1 / 18$ & 0.0207 & 56 & 72 & 193 \\
\hline 10 & 5 & $1 / 14$ & $1 / 18$ & 0.0324 & 70 & 90 & 154 \\
\hline 11 & 5 & $1 / 14$ & $1 / 12$ & 0.0385 & 70 & 60 & 130 \\
\hline 12 & 5 & $1 / 14$ & $1 / 36$ & 0,0156 & 70 & 180 & 321 \\
\hline 13 & 7 & $1 / 14$ & $1 / 36$ & 0.0350 & 98 & 252 & 200 \\
\hline 14 & 13 & $1 / 14$ & $1 / 36$ & 0.0788 & 182 & 468 & 165 \\
\hline TOTAIS & 128 & 1 & 1 & 1.0000 & & & \\
\hline VARIANCIA & & & & & 6388.0000 & 14451,0000 & 7103,8868 \\
\hline MEDIA & & & & & 155.75 & 164.63 & 130.99 \\
\hline C.V. $(\%)$ & & & & & 51.32 & 73.02 & 64.34 \\
\hline
\end{tabular}


Tabela 14 - Mínimo de $7 \mathrm{~cm}$ de circunferência e 10 frutos/galho, árvore 03.

\begin{tabular}{|c|c|c|c|c|c|c|c|}
\hline $\begin{array}{l}\text { Número } \\
\text { do } \\
\text { galho }\end{array}$ & $\begin{array}{c}\text { Número } \\
\text { de } \\
\text { frutos }\end{array}$ & $\mathrm{PE}$ & PPN & PPA & $\begin{array}{l}\text { Estimativa } \\
\text { do } n^{\circ} \text { de } \\
\text { frutos }(P E)\end{array}$ & $\begin{array}{l}\text { Estimativa } \\
\text { do } n^{\circ} \text { de } \\
\text { frutos (PPN) }\end{array}$ & $\begin{array}{l}\text { Esimativa } \\
\text { do } n^{0} \text { de } \\
\text { frutos }(\mathrm{PPA})\end{array}$ \\
\hline 1 & 20 & $1 / 5$ & $1 / 3$ & 0.2845 & 100 & 60 & 70 \\
\hline 2 & 34 & $1 / 5$ & $1 / 6$ & 0.2582 & 170 & 204 & 132 \\
\hline 3 & 18 & $1 / 5$ & $1 / 6$ & 0,1728 & 90 & 108 & 104 \\
\hline 4 & 34 & $1 / 5$ & $1 / 6$ & 0,1166 & 170 & 204 & 292 \\
\hline 5 & 30 & $1 / 5$ & $1 / 6$ & 0.1679 & 150 & 180 & 179 \\
\hline TOTAIS & 136 & 1 & 1 & 1.0000 & & & \\
\hline VARIANCIA & & & & & 1184.0000 & 3920.0000 & 4536,6122 \\
\hline MEDIA & & & & & 136.00 & 151,20 & 155.28 \\
\hline C.V. $(\%)$ & & & & & 25.30 & 414 & 43,38 \\
\hline
\end{tabular}

Tabela 15-Mínimo de $10 \mathrm{~cm}$ de circunferência e 10 frutos/galho, árvore 03.

\begin{tabular}{|c|c|c|c|c|c|c|c|}
\hline $\begin{array}{l}\text { Número } \\
\text { do } \\
\text { gallho }\end{array}$ & $\begin{array}{l}\text { Número } \\
\text { de } \\
\text { frutos }\end{array}$ & PE & PPN & PPA & $\begin{array}{l}\text { Estinativa } \\
\text { do } n^{\circ} \text { de } \\
\text { frutos (PE) }\end{array}$ & $\begin{array}{l}\text { Estimativa } \\
\text { do } n^{\circ} \text { de } \\
\text { frutos (PPN) }\end{array}$ & $\begin{array}{l}\text { Estimativa } \\
\text { do } n^{\circ} \text { de } \\
\text { frutos (PPA) }\end{array}$ \\
\hline 1 & 20 & $1 / 4$ & $1 / 3$ & 0,2845 & 80 & 60 & 70 \\
\hline 2 & 52 & $1 / 4$ & $1 / 3$ & 0,4310 & 208 & 156 & 121 \\
\hline 3 & 34 & $1 / 4$ & $1 / 6$ & 0,1166 & 136 & 204 & 292 \\
\hline 4 & 30 & $1 / 4$ & $1 / 6$ & 0.1679 & 120 & 180 & 179 \\
\hline TOTAIS & 136 & 1 & 1 & 1.0000 & & & \\
\hline VARIANCIA & & & & & 2144,0000 & 3152,0000 & $+458,0668$ \\
\hline MEDIA & & & & & 136.00 & 150,00 & 165.30 \\
\hline C.V. $(\%)$ & & & & & 34.05 & 37.43 & 40.39 \\
\hline
\end{tabular}

Tabela 16 - Mínimo de $10 \mathrm{~cm}$ de circunferência e 20 frutos/galho, árvore 03.

\begin{tabular}{|c|c|c|c|c|c|c|c|}
\hline $\begin{array}{c}\text { Número } \\
\text { do } \\
\text { galho }\end{array}$ & $\begin{array}{c}\text { Numero } \\
\text { de } \\
\text { frutos }\end{array}$ & $\mathrm{PE}$ & PPN & PPA & $\begin{array}{l}\text { Estimativa } \\
\text { do } n^{\circ} \text { de } \\
\text { frutos (PE) }\end{array}$ & $\begin{array}{l}\text { Estimativa } \\
\text { do } n^{\circ} \text { de } \\
\text { frutos (PPN) }\end{array}$ & $\begin{array}{l}\text { Estimativa } \\
\text { do n }{ }^{\circ} \text { de } \\
\text { frutos (PPA) }\end{array}$ \\
\hline 1 & 20 & $1 / 3$ & $1 / 3$ & 0,2845 & 60 & 60 & 70 \\
\hline 2 & 52 & $1 / 3$ & $1 / 3$ & 0.4310 & 156 & 156 & 121 \\
\hline 3 & 64 & $1 / 3$ & $1 / 3$ & 0.2845 & 192 & 192 & 225 \\
\hline TOTAIS & 136 & 1 & 1 & 1.0000 & & & \\
\hline \multicolumn{5}{|c|}{ VARIANCIA } & 3104.0000 & 3104.0000 & 3580.6339 \\
\hline \multicolumn{5}{|c|}{ MEDIA } & 136.00 & 136.00 & 138.63 \\
\hline \multicolumn{5}{|l|}{ C.V. $(\%)$} & 40.97 & 40.97 & +3.16 \\
\hline
\end{tabular}


Tabela 17- Árvore 04.

\begin{tabular}{|c|c|c|c|c|c|c|c|}
\hline $\begin{array}{l}\text { Número } \\
\text { do } \\
\text { galho }\end{array}$ & $\begin{array}{l}\text { Número } \\
\text { de } \\
\text { frutos }\end{array}$ & PE & PPN & PPA & $\begin{array}{l}\text { Estimativa } \\
\text { do } n^{\circ} \text { de } \\
\text { frutos (PE) }\end{array}$ & $\begin{array}{l}\text { Estimativa } \\
\text { do } n^{\circ} \text { de } \\
\text { frutos (PPN) }\end{array}$ & $\begin{array}{l}\text { Estimativa } \\
\text { do } n^{\circ} \text { de } \\
\text { frutos (PPA) }\end{array}$ \\
\hline 1 & 15 & $1 / 21$ & $1 / 24$ & $0.0+70$ & 315 & 361 & 319 \\
\hline 2 & 8 & $1 / 21$ & $1 / 24$ & 0.0249 & 168 & 192 & 322 \\
\hline 3 & 16 & $1 / 21$ & $1 / 12$ & 0,0612 & 336 & 192 & 261 \\
\hline 4 & 11 & $1 / 21$ & $1 / 60$ & 0,0353 & 231 & 660 & 312 \\
\hline 5 & 18 & $1 / 21$ & $1 / 60$ & 0.0353 & 378 & 1080 & 510 \\
\hline 6 & 16 & $1 / 21$ & $1 / 60$ & 0,0572 & 336 & 960 & 280 \\
\hline 7 & 6 & $1 / 21$ & $1 / 60$ & 0,0105 & 126 & 360 & 571 \\
\hline 8 & 27 & $1 / 21$ & $1 / 60$ & 0,0493 & 567 & 1620 & 548 \\
\hline 9 & 16 & $1 / 21$ & $1 / 12$ & 0,1229 & 336 & 192 & 130 \\
\hline 10 & 22 & $1 / 21$ & $1 / 36$ & 0.0421 & 462 & 792 & 523 \\
\hline 11 & 4 & $1 / 21$ & $1 / 36$ & 0,0143 & 84 & 144 & 279 \\
\hline 12 & 13 & $1 / 21$ & $1 / 36$ & 0,0352 & 273 & 468 & 370 \\
\hline 13 & 7 & $1 / 21$ & $1 / 36$ & 0,0213 & 147 & 252 & 329 \\
\hline 14 & 15 & $1 / 21$ & $1 / 9$ & 0,1250 & 315 & 135 & 120 \\
\hline 15 & 12 & $1 / 21$ & $1 / 36$ & 0.0265 & 252 & 432 & 454 \\
\hline 16 & 11 & $1 / 21$ & $1 / 72$ & 0.0387 & 231 & 792 & 284 \\
\hline 17 & 34 & $1 / 21$ & $1 / 72$ & 0.0557 & 714 & 2448 & 610 \\
\hline 18 & 16 & $1 / 21$ & $1 / 18$ & 0,0592 & 336 & 288 & 270 \\
\hline 19 & 11 & $1 / 21$ & $1 / 9$ & 0.0587 & 231 & 99 & 187 \\
\hline 20 & 20 & $1 / 21$ & $1 / 9$ & 0,0587 & 420 & 180 & 341 \\
\hline 21 & 13 & $1 / 21$ & $1 / 9$ & 0.0211 & 273 & 117 & 615 \\
\hline TOTAIS & 311 & 1 & 1 & 1.0000 & & & \\
\hline \multicolumn{4}{|c|}{ VARIANCIA } & & 20397,0000 & 140139,0000 & 24257.8221 \\
\hline \multicolumn{5}{|l|}{ MEDIA } & 311.00 & 560.14 & 363.61 \\
\hline \multicolumn{5}{|l|}{ C.V. $(\%)$} & 45.92 & 66.83 & 42,83 \\
\hline
\end{tabular}

Tabela 18-Mínimo de $7 \mathrm{~cm}$ de circunferencia e 10 frutos/galho, árvore 04.

\begin{tabular}{cccccccc}
\hline $\begin{array}{c}\text { Numero } \\
\text { do } \\
\text { galho }\end{array}$ & $\begin{array}{c}\text { Número } \\
\text { de } \\
\text { frutos }\end{array}$ & PE & PPN & PPA & $\begin{array}{c}\text { Estimativa } \\
\text { do }{ }^{\circ} \text { de } \\
\text { rrutos (PE) }\end{array}$ & $\begin{array}{c}\text { Estimativa } \\
\text { do }{ }^{\circ} \text { de } \\
\text { frutos (PPN) }\end{array}$ & $\begin{array}{c}\text { Estimativa } \\
\text { do }{ }^{\circ} \text { de } \\
\text { frutos (PPA) }\end{array}$ \\
\hline 1 & 24 & $1 / 16$ & $1 / 12$ & 0.0719 & 384 & 288 & 334 \\
2 & 16 & $1 / 16$ & $1 / 12$ & 0,0612 & 256 & 192 & 261 \\
3 & 11 & $1 / 16$ & $1 / 48$ & 0.0374 & 176 & 528 & 294 \\
4 & 18 & $1 / 16$ & $1 / 48$ & 0.0374 & 288 & 864 & 481 \\
5 & 22 & $1 / 16$ & $1 / 48$ & 0.0606 & 352 & 1056 & 363 \\
6 & 27 & $1 / 16$ & $1 / 48$ & 0.0522 & 432 & 1296 & 517 \\
7 & 16 & $1 / 16$ & $1 / 12$ & 0.1229 & 256 & 192 & 130 \\
8 & 26 & $1 / 16$ & $1 / 18$ & 0.0564 & 416 & 468 & 461 \\
9 & 20 & $1 / 16$ & $1 / 18$ & 0.0564 & 320 & 360 & 355 \\
10 & 15 & $1 / 16$ & $1 / 9$ & 0.1250 & 240 & 135 & 120 \\
11 & 12 & $1 / 16$ & $1 / 36$ & 0.0265 & 192 & 432 & 454
\end{tabular}


Tabela 18 - Minimo de $7 \mathrm{~cm}$ de circunferência e 10 frutos/galho, árvore 04 (continuação).

\begin{tabular}{|c|c|c|c|c|c|c|c|}
\hline $\begin{array}{l}\text { Número } \\
\text { do } \\
\text { galho }\end{array}$ & $\begin{array}{l}\text { Número } \\
\text { de } \\
\text { frutos }\end{array}$ & PE & PPN & PPA & $\begin{array}{l}\text { Estimativa } \\
\text { do } n^{\circ} \text { de } \\
\text { frutos (PE) }\end{array}$ & $\begin{array}{l}\text { Estimativa } \\
\text { do } n^{\circ} \text { de } \\
\text { frutos (PPN) }\end{array}$ & $\begin{array}{l}\text { Estimativa } \\
\text { do } n^{\circ} \text { de } \\
\text { frutos (PPA) }\end{array}$ \\
\hline 12 & 11 & $1 / 16$ & $1 / 72$ & 0,0387 & 176 & 792 & 284 \\
\hline 13 & 34 & $1 / 16$ & $1 / 72$ & 0.0557 & 544 & 2448 & 610 \\
\hline 14 & 16 & $1 / 16$ & $1 / 18$ & 0,0592 & 256 & 288 & 270 \\
\hline 15 & 11 & $1 / 16$ & $1 / 6$ & 0.0693 & 176 & 66 & 159 \\
\hline 16 & 33 & $1 / 16$ & $1 / 6$ & 0.0693 & 528 & 198 & 476 \\
\hline TOTAIS & 312 & 1 & 1 & 1.0000 & & & \\
\hline \multicolumn{3}{|c|}{ VARIÁNCIA } & & & 13600.0000 & 125685.0000 & $22780 ., 4758$ \\
\hline \multicolumn{3}{|l|}{ MEDDIA } & & & 312.00 & 600.19 & 348,17 \\
\hline \multicolumn{3}{|l|}{ C.V. $(\%)$} & & & 37,38 & 59.07 & 43,35 \\
\hline
\end{tabular}

Tabela 19- Mínimo de $10 \mathrm{~cm}$ de circunferência e 20 frutos/galho, árvore 04.

\begin{tabular}{|c|c|c|c|c|c|c|c|}
\hline $\begin{array}{l}\text { Número } \\
\text { do } \\
\text { galho }\end{array}$ & $\begin{array}{l}\text { Número } \\
\text { de } \\
\text { frutos }\end{array}$ & $\mathrm{PE}$ & PPN & PPA & $\begin{array}{l}\text { Estimativa } \\
\text { do } n^{\circ} \text { de } \\
\text { frutos (PE) }\end{array}$ & $\begin{array}{l}\text { Estimativa } \\
\text { do } n^{\circ} \text { de } \\
\text { frutos (PPN) }\end{array}$ & $\begin{array}{l}\text { Estimativa } \\
\text { do } n^{\circ} \text { de } \\
\text { frutos (PPA) }\end{array}$ \\
\hline 1 & 40 & $1 / 8$ & $1 / 6$ & 0,1229 & 320 & 240 & 325 \\
\hline 2 & 94 & $1 / 8$ & $1 / 6$ & 0,3207 & 752 & 564 & 293 \\
\hline 3 & 26 & $1 / 8$ & $1 / 18$ & 0.0564 & 208 & 468 & 461 \\
\hline 4 & 20 & $1 / 8$ & $1 / 18$ & 0,0564 & 160 & 360 & 355 \\
\hline 5 & 15 & $1 / 8$ & $1 / 9$ & 0,1250 & 120 & 135 & 120 \\
\hline 6 & 57 & $1 / 8$ & $1 / 18$ & 0,1208 & 456 & 1026 & 472 \\
\hline 7 & 16 & $1 / 8$ & $1 / 18$ & 0.0592 & 128 & 288 & 270 \\
\hline 8 & 44 & $1 / 8$ & $1 / 3$ & 0.1385 & 352 & 132 & 318 \\
\hline TOTAIS & 312 & 1 & 1 & 1.0000 & & & \\
\hline \multicolumn{5}{|c|}{ VARIANCIA } & 40080.0000 & 55563.0000 & 9289.8654 \\
\hline \multicolumn{5}{|c|}{ MEDIA } & 312,00 & 401.63 & 326,70 \\
\hline \multicolumn{5}{|l|}{ C.V. $(\%)$} & 64.17 & 58,69 & 29.50 \\
\hline
\end{tabular}

Tabela 20- Minimo de $15 \mathrm{~cm}$ de circunferência e 30 frutos/galho, árvore 04.

\begin{tabular}{|c|c|c|c|c|c|c|c|}
\hline $\begin{array}{l}\text { Numero } \\
\text { do } \\
\text { galho }\end{array}$ & $\begin{array}{c}\text { Numero } \\
\text { de } \\
\text { frutos }\end{array}$ & PE & PPN & PPA & $\begin{array}{l}\text { Estimativa } \\
\text { do } 1^{\circ} \text { de } \\
\text { frutos (PE) }\end{array}$ & $\begin{array}{l}\text { Estimativa } \\
\text { do } n^{\circ} \text { de } \\
\text { frutos (PPN) }\end{array}$ & $\begin{array}{c}\text { Estimativa } \\
\text { do } n^{\circ} \text { de } \\
\text { frutos (PPA) }\end{array}$ \\
\hline 1 & 134 & $1 / 4$ & $1 / 3$ & 0.4436 & 536 & 402 & 302 \\
\hline 2 & 61 & $1 / 4$ & $1 / 6$ & 0.1610 & 244 & 366 & 379 \\
\hline 3 & 73 & $1 / 4$ & $1 / 6$ & 0,2569 & 292 & 438 & 284 \\
\hline 4 & 44 & $1 / 4$ & $1 / 3$ & 0.1385 & 176 & 132 & 318 \\
\hline TOTAIS & 312 & 1 & 1 & 1.0000 & & & \\
\hline VARIANCIA & & & & & 18424.0000 & 16632.0000 & 967.1936 \\
\hline MEDIA & & & & & 312.00 & 334.50 & 320.69 \\
\hline C.V. $(\%)$ & & & & & +3.50 & 38.55 & 9.70 \\
\hline
\end{tabular}


Tabela 21 - Mínimo de $20 \mathrm{~cm}$ de circunferência e 40 frutos/galho, árvore 04 .

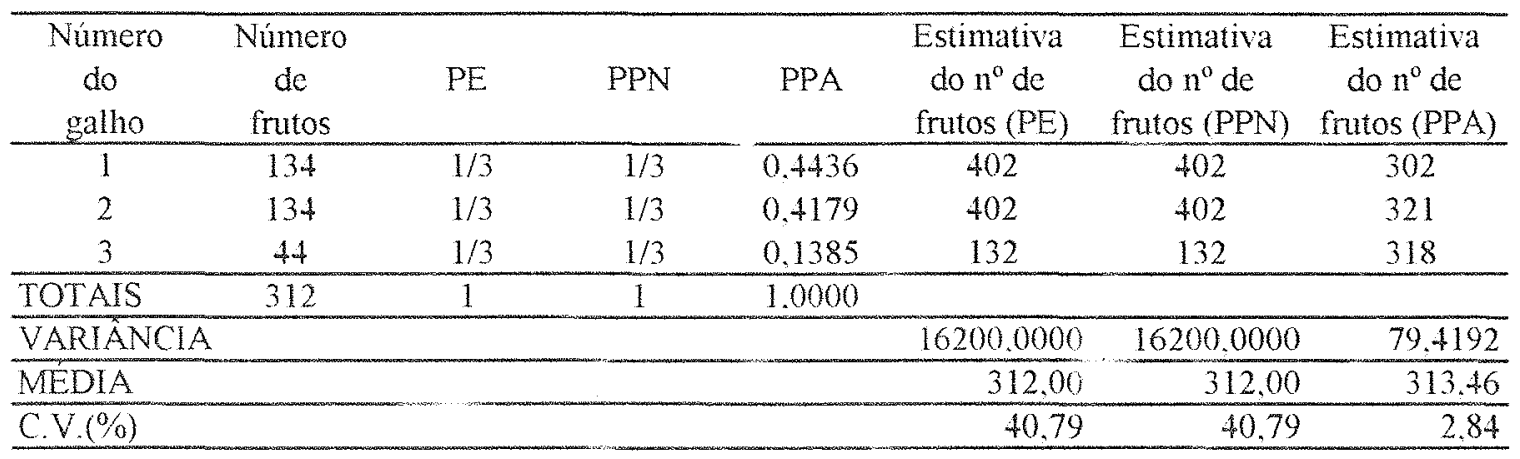

Tabela 22- Árvore 05.

\begin{tabular}{|c|c|c|c|c|c|c|c|}
\hline $\begin{array}{l}\text { Numero } \\
\text { do } \\
\text { galho }\end{array}$ & $\begin{array}{c}\text { Número } \\
\text { de } \\
\text { frutos }\end{array}$ & $\mathrm{PE}$ & PPN & PPA & $\begin{array}{l}\text { Estimativa } \\
\text { do } n^{\circ} \text { de } \\
\text { frutos (PE) }\end{array}$ & $\begin{array}{l}\text { Estimativa } \\
\text { do } n^{\circ} \text { de } \\
\text { frutos (PPN) }\end{array}$ & $\begin{array}{l}\text { Estimativa } \\
\text { do } n^{\circ} \text { de } \\
\text { frutos (PPA) }\end{array}$ \\
\hline 1 & 14 & $1 / 42$ & $1 / 6$ & 0,0623 & 588 & 84 & 225 \\
\hline 2 & 11 & $1 / 42$ & $1 / 96$ & 0.0147 & 462 & 1056 & 748 \\
\hline 3 & 6 & $1 / 42$ & $1 / 96$ & 0.0108 & 252 & 576 & 556 \\
\hline 4 & 10 & $1 / 42$ & $1 / 96$ & 0,0108 & 420 & 960 & 926 \\
\hline 5 & 16 & $1 / 42$ & $1 / 96$ & 0,0363 & 672 & 1536 & 441 \\
\hline 6 & 6 & $1 / 42$ & $1 / 48$ & 0,0239 & 252 & 288 & 251 \\
\hline 7 & 14 & $1 / 42$ & $1 / 96$ & 0,0244 & 588 & 1344 & 575 \\
\hline 8 & 13 & $1 / 42$ & $1 / 96$ & 0.0244 & 546 & 1248 & 534 \\
\hline 9 & 10 & $1 / 42$ & $1 / 24$ & 0.0176 & 420 & 240 & 567 \\
\hline 10 & 11 & $1 / 42$ & $1 / 24$ & 0.0230 & 462 & 264 & 477 \\
\hline 11 & 18 & $1 / 42$ & $1 / 12$ & 0,0662 & 756 & 216 & 272 \\
\hline 12 & 6 & $1 / 42$ & $1 / 48$ & 0.0259 & 252 & 288 & 232 \\
\hline 13 & 8 & $1 / 42$ & $1 / 48$ & 0.0338 & 336 & 384 & 237 \\
\hline 14 & 7 & $1 / 42$ & $1 / 96$ & 0.0183 & 294 & 672 & 383 \\
\hline 15 & 10 & $1 / 42$ & 1/96 & 0.0263 & +20 & 960 & 380 \\
\hline 16 & 9 & $1 / 42$ & $1 / 48$ & 0.0446 & 378 & 432 & 202 \\
\hline 17 & 11 & $1 / 42$ & $1 / 18$ & 0,0326 & 462 & 198 & 338 \\
\hline 18 & 14 & $1 / 42$ & $1 / 54$ & 0,0152 & 588 & 756 & 919 \\
\hline 19 & 15 & $1 / 42$ & $1 / 54$ & 0.0152 & 630 & 810 & 984 \\
\hline 20 & 6 & $1 / 42$ & $1 / 54$ & 0.0098 & 252 & 324 & 615 \\
\hline 21 & 15 & $1 / 42$ & $1 / 36$ & 0,0163 & 630 & 540 & 921 \\
\hline 22 & 9 & $1 / 42$ & $1 / 36$ & 0,0163 & 378 & 324 & 552 \\
\hline 23 & 12 & $1 / 42$ & $1 / 36$ & 0,0228 & 504 & 432 & 527 \\
\hline 24 & 26 & $1 / 42$ & $1 / 36$ & 0.0376 & 1092 & 936 & 691 \\
\hline 25 & 6 & $1 / 42$ & $1 / 18$ & 0.0268 & 252 & 108 & 224 \\
\hline 26 & 8 & $1 / 42$ & $1 / 108$ & 0.0124 & 336 & 864 & 644 \\
\hline 27 & 24 & $1 / 42$ & $1 / 216$ & 0,0158 & 1008 & 5184 & 1517 \\
\hline 28 & 10 & $1 / 42$ & $1 / 216$ & 0.0121 & 420 & 2160 & 825 \\
\hline 29 & 9 & $1 / 42$ & $1 / 108$ & 0.0107 & 378 & 972 & 843 \\
\hline
\end{tabular}


Tabela 22- Árvore 05 (continuação).

\begin{tabular}{|c|c|c|c|c|c|c|c|}
\hline $\begin{array}{l}\text { Número } \\
\text { do } \\
\text { ralho }\end{array}$ & $\begin{array}{l}\text { Número } \\
\text { de } \\
\text { frutos }\end{array}$ & PE & PPN & PPA & $\begin{array}{l}\text { Estimativa } \\
\text { do } n^{\circ} \text { de } \\
\text { fritos (PE) }\end{array}$ & $\begin{array}{l}\text { Estimativa } \\
\text { do n }{ }^{\circ} \text { de } \\
\text { frutos (PPN) }\end{array}$ & $\begin{array}{l}\text { Estimativa } \\
\text { do } n^{\circ} \text { de } \\
\text { frutos (PPA) }\end{array}$ \\
\hline 30 & 16 & $1 / 42$ & $1 / 108$ & 0,0107 & 672 & 1728 & 1499 \\
\hline 31 & 15 & $1 / 42$ & $1 / 162$ & 0,0148 & 630 & 2430 & 1015 \\
\hline 32 & 13 & $1 / 42$ & $1 / 162$ & 0,0201 & 546 & 2106 & 647 \\
\hline 33 & 8 & $1 / 42$ & $1 / 162$ & 0,0078 & 336 & 1296 & 1024 \\
\hline 34 & 13 & $1 / 42$ & $1 / 162$ & 0,0106 & 546 & 2106 & 1222 \\
\hline 35 & 26 & $1 / 42$ & 1/81 & 0.0288 & 1092 & 2106 & 902 \\
\hline 36 & 29 & $1 / 42$ & $1 / 108$ & 0,0229 & 1218 & 3132 & 1266 \\
\hline 37 & 12 & $1 / 42$ & $1 / 216$ & 0,0115 & 504 & 2592 & 1048 \\
\hline 38 & 10 & $1 / 42$ & $1 / 216$ & 0.0115 & 420 & 2160 & 873 \\
\hline 39 & 16 & $1 / 42$ & $1 / 54$ & 0.0258 & 672 & 864 & 621 \\
\hline 40 & 14 & $1 / 42$ & $1 / 36$ & 0,0321 & 588 & 504 & 437 \\
\hline 41 & 33 & $1 / 42$ & $1 / 36$ & 0.0570 & 1386 & 1188 & 579 \\
\hline+2 & 13 & $1 / 42$ & $1 / 18$ & 0.0396 & 546 & 234 & 328 \\
\hline TOTAIS & 552 & 1 & 1 & 1.0000 & & & \\
\hline VARIANCIA & & & & & 69196.0000 & 435124.0000 & 99756.6883 \\
\hline MEDIA & & & & & 552,00 & 1109.57 & 668.23 \\
\hline C.V. $(\%)$ & & & & & 47.65 & 59.45 & +7.27 \\
\hline
\end{tabular}

Tabela 23- Mínimo de $7 \mathrm{~cm}$ de circunferência e 10 frutos/galho, árvore 05 .

\begin{tabular}{cccccccc}
\hline $\begin{array}{c}\text { Número } \\
\text { do } \\
\text { galho }\end{array}$ & $\begin{array}{c}\text { Número } \\
\text { de } \\
\text { frutos }\end{array}$ & PE & PPN & PPA & $\begin{array}{c}\text { Estimativa } \\
\text { do } \text { n }^{\circ} \text { de } \\
\text { frutos (PE) }\end{array}$ & $\begin{array}{c}\text { Estimativa } \\
\text { do } n^{\circ} \text { de } \\
\text { frutos (PPN) }\end{array}$ & $\begin{array}{c}\text { Estimativa } \\
\text { do } \mathrm{n}^{\circ} \text { de } \\
\text { frutos (PPA) }\end{array}$ \\
\hline 1 & 14 & $1 / 28$ & $1 / 6$ & 0,0623 & 392 & 84 & 225 \\
2 & 17 & $1 / 28$ & $1 / 48$ & 0.0209 & 476 & 816 & 812 \\
3 & 26 & $1 / 28$ & $1 / 48$ & 0,0517 & 728 & 1248 & 503 \\
4 & 14 & $1 / 28$ & $1 / 48$ & 0,0363 & 392 & 672 & 386 \\
5 & 13 & $1 / 28$ & $1 / 48$ & 0,0363 & 364 & 624 & 358 \\
6 & 10 & $1 / 28$ & $1 / 24$ & 0.0176 & 280 & 240 & 567 \\
7 & 11 & $1 / 28$ & $1 / 24$ & 0,0230 & 308 & 264 & 477 \\
8 & 18 & $1 / 28$ & $1 / 12$ & 0.0662 & 504 & 216 & 272 \\
9 & 16 & $1 / 28$ & $1 / 24$ & 0,0597 & 448 & 384 & 268 \\
10 & 26 & $1 / 28$ & $1 / 24$ & 0,0892 & 728 & 624 & 291 \\
11 & 11 & $1 / 28$ & $1 / 18$ & 0,0326 & 308 & 198 & 338 \\
12 & 35 & $1 / 28$ & $1 / 18$ & 0,0402 & 980 & 630 & 870 \\
13 & 27 & $1 / 28$ & $1 / 18$ & 0.0326 & 756 & 486 & 829 \\
14 & 12 & $1 / 28$ & $1 / 36$ & 0.0228 & 336 & 432 & 527 \\
15 & 26 & $1 / 28$ & $1 / 36$ & 0.0376 & 728 & 936 & 691 \\
16 & 6 & $1 / 28$ & $1 / 18$ & 0.0268 & 168 & 108 & 224 \\
17 & 42 & $1 / 28$ & $1 / 54$ & 0,0404 & 1176 & 2268 & 1041 \\
18 & 25 & $1 / 28$ & $1 / 54$ & 0.0213 & 700 & 1350 & 1171 \\
19 & 28 & $1 / 28$ & $1 / 81$ & 0.0349 & 784 & 2268 & 803
\end{tabular}


Tabela 23-Minimo de $7 \mathrm{~cm}$ de circunferência e 10 frutos/galho, árvore 05 (continuação).

\begin{tabular}{|c|c|c|c|c|c|c|c|}
\hline $\begin{array}{c}\text { Número } \\
\text { do } \\
\text { galho }\end{array}$ & $\begin{array}{l}\text { Número } \\
\text { de } \\
\text { f utos }\end{array}$ & $P E$ & PPN & PPA & $\begin{array}{l}\text { Estimativa } \\
\text { do } n^{\circ} \text { de } \\
\text { frutos (PE) }\end{array}$ & $\begin{array}{l}\text { Estimativa } \\
\text { do } n^{\circ} \text { de } \\
\text { frutos (PPN) }\end{array}$ & $\begin{array}{l}\text { Estimativa } \\
\text { do } n^{\circ} \text { de } \\
\text { frutos (PPA) }\end{array}$ \\
\hline 20 & 21 & $1 / 28$ & $1 / 81$ & 0,0184 & 588 & 1701 & 1138 \\
\hline 21 & 26 & $1 / 28$ & $1 / 81$ & 0.0288 & 728 & 2106 & 902 \\
\hline 22 & 29 & $1 / 28$ & $1 / 108$ & 0,0229 & 812 & 3132 & 1266 \\
\hline 23 & 12 & $1 / 28$ & $1 / 216$ & 0,0115 & 336 & 2592 & 1048 \\
\hline 24 & 10 & $1 / 28$ & $1 / 216$ & 0.0115 & 280 & 2160 & 873 \\
\hline 25 & 16 & $1 / 28$ & $1 / 54$ & 0.0258 & 448 & 864 & 621 \\
\hline 26 & 14 & $1 / 28$ & $1 / 36$ & 0,0321 & 392 & 504 & 437 \\
\hline 27 & 33 & $1 / 28$ & $1 / 36$ & 0.0570 & 924 & 1188 & 579 \\
\hline 28 & 13 & $1 / 28$ & $1 / 18$ & 0.0396 & 364 & 234 & 328 \\
\hline TOTAIS & 551 & 1 & 1 & 1.0000 & & & \\
\hline \multicolumn{5}{|c|}{ VARIANCIA } & 61052,0000 & 350259,0000 & 86741,3497 \\
\hline \multicolumn{5}{|l|}{ MEDIA } & 551.00 & 1011.75 & 637.32 \\
\hline \multicolumn{5}{|l|}{ C.V. $(0 \%)$} & 44.84 & 58,50 & 46.21 \\
\hline
\end{tabular}

Tabela 24-Mínimo de $10 \mathrm{~cm}$ de circunferência e 20 frutos/galho, árvore 05.

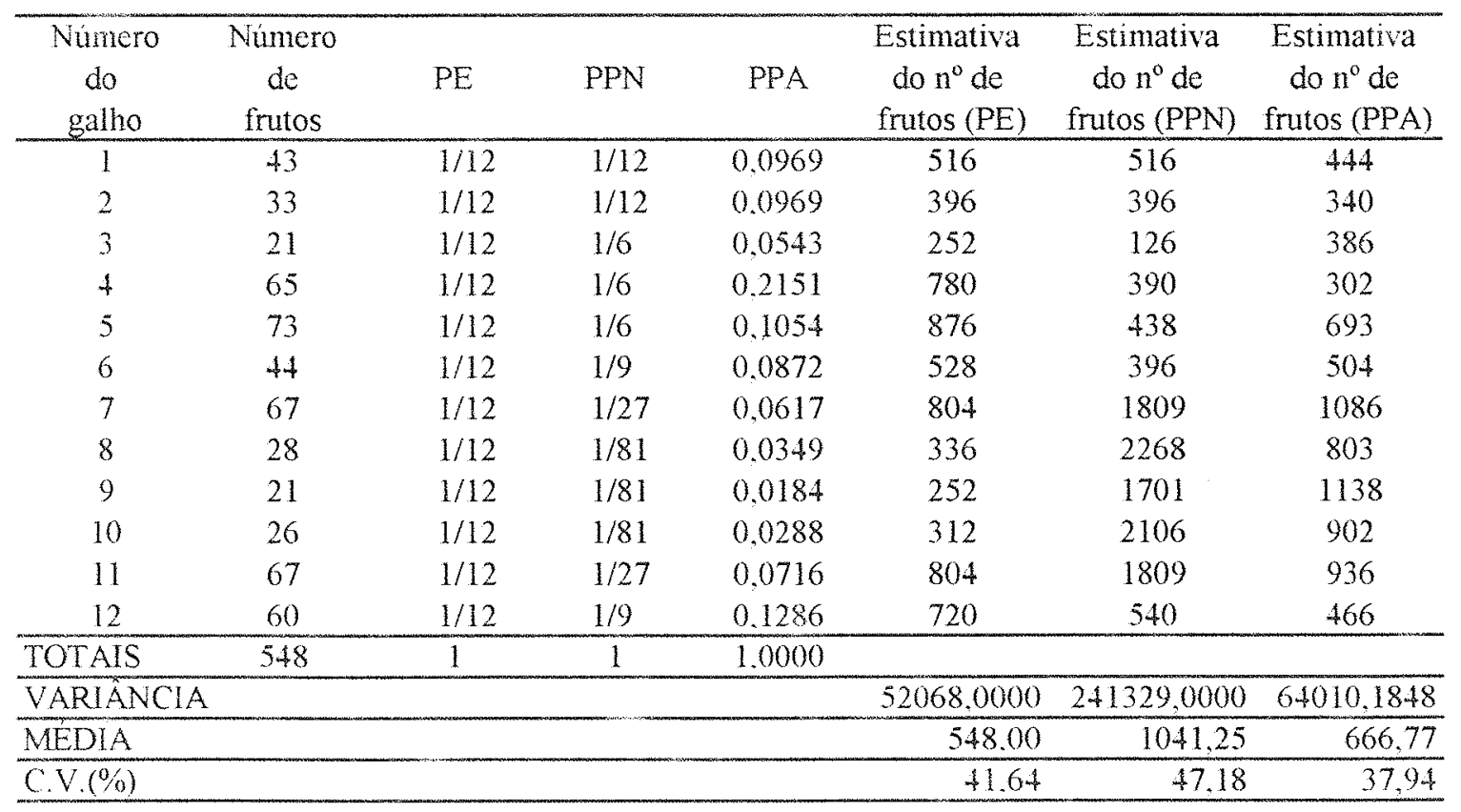


Tabela 25-Mínimo de $15 \mathrm{~cm}$ de circunferência e 30 frutos/galho, árvore 05 .

\begin{tabular}{|c|c|c|c|c|c|c|c|}
\hline $\begin{array}{l}\text { Número } \\
\text { do } \\
\text { galho }\end{array}$ & $\begin{array}{c}\text { Número } \\
\text { de } \\
\text { frutos }\end{array}$ & PE & PPN & PPA & $\begin{array}{l}\text { Estimativa } \\
\text { do } n^{\circ} \text { de } \\
\text { frutos }(\mathrm{PE})\end{array}$ & $\begin{array}{c}\text { Estimativa } \\
\text { do } n^{\circ} \text { de } \\
\text { frutos (PPN) }\end{array}$ & $\begin{array}{l}\text { Estimativa } \\
\text { do } n^{\circ} \text { de } \\
\text { frutos (PPA) }\end{array}$ \\
\hline 1 & 111 & $1 / 4$ & $1 / 3$ & 0,2482 & 444 & 333 & 447 \\
\hline 2 & 138 & $1 / 4$ & $1 / 3$ & 0.3205 & 552 & 414 & 431 \\
\hline 3 & 253 & $1 / 4$ & $1 / 6$ & 0.2700 & 1012 & 1518 & 937 \\
\hline 4 & 60 & $1 / 4$ & $1 / 6$ & 0,1612 & 240 & 360 & 372 \\
\hline TOTAIS & 562 & 1 & 1 & 1.0000 & & & \\
\hline \multicolumn{5}{|c|}{ VARIANCIA } & 80052.0000 & 183905.0000 & 52575,9980 \\
\hline \multicolumn{5}{|c|}{ MEDIA } & 562.00 & 656,25 & 546.70 \\
\hline \multicolumn{5}{|l|}{ C.V. $(\%)$} & 50.34 & 65,35 & 41,94 \\
\hline
\end{tabular}

Tabela 26-Mínimo de $20 \mathrm{~cm}$ de circunferencia e 40 frutos/galho, árvore 05.

\begin{tabular}{|c|c|c|c|c|c|c|c|}
\hline $\begin{array}{l}\text { Número } \\
\text { do } \\
\text { galho }\end{array}$ & $\begin{array}{c}\text { Número } \\
\text { de } \\
\text { frutos }\end{array}$ & $\mathrm{PE}$ & PPN & PPA & $\begin{array}{c}\text { Estimativa } \\
\text { do } n^{\circ} \text { de } \\
\text { frutos (PE) }\end{array}$ & $\begin{array}{l}\text { Estimativa } \\
\text { do } n^{\circ} \text { de } \\
\text { frutos }(\mathrm{PPN})\end{array}$ & $\begin{array}{l}\text { Estimativa } \\
\text { do } n^{\circ} \text { de } \\
\text { frutos (PPA) }\end{array}$ \\
\hline 1 & 111 & $1 / 3$ & $1 / 3$ & 0,2482 & 333 & 333 & 447 \\
\hline 2 & 138 & $1 / 3$ & $1 / 3$ & 0.3205 & 414 & 414 & 431 \\
\hline 3 & 313 & $1 / 3$ & $1 / 3$ & 0.4313 & 939 & 939 & 726 \\
\hline TOTAIS & 562 & 1 & 1 & 1.0000 & & & \\
\hline \multicolumn{5}{|c|}{ VARIANCIA } & 72158.0000 & 72158.0000 & 20371.2826 \\
\hline \multicolumn{5}{|c|}{ MEDIA } & 562.00 & 562,00 & 534.50 \\
\hline \multicolumn{5}{|l|}{$\mathrm{C} . \mathrm{V} .(\%)$} & 47.80 & 47.80 & 26.70 \\
\hline
\end{tabular}

Tabela 27- Árvore 06.

\begin{tabular}{cccccccc}
\hline $\begin{array}{c}\text { Número } \\
\text { do } \\
\text { galho }\end{array}$ & $\begin{array}{c}\text { Número } \\
\text { de } \\
\text { frutos }\end{array}$ & PE & PPN & PPA & $\begin{array}{c}\text { Estimativa } \\
\text { do }{ }^{\circ} \text { de } \\
\text { frutos (PE) }\end{array}$ & $\begin{array}{c}\text { Estimativa } \\
\text { do }{ }^{\circ} \text { de } \\
\text { frutos (PPN) }\end{array}$ & $\begin{array}{c}\text { Estimativa } \\
\text { do }{ }^{\circ} \text { de } \\
\text { frutos (PPA) }\end{array}$ \\
\hline 1 & 14 & $1 / 64$ & $1 / 32$ & 0,0143 & 896 & 448 & 976 \\
2 & 8 & $1 / 64$ & $1 / 64$ & 0,0186 & 512 & 512 & 430 \\
3 & 9 & $1 / 64$ & $1 / 64$ & 0,0137 & 576 & 576 & 658 \\
4 & 6 & $1 / 64$ & $1 / 16$ & 0.0159 & 384 & 96 & 378 \\
5 & 18 & $1 / 64$ & $1 / 32$ & 0,0164 & 1152 & 576 & 1101 \\
6 & 17 & $1 / 64$ & $1 / 32$ & 0,0432 & 1088 & 544 & 394 \\
7 & 15 & $1 / 64$ & $1 / 64$ & 0,0090 & 960 & 960 & 1661 \\
8 & 9 & $1 / 64$ & $1 / 128$ & 0.0083 & 576 & 1152 & 1081 \\
9 & 9 & $1 / 64$ & $1 / 128$ & 0,0120 & 576 & 1152 & 750 \\
10 & 9 & $1 / 64$ & $1 / 32$ & 0,0144 & 576 & 288 & 626 \\
11 & 5 & $1 / 64$ & $1 / 48$ & 0.0092 & 320 & 240 & 541 \\
12 & 6 & $1 / 64$ & $1 / 96$ & 0.0114 & 384 & 576 & 528 \\
13 & 11 & $1 / 64$ & $1 / 96$ & 0.0256 & 704 & 1056 & 430 \\
14 & 16 & $1 / 64$ & $1 / 48$ & 0.0297 & 1024 & 768 & 538 \\
15 & 13 & $1 / 64$ & $1 / 96$ & 0.0111 & 832 & 1248 & 1175
\end{tabular}


Tabela 27- Árvore 06 (continuação).

\begin{tabular}{|c|c|c|c|c|c|c|c|}
\hline $\begin{array}{l}\text { Número } \\
\text { do } \\
\text { galho }\end{array}$ & $\begin{array}{l}\text { Número } \\
\text { de } \\
\text { frutos }\end{array}$ & $P E$ & PPN & PPA & $\begin{array}{l}\text { Estimativa } \\
\text { do } n^{\circ} \mathrm{de} \\
\text { frutos }(\mathrm{PE})\end{array}$ & $\begin{array}{l}\text { Estimativa } \\
\text { do } n^{\circ} \mathrm{de} \\
\text { frutos (PPN) }\end{array}$ & $\begin{array}{l}\text { Estimativa } \\
\text { do } n^{\circ} \text { de } \\
\text { frutos (PPA) }\end{array}$ \\
\hline 16 & 6 & $1 / 64$ & $1 / 192$ & $0.0 \overline{53}$ & 384 & 1152 & 392 \\
\hline 17 & 11 & $1 / 64$ & $1 / 384$ & 0,0145 & 704 & 4224 & 760 \\
\hline 18 & 14 & $1 / 64$ & $1 / 384$ & 0.0145 & 896 & 5376 & 967 \\
\hline 19 & 22 & $1 / 64$ & $1 / 24$ & 0,0409 & 1408 & 528 & 538 \\
\hline 20 & 11 & $1 / 64$ & $1 / 144$ & 0,0097 & 704 & 1584 & 1138 \\
\hline 21 & 20 & $1 / 64$ & $1 / 144$ & 0,0160 & 1280 & 2880 & 1251 \\
\hline 22 & 10 & $1 / 64$ & $1 / 576$ & 0,0065 & 640 & 5760 & 1542 \\
\hline 23 & 12 & $1 / 64$ & $1 / 1152$ & 0,0079 & 768 & 13824 & 1510 \\
\hline 24 & 17 & $1 / 64$ & $1 / 1152$ & 0,0101 & 1088 & 19584 & 1690 \\
\hline 25 & 5 & $1 / 64$ & $1 / 288$ & 0,0039 & 320 & 1440 & 1276 \\
\hline 26 & 7 & $1 / 64$ & $1 / 48$ & 0,0135 & 448 & 336 & 518 \\
\hline 27 & 11 & $1 / 64$ & $1 / 36$ & 0,0154 & 704 & 396 & 715 \\
\hline 28 & 16 & $1 / 64$ & $1 / 144$ & 0,0177 & 1024 & 2304 & 905 \\
\hline 29 & 12 & $1 / 64$ & $1 / 144$ & 0,0177 & 768 & 1728 & 679 \\
\hline 30 & 11 & $1 / 64$ & $1 / 72$ & 0,0187 & 704 & 792 & 588 \\
\hline 31 & 8 & $1 / 64$ & $1 / 2304$ & 0,0048 & 512 & 18432 & 1658 \\
\hline 32 & 8 & $1 / 64$ & $1 / 2304$ & 0.0066 & 512 & 18432 & 1218 \\
\hline 33 & 8 & $1 / 64$ & $1 / 1152$ & 0,0045 & 512 & 9216 & 1797 \\
\hline 34 & 10 & $1 / 64$ & $1 / 576$ & 0.0078 & 640 & 5760 & 1288 \\
\hline 35 & 8 & $1 / 64$ & $1 / 576$ & 0,0139 & 512 & 4608 & 577 \\
\hline 36 & 27 & $1 / 64$ & $1 / 576$ & 0.0139 & 1728 & 15552 & 1949 \\
\hline 37 & 6 & $1 / 64$ & $1 / 144$ & 0,0098 & 384 & 864 & 611 \\
\hline 38 & 14 & $1 / 64$ & $1 / 144$ & 0,0128 & 896 & 2016 & 1094 \\
\hline 39 & 11 & $1 / 64$ & $1 / 144$ & 0,0128 & 704 & 1584 & 859 \\
\hline 40 & 6 & $1 / 64$ & $1 / 32$ & 0.0084 & 384 & 192 & 715 \\
\hline 41 & 15 & $1 / 64$ & $1 / 32$ & 0.0165 & 960 & 480 & 912 \\
\hline 42 & 10 & $1 / 64$ & $1 / 128$ & 0.0143 & 640 & 1280 & 698 \\
\hline 43 & 7 & $1 / 64$ & $1 / 128$ & 0,0143 & 448 & 896 & 489 \\
\hline 44 & 14 & $1 / 64$ & $1 / 64$ & 0,0286 & 896 & 896 & 489 \\
\hline 45 & 17 & $1 / 64$ & $1 / 64$ & 0,0152 & 1088 & 1088 & 1122 \\
\hline 46 & 20 & $1 / 64$ & $1 / 128$ & 0,0151 & 1280 & 2560 & 1329 \\
\hline 47 & 9 & $1 / 64$ & $1 / 128$ & 0,0119 & 576 & 1152 & 757 \\
\hline 48 & 16 & $1 / 64$ & $1 / 16$ & 0.0292 & 1024 & 256 & 548 \\
\hline 49 & 7 & $1 / 64$ & $1 / 64$ & 0,0241 & 448 & 448 & 290 \\
\hline 50 & 7 & $1 / 64$ & $1 / 512$ & 0,0086 & 448 & 3584 & 817 \\
\hline 51 & 21 & $1 / 64$ & $1 / 512$ & 0,0142 & 1344 & 10752 & 1482 \\
\hline 52 & 5 & $1 / 64$ & $1 / 512$ & 0,0097 & 320 & 2560 & 513 \\
\hline 53 & 10 & $1 / 64$ & $1 / 512$ & 0,0173 & 640 & 5120 & 577 \\
\hline 54 & 5 & $1 / 64$ & $1 / 256$ & 0.0088 & 320 & 1280 & 569 \\
\hline 55 & 17 & $1 / 64$ & $1 / 1024$ & 0.0150 & 1088 & 17408 & 1135 \\
\hline 56 & 10 & $1 / 64$ & $1 / 1024$ & 0,0115 & 640 & 10240 & 872 \\
\hline 57 & 5 & $1 / 64$ & $1 / 1024$ & 0.0093 & 320 & 5120 & 538 \\
\hline 58 & 7 & $1 / 64$ & $1 / 1024$ & 0.0121 & 448 & 7168 & 577 \\
\hline
\end{tabular}


Tabela 27- Árvore 06 (continuação).

\begin{tabular}{|c|c|c|c|c|c|c|c|}
\hline $\begin{array}{l}\text { Número } \\
\text { do } \\
\text { galho }\end{array}$ & $\begin{array}{c}\text { Número } \\
\text { de } \\
\text { frutos }\end{array}$ & $\mathrm{PE}$ & PPN & PPA & $\begin{array}{l}\text { Estimativa } \\
\text { do } n^{\circ} \text { de } \\
\text { frutos (PE) }\end{array}$ & $\begin{array}{c}\text { Estimativa } \\
\text { do } n^{\circ} \text { de } \\
\text { frutos (PPN) }\end{array}$ & $\begin{array}{c}\begin{array}{c}\text { Estimativa } \\
\text { do } n^{0} \text { de } \\
\text { frutos (PPA) }\end{array} \\
\end{array}$ \\
\hline 59 & 7 & $1 / 64$ & $1 / 96$ & 0,0122 & 448 & .72 & 572 \\
\hline 60 & 5 & $1 / 64$ & $1 / 96$ & 0,0122 & 320 & 480 & 409 \\
\hline 61 & 26 & $1 / 64$ & $1 / 96$ & 0,0422 & 1664 & 2496 & 616 \\
\hline 62 & 11 & $1 / 64$ & $1 / 16$ & 0,0402 & 704 & 176 & 274 \\
\hline 63 & 7 & $1 / 64$ & $1 / 16$ & 0,0205 & 448 & 112 & 341 \\
\hline 64 & 8 & $1 / 64$ & $1 / 8$ & 0,0270 & 512 & 64 & 297 \\
\hline TOTAIS & 721 & 1 & 1 & 1.0000 & & & \\
\hline VARIANCIA & & & & & 65663,5781 & 2382297.0000 & 143578.6970 \\
\hline MEDIA & & & & & 722.00 & 3516,31 & 839.42 \\
\hline C.V. $(\%)$ & & & & & 35.49 & 43.89 & 45.14 \\
\hline
\end{tabular}

Tabela 28 - Mínimo de $7 \mathrm{~cm}$ de circunferência e 10 frutos/galho, árvore 06.

\begin{tabular}{cccccccc}
\hline $\begin{array}{c}\text { Número } \\
\text { do } \\
\text { galho }\end{array}$ & $\begin{array}{c}\text { Número } \\
\text { de } \\
\text { frutos }\end{array}$ & PE & PPN & PPA & $\begin{array}{c}\text { Estimativa } \\
\text { do } \text { n }^{\circ} \text { de } \\
\text { frutos (PE) }\end{array}$ & $\begin{array}{c}\text { Estimativa } \\
\text { do } n^{\circ} \text { de } \\
\text { frutos (PPN) }\end{array}$ & $\begin{array}{c}\text { Estimativa } \\
\text { do } \text { n }^{\circ} \text { de } \\
\text { frutos (PPA) }\end{array}$ \\
\hline 1 & 41 & $1 / 35$ & $1 / 8$ & 0,0625 & 1435 & 328 & 656 \\
2 & 35 & $1 / 35$ & $1 / 16$ & 0,0595 & 1225 & 560 & 588 \\
3 & 44 & $1 / 35$ & $1 / 16$ & 0,0437 & 1540 & 704 & 1006 \\
4 & 24 & $1 / 35$ & $1 / 24$ & 0,0462 & 840 & 576 & 520 \\
5 & 16 & $1 / 35$ & $1 / 48$ & 0,0297 & 560 & 768 & 538 \\
6 & 13 & $1 / 35$ & $1 / 96$ & 0,0111 & 455 & 1248 & 1175 \\
7 & 11 & $1 / 35$ & $1 / 192$ & 0,0221 & 385 & 2112 & 497 \\
8 & 14 & $1 / 35$ & $1 / 192$ & 0,0221 & 490 & 2688 & 633 \\
9 & 22 & $1 / 35$ & $1 / 24$ & 0,0409 & 770 & 528 & 538 \\
10 & 11 & $1 / 35$ & $1 / 72$ & 0,0121 & 385 & 792 & 910 \\
11 & 20 & $1 / 35$ & $1 / 72$ & 0,0200 & 700 & 1440 & 1001 \\
12 & 12 & $1 / 35$ & $1 / 144$ & 0,0157 & 420 & 1728 & 765 \\
13 & 17 & $1 / 35$ & $1 / 144$ & 0,0198 & 595 & 2448 & 857 \\
14 & 11 & $1 / 35$ & $1 / 36$ & 0,0154 & 385 & 396 & 715 \\
15 & 16 & $1 / 35$ & $1 / 144$ & 0,0177 & 560 & 2304 & 905 \\
16 & 12 & $1 / 35$ & $1 / 144$ & 0,0177 & 420 & 1728 & 679 \\
17 & 11 & $1 / 35$ & $1 / 72$ & 0,0187 & 385 & 792 & 588 \\
18 & 24 & $1 / 35$ & $1 / 288$ & 0,0189 & 840 & 6912 & 1271 \\
19 & 10 & $1 / 35$ & $1 / 288$ & 0,0093 & 350 & 2880 & 1081 \\
20 & 35 & $1 / 35$ & $1 / 144$ & 0,0330 & 1225 & 5040 & 1060 \\
21 & 14 & $1 / 35$ & $1 / 144$ & 0,0128 & 490 & 2016 & 1094 \\
22 & 11 & $1 / 35$ & $1 / 144$ & 0,0128 & 385 & 1584 & 859 \\
23 & 22 & $1 / 35$ & $1 / 16$ & 0,0248 & 770 & 352 & 885 \\
24 & 17 & $1 / 35$ & $1 / 64$ & 0,0286 & 595 & 1088 & 593 \\
25 & 14 & $1 / 35$ & $1 / 64$ & 0,0286 & 490 & 896 & 489 \\
26 & 17 & $1 / 35$ & $1 / 64$ & 0,0152 & 595 & 1088 & 1122 \\
27 & 29 & $1 / 35$ & $1 / 64$ & 0,0269 & 1015 & 1856 & 1076
\end{tabular}


Tabela 28 - Mínimo de $7 \mathrm{~cm}$ de circunferência e 10 frutos/galho, árvore 06 (continuação)

\begin{tabular}{|c|c|c|c|c|c|c|c|}
\hline $\begin{array}{l}\text { Número } \\
\text { do } \\
\text { galho }\end{array}$ & $\begin{array}{l}\text { Número } \\
\text { de } \\
\text { frutos }\end{array}$ & PE & PPN & PPA & $\begin{array}{l}\text { Estimativa } \\
\text { do } n^{\circ} \text { de } \\
\text { frutos }(\mathrm{PE})\end{array}$ & $\begin{array}{l}\text { Estimativa } \\
\text { do } n^{\circ} \text { de } \\
\text { frutos (PPN) }\end{array}$ & $\begin{array}{l}\text { Estimativa } \\
\text { do } n^{\circ} \text { de } \\
\text { frut us (PPA) }\end{array}$ \\
\hline 28 & 16 & $1 / 35$ & $1 / 16$ & 0,0292 & 560 & 256 & 548 \\
\hline 29 & 28 & $1 / 35$ & $1 / 128$ & 0,0279 & 980 & 3584 & 1004 \\
\hline 30 & 17 & $1 / 35$ & $1 / 128$ & 0,0332 & 595 & 2176 & 512 \\
\hline 31 & 15 & $1 / 35$ & $1 / 128$ & 0,0311 & 525 & 1920 & 482 \\
\hline 32 & 17 & $1 / 35$ & $1 / 256$ & 0,0218 & 595 & 4352 & 782 \\
\hline 33 & 10 & $1 / 35$ & $1 / 256$ & 0.0167 & 350 & 2560 & 600 \\
\hline 35 & 29 & $1 / 35$ & $1 / 4$ & 0.0877 & 1015 & 116 & 331 \\
\hline TOTAIS & 693 & 1 & 1 & 1.0000 & & & \\
\hline VARIANCIA & & & & & 112126,0000 & 721259,0000 & 62906,2700 \\
\hline MEDIA & & & & & 693,00 & 1743.77 & 769,47 \\
\hline C.V. $(\%)$ & & & & & 48.32 & 48.70 & 32.60 \\
\hline
\end{tabular}

Tabela 29 - Mínimo de $10 \mathrm{~cm}$ de circunferência e 20 frutos/galho, árvore 06.

\begin{tabular}{|c|c|c|c|c|c|c|c|}
\hline $\begin{array}{l}\text { Número } \\
\text { do } \\
\text { galho }\end{array}$ & $\begin{array}{c}\text { Número } \\
\text { de } \\
\text { frutos }\end{array}$ & $P E$ & PPN & PPA & $\begin{array}{l}\text { Estimativa } \\
\text { do } n^{\circ} \text { de } \\
\text { frutos }(\mathrm{PE})\end{array}$ & $\begin{array}{l}\text { Estimativa } \\
\text { do } n^{\circ} \mathrm{de} \\
\text { frutos (PPN) }\end{array}$ & $\begin{array}{l}\text { Estimativa } \\
\text { do } \mathrm{n}^{\circ} \mathrm{de} \\
\text { frutos (PPA) }\end{array}$ \\
\hline 1 & 41 & $1 / 18$ & $1 / 8$ & 0,0625 & 738 & 328 & 656 \\
\hline 2 & 35 & $1 / 18$ & $1 / 16$ & 0,0595 & 630 & 560 & 588 \\
\hline 3 & 44 & $1 / 18$ & $1 / 16$ & 0,0437 & 792 & 704 & 1006 \\
\hline 4 & 24 & $1 / 18$ & $1 / 24$ & 0.0462 & 432 & 576 & 520 \\
\hline 5 & 60 & $1 / 18$ & $1 / 24$ & 0,0851 & 1080 & 1440 & 705 \\
\hline 6 & 22 & $1 / 18$ & $1 / 24$ & 0,0409 & 396 & 528 & 538 \\
\hline 7 & 84 & $1 / 18$ & $1 / 24$ & 0,0676 & 1512 & 2016 & 1243 \\
\hline 8 & 51 & $1 / 18$ & $1 / 24$ & 0.0600 & 918 & 1224 & 850 \\
\hline 9 & 34 & $1 / 18$ & $1 / 96$ & 0,0312 & 612 & 3264 & 1090 \\
\hline 10 & 35 & $1 / 18$ & $1 / 96$ & 0.0366 & 630 & 3360 & 956 \\
\hline 11 & 25 & $1 / 18$ & $1 / 48$ & 0,0284 & 450 & 1200 & 880 \\
\hline 12 & 40 & $1 / 18$ & $1 / 16$ & 0.0716 & 720 & 640 & 558 \\
\hline 13 & 46 & $1 / 18$ & $1 / 16$ & 0,0526 & 828 & 736 & 874 \\
\hline 14 & 28 & $1 / 18$ & $1 / 64$ & 0,0320 & 504 & 1792 & 874 \\
\hline 15 & 17 & $1 / 18$ & $1 / 64$ & 0.0381 & 306 & 1088 & 446 \\
\hline 16 & 47 & $1 / 18$ & $1 / 32$ & 0.0798 & 846 & 1504 & 589 \\
\hline 17 & 38 & $1 / 18$ & $1 / 16$ & 0,0765 & 684 & 608 & 497 \\
\hline 18 & 29 & $1 / 18$ & $1 / 4$ & 0.0877 & 522 & 116 & 331 \\
\hline TOTAIS & 700 & 1 & 1 & 1.0000 & & & \\
\hline \multicolumn{5}{|c|}{ VARIANCIA } & 80033.0000 & 405461,0000 & 63401,5169 \\
\hline \multicolumn{5}{|c|}{ MEDIA } & 700.00 & 1204.67 & 733,44 \\
\hline \multicolumn{5}{|l|}{ C.V. $(\%)$} & 40.41 & 52.86 & 34,33 \\
\hline
\end{tabular}


Tabela 30 - Mínimo de $15 \mathrm{~cm}$ de circunferência e 30 frutos/galho, árore 06.

\begin{tabular}{|c|c|c|c|c|c|c|c|}
\hline $\begin{array}{l}\text { Número } \\
\text { do } \\
\text { galho }\end{array}$ & $\begin{array}{l}\text { Número } \\
\text { de } \\
\text { frutos }\end{array}$ & PE & PPN & PPA & $\begin{array}{l}\text { Estimativa } \\
\text { do } n^{\circ} \text { de } \\
\text { frutos (PE) }\end{array}$ & $\begin{array}{l}\text { Estimativa } \\
\text { do } \mathrm{n}^{\circ} \text { de } \\
\text { frutos (PPN) }\end{array}$ & $\begin{array}{l}\text { Estimativa } \\
\text { c) } n^{\circ} \mathrm{de} \\
\text { frutos (PPA) }\end{array}$ \\
\hline 1 & 122 & $1 / 9$ & $1 / 3$ & 0,1817 & 1098 & 366 & 672 \\
\hline 2 & 85 & $1 / 9$ & $1 / 9$ & 0,1439 & 765 & 765 & 591 \\
\hline 3 & 106 & $1 / 9$ & $1 / 9$ & 0,1189 & 954 & 954 & 892 \\
\hline 4 & 51 & $1 / 9$ & $1 / 18$ & 0.0657 & 459 & 918 & 776 \\
\hline 5 & 100 & $1 / 9$ & $1 / 18$ & 0,1055 & 900 & 1800 & 948 \\
\hline 6 & 109 & $1 / 9$ & $1 / 6$ & 0,1362 & 981 & 654 & 800 \\
\hline 7 & 45 & $1 / 9$ & $1 / 24$ & 0,0769 & 405 & 1080 & 585 \\
\hline 8 & 47 & $1 / 9$ & $1 / 24$ & 0,0875 & 423 & 1128 & 537 \\
\hline 9 & 38 & $1 / 9$ & $1 / 12$ & 0.0839 & 342 & +56 & 453 \\
\hline TOTAIS & 703 & 1 & 1 & 1.0000 & & & \\
\hline VARIÁNCIA & & & & & 80936,0000 & 137240,0000 & 26496.5167 \\
\hline MEDIA & & & & & 703,00 & 902,33 & 694.92 \\
\hline C.V. $(\%)$ & & & & & 40.47 & 41.06 & 23.42 \\
\hline
\end{tabular}

Tabela 31 - Mínimo de $20 \mathrm{~cm}$ de circunferência e 40 frutos/galho, árvore 06.

\begin{tabular}{|c|c|c|c|c|c|c|c|}
\hline $\begin{array}{c}\text { Número } \\
\text { do } \\
\text { galho }\end{array}$ & $\begin{array}{c}\text { Número } \\
\text { de } \\
\text { frutos }\end{array}$ & $\mathrm{PE}$ & PPN & PPA & $\begin{array}{l}\text { Estimativa } \\
\text { do } n^{\circ} \text { de } \\
\text { frutos (PE) }\end{array}$ & $\begin{array}{l}\text { Estimativa } \\
\text { do } n^{\circ} \text { de } \\
\text { frutos (PPN) }\end{array}$ & $\begin{array}{l}\text { Estimativa } \\
\text { do } n^{\circ} \text { de } \\
\text { frutos (PPA) }\end{array}$ \\
\hline 1 & 122 & $1 / 6$ & $1 / 3$ & 0,1817 & 732 & 366 & 672 \\
\hline 2 & 85 & $1 / 6$ & $1 / 9$ & 0,1439 & 510 & 765 & 591 \\
\hline 3 & 106 & $1 / 6$ & $1 / 9$ & 0,1189 & 636 & 954 & 892 \\
\hline 4 & 151 & $1 / 6$ & $1 / 9$ & 0.1712 & 906 & 1359 & 882 \\
\hline 5 & 109 & $1 / 6$ & $1 / 6$ & 0.1362 & 654 & 654 & 800 \\
\hline 6 & 161 & $1 / 6$ & $1 / 6$ & 0.2482 & 966 & 966 & 649 \\
\hline TOTAIS & 734 & 1 & 1 & 1.0000 & & & \\
\hline VARIÁNCIA & & & & & 25773.0000 & 104907.0000 & 13608,6928 \\
\hline MEDIA & & & & & 734.00 & 844.00 & 747,51 \\
\hline C.V. $(\%)$ & & & & & 21.87 & 38.38 & 15.61 \\
\hline
\end{tabular}


Tabela 32 - Árvore 07.

\begin{tabular}{|c|c|c|c|c|c|c|c|}
\hline $\begin{array}{c}\text { Número } \\
\text { do } \\
\text { galho }\end{array}$ & $\begin{array}{c}\text { Número } \\
\text { de } \\
\text { frutos }\end{array}$ & PE & PPN & PPA & $\begin{array}{l}\text { Estimativa } \\
\text { do } n^{\circ} \text { de } \\
\text { frutos }(\mathrm{PE})\end{array}$ & $\begin{array}{l}\text { Estimativa } \\
\text { do } n^{0} \text { de } \\
\text { frutos (PPN) }\end{array}$ & $\begin{array}{l}\text { Estimativa } \\
\text { do } n^{\circ} \text { de } \\
\text { frutos (PPA) }\end{array}$ \\
\hline 1 & 10 & $1 / 27$ & $1 / 18$ & 0,0484 & 270 & 180 & 207 \\
\hline 2 & 7 & $1 / 27$ & $1 / 36$ & 0,0332 & 189 & 252 & 211 \\
\hline 3 & 12 & $1 / 27$ & $1 / 36$ & 0,0254 & 324 & 432 & 473 \\
\hline 4 & 13 & $1 / 27$ & $1 / 9$ & 0,0833 & 351 & 117 & 156 \\
\hline 5 & 4 & $1 / 27$ & $1 / 36$ & 0,0235 & 108 & 144 & 170 \\
\hline 6 & 12 & $1 / 27$ & $1 / 72$ & 0,0339 & 324 & 864 & 354 \\
\hline 7 & 22 & $1 / 27$ & $1 / 288$ & 0,0255 & 594 & 6336 & 861 \\
\hline 8 & 6 & $1 / 27$ & $1 / 288$ & 0,0188 & 162 & 1728 & 320 \\
\hline 9 & 4 & $1 / 27$ & $1 / 144$ & 0,0160 & 108 & 576 & 251 \\
\hline 10 & 12 & $1 / 27$ & $1 / 18$ & 0.0614 & 324 & 216 & 195 \\
\hline 11 & 17 & $1 / 27$ & $1 / 6$ & 0,1278 & 459 & 102 & 133 \\
\hline 12 & 12 & $1 / 27$ & $1 / 192$ & 0,0146 & 324 & 2304 & 822 \\
\hline 13 & 8 & $1 / 27$ & $1 / 384$ & 0,0129 & 216 & 3072 & 619 \\
\hline 14 & 11 & $1 / 27$ & $1 / 384$ & 0,0169 & 297 & 4224 & 652 \\
\hline 15 & 6 & $1 / 27$ & $1 / 96$ & 0,0250 & 162 & 576 & 240 \\
\hline 16 & 18 & $1 / 27$ & $1 / 48$ & 0.0410 & 486 & 864 & 439 \\
\hline 17 & 4 & $1 / 27$ & $1 / 48$ & 0,0383 & 108 & 192 & 104 \\
\hline 18 & 22 & $1 / 27$ & $1 / 48$ & 0,0383 & 594 & 1056 & 574 \\
\hline 19 & 17 & $1 / 27$ & $1 / 12$ & 0,0795 & 459 & 204 & 214 \\
\hline 20 & 14 & $1 / 27$ & $1 / 48$ & 0,0318 & 378 & 672 & 440 \\
\hline 21 & 14 & $1 / 27$ & $1 / 48$ & 0,0258 & 378 & 672 & 543 \\
\hline 22 & 6 & $1 / 27$ & $1 / 24$ & 0,0144 & 162 & 144 & 416 \\
\hline 23 & 4 & $1 / 27$ & $1 / 24$ & 0,0237 & 108 & 96 & 169 \\
\hline 24 & 17 & $1 / 27$ & $1 / 24$ & 0,0484 & 459 & 408 & 352 \\
\hline 25 & 13 & $1 / 27$ & $1 / 24$ & 0,0183 & 351 & 312 & 709 \\
\hline 26 & 14 & $1 / 27$ & $1 / 24$ & 0.0469 & 378 & 336 & 298 \\
\hline 27 & 7 & $1 / 27$ & $1 / 12$ & 0,0270 & 189 & 84 & 260 \\
\hline TOTAIS & 306 & 1 & 1 & 1.0000 & & & \\
\hline VARIANCIA & & & & & 20232.0000 & 265515,0000 & 35172,2518 \\
\hline MEDIA & & & & & 306.00 & 969,00 & 377,08 \\
\hline C.V. $(\%)$ & & & & & 46.48 & 53,18 & 49,74 \\
\hline
\end{tabular}


Tabela 33 - Mínimo de $7 \mathrm{~cm}$ de circunferencia e 10 frutos/galho, árvore 07.

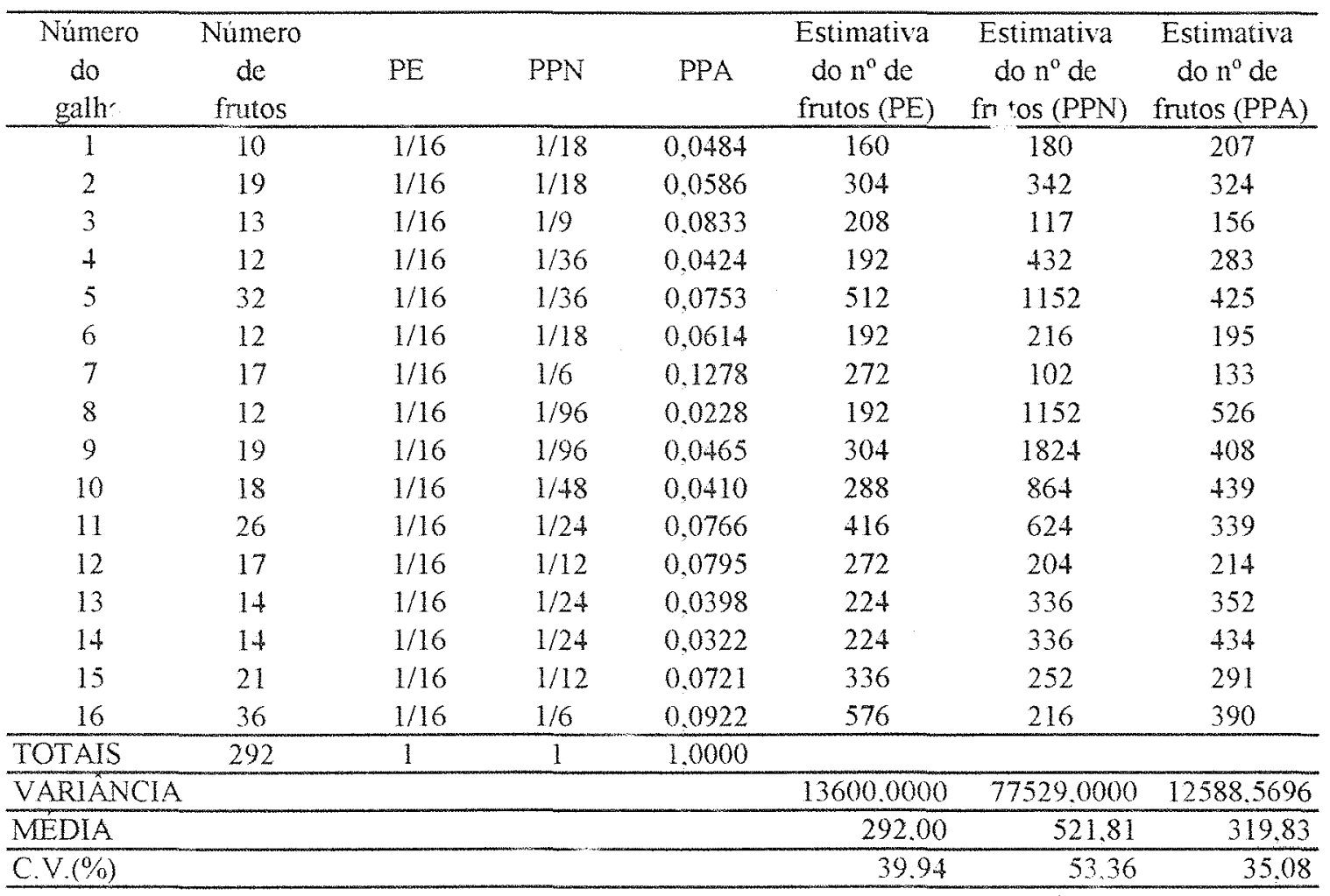

Tabela 34 - Mínimo de $10 \mathrm{~cm}$ de circunferência e 20 frutos/galho, árvore 07.

\begin{tabular}{|c|c|c|c|c|c|c|c|}
\hline $\begin{array}{l}\text { Número } \\
\text { do } \\
\text { galho } \\
\end{array}$ & $\begin{array}{c}\text { Número } \\
\text { de } \\
\text { frutos }\end{array}$ & $\mathrm{PE}$ & PPN & PPA & $\begin{array}{c}\text { Estimativa } \\
\text { do } n^{\circ} \text { de } \\
\text { frutos (PE) }\end{array}$ & $\begin{array}{c}\text { Estimativa } \\
\text { do } n^{\circ} \text { de } \\
\text { frutos (PPN) }\end{array}$ & $\begin{array}{l}\text { Estimativa } \\
\text { do } n^{\circ} \text { de } \\
\text { frutos (PPA) }\end{array}$ \\
\hline & & & & & (PE) & (PPN) & (PPA) \\
\hline 1 & 42 & $1 / 7$ & $1 / 6$ & 0.1381 & 294 & 252 & 304 \\
\hline 2 & 61 & $1 / 7$ & $1 / 6$ & 0.2312 & 427 & 366 & 264 \\
\hline 3 & 17 & $1 / 7$ & $1 / 6$ & 0.1278 & 119 & 102 & 133 \\
\hline 4 & 101 & $1 / 7$ & $1 / 6$ & 0,2666 & 707 & 606 & 379 \\
\hline 5 & 34 & $1 / 7$ & $1 / 12$ & 0.0721 & 238 & 408 & +72 \\
\hline 6 & 21 & $1 / 7$ & $1 / 12$ & 0.0721 & 147 & 252 & 291 \\
\hline 7 & 36 & $1 / 7$ & $1 / 6$ & 0.0922 & 252 & 216 & 390 \\
\hline TOTAIS & 312 & 1 & 1 & 1.0000 & & & \\
\hline VARIÁNCIA & & & & & $3+732.0000$ & $25+46.0000$ & 8266.0997 \\
\hline MEDIA & & & & & 312.00 & $31+.57$ & 319.07 \\
\hline C.V. $(\%)$ & & & & & 59.73 & 50.71 & 28.49 \\
\hline
\end{tabular}


Tabela 35 - Mínimo de $15 \mathrm{~cm}$ de circunferência e 30 frutos/galho, árvore 07.

\begin{tabular}{|c|c|c|c|c|c|c|c|}
\hline $\begin{array}{c}\text { Número } \\
\text { do } \\
\text { galho }\end{array}$ & $\begin{array}{l}\text { Número } \\
\text { de } \\
\text { frutos } \\
\end{array}$ & PE & PPN & PPA & $\begin{array}{l}\text { Estimativa } \\
\text { do } n^{\circ} \text { de } \\
\text { frutos }(\mathrm{PE})\end{array}$ & $\begin{array}{l}\text { Estimativa } \\
\text { do } n^{\circ} \text { de } \\
\text { frutos (PPN) }\end{array}$ & $\begin{array}{c}\text { Estimativa } \\
\text { do } n^{\circ} \text { de } \\
\text { frutos (PPA) }\end{array}$ \\
\hline 1 & 42 & $1 / 5$ & $1 / 6$ & 0,1381 & 210 & 252 & 304 \\
\hline 2 & 61 & $1 / 5$ & $1 / 6$ & 0.2312 & 305 & 366 & 264 \\
\hline 3 & 118 & $1 / 5$ & $1 / 3$ & 0,3943 & 590 & 354 & 299 \\
\hline 4 & 55 & $1 / 5$ & $1 / 6$ & 0,1441 & 275 & 330 & 382 \\
\hline 5 & 36 & $1 / 5$ & $1 / 6$ & 0.0922 & 180 & 216 & 390 \\
\hline TOTAIS & 312 & 1 & 1 & 1.0000 & & & \\
\hline VARIANCIA & & & & & 21306,0000 & 3264,0000 & 1874.0426 \\
\hline MÉDIA & & & & & 312.00 & 303.60 & 327.83 \\
\hline C.V. $(\%)$ & & & & & 46.78 & 18.82 & 13.21 \\
\hline
\end{tabular}

Tabela 36 - Mínimo de $20 \mathrm{~cm}$ de circunferência e 40 frutos/galho, árvore 07.

\begin{tabular}{|c|c|c|c|c|c|c|c|}
\hline $\begin{array}{l}\text { Número } \\
\text { do } \\
\text { galho }\end{array}$ & $\begin{array}{l}\text { Número } \\
\text { de } \\
\text { frutos }\end{array}$ & $\mathrm{PE}$ & PPN & PPA & $\begin{array}{l}\text { Estimativa } \\
\text { do } n^{\circ} \text { de } \\
\text { frutos (PE) }\end{array}$ & $\begin{array}{l}\text { Estimativa } \\
\text { do } n^{\circ} \text { de } \\
\text { frutos (PPN) }\end{array}$ & $\begin{array}{l}\text { Estimativa } \\
\text { do } n^{\circ} \text { de } \\
\text { frutos (PPA) }\end{array}$ \\
\hline 1 & 103 & $1 / 3$ & $1 / 3$ & 0,3693 & 309 & 309 & 279 \\
\hline 2 & 118 & $1 / 3$ & $1 / 3$ & 0,3943 & 354 & 354 & 299 \\
\hline 3 & 91 & $1 / 3$ & $1 / 3$ & 0.2364 & 273 & 273 & 385 \\
\hline TOTAIS & 312 & 1 & 1 & 1.0000 & & & \\
\hline VARIANCIA & & & & & 1098,0000 & 1098,0000 & 1728,7934 \\
\hline MEDIA & & & & & 312,00 & 312.00 & 321,05 \\
\hline C.V. $(\%)$ & & & & & 10.62 & 10.62 & 12.95 \\
\hline
\end{tabular}


Tabela 37 - Árvore 08 .

\begin{tabular}{|c|c|c|c|c|c|c|c|}
\hline $\begin{array}{l}\text { Número } \\
\text { do } \\
\text { galho }\end{array}$ & $\begin{array}{l}\text { Número } \\
\text { de } \\
\text { frutos }\end{array}$ & PE & PPN & PPA & $\begin{array}{l}\text { Estimativa } \\
\text { do } n^{\circ} \text { de } \\
\text { frutos (PE) }\end{array}$ & $\begin{array}{l}\text { Estimativa } \\
\text { do } n^{\circ} \text { de } \\
\text { frutos (PPN) }\end{array}$ & $\begin{array}{l}\text { Estimativa } \\
\text { do } n^{\circ} \text { de } \\
\text { frutos (PPA) }\end{array}$ \\
\hline 1 & 21 & $1 / 9$ & $1 / 6$ & 0,1452 & 189 & 126 & 145 \\
\hline 2 & 15 & $1 / 9$ & $1 / 6$ & 0,1112 & 135 & 90 & 135 \\
\hline 3 & 4 & $1 / 9$ & $1 / 9$ & 0,0517 & 36 & 36 & 77 \\
\hline 4 & 9 & $1 / 9$ & $1 / 18$ & 0,0414 & 81 & 162 & 218 \\
\hline 5 & 15 & $1 / 9$ & $1 / 18$ & 0,1655 & 135 & 270 & 91 \\
\hline 6 & 5 & $1 / 9$ & $1 / 9$ & 0,0517 & 45 & 45 & 97 \\
\hline 7 & 13 & $1 / 9$ & $1 / 12$ & 0,1470 & 117 & 156 & 88 \\
\hline 8 & 18 & $1 / 9$ & $1 / 12$ & 0,1126 & 162 & 216 & 160 \\
\hline 9 & 13 & $1 / 9$ & $1 / 6$ & 0.1738 & 117 & 78 & 75 \\
\hline TOTAIS & 113 & 1 & 1 & 1,0000 & & & \\
\hline VARIANCIA & & & & & 2306,0000 & 4034,0000 & 1402,7129 \\
\hline MEDIA & & & & & 113.00 & 131.00 & 120,55 \\
\hline C.V. $(\%)$ & & & & & 42.50 & 48.48 & 31.07 \\
\hline
\end{tabular}

Tabela 38 - Mínimo de $7 \mathrm{~cm}$ de circunferência e 10 frutos/galho, árvore 08.

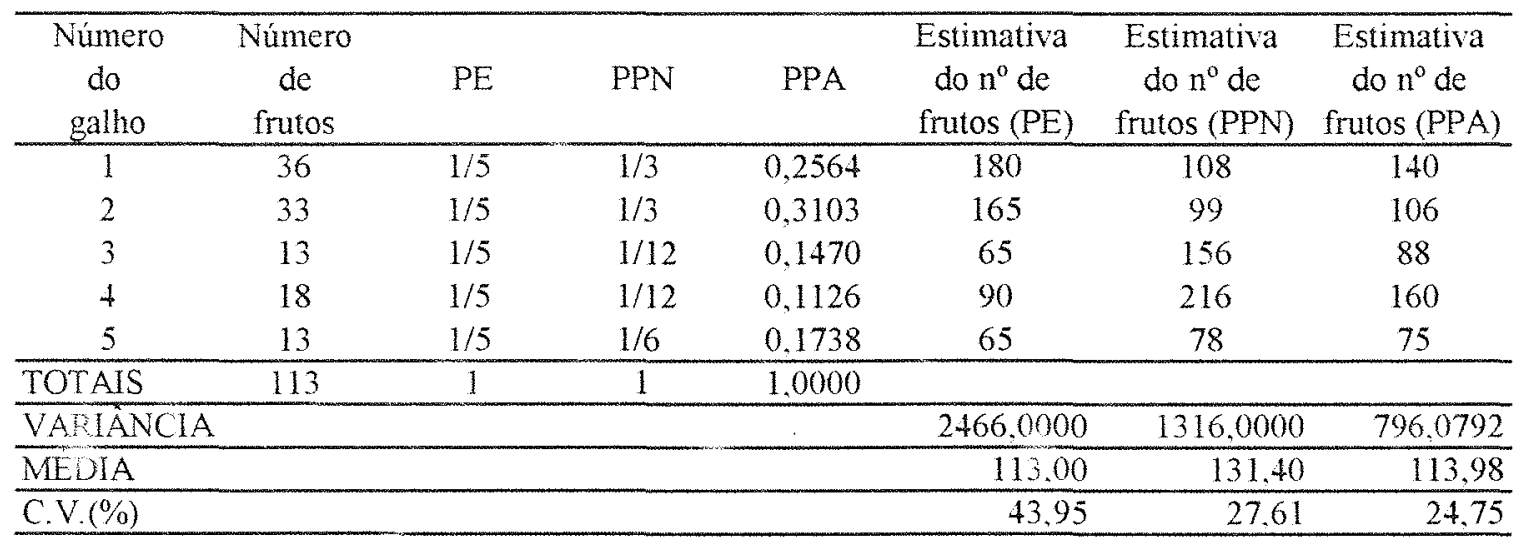

Tabela 39 - Mínimo de $10 \mathrm{~cm}$ de circunferência e 20 frutos/galho, árvore 08.

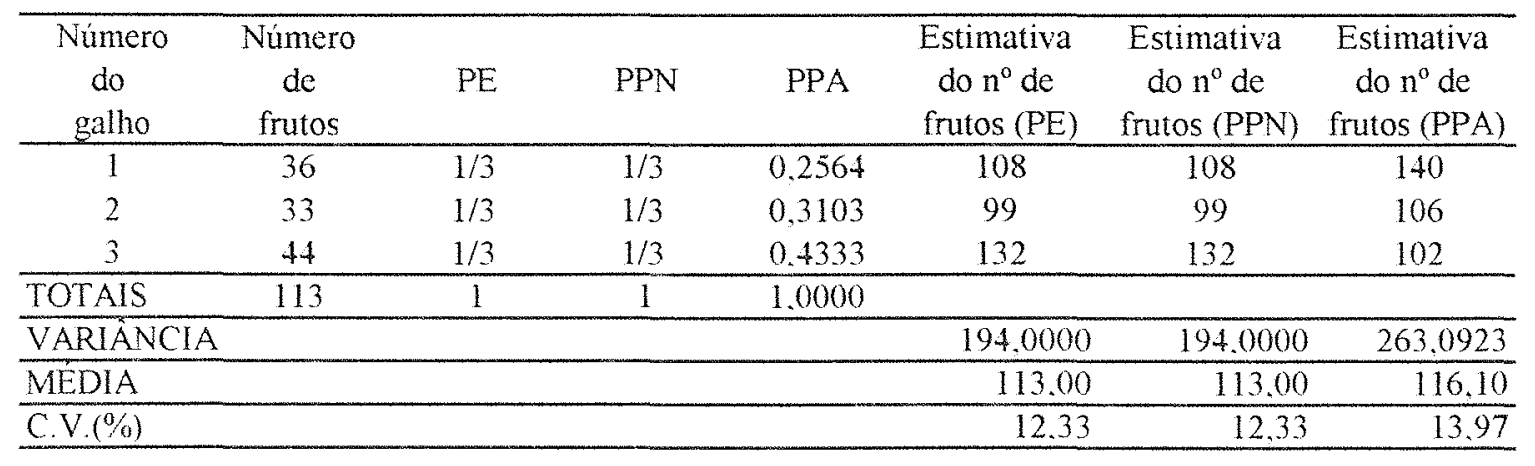


Tabela 40 - Árvore 09.

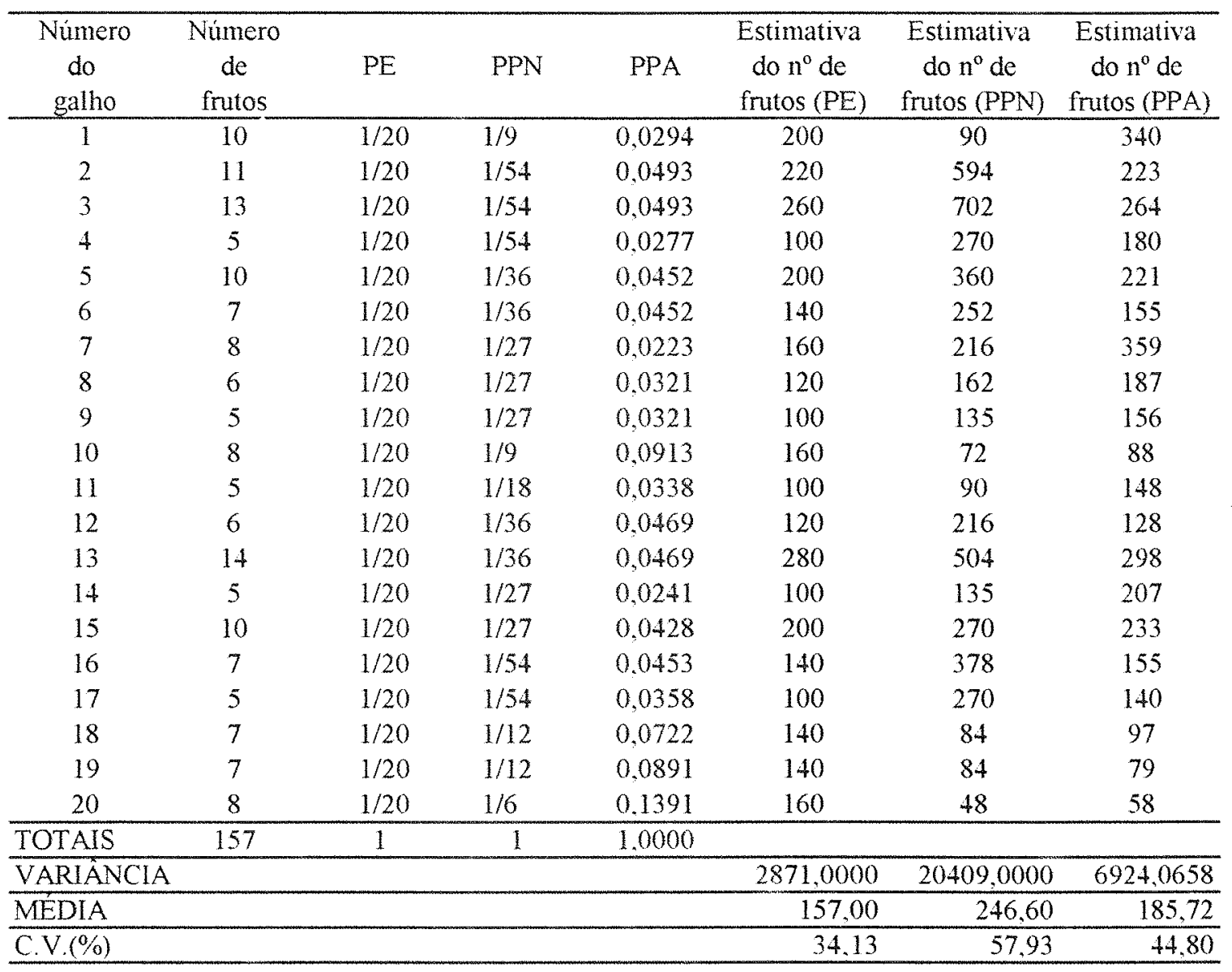

Tabela 41 - Mínimo de $7 \mathrm{~cm}$ de circunferência e 10 frutos/galho, árvore 09.

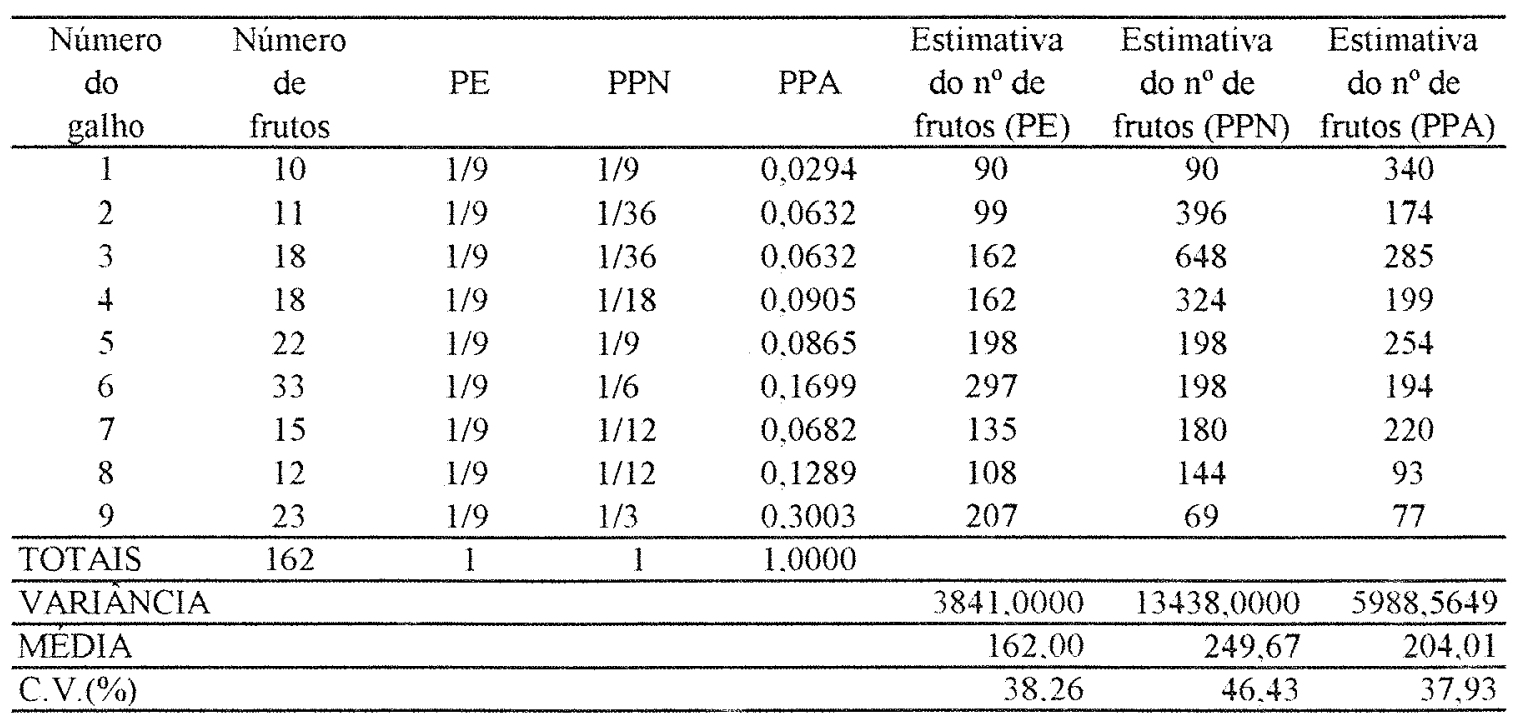


Tabela 42 - Mínimo de $10 \mathrm{~cm}$ de circunferência e 20 frutos/galho, árvore 09.

\begin{tabular}{|c|c|c|c|c|c|c|c|}
\hline $\begin{array}{l}\text { Número } \\
\text { do } \\
\text { galho }\end{array}$ & $\begin{array}{c}\text { Número } \\
\text { de } \\
\text { frutos }\end{array}$ & $\mathrm{PE}$ & PPN & PPA & $\begin{array}{l}\text { Estimativa } \\
\text { do } n^{\circ} \text { de } \\
\text { frutos (PE) }\end{array}$ & $\begin{array}{l}\text { Estimativa } \\
\text { do } n^{0} \text { de } \\
\text { frutos (PPN) }\end{array}$ & $\begin{array}{l}\text { Estimativa } \\
\text { do } n^{\circ} \text { de } \\
\text { frutos (PPA) }\end{array}$ \\
\hline 1 & 62 & $1 / 5$ & $1 / 6$ & 0,2379 & 310 & 372 & 261 \\
\hline 2 & 22 & $1 / 5$ & $1 / 6$ & 0,0949 & 110 & 132 & 232 \\
\hline 3 & 33 & $1 / 5$ & $1 / 6$ & 0,1699 & 165 & 198 & 194 \\
\hline 4 & 27 & $1 / 5$ & $1 / 6$ & 0,1970 & 135 & 162 & 137 \\
\hline 5 & 23 & $1 / 5$ & $1 / 3$ & 0,3003 & 115 & 69 & 77 \\
\hline TOTAIS & 167 & 1 & 1 & 1.0000 & & & \\
\hline VARIANCIA & & & & & 5486,0000 & 10574,0000 & 5242,7194 \\
\hline MEDIA & & & & & 167,00 & 186,60 & 180,07 \\
\hline C.V. $(\%)$ & & & & & 44,35 & 55,11 & 40.21 \\
\hline
\end{tabular}

Tabela 43 - Minimo de $15 \mathrm{~cm}$ de circunferência e 30 frutos/galho, árvore 09.

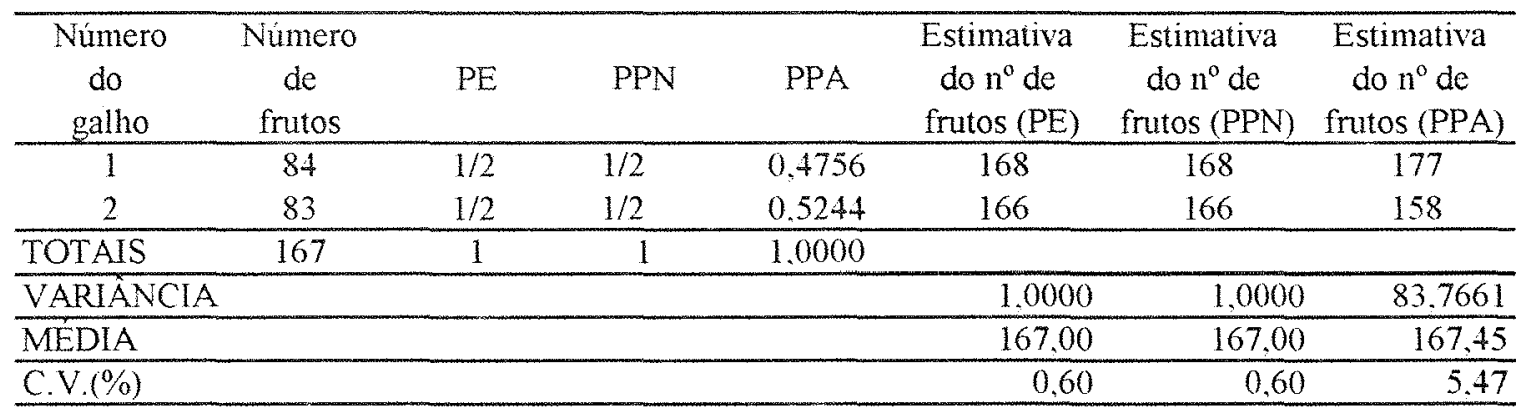

Tabela 44 - Árore 10.

\begin{tabular}{cccccccc}
\hline $\begin{array}{c}\text { Número } \\
\text { do } \\
\text { galho }\end{array}$ & $\begin{array}{c}\text { Número } \\
\text { de } \\
\text { frutos }\end{array}$ & PE & PPN & PPA & $\begin{array}{c}\text { Estimativa } \\
\text { do } n^{\circ} \text { de } \\
\text { frutos (PE) }\end{array}$ & $\begin{array}{c}\text { Estimativa } \\
\text { do } n^{\circ} \text { de } \\
\text { frutos (PPN) }\end{array}$ & $\begin{array}{c}\text { Estimativa } \\
\text { do } n^{\circ} \text { de } \\
\text { frutos (PPA) }\end{array}$ \\
\hline 1 & 6 & $1 / 41$ & $1 / 16$ & 0,0108 & 246 & 96 & 555 \\
2 & 6 & $1 / 41$ & $1 / 16$ & 0,0243 & 246 & 96 & 247 \\
3 & 6 & $1 / 41$ & $1 / 192$ & 0,0128 & 246 & 1152 & 467 \\
4 & 15 & $1 / 41$ & $1 / 192$ & 0,0212 & 615 & 2880 & 707 \\
5 & 15 & $1 / 41$ & $1 / 192$ & 0,0112 & 615 & 2880 & 1339 \\
6 & 24 & $1 / 41$ & $1 / 192$ & 0,0229 & 984 & 4608 & 1050 \\
7 & 6 & $1 / 41$ & $1 / 96$ & 0,0157 & 246 & 576 & 382 \\
8 & 16 & $1 / 41$ & $1 / 96$ & 0,0226 & 656 & 1536 & 708 \\
9 & 12 & $1 / 41$ & $1 / 96$ & 0,0148 & 492 & 1152 & 812 \\
10 & 31 & $1 / 41$ & $1 / 96$ & 0,0302 & 1271 & 2976 & 1027 \\
11 & 9 & $1 / 41$ & $1 / 16$ & 0,0185 & 369 & 144 & 485 \\
12 & 7 & $1 / 41$ & $1 / 16$ & 0,0283 & 287 & 112 & 248 \\
13 & 4 & $1 / 41$ & $1 / 16$ & 0,0283 & 164 & 64 & 141 \\
14 & 29 & $1 / 41$ & $1 / 48$ & 0,0422 & 1189 & 1392 & 687
\end{tabular}


Tabela 44 - Árvore 10 (continuação).

\begin{tabular}{|c|c|c|c|c|c|c|c|}
\hline $\begin{array}{l}\text { Número } \\
\text { do } \\
\text { galho }\end{array}$ & $\begin{array}{l}\text { Número } \\
\text { de } \\
\text { frutos }\end{array}$ & $\mathrm{PE}$ & PPN & PPA & $\begin{array}{l}\text { Estimativa } \\
\text { do } n^{\circ} \text { de } \\
\text { frutos }(\mathrm{PE})\end{array}$ & $\begin{array}{l}\text { Estimativa } \\
\text { do } n^{\circ} \text { de } \\
\text { frutos (PPN) }\end{array}$ & $\begin{array}{l}\text { Estimativa } \\
\text { do } n^{\circ} \text { de } \\
\text { frutos (PPA) }\end{array}$ \\
\hline 15 & 90 & $1 / 41$ & $1 / 48$ & 0,1008 & 3690 & 4320 & 893 \\
\hline 16 & 21 & $1 / 41$ & $1 / 24$ & 0,0426 & 861 & 504 & 493 \\
\hline 17 & 22 & $1 / 41$ & $1 / 96$ & 0,0355 & 902 & 2112 & 619 \\
\hline 18 & 12 & $1 / 41$ & $1 / 192$ & 0,0215 & 492 & 2304 & 558 \\
\hline 19 & 12 & $1 / 41$ & $1 / 384$ & 0,0122 & 492 & 4608 & 986 \\
\hline 20 & 6 & $1 / 41$ & $1 / 384$ & 0,0093 & 246 & 2304 & 644 \\
\hline 21 & 22 & $1 / 41$ & $1 / 96$ & 0,0170 & 902 & 2112 & 1291 \\
\hline 22 & 17 & $1 / 41$ & $1 / 192$ & 0,0197 & 697 & 3264 & 863 \\
\hline 23 & 17 & $1 / 41$ & $1 / 192$ & 0,0151 & 697 & 3264 & 1127 \\
\hline 24 & 15 & $1 / 41$ & $1 / 8$ & 0,0393 & 615 & 120 & 382 \\
\hline 25 & 11 & $1 / 41$ & $1 / 16$ & 0,0374 & 451 & 176 & 294 \\
\hline 26 & 9 & $1 / 41$ & $1 / 32$ & 0.0283 & 369 & 288 & 318 \\
\hline 27 & 19 & $1 / 41$ & $1 / 32$ & 0,0349 & 779 & 608 & 544 \\
\hline 28 & 12 & $1 / 41$ & $1 / 24$ & 0,0195 & 492 & 288 & 615 \\
\hline 29 & 16 & $1 / 41$ & $1 / 96$ & 0,0222 & 656 & 1536 & 722 \\
\hline 30 & 6 & $1 / 41$ & $1 / 288$ & 0,0101 & 246 & 1728 & 592 \\
\hline 31 & 9 & $1 / 41$ & $1 / 288$ & 0,0138 & 369 & 2592 & 653 \\
\hline 32 & 23 & $1 / 41$ & $1 / 288$ & 0,0180 & 943 & 6624 & 1278 \\
\hline 33 & 24 & $1 / 41$ & $1 / 48$ & 0,0379 & 984 & 1152 & 633 \\
\hline 34 & 8 & $1 / 41$ & $1 / 24$ & 0,0194 & 328 & 192 & 413 \\
\hline 35 & 12 & $1 / 41$ & $1 / 24$ & 0,0320 & 492 & 288 & 375 \\
\hline 36 & 32 & $1 / 41$ & $1 / 24$ & 0,0324 & 1312 & 768 & 989 \\
\hline 37 & 26 & $1 / 41$ & $1 / 192$ & 0,0227 & 1066 & 4992 & 1144 \\
\hline 38 & 21 & $1 / 41$ & $1 / 384$ & 0,0119 & 861 & 8064 & 1761 \\
\hline 39 & 30 & $1 / 41$ & $1 / 384$ & 0,0156 & 1230 & 11520 & 1926 \\
\hline 40 & 7 & $1 / 41$ & $1 / 96$ & 0,0164 & 287 & 672 & 427 \\
\hline 41 & 8 & $1 / 41$ & $1 / 48$ & 0,0107 & 328 & 384 & 750 \\
\hline TOTAIS & 693 & 1 & 1 & 1,0000 & & & \\
\hline VARIANCIA & & & & & 327933,0000 & 1543808.0000 & 122428.7849 \\
\hline MEDIA & & & & & 693.00 & 2108.49 & 735,22 \\
\hline C.V. $(\%)$ & & & & & 82.63 & 58.93 & 47.59 \\
\hline
\end{tabular}


Tabela 45 - Mínimo de $7 \mathrm{~cm}$ de circunferência e 10 frutos/galho, árvore 10.

\begin{tabular}{|c|c|c|c|c|c|c|c|}
\hline $\begin{array}{l}\text { Número } \\
\text { do } \\
\text { galho }\end{array}$ & $\begin{array}{l}\text { Número } \\
\text { de } \\
\text { frutos }\end{array}$ & $\mathrm{PE}$ & PPN & PPA & $\begin{array}{l}\text { Estimativa } \\
\text { do } n^{\circ} \text { de } \\
\text { frutos }(\mathrm{PE})\end{array}$ & $\begin{array}{l}\text { Estir ativa } \\
\text { do } \mathrm{n}^{\circ} \mathrm{de} \\
\text { frutos (PPN) }\end{array}$ & $\begin{array}{l}\text { Estimativa } \\
\text { do } n^{\circ} \text { de } \\
\text { frutos (PPA) }\end{array}$ \\
\hline 1 & 12 & $1 / 29$ & $1 / 8$ & 0.0351 & 348 & 96 & 342 \\
\hline 2 & 21 & $1 / 29$ & $1 / 48$ & 0,0382 & 609 & 1008 & 549 \\
\hline 3 & 15 & $1 / 29$ & $1 / 96$ & 0.0126 & 435 & 1440 & 1193 \\
\hline 4 & 24 & $1 / 29$ & $1 / 96$ & 0.0257 & 696 & 2304 & 935 \\
\hline 5 & 22 & $1 / 29$ & $1 / 24$ & 0,0430 & 638 & 528 & 512 \\
\hline 6 & 12 & $1 / 29$ & $1 / 48$ & 0,0166 & 348 & 576 & 723 \\
\hline 7 & 31 & $1 / 29$ & $1 / 48$ & 0,0339 & 899 & 1488 & 915 \\
\hline 8 & 11 & $1 / 29$ & $1 / 8$ & 0,0565 & 319 & 88 & 195 \\
\hline 9 & 29 & $1 / 29$ & $1 / 48$ & 0,0422 & 841 & 1392 & 687 \\
\hline 10 & 90 & $1 / 29$ & $1 / 48$ & 0,1008 & 2610 & +320 & 893 \\
\hline 11 & 21 & $1 / 29$ & $1 / 24$ & 0,0426 & 609 & 504 & 493 \\
\hline 12 & 22 & $1 / 29$ & $1 / 96$ & 0,0355 & 638 & 2112 & 619 \\
\hline 13 & 12 & $1 / 29$ & $1 / 192$ & 0,0215 & 348 & 2304 & 558 \\
\hline 14 & 18 & $1 / 29$ & $1 / 192$ & 0,0215 & 522 & 3456 & 838 \\
\hline 15 & 22 & $1 / 29$ & $1 / 96$ & 0,0170 & 638 & 2112 & 1291 \\
\hline 16 & 17 & $1 / 29$ & $1 / 192$ & 0,0197 & 493 & 3264 & 863 \\
\hline 17 & 17 & $1 / 29$ & $1 / 192$ & 0,0151 & 493 & 3264 & 1127 \\
\hline 18 & 15 & $1 / 29$ & $1 / 8$ & 0,0393 & 435 & 120 & 382 \\
\hline 19 & 11 & $1 / 29$ & $1 / 16$ & 0,0374 & 319 & 176 & 294 \\
\hline 20 & 31 & $1 / 29$ & $1 / 16$ & 0,0632 & 899 & 496 & 490 \\
\hline 21 & 12 & $1 / 29$ & $1 / 24$ & 0.0195 & 348 & 288 & 615 \\
\hline 22 & 16 & $1 / 29$ & $1 / 96$ & 0,0222 & 464 & 1536 & 722 \\
\hline 23 & 38 & $1 / 29$ & $1 / 96$ & 0,0419 & 1102 & 3648 & 907 \\
\hline 24 & 24 & $1 / 29$ & $1 / 48$ & 0,0379 & 696 & 1152 & 633 \\
\hline 25 & 26 & $1 / 29$ & $1 / 12$ & 0,0513 & 754 & 312 & 506 \\
\hline 26 & 32 & $1 / 29$ & $1 / 24$ & 0,0324 & 928 & 768 & 989 \\
\hline 27 & 26 & $1 / 29$ & $1 / 48$ & 0,0350 & 754 & 1248 & 743 \\
\hline 28 & 21 & $1 / 29$ & $1 / 96$ & 0,0184 & 609 & 2016 & 1144 \\
\hline 29 & 30 & $1 / 29$ & $1 / 96$ & 0,0240 & 870 & 2880 & 1251 \\
\hline TOTAIS & 678 & 1 & 1 & 1.0000 & & & \\
\hline VARIANCIA & & & & & 177756,0000 & $8+7252.0000$ & $7+705.5055$ \\
\hline MEDIA & & & & & 678.00 & 1548.14 & 738,23 \\
\hline C.V. $(\%)$ & & & & & 62.18 & 59.46 & 37,02 \\
\hline
\end{tabular}


Tabela 46 - Mínimo de $10 \mathrm{~cm}$ de circunferência e 20 frutos/galho, árvore 10 .

\begin{tabular}{|c|c|c|c|c|c|c|c|}
\hline $\begin{array}{c}\text { Número } \\
\text { do } \\
\text { galho }\end{array}$ & $\begin{array}{c}\text { Número } \\
\text { de } \\
\text { frutos }\end{array}$ & $\mathrm{PE}$ & PPN & PPA & $\begin{array}{l}\text { Estimativa } \\
\text { do } n^{\circ} \text { de } \\
\text { frutos (PE) }\end{array}$ & $\begin{array}{l}\text { Estimativa } \\
\text { do } \mathrm{n}^{\circ} \mathrm{de} \\
\text { frutos (PPN) }\end{array}$ & $\begin{array}{l}\text { Estimativa } \\
\text { do } n^{\circ} \text { de } \\
\text { frut } s \text { (PPA) }\end{array}$ \\
\hline 1 & 21 & $1 / 18$ & $1 / 24$ & 0,0461 & 378 & 504 & $4 \overline{55}$ \\
\hline 2 & 41 & $1 / 18$ & $1 / 24$ & 0,0461 & 738 & 984 & 889 \\
\hline 3 & 22 & $1 / 18$ & $1 / 12$ & 0,0519 & 396 & 264 & 424 \\
\hline 4 & 43 & $1 / 18$ & $1 / 12$ & 0,0609 & 774 & 516 & 706 \\
\hline 5 & 11 & $1 / 18$ & $1 / 8$ & 0,0565 & 198 & 88 & 195 \\
\hline 6 & 29 & $1 / 18$ & $1 / 48$ & 0,0422 & 522 & 1392 & 687 \\
\hline 7 & 90 & $1 / 18$ & $1 / 48$ & 0,1008 & 1620 & 4320 & 893 \\
\hline 8 & 21 & $1 / 18$ & $1 / 24$ & 0,0426 & 378 & 504 & 493 \\
\hline 9 & 22 & $1 / 18$ & $1 / 96$ & 0,0355 & 396 & 2112 & 619 \\
\hline 10 & 31 & $1 / 18$ & $1 / 96$ & 0,0430 & 558 & 2976 & 721 \\
\hline 11 & 57 & $1 / 18$ & $1 / 48$ & 0,0518 & 1026 & 2736 & 1100 \\
\hline 12 & 60 & $1 / 18$ & $1 / 4$ & 0.1399 & 1080 & 240 & 429 \\
\hline 13 & 55 & $1 / 18$ & $1 / 24$ & 0,0764 & 990 & 1320 & 720 \\
\hline 14 & 24 & $1 / 18$ & $1 / 24$ & 0,0452 & 432 & 576 & 531 \\
\hline 15 & 26 & $1 / 18$ & $1 / 12$ & 0,0513 & 468 & 312 & 506 \\
\hline 16 & 32 & $1 / 18$ & $1 / 24$ & 0,0324 & 576 & 768 & 989 \\
\hline 17 & 26 & $1 / 18$ & $1 / 48$ & 0.0350 & 468 & 1248 & 743 \\
\hline 18 & 51 & $1 / 18$ & $1 / 48$ & 0.0423 & 918 & 2448 & 1205 \\
\hline TOTAIS & 662 & 1 & 1 & 1.0000 & & & \\
\hline VARIÁNCIA & & & & & 119400,0000 & 669584,0000 & 65256,2974 \\
\hline MÉDIA & & & & & 662.00 & 1294.89 & 683,64 \\
\hline C.V. $(\%)$ & & & & & 52.20 & 63.19 & 37.37 \\
\hline
\end{tabular}

Tabela 47 - Mínimo de $15 \mathrm{~cm}$ de circunferência e 30 frutos/galho, árvore 10 .

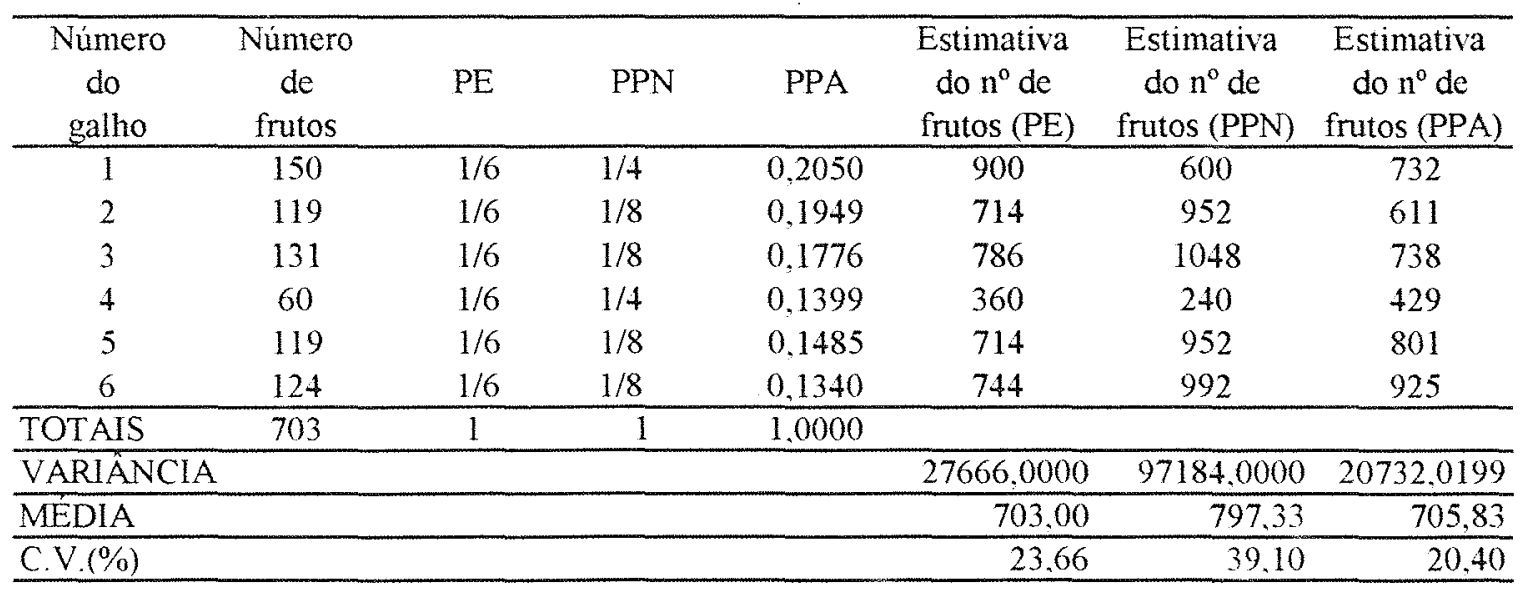


Tabela 48 - Mínimo de $20 \mathrm{~cm}$ de circunferência e 40 frutos/galho. árvore 10 .

\begin{tabular}{|c|c|c|c|c|c|c|c|}
\hline $\begin{array}{l}\text { Número } \\
\text { do } \\
\text { galho }\end{array}$ & $\begin{array}{c}\text { Número } \\
\text { de } \\
\text { frutos }\end{array}$ & PE & PPN & PPA & $\begin{array}{l}\text { Estimativa } \\
\text { do } n^{\circ} \text { de } \\
\text { frutos }(\mathrm{PE})\end{array}$ & $\begin{array}{l}\text { Estimativa } \\
\text { do } n^{\circ} \text { de } \\
\text { frutos (PPN) }\end{array}$ & $\begin{array}{l}\text { Estimativa } \\
\text { do } n^{\circ} \text { de } \\
\text { frutos (PPA) }\end{array}$ \\
\hline 1 & 150 & $1 / 4$ & $1 / 3$ & 0.2384 & 600 & 450 & 629 \\
\hline 2 & 119 & $1 / 4$ & $1 / 6$ & 0.2266 & 476 & 714 & 525 \\
\hline 3 & 131 & $1 / 4$ & $1 / 6$ & 0,2065 & 524 & 786 & 634 \\
\hline 4 & 303 & $1 / 4$ & $1 / 3$ & 0.3285 & 1212 & 909 & 922 \\
\hline TOTAIS & 703 & 1 & 1 & 1.0000 & & & \\
\hline \multicolumn{5}{|c|}{ VARIANCIA } & 88436,0000 & 36771,0000 & 25356.9470 \\
\hline \multicolumn{5}{|c|}{ MEDIA } & 703,00 & 714,75 & 677,78 \\
\hline \multicolumn{5}{|l|}{$\overline{C . V} .(\%)$} & 42,30 & 26.83 & 23,49 \\
\hline
\end{tabular}

Tabela 49 - Árvore 11.

\begin{tabular}{|c|c|c|c|c|c|c|c|}
\hline $\begin{array}{l}\text { Número } \\
\text { do } \\
\text { galho }\end{array}$ & $\begin{array}{c}\text { Número } \\
\text { de } \\
\text { frutos }\end{array}$ & $\mathrm{PE}$ & PPN & PPA & $\begin{array}{l}\text { Estimativa } \\
\text { do } n^{\circ} \text { de } \\
\text { frutos }(P E)\end{array}$ & $\begin{array}{c}\text { Estimativa } \\
\text { do } n^{\circ} \text { de } \\
\text { frutos (PPN) }\end{array}$ & $\begin{array}{c}\begin{array}{c}\text { Estimativa } \\
\text { do } n^{\circ} \text { de } \\
\text { frutos (PPA) }\end{array} \\
\end{array}$ \\
\hline 1 & 17 & $1 / 83$ & $1 / 24$ & 0,0379 & 1411 & 408 & 448 \\
\hline 2 & 9 & $1 / 83$ & $1 / 24$ & 0,0319 & 747 & 216 & 282 \\
\hline 3 & 12 & $1 / 83$ & $1 / 12$ & 0,0327 & 996 & 144 & 367 \\
\hline 4 & 9 & $1 / 83$ & $1 / 216$ & 0,0073 & 747 & 1944 & 1231 \\
\hline 5 & 15 & $1 / 83$ & $1 / 864$ & 0,0162 & 1245 & 12960 & 925 \\
\hline 6 & 6 & $1 / 83$ & $1 / 864$ & 0,0072 & 498 & 5184 & 832 \\
\hline 7 & 17 & $1 / 83$ & $1 / 1728$ & 0,0056 & 1411 & 29376 & 3032 \\
\hline 8 & 18 & $1 / 83$ & $1 / 1728$ & 0,0056 & 1494 & 31104 & 3210 \\
\hline 9 & 5 & $1 / 83$ & $1 / 1728$ & 0,0029 & 415 & 8640 & 1748 \\
\hline 10 & 7 & $1 / 83$ & $1 / 1728$ & 0,0056 & 581 & 12096 & 1248 \\
\hline 11 & 8 & $1 / 83$ & $1 / 216$ & 0,0073 & 664 & 1728 & 1095 \\
\hline 12 & 8 & $1 / 83$ & $1 / 72$ & 0,0064 & 664 & 576 & 1247 \\
\hline 13 & 18 & $1 / 83$ & $1 / 72$ & 0,0158 & 1494 & 1296 & 1136 \\
\hline 14 & 5 & $1 / 83$ & $1 / 96$ & 0,0041 & 415 & 480 & 1218 \\
\hline 15 & 10 & $1 / 83$ & $1 / 192$ & 0,0045 & 830 & 1920 & 2247 \\
\hline 16 & 9 & $1 / 83$ & $1 / 192$ & 0.0061 & 747 & 1728 & 1486 \\
\hline 17 & 10 & $1 / 83$ & $1 / 48$ & 0,0072 & 830 & 480 & 1397 \\
\hline 18 & 9 & $1 / 83$ & $1 / 24$ & 0.0191 & 747 & 216 & 472 \\
\hline 19 & 12 & $1 / 83$ & $1 / 48$ & 0.0128 & 996 & 576 & 936 \\
\hline 20 & 35 & $1 / 83$ & $1 / 384$ & 0.0151 & 2905 & 13440 & 2324 \\
\hline 21 & 12 & $1 / 83$ & $1 / 768$ & 0,0076 & 996 & 9216 & 1585 \\
\hline 22 & 21 & $1 / 83$ & $1 / 768$ & 0,0135 & 1743 & 16128 & 1560 \\
\hline 23 & 6 & $1 / 83$ & $1 / 384$ & 0,0047 & 498 & 2304 & 1265 \\
\hline 24 & 21 & $1 / 83$ & $1 / 384$ & 0.0164 & 1743 & 8064 & 1284 \\
\hline 25 & 19 & $1 / 83$ & $1 / 192$ & 0,0137 & 1577 & 3648 & 1383 \\
\hline 26 & 4 & $1 / 83$ & $1 / 384$ & 0,0069 & 332 & 1536 & 582 \\
\hline 27 & 11 & $1 / 83$ & $1 / 768$ & 0,0045 & 913 & 8448 & 2442 \\
\hline 28 & 19 & $1 / 83$ & $1 / 768$ & 0.0146 & 1577 & 14592 & 1302 \\
\hline 29 & 15 & $1 / 83$ & $1 / 18$ & 0.0397 & 1245 & 270 & 378 \\
\hline
\end{tabular}


Tabela 49 - Árvore 11 (continuação).

\begin{tabular}{|c|c|c|c|c|c|c|c|}
\hline $\begin{array}{l}\text { Número } \\
\text { do } \\
\text { galho }\end{array}$ & $\begin{array}{l}\text { Número } \\
\text { de } \\
\text { frutos }\end{array}$ & $\mathrm{PE}$ & PPN & PPA & $\begin{array}{l}\text { Estimativa } \\
\text { do } n^{\circ} \text { de } \\
\text { frutos (PE) }\end{array}$ & $\begin{array}{l}\text { Estimativa } \\
\text { do } n^{\circ} \text { de } \\
\text { frutos (PPN) }\end{array}$ & $\begin{array}{l}\text { Estimativa } \\
\text { do } n^{\circ} \text { de } \\
\text { frutos (PPA) }\end{array}$ \\
\hline 30 & 8 & $1 / 83$ & $1 / 36$ & 0.0250 & 664 & 288 & 320 \\
\hline 31 & 9 & $1 / 83$ & $1 / 36$ & 0,0198 & 747 & 324 & 455 \\
\hline 32 & 65 & $1 / 83$ & $1 / 18$ & 0,0560 & 5395 & 1170 & 1162 \\
\hline 33 & 26 & $1 / 83$ & $1 / 24$ & 0,0268 & 2158 & 624 & 969 \\
\hline 34 & 9 & $1 / 83$ & $1 / 48$ & 0,0112 & 747 & 432 & 801 \\
\hline 35 & 15 & $1 / 83$ & $1 / 1152$ & 0,0095 & 1245 & 17280 & 1581 \\
\hline 36 & 13 & $1 / 83$ & $1 / 1152$ & 0,0095 & 1079 & 14976 & 1370 \\
\hline 37 & 17 & $1 / 83$ & $1 / 576$ & 0,0091 & 1411 & 9792 & 1869 \\
\hline 38 & 9 & $1 / 83$ & $1 / 576$ & 0,0055 & 747 & 5184 & 1642 \\
\hline 39 & 12 & $1 / 83$ & $1 / 576$ & 0,0055 & 996 & 6912 & 2189 \\
\hline 40 & 7 & $1 / 83$ & $1 / 144$ & 0,0086 & 581 & 1008 & 810 \\
\hline 41 & 15 & $1 / 83$ & $1 / 144$ & 0,0135 & 1245 & 2160 & 1111 \\
\hline 42 & 25 & $1 / 83$ & $1 / 96$ & 0,0229 & 2075 & 2400 & 1093 \\
\hline 43 & 18 & $1 / 83$ & $1 / 96$ & 0.0135 & 1494 & 1728 & 1330 \\
\hline 44 & 6 & $1 / 83$ & $1 / 1152$ & 0,0046 & 498 & 6912 & 1298 \\
\hline 45 & 9 & $1 / 83$ & $1 / 1152$ & 0,0035 & 747 & 10368 & 2544 \\
\hline 46 & 20 & $1 / 83$ & $1 / 1152$ & 0,0108 & 1660 & 23040 & 1846 \\
\hline 47 & 10 & $1 / 83$ & $1 / 1152$ & 0.0075 & 830 & 11520 & 1329 \\
\hline 48 & 20 & $1 / 83$ & $1 / 288$ & 0,0124 & 1660 & 5760 & 1611 \\
\hline 49 & 19 & $1 / 83$ & $1 / 1152$ & 0,0045 & 1577 & 21888 & 4179 \\
\hline 50 & 7 & $1 / 83$ & $1 / 1152$ & 0,0058 & 581 & 8064 & 1217 \\
\hline 51 & 13 & $1 / 83$ & $1 / 576$ & 0,0085 & 1079 & 7488 & 1527 \\
\hline 52 & 5 & $1 / 83$ & $1 / 288$ & 0,0055 & 415 & 1440 & 917 \\
\hline 53 & 6 & $1 / 83$ & $1 / 576$ & 0,0035 & 498 & 3456 & 1706 \\
\hline 54 & 11 & $1 / 83$ & $1 / 576$ & 0,0051 & 913 & 6336 & 2172 \\
\hline 55 & 9 & $1 / 83$ & $1 / 288$ & 0.0070 & 747 & 2592 & 1295 \\
\hline 56 & 18 & $1 / 83$ & $1 / 96$ & 0,0145 & 1494 & 1728 & 1245 \\
\hline 57 & 6 & $1 / 83$ & $1 / 384$ & 0,0064 & 498 & 2304 & 938 \\
\hline 58 & 14 & $1 / 83$ & $1 / 384$ & 0,0106 & 1162 & 5376 & 1324 \\
\hline 59 & 14 & $1 / 83$ & $1 / 192$ & 0,0114 & 1162 & 2688 & 1232 \\
\hline 60 & 5 & $1 / 83$ & $1 / 96$ & 0,0132 & 415 & 480 & 380 \\
\hline 61 & 26 & $1 / 83$ & $1 / 192$ & 0,0177 & 2158 & 4992 & 1465 \\
\hline 62 & 9 & $1 / 83$ & $1 / 192$ & 0,0119 & 747 & 1728 & 758 \\
\hline 63 & 9 & $1 / 83$ & $1 / 30$ & 0,0219 & 747 & 270 & 411 \\
\hline 64 & 5 & $1 / 83$ & $1 / 30$ & 0,0105 & 415 & 150 & 477 \\
\hline 65 & 19 & $1 / 83$ & $1 / 30$ & 0.0299 & 1577 & 570 & 636 \\
\hline 66 & 12 & $1 / 83$ & $1 / 120$ & 0,0065 & 996 & 1440 & 1835 \\
\hline 67 & 11 & $1 / 83$ & $1 / 120$ & 0.0065 & 913 & 1320 & 1682 \\
\hline 68 & 12 & $1 / 83$ & $1 / 120$ & 0,0082 & 996 & 1440 & 1461 \\
\hline 69 & 10 & $1 / 83$ & $1 / 240$ & 0.0078 & 830 & 2400 & 1278 \\
\hline 70 & 20 & $1 / 83$ & $1 / 240$ & 0,0107 & 1660 & 4800 & 1877 \\
\hline 71 & 7 & $1 / 83$ & $1 / 60$ & 0.0136 & 581 & 420 & 514 \\
\hline 72 & 16 & $1 / 83$ & $1 / 120$ & 0,0119 & 1328 & 1920 & 1342 \\
\hline 73 & 8 & $1 / 83$ & $1 / 120$ & 0,0043 & 664 & 960 & 1864 \\
\hline
\end{tabular}


Tabela 49 - Árvore 11 (continuação).

\begin{tabular}{|c|c|c|c|c|c|c|c|}
\hline $\begin{array}{l}\text { Número } \\
\text { do } \\
\text { galho }\end{array}$ & $\begin{array}{l}\text { Número } \\
\text { de } \\
\text { frutos }\end{array}$ & $\mathrm{PE}$ & PPN & PPA & $\begin{array}{l}\text { Estimativa } \\
\text { do } n^{0} \text { de } \\
\text { frutos (PE) }\end{array}$ & $\begin{array}{l}\text { Estimativa } \\
\text { do } n^{\circ} \text { de } \\
\text { frutos ( } \mathrm{PPN} \text { ) }\end{array}$ & $\begin{array}{l}\text { Estimativa } \\
\text { do } n^{\circ} \text { de } \\
\text { frutos (PPA) }\end{array}$ \\
\hline 74 & 0 & $1 / 83$ & $1 / 60$ & 0,0063 & 830 & 600 & 1577 \\
\hline 75 & 8 & $1 / 83$ & $1 / 240$ & 0,0068 & 664 & 1920 & 1171 \\
\hline 76 & 9 & $1 / 83$ & $1 / 240$ & 0,0068 & 747 & 2160 & 1318 \\
\hline 77 & 7 & $1 / 83$ & $1 / 240$ & 0,0058 & 581 & 1680 & 1206 \\
\hline 78 & 6 & $1 / 83$ & $1 / 480$ & 0,0040 & 498 & 2880 & 1489 \\
\hline 79 & 6 & $1 / 83$ & $1 / 960$ & 0.0080 & 498 & 5760 & 747 \\
\hline 80 & 8 & $1 / 83$ & $1 / 1920$ & 0,0057 & 664 & 15360 & 1398 \\
\hline 81 & 24 & $1 / 83$ & $1 / 1920$ & 0,0095 & 1992 & 46080 & 2537 \\
\hline 82 & 19 & $1 / 83$ & $1 / 15$ & 0,0243 & 1577 & 285 & 781 \\
\hline 83 & 5 & $1 / 83$ & $1 / 15$ & 0,0174 & 415 & 75 & 287 \\
\hline TOTAIS & 1073 & 1 & 1 & 1.0000 & & & \\
\hline VARIANCIA & & & & & 368689,1928 & 4863916.8000 & 315046,3324 \\
\hline MÉDIA & & & & & 1073,00 & 5706,58 & 1328.16 \\
\hline C.V. $(\%)$ & & & & & 56,59 & 38,65 & 42.26 \\
\hline
\end{tabular}

Tabela 50 - Mínimo de $7 \mathrm{~cm}$ de circunferência e 10 frutos/galho, árvore 11.

\begin{tabular}{|c|c|c|c|c|c|c|c|}
\hline $\begin{array}{l}\text { Número } \\
\text { do } \\
\text { galho }\end{array}$ & $\begin{array}{l}\text { Número } \\
\text { de } \\
\text { frutos }\end{array}$ & PE & PPN & PPA & $\begin{array}{l}\text { Estimativa } \\
\text { do } n^{\circ} \text { de } \\
\text { frutos (PE) }\end{array}$ & $\begin{array}{c}\text { Estimativa } \\
\text { do } n^{\circ} \text { de } \\
\text { frutos (PPN) }\end{array}$ & $\begin{array}{l}\text { Estimativa } \\
\text { do } n^{\circ} \text { de } \\
\text { frutos (PPA) }\end{array}$ \\
\hline 1 & 26 & $1 / 48$ & $1 / 12$ & 0,0698 & 1248 & 312 & 373 \\
\hline 2 & 12 & $1 / 48$ & $1 / 12$ & 0,0327 & 576 & 144 & 367 \\
\hline 3 & 9 & $1 / 48$ & $1 / 96$ & 0,0091 & 432 & 864 & 989 \\
\hline 4 & 21 & $1 / 48$ & $1 / 192$ & 0,0292 & 1008 & 4032 & 720 \\
\hline 5 & 17 & $1 / 48$ & $1 / 576$ & 0,0082 & 816 & 9792 & 2081 \\
\hline 6 & 18 & $1 / 48$ & $1 / 576$ & 0,0082 & 864 & 10368 & 2204 \\
\hline 7 & 12 & $1 / 48$ & $1 / 576$ & 0,0082 & 576 & 6912 & 1469 \\
\hline 8 & 26 & $1 / 48$ & $1 / 48$ & 0,0172 & 1248 & 1248 & 1510 \\
\hline 9 & 24 & $1 / 48$ & $1 / 48$ & 0,0146 & 1152 & 1152 & 1643 \\
\hline 10 & 10 & $1 / 48$ & $1 / 48$ & 0,0072 & 480 & 480 & 1397 \\
\hline 11 & 12 & $1 / 48$ & $1 / 24$ & 0,0150 & 576 & 288 & 798 \\
\hline 12 & 35 & $1 / 48$ & $1 / 192$ & 0.0177 & 1680 & 6720 & 1980 \\
\hline 13 & 12 & $1 / 48$ & $1 / 384$ & 0,0089 & 576 & 4608 & 1350 \\
\hline 14 & 21 & $1 / 48$ & $1 / 384$ & 0.0158 & 1008 & 8064 & 1329 \\
\hline 15 & 27 & $1 / 48$ & $1 / 96$ & 0,0248 & 1296 & 2592 & 1090 \\
\hline 16 & 19 & $1 / 48$ & $1 / 96$ & 0,0161 & 912 & 1824 & 1178 \\
\hline 17 & 34 & $1 / 48$ & $1 / 96$ & 0,0305 & 1632 & 3264 & 1115 \\
\hline 18 & 15 & $1 / 48$ & $1 / 18$ & 0,0397 & 720 & 270 & 378 \\
\hline 19 & 17 & $1 / 48$ & $1 / 18$ & 0,0448 & 816 & 306 & 380 \\
\hline 20 & 65 & $1 / 48$ & $1 / 18$ & 0,0560 & 3120 & 1170 & 1162 \\
\hline 21 & 26 & $1 / 48$ & $1 / 24$ & 0,0268 & 1248 & 624 & 969 \\
\hline 22 & 15 & $1 / 48$ & $1 / 384$ & 0,0131 & 720 & 5760 & 1147 \\
\hline 23 & 13 & $1 / 48$ & $1 / 384$ & 0,0131 & 624 & 4992 & 994 \\
\hline
\end{tabular}


143.

Tabela 50 - Mínimo de $7 \mathrm{~cm}$ de circunferência e 10 frutos/galho, árvore 11 (continuação).

\begin{tabular}{|c|c|c|c|c|c|c|c|}
\hline $\begin{array}{l}\text { Número } \\
\text { do } \\
\text { galho }\end{array}$ & $\begin{array}{l}\text { Número } \\
\text { de } \\
\text { frutos }\end{array}$ & $\mathrm{PE}$ & PPN & PPA & $\begin{array}{l}\text { Estimativa } \\
\text { do } \mathrm{n}^{\circ} \text { de } \\
\text { frutos }(\mathrm{PE})\end{array}$ & $\begin{array}{l}\text { Estimativa } \\
\text { do } n^{\circ} \text { de } \\
\text { frutos (PPN) }\end{array}$ & $\begin{array}{l}\text { Estimativa } \\
\text { do } n^{\circ} \text { de } \\
\text { frutos (PPA) }\end{array}$ \\
\hline 24 & 17 & 118 & $1 / 192$ & 0,0125 & 816 & 3264 & 1356 \\
\hline 25 & 22 & $1 / 48$ & $1 / 96$ & 0,0151 & 1056 & 2112 & 1456 \\
\hline 26 & 22 & $1 / 48$ & $1 / 48$ & 0,0186 & 1056 & 1056 & 1182 \\
\hline 27 & 25 & $1 / 48$ & $1 / 96$ & 0,0229 & 1200 & 2400 & 1093 \\
\hline 28 & 18 & $1 / 48$ & $1 / 96$ & 0,0135 & 864 & 1728 & 1330 \\
\hline 29 & 15 & $1 / 48$ & $1 / 576$ & 0,0082 & 720 & 8640 & 1838 \\
\hline 30 & 20 & $1 / 48$ & $1 / 1152$ & 0,0108 & 960 & 23040 & 1846 \\
\hline 31 & 10 & $1 / 48$ & $1 / 1152$ & 0,0075 & 480 & 11520 & 1329 \\
\hline 32 & 20 & $1 / 48$ & $1 / 288$ & 0,0124 & 960 & 5760 & 1611 \\
\hline 33 & 26 & $1 / 48$ & $1 / 288$ & 0,0133 & 1248 & 7488 & 1957 \\
\hline 34 & 13 & $1 / 48$ & $1 / 288$ & 0,0110 & 624 & 3744 & 1184 \\
\hline 35 & 30 & $1 / 48$ & $1 / 144$ & 0,0155 & 1440 & 4320 & 1932 \\
\hline 36 & 18 & $1 / 48$ & $1 / 96$ & 0,0145 & 864 & 1728 & 1245 \\
\hline 37 & 20 & $1 / 48$ & $1 / 192$ & 0,0170 & 960 & 3840 & 1179 \\
\hline 38 & 14 & $1 / 48$ & $1 / 192$ & 0,0114 & 672 & 2688 & 1232 \\
\hline 39 & 40 & $1 / 48$ & $1 / 48$ & 0,0428 & 1920 & 1920 & 935 \\
\hline 40 & 14 & $1 / 48$ & $1 / 12$ & 0,0351 & 672 & 168 & 399 \\
\hline 41 & 19 & $1 / 48$ & $1 / 24$ & 0,0324 & 912 & 456 & 587 \\
\hline 42 & 23 & $1 / 48$ & $1 / 48$ & 0,0142 & 1104 & 1104 & 1623 \\
\hline 43 & 42 & $1 / 48$ & $1 / 48$ & 0,0289 & 2016 & 2016 & 1453 \\
\hline 44 & 31 & $1 / 48$ & $1 / 24$ & 0,0323 & 1488 & 744 & 959 \\
\hline 45 & 10 & $1 / 48$ & $1 / 48$ & 0.0069 & 480 & 480 & 1456 \\
\hline 46 & 17 & $1 / 48$ & $1 / 96$ & 0,0148 & 816 & 1632 & 1149 \\
\hline 47 & 53 & $1 / 48$ & $1 / 96$ & 0,0358 & 2544 & 5088 & 1480 \\
\hline 48 & 24 & $1 / 48$ & $1 / 12$ & 0.0263 & 1152 & 288 & 911 \\
\hline TOTAIS & 1049 & & & 1.0000 & & & \\
\hline MEDIA & & & & & 227013,0000 & 2525526,0000 & 230543,4167 \\
\hline VARIANCIA & & & & & 1049.00 & 3604,38 & 1236,40 \\
\hline C.V. $(\%)$ & & & & & 45.42 & 44,09 & 38,83 \\
\hline
\end{tabular}

Tabela 51 - Mínimo de $10 \mathrm{~cm}$ de circunferência e 20 frutos/galho, árvore 11.

\begin{tabular}{cccccccc}
\hline $\begin{array}{c}\text { Número } \\
\text { do } \\
\text { galho }\end{array}$ & $\begin{array}{c}\text { Número } \\
\text { de } \\
\text { frutos }\end{array}$ & PE & PPN & PPA & $\begin{array}{c}\text { Estimativa } \\
\text { do } \mathrm{n}^{\circ} \text { de } \\
\text { frutos (PE) }\end{array}$ & $\begin{array}{c}\text { Estimativa } \\
\text { do } \mathrm{n}^{\circ} \text { de } \\
\text { frutos (PPN) }\end{array}$ & $\begin{array}{c}\text { Estimativa } \\
\text { do } \mathrm{n}^{\circ} \text { de } \\
\text { frutos (PPA) }\end{array}$ \\
\hline 1 & 40 & $1 / 25$ & $1 / 6$ & 0,1025 & 1000 & 240 & 390 \\
2 & 21 & $1 / 25$ & $1 / 96$ & 0,0341 & 525 & 2016 & 616 \\
3 & 52 & $1 / 25$ & $1 / 96$ & 0,0287 & 1300 & 4992 & 1815 \\
4 & 26 & $1 / 25$ & $1 / 48$ & 0,0172 & 650 & 1248 & 1510 \\
5 & 34 & $1 / 25$ & $1 / 24$ & 0,0218 & 850 & 816 & 1562 \\
6 & 35 & $1 / 25$ & $1 / 96$ & 0,0200 & 875 & 3360 & 1749 \\
7 & 32 & $1 / 25$ & $1 / 96$ & 0,0279 & 800 & 3072 & 1145 \\
8 & 27 & $1 / 25$ & $1 / 48$ & 0,0280 & 675 & 1296 & 963 \\
9 & 54 & $1 / 25$ & $1 / 24$ & 0,0528 & 1350 & 1296 & 1023
\end{tabular}


Tabela 51 - Mínimo de $10 \mathrm{~cm}$ de circunferência e 20 frutos/galho, árvore 11 (continuação).

\begin{tabular}{|c|c|c|c|c|c|c|c|}
\hline $\begin{array}{l}\text { Número } \\
\text { do } \\
\text { galho }\end{array}$ & $\begin{array}{l}\text { Número } \\
\text { de } \\
\text { frutos }\end{array}$ & PE & PPN & PPA & $\begin{array}{l}\text { Estimativa } \\
\text { do } n^{\circ} \text { de } \\
\text { frutos (PE) }\end{array}$ & $\begin{array}{l}\text { Estimativa } \\
\text { do } n^{\circ} \text { de } \\
\text { frutos (PPN) }\end{array}$ & $\begin{array}{l}\text { Estimativa } \\
\text { do } n^{\circ} \text { de } \\
\text { frutos (PPA) }\end{array}$ \\
\hline 10 & 97 & $1 / 25$ & $1 / 6$ & 0,1294 & 2425 & 582 & 691 \\
\hline 11 & 26 & $1 / 25$ & $1 / 24$ & 0,0268 & 650 & 624 & 969 \\
\hline 12 & 70 & $1 / 25$ & $1 / 48$ & 0,0538 & 1750 & 3360 & 1301 \\
\hline 13 & 45 & $1 / 25$ & $1 / 96$ & 0,0134 & 1125 & 4320 & 3361 \\
\hline 14 & 22 & $1 / 25$ & $1 / 96$ & 0,0052 & 550 & 2112 & 4207 \\
\hline 15 & 43 & $1 / 25$ & $1 / 48$ & 0,0364 & 1075 & 2064 & 1181 \\
\hline 16 & 51 & $1 / 25$ & $1 / 288$ & 0,0265 & 1275 & 14688 & 1923 \\
\hline 17 & 20 & $1 / 25$ & $1 / 288$ & 0,0124 & 500 & 5760 & 1611 \\
\hline 18 & 46 & $1 / 25$ & $1 / 144$ & 0,0243 & 1150 & 6624 & 1896 \\
\hline 19 & 30 & $1 / 25$ & $1 / 144$ & 0.0155 & 750 & 4320 & 1932 \\
\hline 20 & 52 & $1 / 25$ & $1 / 48$ & 0,0428 & 1300 & 2496 & 1215 \\
\hline 21 & 40 & $1 / 25$ & $1 / 48$ & 0,0428 & 1000 & 1920 & 935 \\
\hline 22 & 103 & $1 / 25$ & $1 / 9$ & 0,0893 & 2575 & 927 & 1154 \\
\hline 23 & 31 & $1 / 25$ & $1 / 18$ & 0,0382 & 775 & 558 & 811 \\
\hline 24 & 85 & $1 / 25$ & $1 / 18$ & 0,0680 & 2125 & 1530 & 1250 \\
\hline 25 & 24 & $1 / 25$ & $1 / 9$ & 0.0312 & 600 & 216 & 770 \\
\hline TOTAIS & 1106 & 1 & 1 & 1.0000 & & & \\
\hline VARIANCIA & & & & & 314670.0000 & 1860303,0000 & 294067.8172 \\
\hline MEDIA & & & & & 1106.00 & 2817.48 & 1439.18 \\
\hline C.V. $(\%)$ & & & & & 50.72 & 48.41 & 37.68 \\
\hline
\end{tabular}

Tabela 52 - Mínimo de $15 \mathrm{~cm}$ de circunferência e 30 frutos/galho, árvore 11.

\begin{tabular}{|c|c|c|c|c|c|c|c|}
\hline $\begin{array}{l}\text { Número } \\
\text { do } \\
\text { galho }\end{array}$ & $\begin{array}{l}\text { Número } \\
\text { de } \\
\text { frutos }\end{array}$ & $\mathrm{PE}$ & PPN & PPA & $\begin{array}{l}\text { Estimativa } \\
\text { do } n^{\circ} \text { de } \\
\text { frutos (PE) }\end{array}$ & $\begin{array}{l}\text { Estimativa } \\
\text { do } n^{\circ} \text { de } \\
\text { frutos (PPN) }\end{array}$ & $\begin{array}{l}\text { Estimativa } \\
\text { do } n^{\circ} \text { de } \\
\text { frutos (PPA) }\end{array}$ \\
\hline 1 & 40 & $1 / 14$ & $1 / 6$ & 0,1025 & 560 & 240 & 390 \\
\hline 2 & 150 & $1 / 14$ & $1 / 12$ & 0,1018 & 2100 & 1800 & 1474 \\
\hline 3 & 94 & $1 / 14$ & $1 / 24$ & 0,0760 & 1316 & 2256 & 1237 \\
\hline 4 & 54 & $1 / 14$ & $1 / 24$ & 0,0528 & 756 & 1296 & 1023 \\
\hline 5 & 97 & $1 / 14$ & $1 / 6$ & 0,1404 & 1358 & 582 & 691 \\
\hline 6 & 127 & $1 / 14$ & $1 / 18$ & 0,0795 & 1778 & 2286 & 1597 \\
\hline 7 & 43 & $1 / 14$ & $1 / 36$ & 0,0400 & 602 & 1548 & 1075 \\
\hline 8 & 71 & $1 / 14$ & $1 / 72$ & 0,0533 & 994 & 5112 & 1333 \\
\hline 9 & 76 & $1 / 14$ & $1 / 72$ & 0,0332 & 1064 & 5472 & 2289 \\
\hline 10 & 52 & $1 / 14$ & $1 / 36$ & 0,0470 & 728 & 1872 & 1107 \\
\hline 11 & 40 & $1 / 14$ & $1 / 36$ & 0.0470 & 560 & 1440 & 851 \\
\hline 12 & 103 & $1 / 14$ & $1 / 6$ & 0,1035 & 1442 & 618 & 995 \\
\hline 13 & 31 & $1 / 14$ & $1 / 12$ & 0.0443 & 434 & 372 & 699 \\
\hline 14 & 85 & $1 / 14$ & $1 / 12$ & 0.0788 & 1190 & 1020 & 1078 \\
\hline TOTAIS & 1063 & 1 & 1 & 1.0000 & & & \\
\hline VARIÂNCIA & & & & & 233682,0000 & 944154,0000 & 173891.0324 \\
\hline MEDIA & & & & & 1063.00 & 1851,00 & 1131.48 \\
\hline C.V. $(\%)$ & & & & & 45,48 & 52.49 & 36,85 \\
\hline
\end{tabular}


Tabela 53 - Mínimo de $20 \mathrm{~cm}$ de circunferência e 40 frutos/galho, árvore 11 .

\begin{tabular}{|c|c|c|c|c|c|c|c|}
\hline $\begin{array}{l}\text { Número } \\
\text { do } \\
\text { galho }\end{array}$ & $\begin{array}{c}\text { Número } \\
\text { de } \\
\text { frutos }\end{array}$ & PE & PPN & PPA & $\begin{array}{l}\text { Estimativa } \\
\text { do } n^{\circ} \text { le } \\
\text { frutos }(\mathrm{PE})\end{array}$ & $\begin{array}{l}\text { Estimativa } \\
\text { do } n^{\circ} \text { de } \\
\text { frutos (PPN) } \\
\end{array}$ & $\begin{array}{l}\text { Estimativa } \\
\text { do } n^{\circ} \text { de } \\
\text { frutos (PPA) }\end{array}$ \\
\hline 1 & 40 & $1 / 9$ & $1 / 6$ & 0.1025 & 360 & 240 & 390 \\
\hline 2 & 150 & $1 / 9$ & $1 / 12$ & 0,1018 & 1350 & 1800 & 1474 \\
\hline 3 & 173 & $1 / 9$ & $1 / 12$ & 0,1288 & 1557 & 2076 & 1343 \\
\hline 4 & 97 & $1 / 9$ & $1 / 6$ & 0,1404 & 873 & 582 & 691 \\
\hline 5 & 127 & $1 / 9$ & $1 / 18$ & 0,0795 & 1143 & 2286 & 1597 \\
\hline 6 & 190 & $1 / 9$ & $1 / 18$ & 0,1264 & 1710 & 3420 & 1503 \\
\hline 7 & 92 & $1 / 9$ & $1 / 18$ & 0,0940 & 828 & 1656 & 979 \\
\hline 8 & 103 & $1 / 9$ & $1 / 6$ & 0,1035 & 927 & 618 & 995 \\
\hline 9 & 140 & $1 / 9$ & $1 / 6$ & 0,1232 & 1260 & 840 & 1137 \\
\hline TOTAIS & 1112 & 1 & 1 & 1.0000 & & & \\
\hline \multicolumn{5}{|c|}{ VARIÁNCIA } & 152616.0000 & 732486,0000 & 139735.6164 \\
\hline \multicolumn{5}{|c|}{ MÉDIA } & 1112.00 & 1502,00 & 1123,25 \\
\hline \multicolumn{5}{|l|}{$\overline{C . V .(\%)}$} & 35,13 & 56.98 & 33,28 \\
\hline
\end{tabular}

Tabela 54 - Mínimo de $25 \mathrm{~cm}$ de circunferência e 50 frutos/galho, árvore 11.

\begin{tabular}{|c|c|c|c|c|c|c|c|}
\hline $\begin{array}{l}\text { Número } \\
\text { do } \\
\text { galho }\end{array}$ & $\begin{array}{l}\text { Numero } \\
\text { de } \\
\text { frutos }\end{array}$ & $\mathrm{PE}$ & PPN & PPA & $\begin{array}{l}\text { Estimativa } \\
\text { do } \mathrm{n}^{\circ} \text { de } \\
\text { frutos }(\mathrm{PE})\end{array}$ & $\begin{array}{l}\text { Estimativa } \\
\text { do } \mathrm{n}^{\circ} \mathrm{de} \\
\text { frutos (PPN) }\end{array}$ & $\begin{array}{l}\text { Estimativa } \\
\text { do } \mathrm{n}^{\circ} \text { de } \\
\text { frutos (PPA) }\end{array}$ \\
\hline 1 & 373 & $1 / 5$ & $1 / 3$ & 0,3330 & 1865 & 1119 & 1120 \\
\hline 2 & 97 & $1 / 5$ & $1 / 6$ & 0,1404 & 485 & 582 & 691 \\
\hline 3 & 317 & $1 / 5$ & $1 / 12$ & 0,1721 & 1585 & 3804 & 1842 \\
\hline 4 & 92 & $1 / 5$ & $1 / 12$ & 0,1279 & 460 & 1104 & 719 \\
\hline 5 & 243 & $1 / 5$ & $1 / 3$ & 0,2266 & 1215 & 729 & 1072 \\
\hline TOTAIS & 1122 & 1 & 1 & 1.0000 & & & \\
\hline \multicolumn{5}{|c|}{ VARIÂNCIA } & 323816,0000 & 699540,0000 & 136659,5762 \\
\hline \multicolumn{5}{|l|}{ MEDIA } & 1122,00 & 1467.60 & 1088,96 \\
\hline \multicolumn{5}{|l|}{ C.V. $(\%)$} & 50.72 & 56.99 & 33.95 \\
\hline
\end{tabular}


Tabela 55 - Árvore 12.

\begin{tabular}{|c|c|c|c|c|c|c|c|}
\hline $\begin{array}{l}\text { Número } \\
\text { do } \\
\text { galho }\end{array}$ & $\begin{array}{l}\text { Número } \\
\text { de } \\
\text { frutos }\end{array}$ & $\mathrm{PE}$ & PPN & PPA & $\begin{array}{l}\text { Estimativa } \\
\text { do } n^{\circ} \text { de } \\
\text { frutos (PE) }\end{array}$ & $\begin{array}{l}\text { Estimativa } \\
\text { do } n^{\circ} \text { de } \\
\text { frutos (PPN) }\end{array}$ & $\begin{array}{l}\text { Estimativa } \\
\text { do } \mathfrak{n}^{0} \text { de } \\
\text { frutos (PPA) }\end{array}$ \\
\hline 1 & 32 & $1 / 42$ & $1 / 36$ & 0.1285 & 1344 & 1152 & 1122 \\
\hline 2 & 9 & $1 / 42$ & $1 / 72$ & 0,0137 & 378 & 648 & 657 \\
\hline 3 & 10 & $1 / 42$ & $1 / 72$ & 0,0067 & 420 & 720 & 1489 \\
\hline 4 & 7 & $1 / 42$ & $1 / 36$ & 0,0205 & 294 & 252 & 341 \\
\hline 5 & 9 & $1 / 42$ & $1 / 72$ & 0,0174 & 378 & 648 & 519 \\
\hline 6 & 28 & $1 / 42$ & $1 / 72$ & 0,0174 & 1176 & 2016 & 1614 \\
\hline 7 & 7 & $1 / 42$ & $1 / 144$ & 0,0155 & 294 & 1008 & 450 \\
\hline 8 & 63 & $1 / 42$ & $1 / 144$ & 0,0263 & 2646 & 9072 & 2399 \\
\hline 9 & 60 & $1 / 42$ & $1 / 72$ & 0,0469 & 2520 & 4320 & 1280 \\
\hline 10 & 9 & $1 / 42$ & $1 / 36$ & 0,0154 & 378 & 324 & 585 \\
\hline 11 & 25 & $1 / 42$ & $1 / 36$ & 0,0490 & 1050 & 900 & 510 \\
\hline 12 & 9 & $1 / 42$ & $1 / 36$ & 0,0176 & 378 & 324 & 510 \\
\hline 13 & 9 & $1 / 42$ & $1 / 9$ & 0,0427 & 378 & 81 & 211 \\
\hline 14 & 45 & $1 / 42$ & $1 / 12$ & 0,0660 & 1890 & 540 & 682 \\
\hline 15 & 16 & $1 / 42$ & $1 / 12$ & 0,0448 & 672 & 192 & 357 \\
\hline 16 & 4 & $1 / 42$ & $1 / 144$ & 0,0106 & 168 & 576 & 378 \\
\hline 17 & 26 & $1 / 42$ & $1 / 144$ & 0,0131 & 1092 & 3744 & 1991 \\
\hline 18 & 19 & $1 / 42$ & $1 / 144$ & 0,0131 & 798 & 2736 & 1455 \\
\hline 19 & 5 & $1 / 42$ & $1 / 144$ & 0,0084 & 210 & 720 & 598 \\
\hline 20 & 10 & $1 / 42$ & $1 / 36$ & 0,0306 & 420 & 360 & 327 \\
\hline 21 & 4 & $1 / 42$ & $1 / 36$ & 0,0056 & 168 & 144 & 713 \\
\hline 22 & 9 & $1 / 42$ & $1 / 24$ & 0,0347 & 378 & 216 & 259 \\
\hline 23 & 15 & $1 / 42$ & $1 / 72$ & 0,0193 & 630 & 1080 & 778 \\
\hline 24 & 64 & $1 / 42$ & $1 / 288$ & 0,0141 & 2688 & 18432 & 4526 \\
\hline 25 & 15 & $1 / 42$ & $1 / 288$ & 0,0141 & 630 & 4320 & 1061 \\
\hline 26 & 8 & $1 / 42$ & $1 / 288$ & 0,0069 & 336 & 2304 & 1155 \\
\hline 27 & 19 & $1 / 42$ & $1 / 288$ & 0.0141 & 798 & 5472 & 1344 \\
\hline 28 & 23 & $1 / 42$ & $1 / 72$ & 0.0378 & 966 & 1656 & 609 \\
\hline 29 & 25 & $1 / 42$ & $1 / 18$ & 0,0427 & 1050 & 450 & 586 \\
\hline 30 & 18 & $1 / 42$ & $1 / 36$ & 0,0204 & 756 & 648 & 882 \\
\hline 31 & 47 & $1 / 42$ & $1 / 36$ & 0,0278 & 1974 & 1692 & 1692 \\
\hline 32 & 45 & $1 / 42$ & $1 / 18$ & 0.0375 & 1890 & 810 & 1199 \\
\hline 33 & 17 & $1 / 42$ & $1 / 72$ & 0,0155 & 714 & 1224 & 1098 \\
\hline 34 & 17 & $1 / 42$ & $1 / 72$ & 0,0155 & 714 & 1224 & 1098 \\
\hline 35 & 24 & $1 / 42$ & $1 / 144$ & 0,0230 & 1008 & 3456 & 1045 \\
\hline 36 & 21 & $1 / 42$ & $1 / 144$ & 0,0136 & 882 & 3024 & 1545 \\
\hline 37 & 26 & $1 / 42$ & $1 / 72$ & 0,0241 & 1092 & 1872 & 1077 \\
\hline 38 & 10 & $1 / 42$ & $1 / 18$ & 0,0273 & 420 & 180 & 367 \\
\hline 39 & 62 & $1 / 42$ & $1 / 108$ & 0,0437 & 2604 & 6696 & 1418 \\
\hline 40 & 38 & $1 / 42$ & $1 / 108$ & 0,0310 & 1596 & 4104 & 1225 \\
\hline 41 & 4 & $1 / 42$ & $1 / 108$ & 0,0121 & 168 & 432 & 330 \\
\hline 42 & 25 & $1 / 42$ & $1 / 36$ & 0.0151 & 1050 & 900 & 1658 \\
\hline TOTAIS & 938 & 1 & 1 & 1.0000 & & & \\
\hline \multicolumn{5}{|c|}{ VARIANCIA } & 513968.0000 & 2685329,0000 & 448699.9724 \\
\hline \multicolumn{5}{|c|}{ MEDIA } & 938.00 & 2158,79 & 1027,10 \\
\hline \multicolumn{5}{|l|}{ C.V. $(\%)$} & 76.43 & 75.91 & 65.22 \\
\hline
\end{tabular}


Tabela 56 - Mínimo de $7 \mathrm{~cm}$ de circunferência e 10 frutos/galho, árore 12.

\begin{tabular}{|c|c|c|c|c|c|c|c|}
\hline $\begin{array}{l}\text { Número } \\
\text { do } \\
\text { galho }\end{array}$ & $\begin{array}{c}\text { Número } \\
\text { de } \\
\text { frutos }\end{array}$ & $\mathrm{PE}$ & PPN & PPA & $\begin{array}{l}\text { Estimativa } \\
\text { do } n^{\circ} \text { de } \\
\text { frutos (PE) }\end{array}$ & $\begin{array}{l}\text { Estimativa } \\
\text { do } n^{\circ} \text { de } \\
\text { frutos (PPN) }\end{array}$ & $\begin{array}{l}\text { Estimativa } \\
\text { do } n^{\circ} \text { de } \\
\text { frutos (PPA) }\end{array}$ \\
\hline 1 & 32 & $1 / 29$ & $1 / 24$ & 0,0638 & 928 & 76 & 501 \\
\hline 2 & 19 & $1 / 29$ & $1 / 24$ & 0,0329 & 551 & 456 & 577 \\
\hline 3 & 48 & $1 / 29$ & $1 / 12$ & 0,0236 & 1392 & 576 & 2035 \\
\hline 4 & 80 & $1 / 29$ & $1 / 24$ & 0.0567 & 2320 & 1920 & 1411 \\
\hline 5 & 60 & $1 / 29$ & $1 / 24$ & 0,0635 & 1740 & 1440 & 944 \\
\hline 6 & 36 & $1 / 29$ & $1 / 12$ & 0,0769 & 1044 & 432 & 468 \\
\hline 7 & 45 & $1 / 29$ & $1 / 12$ & 0,0660 & 1305 & 540 & 682 \\
\hline 8 & 16 & $1 / 29$ & $1 / 12$ & 0,0448 & 464 & 192 & 357 \\
\hline 9 & 30 & $1 / 29$ & $1 / 48$ & 0,0242 & 870 & 1440 & 1239 \\
\hline 10 & 24 & $1 / 29$ & $1 / 48$ & 0,0242 & 696 & 1152 & 992 \\
\hline 11 & 14 & $1 / 29$ & $1 / 24$ & 0,0328 & 406 & 336 & 426 \\
\hline 12 & 15 & $1 / 29$ & $1 / 36$ & 0.0256 & 435 & 540 & 587 \\
\hline 13 & 64 & $1 / 29$ & $1 / 108$ & 0,0218 & 1856 & 6912 & 2933 \\
\hline 14 & 23 & $1 / 29$ & $1 / 108$ & 0,0218 & 667 & 2484 & 1054 \\
\hline 15 & 19 & $1 / 29$ & $1 / 108$ & 0,0218 & 551 & 2052 & 871 \\
\hline 16 & 23 & $1 / 29$ & $1 / 36$ & 0,0501 & 667 & 828 & 459 \\
\hline 17 & 25 & $1 / 29$ & $1 / 18$ & 0,0427 & 725 & 450 & 586 \\
\hline 18 & 18 & $1 / 29$ & $1 / 36$ & 0.0204 & 522 & 648 & 882 \\
\hline 19 & 47 & $1 / 29$ & $1 / 36$ & 0,0278 & 1363 & 1692 & 1692 \\
\hline 20 & 45 & $1 / 29$ & $1 / 18$ & 0,0375 & 1305 & 810 & 1199 \\
\hline 21 & 17 & $1 / 29$ & $1 / 72$ & 0,0155 & 493 & 1224 & 1098 \\
\hline 22 & 17 & $1 / 29$ & $1 / 72$ & 0,0155 & 493 & 1224 & 1098 \\
\hline 23 & 24 & $1 / 29$ & $1 / 144$ & 0,0230 & 696 & 3456 & 1045 \\
\hline 24 & 21 & $1 / 29$ & $1 / 144$ & 0,0136 & 609 & 3024 & 1545 \\
\hline 25 & 26 & $1 / 29$ & $1 / 72$ & 0,0241 & 754 & 1872 & 1077 \\
\hline 26 & 10 & $1 / 29$ & $1 / 18$ & 0,0273 & 290 & 180 & 367 \\
\hline 27 & 62 & $1 / 29$ & $1 / 72$ & 0,0508 & 1798 & 4464 & 1220 \\
\hline 28 & 42 & $1 / 29$ & $1 / 72$ & 0,0360 & 1218 & 3024 & 1166 \\
\hline 29 & 25 & $1 / 29$ & $1 / 36$ & 0.0151 & 725 & 900 & 1658 \\
\hline TOTAIS & 927 & 1 & 1 & 1.0000 & & & \\
\hline VARIÁNCIA & & & & & 258965,0000 & 932176.0000 & 262320,5046 \\
\hline MEDIA & & & & & 927,00 & 1552,97 & 1040.29 \\
\hline C.V. $(\%)$ & & & & & 54,90 & 62,17 & 49.23 \\
\hline
\end{tabular}

Tabela 57 - Mínimo de $10 \mathrm{~cm}$ de circunferência e 20 frutos/galho, árvore 12.

\begin{tabular}{cccccccc}
\hline $\begin{array}{c}\text { Número } \\
\text { do } \\
\text { galho }\end{array}$ & $\begin{array}{c}\text { Número } \\
\text { de } \\
\text { frutos }\end{array}$ & PE & PPN & PPA & $\begin{array}{c}\text { Estimativa } \\
\text { do } n^{\circ} \text { de } \\
\text { frutos (PE) }\end{array}$ & $\begin{array}{c}\text { Estimativa } \\
\text { do }{ }^{\circ} \text { de } \\
\text { frutos (PPN) }\end{array}$ & $\begin{array}{c}\text { Estimativa } \\
\text { do } n^{\circ} \text { de } \\
\text { frutos (PPA) }\end{array}$ \\
\hline 1 & 32 & $1 / 22$ & $1 / 24$ & 0,0638 & 704 & 768 & 501 \\
2 & 19 & $1 / 22$ & $1 / 24$ & 0,0329 & 418 & 456 & 577 \\
3 & 48 & $1 / 22$ & $1 / 12$ & 0,0236 & 1056 & 576 & 2035 \\
4 & 80 & $1 / 22$ & $1 / 24$ & 0,0567 & 1760 & 1920 & 1411 \\
5 & 60 & $1 / 22$ & $1 / 24$ & 0,0635 & 1320 & 1440 & 944
\end{tabular}


Tabela 57 - Mínimo de $10 \mathrm{~cm}$ de circunferência e 20 frutos/galho, árvore 12 (continuação).

\begin{tabular}{|c|c|c|c|c|c|c|c|}
\hline $\begin{array}{l}\text { Número } \\
\text { do } \\
\text { galho }\end{array}$ & $\begin{array}{l}\text { Número } \\
\text { de } \\
\text { frutos }\end{array}$ & $\mathrm{PE}$ & PPN & PPA & $\begin{array}{l}\text { Estimativa } \\
\text { do } \mathrm{n}^{\circ} \mathrm{de} \\
\text { frutos (PE) }\end{array}$ & $\begin{array}{l}\text { Estimativa } \\
\text { do } n^{\circ} \text { de } \\
\text { frutos (PPN) }\end{array}$ & $\begin{array}{l}\text { Estimativa } \\
\text { do } n^{\circ} \text { de } \\
\text { frutos (PPA) }\end{array}$ \\
\hline 6 & 36 & $1 / 22$ & $1 / 12$ & 0,0769 & 792 & 432 & 468 \\
\hline 7 & 67 & $1 / 22$ & $1 / 6$ & 0,1108 & 1474 & 402 & 605 \\
\hline 8 & 30 & $1 / 22$ & $1 / 24$ & 0,0406 & 660 & 720 & 739 \\
\hline 9 & 24 & $1 / 22$ & $1 / 24$ & 0.0406 & 528 & 576 & 591 \\
\hline 10 & 15 & $1 / 22$ & $1 / 36$ & 0,0256 & 330 & 540 & 587 \\
\hline 11 & 64 & $1 / 22$ & $1 / 72$ & 0,0327 & 1408 & 4608 & 1955 \\
\hline 12 & 42 & $1 / 22$ & $1 / 72$ & 0,0327 & 924 & 3024 & 1283 \\
\hline 13 & 23 & $1 / 22$ & $1 / 36$ & 0,0501 & 506 & 828 & 459 \\
\hline 14 & 25 & $1 / 22$ & $1 / 18$ & 0,0427 & 550 & 450 & 586 \\
\hline 15 & 65 & $1 / 22$ & $1 / 18$ & 0,0482 & 1430 & 1170 & 1349 \\
\hline 16 & 45 & $1 / 22$ & $1 / 18$ & 0,0375 & 990 & 810 & 1199 \\
\hline 17 & 35 & $1 / 22$ & $1 / 36$ & 0,0310 & 770 & 1260 & 1130 \\
\hline 18 & 24 & $1 / 22$ & $1 / 144$ & 0,0230 & 528 & 3456 & 1045 \\
\hline 19 & 21 & $1 / 22$ & $1 / 144$ & 0,0136 & 462 & 3024 & 1545 \\
\hline 20 & 26 & $1 / 22$ & $1 / 72$ & 0,0241 & 572 & 1872 & 1077 \\
\hline 21 & 104 & $1 / 22$ & $1 / 18$ & 0.1101 & 2288 & 1872 & 945 \\
\hline 22 & 25 & $1 / 22$ & $1 / 18$ & 0,0191 & 550 & 450 & 1308 \\
\hline TOTAIS & 910 & 1 & 1 & 1.0000 & & & \\
\hline VARIÁNCIA & & & & & 250356,0000 & 573570,0000 & $175+33,5019$ \\
\hline MEDIA & & & & & 910.00 & 1393,36 & 1015,39 \\
\hline C.V. $(\%)$ & & & & & 54.98 & 54,35 & 41.25 \\
\hline
\end{tabular}

Tabela 58 - Mínimo de $15 \mathrm{~cm}$ de circunferência e 30 frutos/galho, árvore 12.

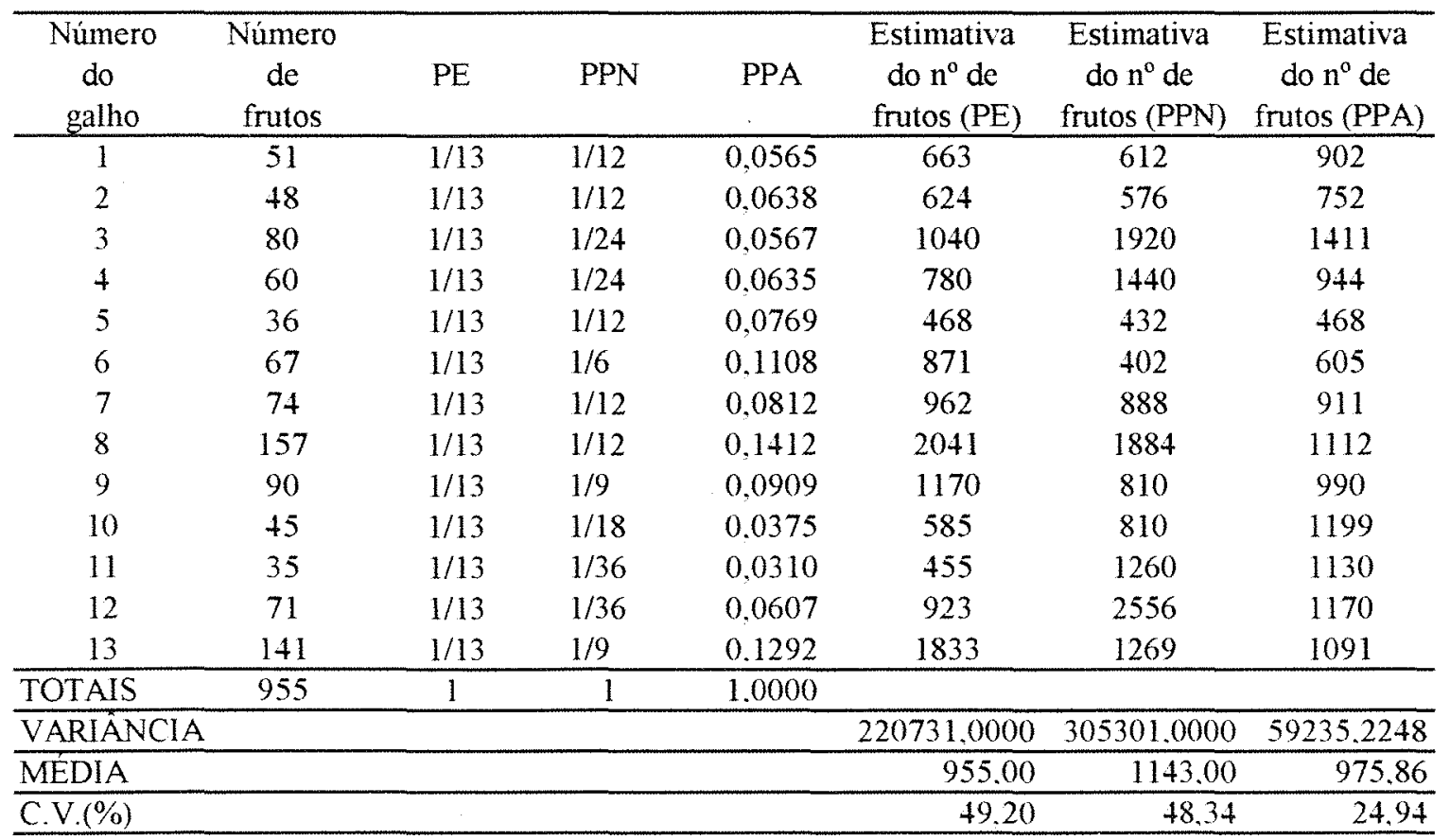


Tabela 59 - Mínimo de $20 \mathrm{~cm}$ de circunferência e 40 frutos/galho. árvore 12.

\begin{tabular}{|c|c|c|c|c|c|c|c|}
\hline $\begin{array}{c}\text { Número } \\
\text { do } \\
\text { galho }\end{array}$ & $\begin{array}{c}\text { Número } \\
\text { de } \\
\text { frutos }\end{array}$ & PE & PPN & PPA & $\begin{array}{c}\text { Estimativa } \\
\text { do } n^{\circ} \text { de } \\
\text { frutos (PE) }\end{array}$ & $\begin{array}{l}\text { Estimativa } \\
\text { do } n^{\circ} \mathrm{de} \\
\text { frutos (PPN) }\end{array}$ & $\begin{array}{l}\text { Estimativa } \\
\text { do } n^{\circ} \text { de } \\
\text { frutos (PPA) }\end{array}$ \\
\hline 1 & 99 & $1 / 8$ & $1 / 6$ & 0,1203 & 792 & 594 & 823 \\
\hline 2 & 197 & $1 / 8$ & $1 / 6$ & 0,1972 & 1576 & 1182 & 999 \\
\hline 3 & 67 & $1 / 8$ & $1 / 6$ & 0,1108 & 536 & 402 & 605 \\
\hline 4 & 74 & $1 / 8$ & $1 / 12$ & 0,0812 & 592 & 888 & 911 \\
\hline 5 & 157 & $1 / 8$ & $1 / 12$ & 0,1412 & 1256 & 1884 & 1112 \\
\hline 6 & 90 & $1 / 8$ & $1 / 9$ & 0,0909 & 720 & 810 & 990 \\
\hline 7 & 152 & $1 / 8$ & $1 / 9$ & 0,1292 & 1216 & 1368 & 1177 \\
\hline 8 & 141 & $1 / 8$ & $1 / 9$ & 0,1292 & 1128 & 1269 & 1091 \\
\hline TOTAIS & 977 & 1 & 1 & 1.0000 & & & \\
\hline \multicolumn{5}{|c|}{ VARIÂNCIA } & 119952.0000 & 185339,0000 & 28126,5848 \\
\hline \multicolumn{5}{|c|}{ MEDIA } & 977.00 & 1049,63 & 963,47 \\
\hline \multicolumn{5}{|l|}{ C.V. $(\%)$} & 35.45 & 41,02 & 17,41 \\
\hline
\end{tabular}

Tabela 60 - Mínimo de $25 \mathrm{~cm}$ de circunferência e 50 frutos/galho, árvore 12 .

\begin{tabular}{|c|c|c|c|c|c|c|c|}
\hline $\begin{array}{l}\text { Número } \\
\text { do } \\
\text { galho }\end{array}$ & $\begin{array}{l}\text { Número } \\
\text { de } \\
\text { frutos }\end{array}$ & PE & PPN & PPA & $\begin{array}{l}\text { Estimativa } \\
\text { do } \mathrm{n}^{\circ} \mathrm{de} \\
\text { frutos (PE) }\end{array}$ & $\begin{array}{l}\text { Estimativa } \\
\text { do } n^{\circ} \text { de } \\
\text { frutos (PPN) }\end{array}$ & $\begin{array}{l}\text { Estimativa } \\
\text { do } \mathrm{n}^{\circ} \text { de } \\
\text { frutos (PPA) }\end{array}$ \\
\hline 1 & 99 & $1 / 6$ & $1 / 6$ & 0,1203 & 594 & 594 & 823 \\
\hline 2 & 197 & $1 / 6$ & $1 / 6$ & 0,1972 & 1182 & 1182 & 999 \\
\hline 3 & 301 & $1 / 6$ & $1 / 3$ & 0,3332 & 1806 & 903 & 903 \\
\hline 4 & 90 & $1 / 6$ & $1 / 9$ & 0,0909 & 540 & 810 & 990 \\
\hline 5 & 152 & $1 / 6$ & $1 / 9$ & 0,1292 & 912 & 1368 & 1177 \\
\hline 6 & 141 & $1 / 6$ & $1 / 9$ & 0.1292 & 846 & 1269 & 1091 \\
\hline TOTAIS & 980 & 1 & 1 & 1,0000 & & & \\
\hline VARIANNCIA & & & & & 181376,0000 & 62828,0000 & 11614,5578 \\
\hline MEDIA & & & & & 980,00 & 1021.00 & 997.22 \\
\hline C.V. $(\%)$ & & & & & 43,46 & 24,55 & 10.81 \\
\hline
\end{tabular}


Tabela 61 - Árvore 13.

\begin{tabular}{|c|c|c|c|c|c|c|c|}
\hline $\begin{array}{l}\text { Número } \\
\text { do } \\
\text { galho }\end{array}$ & $\begin{array}{l}\text { Número } \\
\text { de } \\
\text { frutos }\end{array}$ & $\mathrm{PE}$ & PPN & PPA & $\begin{array}{l}\text { Estimativa } \\
\text { do } n^{0} \text { de } \\
\text { frutos }(\mathrm{PE})\end{array}$ & $\begin{array}{l}\text { Estimativa } \\
\text { do } n^{\circ} \text { de } \\
\text { frutos (PPN) }\end{array}$ & $\begin{array}{l}\text { Estimativa } \\
\text { do } n^{\circ} \text { de } \\
\text { frutos (PPA) }\end{array}$ \\
\hline 1 & 5 & $1 / 61$ & $1 / 12$ & 0,0042 & 305 & 60 & 1199 \\
\hline 2 & 9 & $1 / 61$ & $1 / 72$ & 0.0143 & 549 & 648 & 627 \\
\hline 3 & 20 & $1 / 61$ & $1 / 72$ & 0,0195 & 1220 & 1440 & 1024 \\
\hline 4 & 13 & $1 / 61$ & $1 / 72$ & 0,0195 & 793 & 936 & 666 \\
\hline 5 & 4 & $1 / 61$ & $1 / 24$ & 0,0133 & 244 & 96 & 300 \\
\hline 6 & 16 & $1 / 61$ & $1 / 24$ & 0.0369 & 976 & 384 & 434 \\
\hline 7 & 9 & $1 / 61$ & $1 / 48$ & 0,0156 & 549 & 432 & 577 \\
\hline 8 & 11 & $1 / 61$ & $1 / 48$ & 0,0212 & 671 & 528 & 518 \\
\hline 9 & 19 & $1 / 61$ & $1 / 48$ & 0,0320 & 1159 & 912 & 593 \\
\hline 10 & 9 & $1 / 61$ & $1 / 48$ & 0,0142 & 549 & 432 & 632 \\
\hline 11 & 9 & $1 / 61$ & $1 / 48$ & 0,0375 & 549 & 432 & 240 \\
\hline 12 & 22 & $1 / 61$ & $1 / 192$ & 0,0260 & 1342 & 4224 & 846 \\
\hline 13 & 24 & $1 / 61$ & $1 / 192$ & 0,0146 & 1464 & 4608 & 1641 \\
\hline 14 & 10 & $1 / 61$ & $1 / 96$ & 0.0260 & 610 & 960 & 384 \\
\hline 15 & 22 & $1 / 61$ & $1 / 24$ & 0,0280 & 1342 & 528 & 785 \\
\hline 16 & 26 & $1 / 61$ & $1 / 48$ & 0,0194 & 1586 & 1248 & 1340 \\
\hline 17 & 17 & $1 / 61$ & $1 / 48$ & 0,0086 & 1037 & 816 & 1971 \\
\hline 18 & 11 & $1 / 61$ & $1 / 24$ & 0,0161 & 671 & 264 & 681 \\
\hline 19 & 22 & $1 / 61$ & $1 / 96$ & 0,0182 & 1342 & 2112 & 1208 \\
\hline 20 & 11 & $1 / 61$ & $1 / 96$ & 0,0110 & 671 & 1056 & 999 \\
\hline 21 & 26 & $1 / 61$ & $1 / 96$ & 0,0198 & 1586 & 2496 & 1316 \\
\hline 22 & 14 & $1 / 61$ & $1 / 96$ & 0,0156 & 854 & 1344 & 897 \\
\hline 23 & 8 & $1 / 61$ & $1 / 16$ & 0,0107 & 488 & 128 & 751 \\
\hline 24 & 7 & $1 / 61$ & $1 / 32$ & 0,0086 & 427 & 224 & 817 \\
\hline 25 & 5 & $1 / 61$ & $1 / 128$ & 0,0160 & 305 & 640 & 313 \\
\hline 26 & 15 & $1 / 61$ & $1 / 128$ & 0,0208 & 915 & 1920 & 720 \\
\hline 27 & 18 & $1 / 61$ & $1 / 128$ & 0,0085 & 1098 & 2304 & 2108 \\
\hline 28 & 27 & $1 / 61$ & $1 / 256$ & 0.0165 & 1647 & 6912 & 1638 \\
\hline 29 & 5 & $1 / 61$ & $1 / 256$ & 0,0054 & 305 & 1280 & 929 \\
\hline 30 & 12 & $1 / 61$ & $1 / 32$ & 0,0099 & 732 & 384 & 1213 \\
\hline 31 & 12 & $1 / 61$ & $1 / 64$ & 0.0158 & 732 & 768 & 757 \\
\hline 32 & 17 & $1 / 61$ & $1 / 64$ & 0,0116 & 1037 & 1088 & 1460 \\
\hline 33 & 30 & $1 / 61$ & $1 / 96$ & 0,0259 & 1830 & 2880 & 1157 \\
\hline 34 & 21 & $1 / 61$ & $1 / 192$ & 0.0167 & 1281 & 4032 & 1257 \\
\hline 35 & 21 & $1 / 61$ & $1 / 192$ & 0,0206 & 1281 & 4032 & 1018 \\
\hline 36 & 11 & $1 / 61$ & $1 / 96$ & 0,0121 & 671 & 1056 & 907 \\
\hline 37 & 20 & $1 / 61$ & $1 / 192$ & 0,0164 & 1220 & 3840 & 1220 \\
\hline 38 & 12 & $1 / 61$ & $1 / 384$ & 0.0122 & 732 & 4608 & 980 \\
\hline 39 & 9 & $1 / 61$ & $1 / 384$ & 0,0085 & 549 & 3456 & 1059 \\
\hline 40 & 20 & $1 / 61$ & $1 / 192$ & 0.0131 & 1220 & 3840 & 1529 \\
\hline 41 & 7 & $1 / 61$ & $1 / 192$ & 0,0074 & 427 & 1344 & 951 \\
\hline 42 & 13 & $1 / 61$ & $1 / 192$ & 0,0098 & 793 & 2496 & 1330 \\
\hline 43 & 9 & $1 / 61$ & $1 / 192$ & 0,0068 & 549 & 1728 & 1326 \\
\hline 44 & 14 & $1 / 61$ & $1 / 32$ & 0.0085 & 854 & 448 & 1646 \\
\hline
\end{tabular}


Tabela 61 - Árvore 13 (continuação).

\begin{tabular}{|c|c|c|c|c|c|c|c|}
\hline $\begin{array}{l}\text { Número } \\
\text { do } \\
\text { galho }\end{array}$ & $\begin{array}{l}\text { Número } \\
\text { de } \\
\text { frutos }\end{array}$ & PE & PPN & PPA & $\begin{array}{l}\text { Estimativa } \\
\text { do } \mathrm{n}^{\circ} \text { de } \\
\text { frutos (PE) }\end{array}$ & $\begin{array}{l}\text { Estimativa } \\
\text { do } \mathrm{n}^{\circ} \text { de } \\
\text { frutos (PPN) }\end{array}$ & $\begin{array}{l}\text { Estimativa } \\
\text { do } n^{\circ} \text { de } \\
\text { frutos (PPA) }\end{array}$ \\
\hline 45 & $1^{r}$ & $1 / 61$ & $1 / 32$ & 0,0151 & 610 & 320 & 661 \\
\hline 46 & 7 & $1 / 61$ & $1 / 48$ & 0.0067 & 427 & 336 & 1039 \\
\hline 47 & 16 & $1 / 61$ & $1 / 96$ & 0,0220 & 976 & 1536 & 728 \\
\hline 48 & 17 & $1 / 61$ & $1 / 96$ & 0,0168 & 1037 & 1632 & 1011 \\
\hline 49 & 20 & $1 / 61$ & $1 / 96$ & 0.0242 & 1220 & 1920 & 827 \\
\hline 50 & 13 & $1 / 61$ & $1 / 96$ & 0,0146 & 793 & 1248 & 889 \\
\hline 51 & 17 & $1 / 61$ & $1 / 128$ & 0,0208 & 1037 & 2176 & 815 \\
\hline 52 & 16 & $1 / 61$ & $1 / 128$ & 0,0064 & 976 & 2048 & 2486 \\
\hline 53 & 7 & $1 / 61$ & $1 / 64$ & 0,0216 & 427 & 448 & 325 \\
\hline 54 & 28 & $1 / 61$ & $1 / 128$ & 0,0272 & 1708 & 3584 & 1029 \\
\hline 55 & 27 & $1 / 61$ & $1 / 128$ & 0,0272 & 1647 & 3456 & 993 \\
\hline 56 & 15 & $1 / 61$ & $1 / 64$ & 0,0196 & 915 & 960 & 766 \\
\hline 57 & 20 & $1 / 61$ & $1 / 192$ & 0,0135 & 1220 & 3840 & 1476 \\
\hline 58 & 15 & $1 / 61$ & $1 / 192$ & 0,0135 & 915 & 2880 & 1107 \\
\hline 59 & 12 & $1 / 61$ & $1 / 96$ & 0.0219 & 732 & 1152 & 547 \\
\hline 60 & 4 & $1 / 61$ & $1 / 96$ & 0,0068 & 244 & 384 & 591 \\
\hline 61 & 8 & $1 / 61$ & $1 / 32$ & 0.0083 & 488 & 256 & 969 \\
\hline TOTAIS & 894 & 1 & 1 & 1.0000 & & & \\
\hline VARIÂNCIA & & & & & 119719.6721 & 1046477,0000 & 163659.4738 \\
\hline MEDIA & & & & & 894,00 & 1697,38 & 987,29 \\
\hline C.V. $(\%)$ & & & & & 38,70 & 60,27 & 40,98 \\
\hline
\end{tabular}

Tabela 62 - Mínimo de $7 \mathrm{~cm}$ de circunferência e 10 frutos/galho, árvore 13.

\begin{tabular}{cccccccc}
\hline $\begin{array}{c}\text { Numero } \\
\text { do } \\
\text { galho }\end{array}$ & $\begin{array}{c}\text { Número } \\
\text { de } \\
\text { frutos }\end{array}$ & PE & PPN & PPA & $\begin{array}{c}\text { Estimativa } \\
\text { do } n^{\circ} \text { de } \\
\text { frutos (PE) }\end{array}$ & $\begin{array}{c}\text { Estimativa } \\
\text { do } n^{\circ} \text { de } \\
\text { frutos (PPN) }\end{array}$ & $\begin{array}{c}\text { Estimativa } \\
\text { do } n^{\circ} \text { de } \\
\text { frutos (PPA) }\end{array}$ \\
\hline 1 & 55 & $1 / 36$ & $1 / 6$ & 0,0709 & 1980 & 330 & 775,595538 \\
2 & 16 & $1 / 36$ & $1 / 24$ & 0,0369 & 576 & 384 & 434 \\
3 & 20 & $1 / 36$ & $1 / 24$ & 0,0369 & 720 & 480 & 543 \\
4 & 28 & $1 / 36$ & $1 / 24$ & 0,0463 & 1008 & 672 & 605 \\
5 & 47 & $1 / 36$ & $1 / 48$ & 0,0635 & 1692 & 2256 & 740 \\
6 & 10 & $1 / 36$ & $1 / 48$ & 0,0406 & 360 & 480 & 246 \\
7 & 22 & $1 / 36$ & $1 / 24$ & 0,0280 & 792 & 528 & 785 \\
8 & 43 & $1 / 36$ & $1 / 24$ & 0,0280 & 1548 & 1032 & 1534 \\
9 & 11 & $1 / 36$ & $1 / 24$ & 0,0161 & 396 & 264 & 681 \\
10 & 22 & $1 / 36$ & $1 / 96$ & 0,0182 & 792 & 2112 & 1208 \\
11 & 11 & $1 / 36$ & $1 / 96$ & 0,0110 & 396 & 1056 & 999 \\
12 & 26 & $1 / 36$ & $1 / 96$ & 0,0198 & 936 & 2496 & 1316 \\
13 & 14 & $1 / 36$ & $1 / 96$ & 0,0156 & 504 & 1344 & 897 \\
14 & 20 & $1 / 36$ & $1 / 16$ & 0,0473 & 720 & 320 & 423 \\
15 & 50 & $1 / 36$ & $1 / 16$ & 0.0391 & 1800 & 800 & 1279 \\
16 & 42 & $1 / 36$ & $1 / 16$ & 0,0374 & 1512 & 672 & 1124
\end{tabular}


Tabela 62 - Mínimo de $7 \mathrm{~cm}$ de circunferência e 10 frutos/galho, árvore 13 (continuação).

\begin{tabular}{|c|c|c|c|c|c|c|c|}
\hline $\begin{array}{l}\text { Número } \\
\text { do } \\
\text { galho }\end{array}$ & $\begin{array}{c}\text { Número } \\
\text { de } \\
\text { frutos }\end{array}$ & $\mathrm{PE}$ & PPN & PPA & $\begin{array}{l}\text { Estimativa } \\
\text { do } n^{\circ} \text { de } \\
\text { frutos }(\mathrm{PE})\end{array}$ & $\begin{array}{l}\text { Estimativa } \\
\text { do } \mathrm{n}^{\circ} \mathrm{de} \\
\text { frutos (PPN) }\end{array}$ & $\begin{array}{l}\text { Estimativa } \\
\text { do } n^{\circ} \text { de } \\
\text { frutos (PPA) }\end{array}$ \\
\hline 17 & 30 & $1 / 36$ & $1 / 96$ & 0,0259 & 1080 & 2880 & 117 \\
\hline 18 & 21 & $1 / 36$ & $1 / 192$ & 0,0167 & 756 & 4032 & 1257 \\
\hline 19 & 21 & $1 / 36$ & $1 / 192$ & 0,0206 & 756 & 4032 & 1018 \\
\hline 20 & 11 & $1 / 36$ & $1 / 96$ & 0,0121 & 396 & 1056 & 907 \\
\hline 21 & 20 & $1 / 36$ & $1 / 192$ & 0,0164 & 720 & 3840 & 1220 \\
\hline 22 & 21 & $1 / 36$ & $1 / 192$ & 0,0207 & 756 & 4032 & 1012 \\
\hline 23 & 27 & $1 / 36$ & $1 / 96$ & 0,0204 & 972 & 2592 & 1321 \\
\hline 24 & 22 & $1 / 36$ & $1 / 96$ & 0.0166 & 792 & 2112 & 1329 \\
\hline 25 & 24 & $1 / 36$ & $1 / 16$ & 0,0236 & 864 & 384 & 1016 \\
\hline 26 & 16 & $1 / 36$ & $1 / 64$ & 0,0239 & 576 & 1024 & 670 \\
\hline 27 & 17 & $1 / 36$ & $1 / 64$ & 0,0183 & 612 & 1088 & 930 \\
\hline 28 & 20 & $1 / 36$ & $1 / 64$ & 0,0263 & 720 & 1280 & 761 \\
\hline 29 & 13 & $1 / 36$ & $1 / 64$ & 0,0159 & 468 & 832 & 818 \\
\hline 30 & 40 & $1 / 36$ & $1 / 32$ & 0,0488 & 1440 & 1280 & 819 \\
\hline 31 & 28 & $1 / 36$ & $1 / 128$ & 0,0272 & 1008 & 3584 & 1029 \\
\hline 32 & 27 & $1 / 36$ & $1 / 128$ & 0,0272 & 972 & 3456 & 993 \\
\hline 33 & 15 & $1 / 36$ & $1 / 64$ & 0,0196 & 540 & 960 & 766 \\
\hline 34 & 20 & $1 / 36$ & $1 / 64$ & 0,0177 & 720 & 1280 & 1130 \\
\hline 35 & 15 & $1 / 36$ & $1 / 64$ & 0,0177 & 540 & 960 & 848 \\
\hline 36 & 16 & $1 / 36$ & $1 / 32$ & 0,0287 & 576 & 512 & 558 \\
\hline TOTAIS & 861 & 1 & 1 & 1.0000 & & & \\
\hline \multicolumn{5}{|c|}{ VARIÁNCIA } & 141275,0000 & 575542,0000 & 94943,7563 \\
\hline \multicolumn{5}{|c|}{ MEDIA } & 861.00 & 1567.83 & 920.77 \\
\hline \multicolumn{5}{|l|}{ C.V. $(\%)$} & 43,65 & 48.39 & 33.46 \\
\hline
\end{tabular}

Tabela 63 - Mínimo de $10 \mathrm{~cm}$ de circunferência e 20 frutos/galho, árvore 13.

\begin{tabular}{cccccccc}
\hline $\begin{array}{c}\text { Número } \\
\text { do } \\
\text { galho }\end{array}$ & $\begin{array}{c}\text { Número } \\
\text { de } \\
\text { frutos }\end{array}$ & PE & PPN & PPA & $\begin{array}{c}\text { Estimativa } \\
\text { do } n^{\circ} \text { de } \\
\text { frutos (PE) }\end{array}$ & $\begin{array}{c}\text { Estimativa } \\
\text { do } n^{\circ} \text { de } \\
\text { frutos (PPN) }\end{array}$ & $\begin{array}{c}\text { Estimativa } \\
\text { do } n^{\circ} \text { de } \\
\text { frutos (PPA) }\end{array}$ \\
\hline 1 & 55 & $1 / 20$ & $1 / 6$ & 0,0709 & 854 & 448 & 976 \\
2 & 36 & $1 / 20$ & $1 / 12$ & 0,0737 & 488 & 512 & 430 \\
3 & 28 & $1 / 20$ & $1 / 24$ & 0,0463 & 488 & 512 & 430 \\
4 & 66 & $1 / 20$ & $1 / 24$ & 0,1041 & 488 & 512 & 430 \\
5 & 22 & $1 / 20$ & $1 / 24$ & 0,0280 & 488 & 512 & 430 \\
6 & 43 & $1 / 20$ & $1 / 24$ & 0,0280 & 860 & 1032 & 1534 \\
7 & 33 & $1 / 20$ & $1 / 24$ & 0,0365 & 660 & 792 & 903 \\
8 & 40 & $1 / 20$ & $1 / 24$ & 0,0442 & 800 & 960 & 905 \\
9 & 20 & $1 / 20$ & $1 / 16$ & 0,0473 & 400 & 320 & 423 \\
10 & 50 & $1 / 20$ & $1 / 16$ & 0,0391 & 1000 & 800 & 1279 \\
11 & 42 & $1 / 20$ & $1 / 16$ & 0,0374 & 840 & 672 & 1124 \\
12 & 30 & $1 / 20$ & $1 / 96$ & 0,0259 & 600 & 2880 & 1157 \\
13 & 42 & $1 / 20$ & $1 / 96$ & 0,0373 & 840 & 4032 & 1125
\end{tabular}


Tabela 63 - Mínimo de $10 \mathrm{~cm}$ de circunferência e 20 frutos/galho, árvore 13 (continuação).

\begin{tabular}{|c|c|c|c|c|c|c|c|}
\hline $\begin{array}{l}\text { Número } \\
\text { do } \\
\text { galho }\end{array}$ & $\begin{array}{l}\text { Número } \\
\text { de } \\
\text { frutos }\end{array}$ & $\mathrm{PE}$ & PPN & PPA & $\begin{array}{l}\text { Estimativa } \\
\text { do } n^{\circ} \text { de } \\
\text { frutos (PE) }\end{array}$ & $\begin{array}{l}\text { Estimativa } \\
\text { do } n^{\circ} \text { de } \\
\text { frutos (PPN) }\end{array}$ & $\begin{array}{l}\text { Estimativa } \\
\text { do } n^{\circ} \text { de } \\
\text { frutos (PPA) }\end{array}$ \\
\hline 14 & 52 & $1 / 20$ & $1 / 48$ & 0,0493 & 1100 & 330 & 776 \\
\hline 15 & 49 & $1 / 20$ & $1 / 48$ & 0,0370 & 720 & 432 & 488 \\
\hline 16 & 44 & $1 / 20$ & $1 / 16$ & 0,0540 & 560 & 672 & 605 \\
\hline 17 & 36 & $1 / 20$ & $1 / 16$ & 0,0540 & 1320 & 1584 & 634 \\
\hline 18 & 40 & $1 / 20$ & $1 / 32$ & 0,0488 & 440 & 528 & 785 \\
\hline 19 & 84 & $1 / 20$ & $1 / 32$ & 0,0740 & 1680 & 2688 & 1135 \\
\hline 20 & 59 & $1 / 20$ & $1 / 16$ & 0,0641 & 1180 & 944 & 921 \\
\hline TOTAIS & 871 & 1 & 1 & 1.0000 & & & \\
\hline VARIÁNCIA & & & & & 89095,0000 & 422238,0000 & 75060,1912 \\
\hline MEDIA & & & & & 871.00 & 1303,70 & 923,71 \\
\hline C.V. $(\%)$ & & & & & 34,27 & 49,84 & 29,66 \\
\hline
\end{tabular}

Tabela 64 - Mínimo de $15 \mathrm{~cm}$ de circunferência e 30 frutos/galho, árvore 13.

\begin{tabular}{|c|c|c|c|c|c|c|c|}
\hline $\begin{array}{l}\text { Número } \\
\text { do } \\
\text { galho }\end{array}$ & $\begin{array}{l}\text { Número } \\
\text { de } \\
\text { frutos }\end{array}$ & PE & PPN & PPA & $\begin{array}{l}\text { Estimativa } \\
\text { do } n^{\circ} \mathrm{de} \\
\text { frutos (PE) }\end{array}$ & $\begin{array}{l}\text { Estimativa } \\
\text { do } n^{\circ} \text { de } \\
\text { frutos (PPN) }\end{array}$ & $\begin{array}{l}\text { Estimativa } \\
\text { do } n^{\circ} \text { de } \\
\text { frutos (PPA) }\end{array}$ \\
\hline 1 & 55 & $1 / 8$ & $1 / 6$ & 0,0709 & 440 & 330 & 776 \\
\hline 2 & 130 & $1 / 8$ & $1 / 6$ & 0,2241 & 1040 & 780 & 580 \\
\hline 3 & 67 & $1 / 8$ & $1 / 12$ & 0,0561 & 536 & 804 & 1195 \\
\hline 4 & 85 & $1 / 8$ & $1 / 12$ & 0,0807 & 680 & 1020 & 1053 \\
\hline 5 & 86 & $1 / 8$ & $1 / 8$ & 0,0864 & 688 & 688 & 995 \\
\hline 6 & 216 & $1 / 8$ & $1 / 8$ & 0,1869 & 1728 & 1728 & 1156 \\
\hline 7 & 107 & $1 / 8$ & $1 / 8$ & 0,1080 & 856 & 856 & 991 \\
\hline 8 & 183 & $1 / 8$ & $1 / 8$ & 0,1869 & 1464 & 1464 & 979 \\
\hline TOTAIS & 929 & 1 & 1 & 1.0000 & & & \\
\hline VARIÁNCIA & & & & & 151979,5000 & 128998,0000 & 43349,6245 \\
\hline MEDDIA & & & & & 929.00 & 958,75 & 965,59 \\
\hline C.V. $(\%)$ & & & & & 41.96 & 37,46 & 21,56 \\
\hline
\end{tabular}

Tabela 65 - Mínimo de $20 \mathrm{~cm}$ de circunferência e 40 frutos/galho. árvore 13.

\begin{tabular}{|c|c|c|c|c|c|c|c|}
\hline $\begin{array}{l}\text { Número } \\
\text { do } \\
\text { galho }\end{array}$ & $\begin{array}{c}\text { Número } \\
\text { de } \\
\text { frutos }\end{array}$ & $\mathrm{PE}$ & PPN & PPA & $\begin{array}{l}\text { Estimativa } \\
\text { do } n^{\circ} \text { de } \\
\text { frutos (PE) }\end{array}$ & $\begin{array}{c}\text { Estimativa } \\
\text { do } n^{\circ} \text { de } \\
\text { frutos (PPN) }\end{array}$ & $\begin{array}{l}\text { Estimativa } \\
\text { do } n^{\circ} \text { de } \\
\text { frutos (PPA) }\end{array}$ \\
\hline 1 & 185 & $1 / 4$ & $1 / 4$ & 0,2682 & 740 & 740 & 690 \\
\hline 2 & 152 & $1 / 4$ & $1 / 4$ & 0,1637 & 608 & 608 & 929 \\
\hline 3 & 302 & $1 / 4$ & $1 / 4$ & 0,2841 & 1208 & 1208 & 1063 \\
\hline 4 & 290 & $1 / 4$ & $1 / 4$ & 0.2841 & 1160 & 1160 & 1021 \\
\hline TOTAIS & 929 & 1 & 1 & 1.0000 & & & \\
\hline VARIÂNCIA & & & & & 2669.9508 & 2047.5468 & 4725,3141 \\
\hline MÉDIA & & & & & 58467.00 & 58467,00 & 7372,69 \\
\hline C.V. $(\%)$ & & & & & 26.03 & 26,03 & 9.28 \\
\hline
\end{tabular}


Tabela 66 - Árvore 14.

\begin{tabular}{|c|c|c|c|c|c|c|c|}
\hline $\begin{array}{l}\text { Número } \\
\text { do } \\
\text { galho }\end{array}$ & $\begin{array}{l}\text { Número } \\
\text { de } \\
\text { frutos }\end{array}$ & PE & PPN & PPA & $\begin{array}{l}\text { Estimativa } \\
\text { do } n^{\circ} \text { de } \\
\text { frutos }(\mathrm{PE})\end{array}$ & $\begin{array}{l}\text { Estimativa } \\
\text { do } \mathrm{n}^{\circ} \mathrm{de} \\
\text { frutos (PPN) }\end{array}$ & $\begin{array}{l}\text { Estimativa } \\
\text { do } n^{\circ} \text { de } \\
\text { frutos (PPA) }\end{array}$ \\
\hline 1 & 8 & $1 / 17$ & $1 / 36$ & 0,0190 & 136 & 288 & 421 \\
\hline 2 & 9 & $1 / 17$ & $1 / 36$ & 0,0248 & 153 & 324 & 363 \\
\hline 3 & 4 & $1 / 17$ & $1 / 18$ & 0,0355 & 68 & 72 & 113 \\
\hline 4 & 10 & $1 / 17$ & $1 / 18$ & 0,0355 & 170 & 180 & 282 \\
\hline 5 & 6 & $1 / 17$ & $1 / 12$ & 0,0683 & 102 & 72 & 88 \\
\hline 6 & 13 & $1 / 17$ & $1 / 12$ & 0,1898 & 221 & 156 & 68 \\
\hline 7 & 4 & $1 / 17$ & $1 / 18$ & 0,0707 & 68 & 72 & 57 \\
\hline 8 & 6 & $1 / 17$ & $1 / 54$ & 0,0319 & 102 & 324 & 188 \\
\hline 9 & 9 & $1 / 17$ & $1 / 54$ & 0,0221 & 153 & 486 & 407 \\
\hline 10 & 6 & $1 / 17$ & $1 / 54$ & 0,0717 & 102 & 324 & 84 \\
\hline 11 & 8 & $1 / 17$ & $1 / 9$ & 0,0491 & 136 & 72 & 163 \\
\hline 12 & 5 & $1 / 17$ & $1 / 9$ & 0,0491 & 85 & 45 & 102 \\
\hline 13 & 11 & $1 / 17$ & $1 / 18$ & 0,0328 & 187 & 198 & 335 \\
\hline 14 & 7 & $1 / 17$ & $1 / 18$ & 0,0670 & 119 & 126 & 104 \\
\hline 15 & 6 & $1 / 17$ & $1 / 18$ & 0,0519 & 102 & 108 & 116 \\
\hline 16 & 19 & $1 / 17$ & $1 / 18$ & 0,1168 & 323 & 342 & 163 \\
\hline 17 & 7 & $1 / 17$ & $1 / 9$ & 0,0639 & 119 & 63 & 110 \\
\hline TOTAIS & 138 & 1 & 1 & 1,0000 & & & \\
\hline VARIÂNCIA & & & & & 3817,0000 & 10803,0000 & 8657.6345 \\
\hline MÉDIA & & & & & 138,00 & 191.29 & 186,02 \\
\hline C.V. $(\%)$ & & & & & 44,77 & 54,33 & 50.02 \\
\hline
\end{tabular}

Tabela 67 - Mínimo de $7 \mathrm{~cm}$ de circunferência e 10 frutos/galho, árvore 14 .

\begin{tabular}{|c|c|c|c|c|c|c|c|}
\hline $\begin{array}{l}\text { Número } \\
\text { do } \\
\text { galho }\end{array}$ & $\begin{array}{c}\text { Número } \\
\text { de } \\
\text { frutos }\end{array}$ & PE & PPN & PPA & $\begin{array}{l}\text { Estimativa } \\
\text { do } n^{\circ} \text { de } \\
\text { frutos (PE) }\end{array}$ & $\begin{array}{l}\text { Estimativa } \\
\text { do } n^{\circ} \text { de } \\
\text { frutos (PPN) }\end{array}$ & $\begin{array}{l}\text { Estimativa } \\
\text { do } n^{0} \text { de } \\
\text { frutos (PPA) }\end{array}$ \\
\hline 1 & 19 & $1 / 6$ & $1 / 12$ & 0,0634 & 114 & 228 & 300 \\
\hline 2 & 14 & $1 / 6$ & $1 / 12$ & 0,0513 & 84 & 168 & 273 \\
\hline 3 & 21 & $1 / 6$ & $1 / 6$ & 0,2581 & 126 & 126 & 81 \\
\hline 4 & 40 & $1 / 6$ & $1 / 3$ & 0,2946 & 240 & 120 & 136 \\
\hline 5 & 18 & $1 / 6$ & $1 / 6$ & 0,1236 & 108 & 108 & 146 \\
\hline 6 & 32 & $1 / 6$ & $1 / 6$ & 0.2089 & 192 & 192 & 153 \\
\hline TOTAIS & 144 & 1 & 1 & 1,0000 & & & \\
\hline VARIANCIA & & & & & 2949,0000 & 1491.0000 & 3447,9000 \\
\hline MEDIA & & & & & 144.00 & 157,00 & 181,39 \\
\hline$\overline{C . V .}(\%)$ & & & & & 37.71 & 24.59 & 32.37 \\
\hline
\end{tabular}


Tabela 68 - Mínimo de $10 \mathrm{~cm}$ de circunferência e 10 frutos/galho, árvore 14.

\begin{tabular}{|c|c|c|c|c|c|c|c|}
\hline $\begin{array}{l}\text { Número } \\
\text { do } \\
\text { galho } \\
\end{array}$ & $\begin{array}{c}\text { Número } \\
\text { de } \\
\text { frutos } \\
\end{array}$ & PE & PPN & PPA & $\begin{array}{l}\text { Estimativa } \\
\text { do } n^{0} \text { de } \\
\text { frutos (PE) }\end{array}$ & $\begin{array}{c}\text { Estimativa } \\
\text { do } \mathrm{n}^{\circ} \text { de } \\
\text { frutos (PPN) }\end{array}$ & $\begin{array}{l}\text { Estimativa } \\
\text { do } \mathrm{n}^{0} \text { de } \\
\text { frutos (PPA) }\end{array}$ \\
\hline 1 & 33 & $1 / 5$ & 16 & 0,1147 & 165 & 198 & 288 \\
\hline 2 & 21 & $1 / 5$ & $1 / 6$ & 0.2581 & 105 & 126 & 81 \\
\hline 3 & 40 & $1 / 5$ & $1 / 3$ & 0,2946 & 200 & 120 & 136 \\
\hline 4 & 18 & $1 / 5$ & $1 / 6$ & 0,1236 & 90 & 108 & 146 \\
\hline 5 & 32 & $1 / 5$ & $1 / 6$ & 0.2089 & 160 & 192 & 153 \\
\hline TOTAIS & 144 & 1 & 1 & 1.0000 & & & \\
\hline VARIÁNCIA & & & & & 1663,0000 & 1341,0000 & 3427,1077 \\
\hline MÉDIA & & & & & 144,00 & 148,80 & 160.71 \\
\hline C.V. $(\%)$ & & & & & 28,32 & 24.61 & 36,43 \\
\hline
\end{tabular}

Tabela 69 - Mínimo de $10 \mathrm{~cm}$ de circunferência e 20 frutos/galho, árvore 14 .

\begin{tabular}{|c|c|c|c|c|c|c|c|}
\hline $\begin{array}{l}\text { Número } \\
\text { do } \\
\text { galho }\end{array}$ & $\begin{array}{l}\text { Número } \\
\text { de } \\
\text { frutos }\end{array}$ & PE & PPN & PPA & $\begin{array}{l}\text { Estimativa } \\
\text { do } n^{\circ} \text { de } \\
\text { frutos }(\mathrm{PE})\end{array}$ & $\begin{array}{l}\text { Estimativa } \\
\text { do } n^{\circ} \text { de } \\
\text { frutos (PPN) }\end{array}$ & $\begin{array}{l}\text { Estimativa } \\
\text { do } n^{\circ} \text { de } \\
\text { frutos (PPA) }\end{array}$ \\
\hline 1 & 33 & $1 / 4$ & $1 / 6$ & 0,1147 & 132 & 198 & 288 \\
\hline 2 & 21 & $1 / 4$ & $1 / 6$ & 0,2581 & 84 & 126 & 81 \\
\hline 3 & 40 & $1 / 4$ & $1 / 3$ & 0,2946 & 160 & 120 & 136 \\
\hline 4 & 50 & $1 / 4$ & $1 / 3$ & 0.3326 & 200 & 150 & 150 \\
\hline TOTAIS & 144 & 1 & 1 & 1.0000 & & & \\
\hline VARIÁNCIA & & & & & 1793,0000 & 753,0000 & 3422,6660 \\
\hline MEDIA & & & & & 144,00 & 148.50 & 163,78 \\
\hline C.V. $(\%)$ & & & & & 29.41 & 18.48 & 35,72 \\
\hline
\end{tabular}

Tabela 70 - Mínimo de $15 \mathrm{~cm}$ de circunferência e 30 frutos/galho, árvore 14 .

\begin{tabular}{|c|c|c|c|c|c|c|c|}
\hline $\begin{array}{l}\text { Número } \\
\text { do } \\
\text { galho }\end{array}$ & $\begin{array}{l}\text { Número } \\
\text { de } \\
\text { frutos }\end{array}$ & PE & PPN & PPA & $\begin{array}{l}\text { Estimativa } \\
\text { do } n^{\circ} \text { de } \\
\text { frutos (PE) }\end{array}$ & $\begin{array}{l}\text { Estimativa } \\
\text { do } n^{\circ} \text { de } \\
\text { frutos }(\mathrm{PPN})\end{array}$ & $\begin{array}{l}\text { Estimativa } \\
\text { do } n^{\circ} \text { de } \\
\text { frutos (PPA) }\end{array}$ \\
\hline 1 & 57 & $1 / 3$ & $1 / 3$ & 0,3728 & 171 & 171 & 153 \\
\hline 2 & 40 & $1 / 3$ & $1 / 3$ & 0,2946 & 120 & 120 & 136 \\
\hline 3 & 50 & $1 / 3$ & $1 / 3$ & 0.3326 & 150 & 150 & 150 \\
\hline TOTAIS & 147 & 1 & 1 & 1.0000 & & & \\
\hline VARIÂNCIA & & & & & 438,0000 & 438,0000 & 53,6899 \\
\hline MEDIA & & & & & 147.00 & 147,00 & 146,34 \\
\hline C.V. $(\%)$ & & & & & 14,24 & 14.24 & 5,01 \\
\hline
\end{tabular}


Tabela 71 - Árvore 15.

\begin{tabular}{|c|c|c|c|c|c|c|c|}
\hline $\begin{array}{l}\text { Número } \\
\text { do } \\
\text { galho } \\
\end{array}$ & $\begin{array}{c}\text { Número } \\
\text { de } \\
\text { frutos } \\
\end{array}$ & $\mathrm{PE}$ & PPN & PPA & $\begin{array}{l}\text { Estimativa } \\
\text { do } n^{\circ} \text { de } \\
\text { frutos (PE) }\end{array}$ & $\begin{array}{l}\text { Estimativa } \\
\text { do } n^{\circ} \text { de } \\
\text { frutos (PPN) }\end{array}$ & $\begin{array}{l}\text { Estimativa } \\
\text { do } n^{\circ} \text { de } \\
\text { frutos (PPA) }\end{array}$ \\
\hline 1 & 13 & $1 \cdot 6$ & $1 / 18$ & 0.0573 & 208 & 234 & 227 \\
\hline 2 & 8 & $1 / 16$ & $1 / 18$ & 0,0573 & 128 & 144 & 140 \\
\hline 3 & 15 & $1 / 16$ & $1 / 18$ & 0,0779 & 240 & 270 & 192 \\
\hline 4 & 4 & $1 / 16$ & $1 / 6$ & 0,0308 & 64 & 24 & 130 \\
\hline 5 & 12 & $1 / 16$ & $1 / 18$ & 0,0957 & 192 & 216 & 125 \\
\hline 6 & 10 & $1 / 16$ & $1 / 18$ & 0,0425 & 160 & 180 & 235 \\
\hline 7 & 8 & $1 / 16$ & $1 / 18$ & 0,0425 & 128 & 144 & 188 \\
\hline 8 & 7 & $1 / 16$ & $1 / 18$ & 0,0392 & 112 & 126 & 179 \\
\hline 9 & 13 & $1 / 16$ & $1 / 18$ & 0,0882 & 208 & 234 & 147 \\
\hline 10 & 9 & $1 / 16$ & $1 / 18$ & 0,0534 & 144 & 162 & 169 \\
\hline 11 & 4 & $1 / 16$ & $1 / 12$ & 0,0267 & 64 & 48 & 150 \\
\hline 12 & 9 & $1 / 16$ & $1 / 48$ & 0,0495 & 144 & 432 & 182 \\
\hline 13 & 15 & $1 / 16$ & $1 / 48$ & 0,0969 & 240 & 720 & 155 \\
\hline 14 & 11 & $1 / 16$ & $1 / 24$ & 0,0937 & 176 & 264 & 117 \\
\hline 15 & 17 & $1 / 16$ & $1 / 12$ & 0,1067 & 272 & 204 & 159 \\
\hline 16 & 5 & $1 / 16$ & $1 / 12$ & 0.0417 & 80 & 60 & 120 \\
\hline TOTAIS & 160 & 1 & 1 & 1,0000 & & & \\
\hline \multicolumn{5}{|c|}{ VARIANCIA } & 3679,7500 & 14934.0000 & 838,2708 \\
\hline \multicolumn{5}{|c|}{ MEDIA } & 160.00 & 216.38 & 163,47 \\
\hline \multicolumn{5}{|l|}{ C.V. $(\%)$} & 37.91 & 56.48 & 17.71 \\
\hline
\end{tabular}

Tabela 72 - Mínimo de $7 \mathrm{~cm}$ de circunferência e 10 frutos/galho, árvore 15.

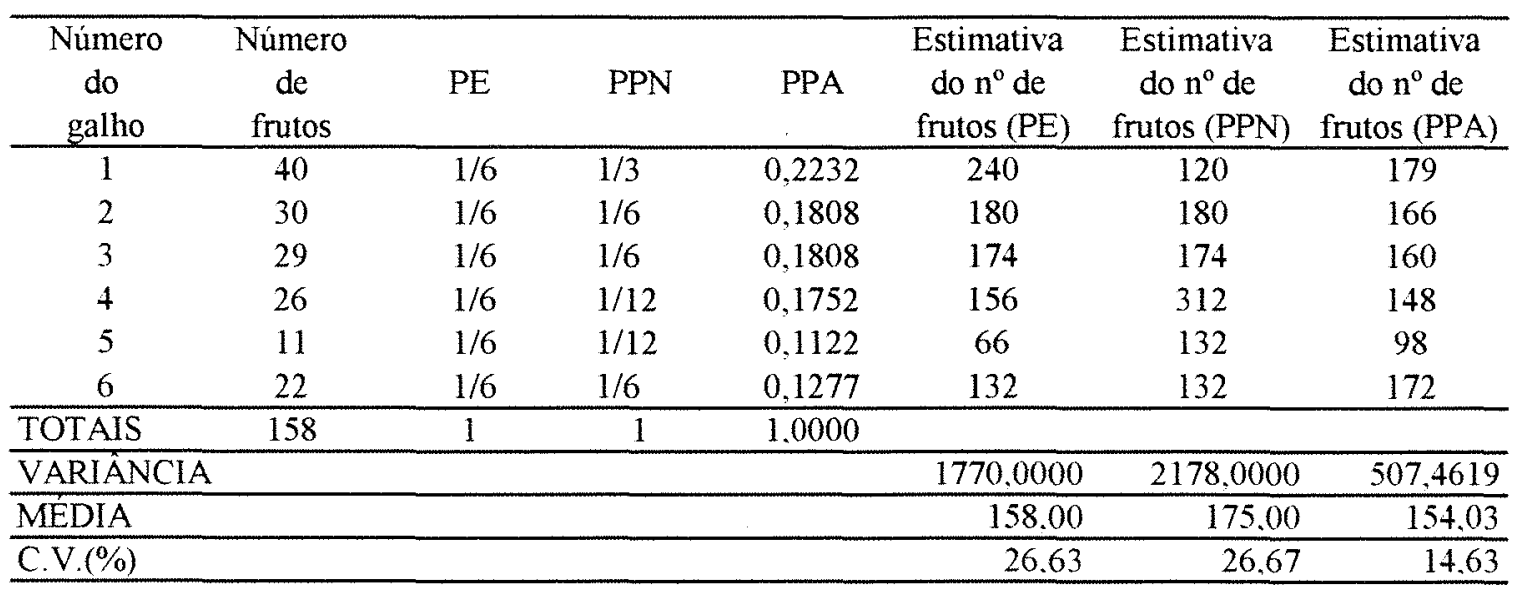


Tabela 73 - Mínimo de $10 \mathrm{~cm}$ de circunferência e 10 frutos/galho, árvore 15.

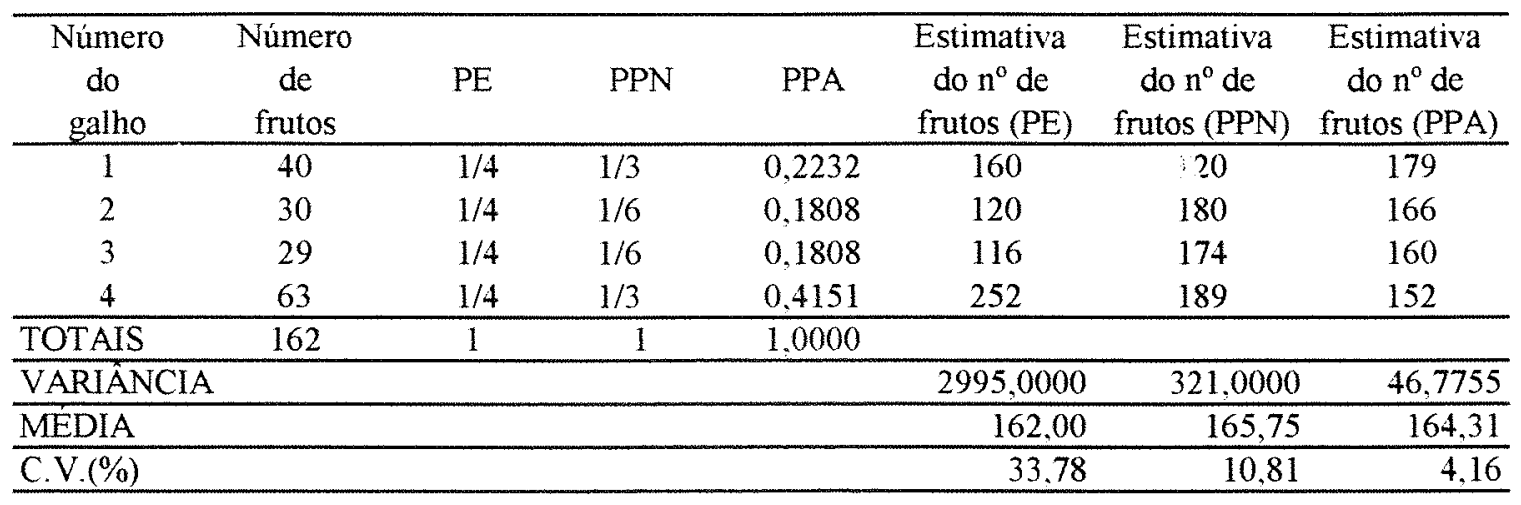

Tabela 74 - Árvore 16.

\begin{tabular}{|c|c|c|c|c|c|c|c|}
\hline $\begin{array}{l}\text { Número } \\
\text { do } \\
\text { galho }\end{array}$ & $\begin{array}{c}\text { Número } \\
\text { de } \\
\text { frutos }\end{array}$ & $\mathrm{PE}$ & PPN & PPA & $\begin{array}{l}\text { Estimativa } \\
\text { do } n^{\circ} \text { de } \\
\text { frutos }(\mathrm{PE})\end{array}$ & $\begin{array}{l}\text { Estimativa } \\
\text { do } n^{\circ} \mathrm{de} \\
\text { frutos (PPN) }\end{array}$ & $\begin{array}{l}\text { Estimativa } \\
\text { do } n^{\circ} \text { de } \\
\text { frutos (PPA) }\end{array}$ \\
\hline 1 & 18 & $1 / 39$ & $1 / 32$ & 0.0171 & 702 & 576 & 1050 \\
\hline 2 & 5 & $1 / 39$ & $1 / 32$ & 0,0126 & 195 & 160 & 397 \\
\hline 3 & 13 & $1 / 39$ & $1 / 32$ & 0,0341 & 507 & 416 & 382 \\
\hline 4 & 11 & $1 / 39$ & $1 / 32$ & 0,0445 & 429 & 352 & 247 \\
\hline 5 & 5 & $1 / 39$ & $1 / 24$ & 0,0114 & 195 & 120 & 437 \\
\hline 6 & 11 & $1 / 39$ & $1 / 48$ & 0,0187 & 429 & 528 & 587 \\
\hline 7 & 8 & $1 / 39$ & $1 / 96$ & 0,0105 & 312 & 768 & 760 \\
\hline 8 & 13 & $1 / 39$ & $1 / 96$ & 0,0165 & 507 & 1248 & 790 \\
\hline 9 & 6 & $1 / 39$ & $1 / 24$ & 0,0224 & 234 & 144 & 268 \\
\hline 10 & 6 & $1 / 39$ & $1 / 12$ & 0,0204 & 234 & 72 & 295 \\
\hline 11 & 8 & $1 / 39$ & $1 / 12$ & 0,0566 & 312 & 96 & 141 \\
\hline 12 & 6 & $1 / 39$ & $1 / 48$ & 0,0150 & 234 & 288 & 399 \\
\hline 13 & 16 & $1 / 39$ & $1 / 48$ & 0,0294 & 624 & 768 & 543 \\
\hline 14 & 5 & $1 / 39$ & $1 / 24$ & 0,0664 & 195 & 120 & 75 \\
\hline 15 & 16 & $1 / 39$ & $1 / 12$ & 0,0470 & 624 & 192 & 341 \\
\hline 16 & 14 & $1 / 39$ & $1 / 36$ & 0,0317 & 546 & 504 & 441 \\
\hline 17 & 11 & $1 / 39$ & $1 / 108$ & 0,0138 & 429 & 1188 & 799 \\
\hline 18 & 8 & $1 / 39$ & $1 / 108$ & 0,0198 & 312 & 864 & 403 \\
\hline 19 & 17 & $1 / 39$ & $1 / 108$ & 0,0667 & 663 & 1836 & 255 \\
\hline 20 & 18 & $1 / 39$ & $1 / 72$ & 0,0170 & 702 & 1296 & 1060 \\
\hline 21 & 11 & $1 / 39$ & $1 / 72$ & 0,0222 & 429 & 792 & 496 \\
\hline 22 & 11 & $1 / 39$ & $1 / 48$ & 0,0182 & 429 & 528 & 605 \\
\hline 23 & 13 & $1 / 39$ & $1 / 48$ & 0,0284 & 507 & 624 & 458 \\
\hline 24 & 10 & $1 / 39$ & $1 / 24$ & 0,0935 & 390 & 240 & 107 \\
\hline 25 & 5 & $1 / 39$ & $1 / 64$ & 0,0080 & 195 & 320 & 626 \\
\hline 26 & 19 & $1 / 39$ & $1 / 128$ & 0,0186 & 741 & 2432 & 1020 \\
\hline 27 & 7 & $1 / 39$ & $1 / 128$ & 0,0073 & 273 & 896 & 962 \\
\hline 28 & 17 & $1 / 39$ & $1 / 32$ & 0,0488 & 663 & 544 & 348 \\
\hline 29 & 10 & $1 / 39$ & $1 / 64$ & 0,0183 & 390 & 640 & 545 \\
\hline
\end{tabular}


Tabela 74 - Árvore 16 (continuação).

\begin{tabular}{|c|c|c|c|c|c|c|c|}
\hline $\begin{array}{l}\text { Número } \\
\text { do } \\
\text { galho }\end{array}$ & $\begin{array}{l}\text { Número } \\
\text { de } \\
\text { frutos }\end{array}$ & PE & PPN & PPA & $\begin{array}{l}\text { Estimativa } \\
\text { do } \mathrm{n}^{\circ} \text { de } \\
\text { frutos (PF }\end{array}$ & $\begin{array}{l}\text { Estimativa } \\
\text { do } n^{\circ} \text { de } \\
\text { frutos (PPN) }\end{array}$ & $\begin{array}{l}\text { Estimativa } \\
\text { do } \mathrm{n}^{\circ} \mathrm{de} \\
\text { frutos (PPA) }\end{array}$ \\
\hline 30 & 12 & $1 / 39$ & $1 / 64$ & 0,0227 & 468 & 768 & 530 \\
\hline 31 & 5 & $1 / 39$ & $1 / 32$ & 0,0166 & 195 & 160 & 301 \\
\hline 32 & 10 & $1 / 39$ & $1 / 48$ & 0,0339 & 390 & 480 & 295 \\
\hline 33 & 4 & $1 / 39$ & $1 / 48$ & 0,0122 & 156 & 192 & 328 \\
\hline 34 & 13 & $1 / 39$ & $1 / 288$ & 0,0147 & 507 & 3744 & 887 \\
\hline 35 & 11 & $1 / 39$ & $1 / 288$ & 0,0057 & 429 & 3168 & 1921 \\
\hline 36 & 17 & $1 / 39$ & $1 / 144$ & 0,0161 & 663 & 2448 & 1056 \\
\hline 37 & 9 & $1 / 39$ & $1 / 144$ & 0,0123 & 351 & 1296 & 730 \\
\hline 38 & 6 & $1 / 39$ & $1 / 32$ & 0,0127 & 234 & 192 & 472 \\
\hline 39 & 11 & $1 / 39$ & $1 / 32$ & 0.0183 & 429 & 352 & 601 \\
\hline TOTAIS & 416 & 1 & 1 & 1,0000 & & & \\
\hline \multicolumn{5}{|c|}{ VARIÂNCIA } & 26691,7436 & 229451,5000 & 75995,9808 \\
\hline \multicolumn{5}{|c|}{ MÉDIA } & 416.00 & 803,90 & 563,11 \\
\hline \multicolumn{5}{|l|}{ C.V. $(\%)$} & 39,27 & 59,59 & 48,96 \\
\hline
\end{tabular}

Tabela 75 - Mínimo de $7 \mathrm{~cm}$ de circunferência e 10 frutos/galho, árvore 16.

\begin{tabular}{cccccccc}
\hline $\begin{array}{c}\text { Número } \\
\text { do } \\
\text { galho }\end{array}$ & $\begin{array}{c}\text { Número } \\
\text { de } \\
\text { frutos }\end{array}$ & PE & PPN & PPA & $\begin{array}{c}\text { Estimativa } \\
\text { do } \mathrm{n}^{0} \text { de } \\
\text { frutos (PE) }\end{array}$ & $\begin{array}{c}\text { Estimativa } \\
\text { do } \mathrm{n}^{0} \text { de } \\
\text { frutos (PPN) }\end{array}$ & $\begin{array}{c}\text { Estimativa } \\
\text { do } \mathrm{n}^{0} \text { de } \\
\text { frutos (PPA) }\end{array}$ \\
\hline 1 & 23 & $1 / 21$ & $1 / 16$ & 0,0297 & 483 & 368 & 773 \\
2 & 13 & $1 / 21$ & $1 / 32$ & 0,0341 & 273 & 416 & 382 \\
3 & 11 & $1 / 21$ & $1 / 32$ & 0,0445 & 231 & 352 & 247 \\
4 & 46 & $1 / 21$ & $1 / 8$ & 0,0795 & 966 & 368 & 578 \\
5 & 14 & $1 / 21$ & $1 / 8$ & 0,0635 & 294 & 112 & 221 \\
6 & 27 & $1 / 21$ & $1 / 8$ & 0,1244 & 567 & 216 & 217 \\
7 & 16 & $1 / 21$ & $1 / 12$ & 0,0470 & 336 & 192 & 341 \\
8 & 14 & $1 / 21$ & $1 / 36$ & 0,0317 & 294 & 504 & 441 \\
9 & 36 & $1 / 21$ & $1 / 36$ & 0,1003 & 756 & 1296 & 359 \\
10 & 18 & $1 / 21$ & $1 / 72$ & 0,0170 & 378 & 1296 & 1060 \\
11 & 11 & $1 / 21$ & $1 / 72$ & 0,0222 & 231 & 792 & 496 \\
12 & 31 & $1 / 21$ & $1 / 24$ & 0,0466 & 651 & 744 & 665 \\
13 & 10 & $1 / 21$ & $1 / 24$ & 0,0935 & 210 & 240 & 107 \\
14 & 33 & $1 / 21$ & $1 / 24$ & 0,0384 & 693 & 792 & 859 \\
15 & 17 & $1 / 21$ & $1 / 24$ & 0,0553 & 357 & 408 & 307 \\
16 & 10 & $1 / 21$ & $1 / 48$ & 0,0208 & 210 & 480 & 481
\end{tabular}


Tabela 75 - Mínimo de $7 \mathrm{~cm}$ de circunferência e 10 frutos/galho, árvore 16 (contiuação).

\begin{tabular}{|c|c|c|c|c|c|c|c|}
\hline $\begin{array}{l}\text { Número } \\
\text { do } \\
\text { galho }\end{array}$ & $\begin{array}{c}\text { Número } \\
\text { de } \\
\text { frutos }\end{array}$ & PE & PPN & PPA & $\begin{array}{l}\text { Estimativa } \\
\text { do } n^{\circ} \text { de } \\
\text { frutos }(\mathrm{PE})\end{array}$ & $\begin{array}{l}\text { Estimativa } \\
\text { do } n^{\circ} \text { de } \\
\text { frutos (PPN) }\end{array}$ & $\begin{array}{l}\text { Estimativa } \\
\text { do } n^{\circ} \text { de } \\
\text { frutos (PPA) }\end{array}$ \\
\hline 17 & 12 & $1 / 21$ & $1 / 48$ & 0,0257 & 252 & 576 & 467 \\
\hline 18 & 14 & $1 / 21$ & $1 / 32$ & 0,0389 & 294 & 448 & 360 \\
\hline 19 & 24 & $1 / 21$ & $1 / 64$ & 0,0313 & 504 & 1536 & 767 \\
\hline 20 & 26 & $1 / 21$ & $1 / 64$ & 0,0247 & 546 & 1664 & 1052 \\
\hline 21 & 17 & $1 / 21$ & $1 / 16$ & 0,0310 & 357 & 272 & 549 \\
\hline TOTAIS & 423 & 1 & 1 & 1.0000 & & & \\
\hline \multicolumn{2}{|c|}{ VARIÂNCIA } & & & & 41067,8095 & 113119,0000 & 53749.2002 \\
\hline \multicolumn{2}{|c|}{ MÉDIA } & & & & 423,00 & 622,48 & 510,88 \\
\hline \multicolumn{2}{|l|}{ C.V. $(\%)$} & & & & 47,91 & 54,03 & 45,38 \\
\hline
\end{tabular}

Tabela 76 - Mínimo de $10 \mathrm{~cm}$ de circunferência e 10 frutos/galho, árvore 16.

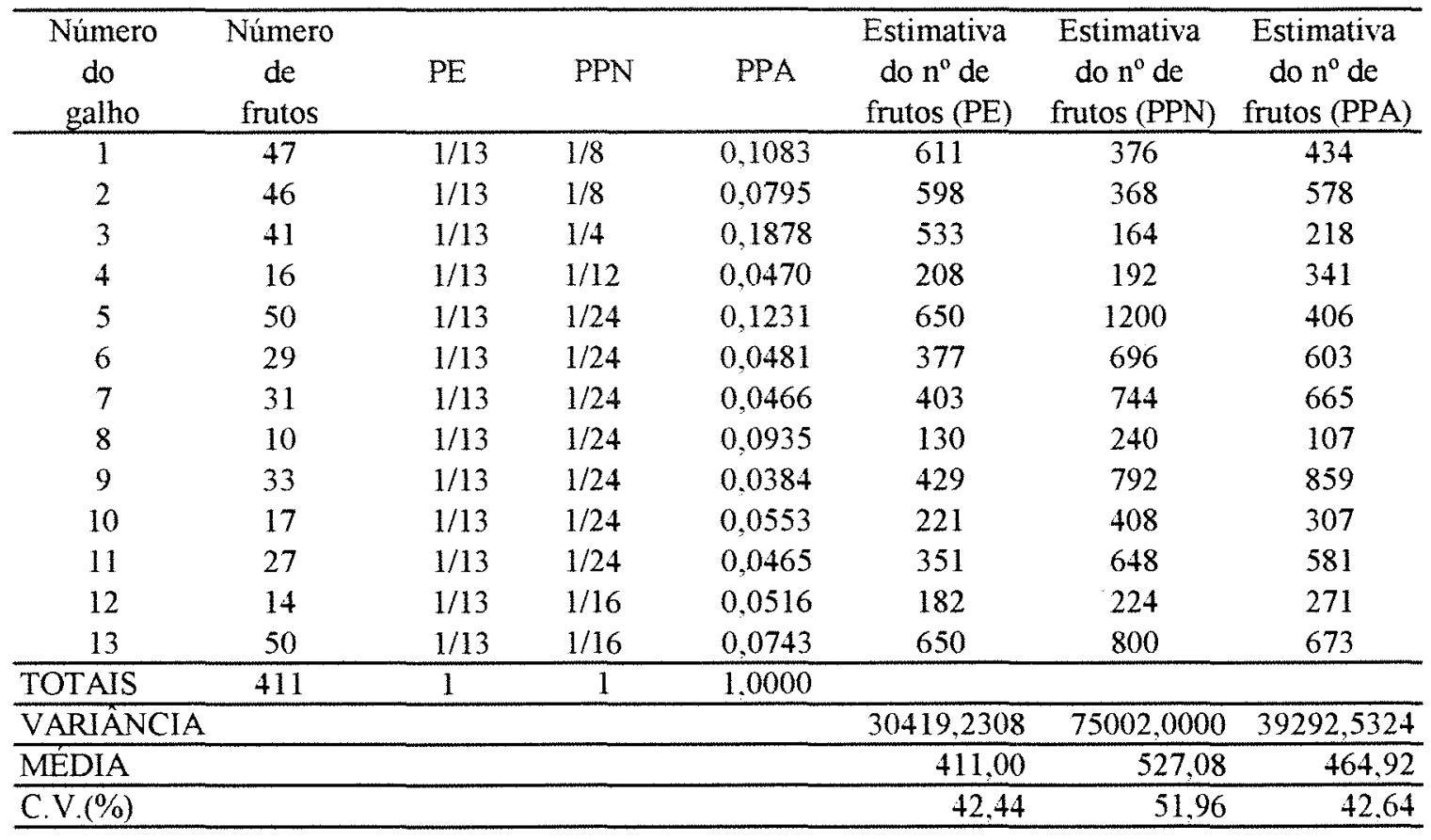


Tabela 77 - Mínimo de $10 \mathrm{~cm}$ de circunferência e 20 frutos/galho, árvore 16.

\begin{tabular}{|c|c|c|c|c|c|c|c|}
\hline $\begin{array}{l}\text { Número } \\
\text { do } \\
\text { galho }\end{array}$ & $\begin{array}{l}\text { Número } \\
\text { de } \\
\text { frutos }\end{array}$ & PE & PPN & PPA & $\begin{array}{l}\text { Estimativa } \\
\text { do } n^{\circ} \text { de } \\
\text { frutos (PE) }\end{array}$ & $\begin{array}{l}\text { Estimativa } \\
\text { do } n^{\circ} \text { de } \\
\text { frutos (PPN) }\end{array}$ & $\begin{array}{l}\text { Estimativa } \\
\text { do } n^{\circ} \text { de } \\
\text { frutos (PPA) }\end{array}$ \\
\hline 1 & 47 & $1 / 9$ & $1^{\prime}$ & 0,1083 & 423 & 376 & 434 \\
\hline 2 & 46 & $1 / 9$ & $1 / 8$ & 0,0795 & 414 & 368 & 578 \\
\hline 3 & 41 & $1 / 9$ & $1 / 4$ & 0,1878 & 369 & 164 & 218 \\
\hline 4 & 50 & $1 / 9$ & $1 / 16$ & 0,1416 & 450 & 800 & 353 \\
\hline 5 & 29 & $1 / 9$ & $1 / 16$ & 0,0553 & 261 & 464 & 524 \\
\hline 6 & 42 & $1 / 9$ & $1 / 8$ & 0,1612 & 378 & 336 & 261 \\
\hline 7 & 33 & $1 / 9$ & $1 / 16$ & 0,0635 & 297 & 528 & 520 \\
\hline 8 & 44 & $1 / 9$ & $1 / 16$ & 0,0768 & 396 & 704 & 573 \\
\hline 9 & 82 & $1 / 9$ & $1 / 8$ & 0.1259 & 738 & 656 & 651 \\
\hline TOTAIS & 414 & 1 & 1 & 1.0000 & & & \\
\hline \multicolumn{2}{|c|}{ VARIÁNCIA } & & & & 16809.2222 & 39722,0000 & 24603,9350 \\
\hline \multicolumn{2}{|l|}{ MEDIA } & & & & 414.00 & 488,44 & 456,94 \\
\hline \multicolumn{2}{|l|}{ C.V. $(\%)$} & & & & 31,32 & 40,80 & 34,33 \\
\hline
\end{tabular}

Tabela 78 - Mínimo de $15 \mathrm{~cm}$ de circunferência e 30 frutos/galho, árvore 16.

\begin{tabular}{|c|c|c|c|c|c|c|c|}
\hline $\begin{array}{l}\text { Número } \\
\text { do } \\
\text { galho }\end{array}$ & $\begin{array}{c}\text { Número } \\
\text { de } \\
\text { frutos }\end{array}$ & $\mathrm{PE}$ & PPN & PPA & $\begin{array}{l}\text { Estimativa } \\
\text { do } n^{\circ} \text { de } \\
\text { frutos (PE) }\end{array}$ & $\begin{array}{l}\text { Estimativa } \\
\text { do } n^{\circ} \text { de } \\
\text { frutos (PPN) }\end{array}$ & $\begin{array}{l}\text { Estimativa } \\
\text { do } n^{\circ} \text { de } \\
\text { frutos (PPA) }\end{array}$ \\
\hline 1 & 97 & $1 / 6$ & $1 / 4$ & 0,1878 & 582 & 388 & 516 \\
\hline 2 & 41 & $1 / 6$ & $1 / 4$ & 0,1878 & 246 & 164 & 218 \\
\hline 3 & 97 & $1 / 6$ & $1 / 8$ & 0,1888 & 582 & 776 & 514 \\
\hline 4 & 42 & $1 / 6$ & $1 / 8$ & 0,1694 & 252 & 336 & 248 \\
\hline 5 & 77 & $1 / 6$ & $1 / 8$ & 0,1403 & 462 & 616 & 549 \\
\hline 6 & 82 & $1 / 6$ & $1 / 8$ & 0.1259 & 492 & 656 & 651 \\
\hline TOTAIS & 436 & 1 & 1 & 1,0000 & & & \\
\hline VARIÂNCIA & & & & & 15847,3333 & 44296.0000 & 23663,8524 \\
\hline MEDIA & & & & & 436.00 & 489.33 & 449,45 \\
\hline C.V. $(\%)$ & & & & & 28,87 & 43,01 & 34.23 \\
\hline
\end{tabular}

Tabela 79 - Mínimo de $20 \mathrm{~cm}$ de circunferência e 40 frutos/galho, árvore 16.

\begin{tabular}{|c|c|c|c|c|c|c|c|}
\hline $\begin{array}{l}\text { Número } \\
\text { do } \\
\text { galho }\end{array}$ & $\begin{array}{l}\text { Número } \\
\text { de } \\
\text { frutos }\end{array}$ & $P E$ & PPN & PPA & $\begin{array}{l}\text { Estimativa } \\
\text { do } n^{\circ} \text { de } \\
\text { frutos }(\mathrm{PE})\end{array}$ & $\begin{array}{l}\text { Estimativa } \\
\text { do } n^{\circ} \text { de } \\
\text { frutos (PPN) }\end{array}$ & $\begin{array}{l}\text { Estimativa } \\
\text { do } n^{\circ} \text { de } \\
\text { frutos (PPA) }\end{array}$ \\
\hline 1 & 97 & $1 / 4$ & $1 / 4$ & 0,1878 & 388 & 388 & 516 \\
\hline 2 & 41 & $1 / 4$ & $1 / 4$ & 0,1878 & 164 & 164 & 218 \\
\hline 3 & 139 & $1 / 4$ & $1 / 4$ & 0,3582 & 556 & 556 & 388 \\
\hline 4 & 159 & $1 / 4$ & $1 / 4$ & 0.2662 & 636 & 636 & 597 \\
\hline TOTAIS & 436 & 1 & 1 & 1.0000 & & & \\
\hline VARIÂNCIA & & & & & 32096.0000 & 32096.0000 & 16652.6042 \\
\hline MEDIA & & & & & 436.00 & 436,00 & 430,04 \\
\hline C.V. $(\%)$ & & & & & 41.09 & 41,09 & 30,01 \\
\hline
\end{tabular}


Tabela 80 - Árvore 17.

\begin{tabular}{|c|c|c|c|c|c|c|c|}
\hline $\begin{array}{l}\text { Número } \\
\text { do } \\
\text { galho }\end{array}$ & $\begin{array}{c}\text { Número } \\
\text { de } \\
\text { frutos }\end{array}$ & PE & PPN & PPA & $\begin{array}{l}\text { Estimativa } \\
\text { do } \mathrm{n}^{\circ} \mathrm{de} \\
\text { frutos (PE) }\end{array}$ & $\begin{array}{l}\text { Estimativa } \\
\text { do } n^{\circ} \mathrm{de} \\
\text { frutos (PPN) }\end{array}$ & $\begin{array}{l}\text { Estimativa } \\
\text { do } n^{\circ} \text { de } \\
\text { frutos (PPA) }\end{array}$ \\
\hline 1 & 5 & $1 / 41$ & $1 / 24$ & 0,0200 & 246 & 144 & 300 \\
\hline 2 & 24 & $1 / 41$ & $1 / 24$ & 0,0355 & 984 & 576 & 675 \\
\hline 3 & 16 & $1 / 41$ & $1 / 24$ & 0,0439 & 656 & 384 & 365 \\
\hline 4 & 41 & $1 / 41$ & $1 / 48$ & 0,0499 & 1681 & 1968 & 821 \\
\hline 5 & 10 & $1 / 41$ & $1 / 576$ & 0,0059 & 410 & 5760 & 1694 \\
\hline 6 & 16 & $1 / 41$ & $1 / 576$ & 0.0151 & 656 & 9216 & 1059 \\
\hline 7 & 8 & $1 / 41$ & $1 / 576$ & 0,0052 & 328 & 4608 & 1536 \\
\hline 8 & 13 & $1 / 41$ & $1 / 576$ & 0,0075 & 533 & 7488 & 1733 \\
\hline 9 & 4 & $1 / 41$ & $1 / 288$ & 0,0093 & 164 & 1152 & 428 \\
\hline 10 & 13 & $1 / 41$ & $1 / 192$ & 0.0144 & 533 & 2496 & 902 \\
\hline 11 & 7 & $1 / 41$ & $1 / 192$ & 0,0144 & 287 & 1344 & 486 \\
\hline 12 & 18 & $1 / 41$ & $1 / 24$ & 0,0219 & 738 & 432 & 822 \\
\hline 13 & 17 & $1 / 41$ & $1 / 24$ & 0,0541 & 697 & 408 & 314 \\
\hline 14 & 15 & $1 / 41$ & $1 / 144$ & 0,0101 & 615 & 2160 & 1490 \\
\hline 15 & 11 & $1 / 41$ & $1 / 144$ & 0,0101 & 451 & 1584 & 1093 \\
\hline 16 & 15 & $1 / 41$ & $1 / 288$ & 0,0093 & 615 & 4320 & 1617 \\
\hline 17 & 11 & $1 / 41$ & $1 / 288$ & 0,0165 & 451 & 3168 & 667 \\
\hline 18 & 14 & $1 / 41$ & $1 / 96$ & 0,0180 & 574 & 1344 & 779 \\
\hline 19 & 27 & $1 / 41$ & $1 / 96$ & 0,0367 & 1107 & 2592 & 736 \\
\hline 20 & 12 & $1 / 41$ & $1 / 24$ & 0.0447 & 492 & 288 & 269 \\
\hline 21 & 24 & $1 / 41$ & $1 / 9$ & 0,0323 & 984 & 216 & 744 \\
\hline 22 & 21 & $1 / 41$ & $1 / 72$ & 0.0168 & 861 & 1512 & 1249 \\
\hline 23 & 40 & $1 / 41$ & $1 / 72$ & 0,0213 & 1640 & 2880 & 1879 \\
\hline 24 & 20 & $1 / 41$ & $1 / 36$ & 0,0265 & 820 & 720 & 756 \\
\hline 25 & 18 & $1 / 41$ & $1 / 18$ & 0,0287 & 738 & 324 & 627 \\
\hline 26 & 22 & $1 / 41$ & $1 / 144$ & 0.0242 & 902 & 3168 & 910 \\
\hline 27 & 12 & $1 / 41$ & $1 / 144$ & 0,0107 & 492 & 1728 & 1117 \\
\hline 28 & 17 & $1 / 41$ & $1 / 72$ & 0,0234 & 697 & 1224 & 727 \\
\hline 29 & 17 & $1 / 41$ & $1 / 72$ & 0,0228 & 697 & 1224 & 744 \\
\hline 30 & 6 & $1 / 41$ & $1 / 72$ & 0,0117 & 246 & 432 & 515 \\
\hline 31 & 13 & $1 / 41$ & $1 / 18$ & 0,0363 & 533 & 234 & 359 \\
\hline 32 & 5 & $1 / 41$ & $1 / 12$ & 0,0151 & 205 & 60 & 330 \\
\hline 33 & 4 & $1 / 41$ & $1 / 72$ & 0,0327 & 164 & 288 & 122 \\
\hline 34 & 12 & $1 / 41$ & $1 / 72$ & 0.0327 & 492 & 864 & 367 \\
\hline 35 & 41 & $1 / 41$ & $1 / 288$ & 0,0671 & 1681 & 11808 & 611 \\
\hline 36 & 12 & $1 / 41$ & $1 / 288$ & 0.0207 & 492 & 3456 & 579 \\
\hline 37 & 14 & $1 / 41$ & $1 / 144$ & 0,0430 & 574 & 2016 & 325 \\
\hline 38 & 5 & $1 / 41$ & $1 / 72$ & 0.0187 & 205 & 360 & 267 \\
\hline 39 & 8 & $1 / 41$ & $1 / 72$ & 0,0187 & 328 & 576 & 428 \\
\hline 40 & 13 & $1 / 41$ & $1 / 72$ & 0,0332 & 533 & 936 & 391 \\
\hline 41 & 5 & $1 / 41$ & $1 / 6$ & 0,0210 & 205 & 30 & 238 \\
\hline TOTAIS & 627 & 1 & 1 & 1.0000 & & & \\
\hline \multicolumn{5}{|c|}{ VARIÁNCIA } & \multicolumn{3}{|c|}{$148772.4958 \quad 1244966,1823 \quad 149355,4100$} \\
\hline \multicolumn{5}{|c|}{ MÉDIA } & 627.00 & 2085.07 & 757.83 \\
\hline \multicolumn{5}{|l|}{ C.V. $(\%)$} & 61.52 & 53,51 & 51,00 \\
\hline
\end{tabular}


Tabela 81 - Mínimo de $7 \mathrm{~cm}$ de circunferência e 10 frutos/galho, árvore 17 .

\begin{tabular}{cccccccc}
\hline $\begin{array}{c}\text { Número } \\
\text { do } \\
\text { galho }\end{array}$ & $\begin{array}{c}\text { Número } \\
\text { de } \\
\text { frutos }\end{array}$ & PE & PPN & PPA & $\begin{array}{c}\text { Estimativa } \\
\text { do } \text { n }^{\circ} \text { de } \\
\text { frutos (PE) }\end{array}$ & $\begin{array}{c}\text { Estimativa } \\
\text { do } \mathrm{n}^{\circ} \text { de } \\
\text { frutos (PPN) }\end{array}$ & $\begin{array}{c}\text { Estimativa } \\
\text { do } \mathbf{n}^{\circ} \text { de } \\
\text { frutos (PPA) }\end{array}$ \\
\hline 1 & 34 & $1 / 24$ & $1 / 12$ & 0,0555 & 816 & 408 & 612 \\
2 & 16 & $1 / 24$ & $1 / 24$ & 0,0439 & 384 & 384 & 365 \\
3 & 41 & $1 / 24$ & $1 / 48$ & 0,0499 & 984 & 1968 & 821 \\
4 & 26 & $1 / 24$ & $1 / 192$ & 0,0268 & 624 & 4992 & 969 \\
5 & 25 & $1 / 24$ & $1 / 192$ & 0,0162 & 600 & 4800 & 1540 \\
6 & 20 & $1 / 24$ & $1 / 96$ & 0,0288 & 480 & 1920 & 694 \\
7 & 18 & $1 / 24$ & $1 / 24$ & 0,0219 & 432 & 432 & 822 \\
8 & 17 & $1 / 24$ & $1 / 24$ & 0,0541 & 408 & 408 & 314 \\
9 & 56 & $1 / 24$ & $1 / 48$ & 0,0459 & 1344 & 2688 & 1220 \\
10 & 14 & $1 / 24$ & $1 / 96$ & 0,0180 & 336 & 1344 & 779 \\
11 & 27 & $1 / 24$ & $1 / 96$ & 0,0367 & 648 & 2592 & 736 \\
12 & 12 & $1 / 24$ & $1 / 24$ & 0,0447 & 288 & 288 & 269 \\
13 & 24 & $1 / 24$ & $1 / 9$ & 0,0323 & 576 & 216 & 744 \\
14 & 21 & $1 / 24$ & $1 / 72$ & 0,0168 & 504 & 1512 & 1249 \\
15 & 40 & $1 / 24$ & $1 / 72$ & 0,0213 & 960 & 2880 & 1879 \\
16 & 20 & $1 / 24$ & $1 / 36$ & 0,0265 & 480 & 720 & 756 \\
17 & 18 & $1 / 24$ & $1 / 18$ & 0,0287 & 432 & 324 & 627 \\
18 & 37 & $1 / 24$ & $1 / 72$ & 0,0349 & 888 & 2664 & 1059 \\
19 & 17 & $1 / 24$ & $1 / 72$ & 0,0234 & 408 & 1224 & 727 \\
20 & 26 & $1 / 24$ & $1 / 36$ & 0,0345 & 624 & 936 & 754 \\
21 & 13 & $1 / 24$ & $1 / 18$ & 0,0363 & 312 & 234 & 359 \\
22 & 53 & $1 / 24$ & $1 / 12$ & 0,1495 & 1272 & 636 & 354 \\
23 & 14 & $1 / 24$ & $1 / 12$ & 0,0733 & 336 & 168 & 191 \\
24 & 29 & $1 / 24$ & $1 / 6$ & 0,0802 & 696 & 174 & 362 \\
\hline TOTAIS & 618 & 1 & 1 & 1,0000 & & & \\
\hline VARIANCIA & & & & & 99659,8333 & 633215.6667 & 149220,9474 \\
\hline MEDIA & & & & & 618.00 & 1413,00 & 758,41 \\
\hline C.V.(\%) & & & & & 51.08 & 56,32 & 50,93 \\
\hline & & & & & & & \\
\hline
\end{tabular}


Tabela 82 - Mínimo de $10 \mathrm{~cm}$ de circunferência e 20 frutos/galho, árvore 17.

\begin{tabular}{|c|c|c|c|c|c|c|c|}
\hline $\begin{array}{l}\text { Número } \\
\text { do } \\
\text { galho }\end{array}$ & $\begin{array}{l}\text { Número } \\
\text { de } \\
\text { frutos }\end{array}$ & PE & PPN & PPA & $\begin{array}{l}\text { Estimativa } \\
\text { do } n^{\circ} \text { de } \\
\text { frutos (PE) }\end{array}$ & $\begin{array}{l}\text { Estimativa } \\
\text { do } n^{\circ} \text { de } \\
\text { frutos (PPN) }\end{array}$ & $\begin{array}{l}\text { Estimativa } \\
\text { do } \mathrm{n}^{\circ} \text { de } \\
\text { frutos (PPA) }\end{array}$ \\
\hline 1 & 34 & $1 / 13$ & $1 / 12$ & 0,055 & 442 & 408 & 612 \\
\hline 2 & 41 & $1 / 13$ & $1 / 24$ & 0,0679 & 533 & 984 & 604 \\
\hline 3 & 71 & $1 / 13$ & $1 / 24$ & 0,0978 & 923 & 1704 & 726 \\
\hline 4 & 35 & $1 / 13$ & $1 / 12$ & 0,0774 & 455 & 420 & 452 \\
\hline 5 & 56 & $1 / 13$ & $1 / 24$ & 0,0657 & 728 & 1344 & 853 \\
\hline 6 & 41 & $1 / 13$ & $1 / 24$ & 0,0782 & 533 & 984 & 525 \\
\hline 7 & 24 & $1 / 13$ & $1 / 9$ & 0,0323 & 312 & 216 & 744 \\
\hline 8 & 61 & $1 / 13$ & $1 / 18$ & 0,0550 & 793 & 1098 & 1108 \\
\hline 9 & 20 & $1 / 13$ & $1 / 18$ & 0,0382 & 260 & 360 & 523 \\
\hline 10 & 55 & $1 / 13$ & $1 / 18$ & 0,0762 & 715 & 990 & 722 \\
\hline 11 & 26 & $1 / 13$ & $1 / 18$ & 0,0529 & 338 & 468 & 491 \\
\hline 12 & 90 & $1 / 13$ & $1 / 6$ & 0,2228 & 1170 & 540 & 404 \\
\hline 13 & 29 & $1 / 13$ & $1 / 6$ & 0,0802 & 377 & 174 & 362 \\
\hline TOTAIS & 583 & 1 & 1 & 1.0000 & & & \\
\hline VARIÁNCIA & & & & & 85363,9836 & 182988,0156 & 65760,3150 \\
\hline MEDIA & & & & & 583,00 & 745,38 & 625,10 \\
\hline C.V. $(\%)$ & & & & & 50.12 & 57.39 & 41,02 \\
\hline
\end{tabular}

Tabela 83 - Mínimo de $15 \mathrm{~cm}$ de circunferência e 30 frutos/galho, árvore 17.

\begin{tabular}{|c|c|c|c|c|c|c|c|}
\hline $\begin{array}{l}\text { Número } \\
\text { do } \\
\text { galho }\end{array}$ & $\begin{array}{c}\text { Número } \\
\text { de } \\
\text { frutos }\end{array}$ & PE & PPN & PPA & $\begin{array}{l}\text { Estimativa } \\
\text { do } n^{\circ} \text { de } \\
\text { frutos (PE) }\end{array}$ & $\begin{array}{c}\text { Estimativa } \\
\text { do } \mathrm{n}^{\circ} \mathrm{de} \\
\text { frutos (PPN) }\end{array}$ & 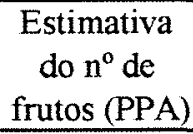 \\
\hline 1 & 162 & $1 / 5$ & $1 / 6$ & 0,2212 & 810 & 972 & 732 \\
\hline 2 & 144 & $1 / 5$ & $1 / 6$ & 0,2212 & 720 & 864 & 651 \\
\hline 3 & 123 & $1 / 5$ & $1 / 6$ & 0,1068 & 615 & 738 & 1152 \\
\hline 4 & 95 & $1 / 5$ & $1 / 6$ & 0,1478 & 475 & 570 & 643 \\
\hline 5 & 230 & $1 / 5$ & $1 / 3$ & 0,3030 & 1150 & 690 & 759 \\
\hline TOTAIS & 754 & 1 & 1 & 1,0000 & & & \\
\hline VARIÁNCIA & & & & & 51026,8000 & 9067,3333 & 21081,4506 \\
\hline MÉDIA & & & & & 754,00 & 766.80 & 787,39 \\
\hline C.V. $(\%)$ & & & & & 29.96 & 12.42 & 18,44 \\
\hline
\end{tabular}


Tabela 84 - Mínimo de $20 \mathrm{~cm}$ de circunferência e 40 frutos/galho, árvore 17.

\begin{tabular}{|c|c|c|c|c|c|c|c|}
\hline $\begin{array}{l}\text { Número } \\
\text { do } \\
\text { galho }\end{array}$ & $\begin{array}{l}\text { Número } \\
\text { de } \\
\text { frutos } \\
\end{array}$ & $P E$ & PPN & PPA & $\begin{array}{c}\text { Estimativa } \\
\text { do } n^{\circ} \text { de } \\
\text { frutos }(\mathrm{PE})\end{array}$ & $\begin{array}{l}\text { Estimativa } \\
\text { do } \mathrm{n}^{\circ} \text { de } \\
\text { frutos (PPN) }\end{array}$ & $\begin{array}{l}\text { Estimativa } \\
\text { do } n^{\circ} \mathrm{de} \\
\text { frutos (PPA) }\end{array}$ \\
\hline 1 & 306 & $1 / 3$ & $1 / 3$ & 0,4424 & 918 & 918 & 692 \\
\hline 2 & 218 & $1 / 3$ & $1 / 3$ & 0,2546 & 654 & 654 & 856 \\
\hline 3 & 230 & $1 / 3$ & $1 / 3$ & 0,3030 & 690 & 690 & 759 \\
\hline TOTAIS & 754 & 1 & 1 & 1.0000 & & & \\
\hline VARIÁNCIA & & & & & 4698,6667 & 4698,6667 & 2668.9545 \\
\hline MEDIA & & & & & 754,00 & 754,00 & 769,00 \\
\hline C.V. $(\%)$ & & & & & 9.09 & 9,09 & 6,72 \\
\hline
\end{tabular}

Tabela 85 - Árvore 18.

\begin{tabular}{|c|c|c|c|c|c|c|c|}
\hline $\begin{array}{l}\text { Número } \\
\text { do } \\
\text { galho }\end{array}$ & $\begin{array}{l}\text { Número } \\
\text { de } \\
\text { frutos }\end{array}$ & PE & PPN & PPA & $\begin{array}{l}\text { Estimativa } \\
\text { do } n^{\circ} \text { de } \\
\text { frutos (PE) }\end{array}$ & $\begin{array}{l}\text { Estimativa } \\
\text { do } n^{\circ} \mathrm{de} \\
\text { frutos (PPN) }\end{array}$ & $\begin{array}{l}\text { Estimativa } \\
\text { do } \mathrm{n}^{\circ} \text { de } \\
\text { frutos (PPA) }\end{array}$ \\
\hline 1 & 5 & $1 / 71$ & $1 / 36$ & 0,0072 & 355 & 180 & 694 \\
\hline 2 & 7 & $1 / 71$ & $1 / 36$ & 0,0072 & 497 & 252 & 972 \\
\hline 3 & 6 & $1 / 71$ & $1 / 36$ & 0,0063 & 426 & 216 & 952 \\
\hline 4 & 5 & $1 / 71$ & $1 / 72$ & 0,0059 & 355 & 360 & 841 \\
\hline 5 & 17 & $1 / 71$ & $1 / 72$ & 0.0134 & 1207 & 1224 & 1272 \\
\hline 6 & 7 & $1 / 71$ & $1 / 36$ & 0,0112 & 497 & 252 & 623 \\
\hline 7 & 10 & $1 / 71$ & $1 / 72$ & 0,0144 & 710 & 720 & 695 \\
\hline 8 & 7 & $1 / 71$ & $1 / 144$ & 0,0072 & 497 & 1008 & 973 \\
\hline 9 & 9 & $1 / 71$ & $1 / 144$ & 0,0072 & 639 & 1296 & 1251 \\
\hline 10 & 13 & $1 / 71$ & $1 / 72$ & 0,0113 & 923 & 936 & 1146 \\
\hline 11 & 8 & $1 / 71$ & $1 / 72$ & 0,0202 & 568 & 576 & 397 \\
\hline 12 & 20 & $1 / 71$ & $1 / 288$ & 0,0149 & 1420 & 5760 & 1338 \\
\hline 13 & 8 & $1 / 71$ & $1 / 288$ & 0,0114 & 568 & 2304 & 699 \\
\hline 14 & 13 & $1 / 71$ & $1 / 144$ & 0,0117 & 923 & 1872 & 1108 \\
\hline 15 & 20 & $1 / 71$ & $1 / 48$ & 0,0182 & 1420 & 960 & 1102 \\
\hline 16 & 13 & $1 / 71$ & $1 / 48$ & 0,0182 & 923 & 624 & 716 \\
\hline 17 & 9 & $1 / 71$ & $1 / 96$ & 0,0100 & 639 & 864 & 899 \\
\hline 18 & 15 & $1 / 71$ & $1 / 384$ & 0,0061 & 1065 & 5760 & 2456 \\
\hline 19 & 8 & $1 / 71$ & $1 / 384$ & 0,0045 & 568 & 3072 & 1783 \\
\hline 20 & 14 & $1 / 71$ & $1 / 192$ & 0,0060 & 994 & 2688 & 2349 \\
\hline 21 & 21 & $1 / 71$ & $1 / 96$ & 0,0139 & 1491 & 2016 & 1506 \\
\hline 22 & 11 & $1 / 71$ & $1 / 192$ & 0,0058 & 781 & 2112 & 1890 \\
\hline 23 & 9 & $1 / 71$ & $1 / 1152$ & 0,0065 & 639 & 10368 & 1392 \\
\hline 24 & 11 & $1 / 71$ & $1 / 1152$ & 0,0065 & 781 & 12672 & 1701 \\
\hline 25 & 15 & $1 / 71$ & $1 / 576$ & 0,0083 & 1065 & 8640 & 1812 \\
\hline 26 & 4 & $1 / 71$ & $1 / 576$ & 0,0021 & 284 & 2304 & 1933 \\
\hline 27 & 5 & $1 / 71$ & $1 / 144$ & 0,0076 & 355 & 720 & 661 \\
\hline 28 & 14 & $1 / 71$ & $1 / 144$ & 0,0058 & 994 & 2016 & 2416 \\
\hline 29 & 16 & $1 / 71$ & $1 / 144$ & 0,0102 & 1136 & 2304 & 1566 \\
\hline 30 & 5 & $1 / 71$ & $1 / 576$ & 0,0037 & 355 & 2880 & 1339 \\
\hline 31 & 15 & $1 / 71$ & $1 / 576$ & 0,0073 & 1065 & 8640 & 2049 \\
\hline
\end{tabular}


Tabela 85 - Árvore 18 (continuação).

\begin{tabular}{|c|c|c|c|c|c|c|c|}
\hline $\begin{array}{l}\text { Número } \\
\text { do } \\
\text { galho }\end{array}$ & $\begin{array}{c}\text { Número } \\
\text { de } \\
\text { frutos }\end{array}$ & $\mathrm{PE}$ & PPN & PPA & $\begin{array}{l}\text { Estimativa } \\
\text { do } n^{\circ} \text { de } \\
\text { frutos }(\mathrm{PE})\end{array}$ & $\begin{array}{l}\text { Estimativa } \\
\text { do } n^{\circ} \text { de } \\
\text { frutos (PPN) }\end{array}$ & 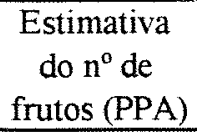 \\
\hline 32 & 6 & $1 / 71$ & 1, 288 & 0,0049 & 426 & 1728 & 1221 \\
\hline 33 & 14 & $1 / 71$ & $1 / 288$ & 0,0116 & 994 & 4032 & 1204 \\
\hline 34 & 10 & $1 / 71$ & $1 / 576$ & 0,0038 & 710 & 5760 & 2656 \\
\hline 35 & 14 & $1 / 71$ & $1 / 576$ & 0,0054 & 994 & 8064 & 2582 \\
\hline 36 & 7 & $1 / 71$ & $1 / 288$ & 0,0046 & 497 & 2016 & 1513 \\
\hline 37 & 6 & $1 / 71$ & $1 / 288$ & 0,0046 & 426 & 1728 & 1297 \\
\hline 38 & 6 & $1 / 71$ & $1 / 24$ & 0,0116 & 426 & 144 & 517 \\
\hline 39 & 10 & $1 / 71$ & $1 / 48$ & 0,0205 & 710 & 480 & 487 \\
\hline 40 & 16 & $1 / 71$ & $1 / 48$ & 0,0339 & 1136 & 768 & 472 \\
\hline 41 & 7 & $1 / 71$ & $1 / 288$ & 0,0166 & 497 & 2016 & 421 \\
\hline 42 & 18 & $1 / 71$ & $1 / 288$ & 0,0461 & 1278 & 5184 & 390 \\
\hline 43 & 9 & $1 / 71$ & $1 / 288$ & 0,0226 & 639 & 2592 & 398 \\
\hline 44 & 6 & $1 / 71$ & $1 / 96$ & 0,0176 & 426 & 576 & 340 \\
\hline 45 & 17 & $1 / 71$ & $1 / 96$ & 0,0438 & 1207 & 1632 & 388 \\
\hline 46 & 10 & $1 / 71$ & $1 / 1152$ & 0,0150 & 710 & 11520 & 665 \\
\hline 47 & 13 & $1 / 71$ & $1 / 1152$ & 0,0150 & 923 & 14976 & 865 \\
\hline 48 & 6 & $1 / 71$ & $1 / 576$ & 0,0108 & 426 & 3456 & 555 \\
\hline 49 & 19 & $1 / 71$ & $1 / 288$ & 0,0230 & 1349 & 5472 & 826 \\
\hline 50 & 4 & $1 / 71$ & $1 / 288$ & 0,0071 & 284 & 1152 & 564 \\
\hline 51 & 12 & $1 / 71$ & $1 / 48$ & 0,0316 & 852 & 576 & 380 \\
\hline 52 & 10 & $1 / 71$ & $1 / 48$ & 0,0316 & 710 & 480 & 317 \\
\hline 53 & 7 & $1 / 71$ & $1 / 6$ & 0,0247 & 497 & 42 & 284 \\
\hline 54 & 18 & $1 / 71$ & $1 / 9$ & 0,0283 & 1278 & 162 & 635 \\
\hline 55 & 13 & $1 / 71$ & $1 / 72$ & 0,0130 & 923 & 936 & 1000 \\
\hline 56 & 8 & $1 / 71$ & $1 / 144$ & 0,0099 & 568 & 1152 & 810 \\
\hline 57 & 13 & $1 / 71$ & $1 / 144$ & 0,0222 & 923 & 1872 & 585 \\
\hline 58 & 6 & $1 / 71$ & $1 / 36$ & 0,0131 & 426 & 216 & 459 \\
\hline 59 & 14 & $1 / 71$ & $1 / 36$ & 0,0334 & 994 & 504 & 419 \\
\hline 60 & 11 & $1 / 71$ & $1 / 36$ & 0,0334 & 781 & 396 & 329 \\
\hline 61 & 14 & $1 / 71$ & $1 / 108$ & 0,0178 & 994 & 1512 & 788 \\
\hline 62 & 9 & $1 / 71$ & $1 / 108$ & 0,0107 & 639 & 972 & 838 \\
\hline 63 & 9 & $1 / 71$ & $1 / 432$ & 0,0078 & 639 & 3888 & 1156 \\
\hline 64 & 16 & $1 / 71$ & $1 / 432$ & 0,0129 & 1136 & 6912 & 1244 \\
\hline 65 & 14 & $1 / 71$ & $1 / 216$ & 0,0109 & 994 & 3024 & 1282 \\
\hline 66 & 11 & $1 / 71$ & $1 / 108$ & 0.0146 & 781 & 1188 & 753 \\
\hline 67 & 14 & $1 / 71$ & $1 / 108$ & 0,0228 & 994 & 1512 & 613 \\
\hline 68 & 8 & $1 / 71$ & $1 / 432$ & 0.0095 & 568 & 3456 & 841 \\
\hline 69 & 15 & $1 / 71$ & $1 / 432$ & 0,0157 & 1065 & 6480 & 954 \\
\hline 70 & 18 & $1 / 71$ & $1 / 216$ & 0.0133 & 1278 & 3888 & 1348 \\
\hline 71 & 5 & $1 / 71$ & $1 / 18$ & 0.0138 & 355 & 90 & 363 \\
\hline TOTAIS & 783 & 1 & 1 & 1.0000 & & & \\
\hline VARIÂNCIA & & & & & 66660,3380 & 1661055,1343 & 229335,7267 \\
\hline MÉDIA & & & & & 783,00 & 2790.85 & 1032.25 \\
\hline C.V. $(\%)$ & & & & & 32,97 & 46.18 & 46,39 \\
\hline
\end{tabular}


Tabela 86 - Mínimo de $7 \mathrm{~cm}$ de circunferência e 10 frutos/galho, árvore 18.

\begin{tabular}{|c|c|c|c|c|c|c|c|}
\hline $\begin{array}{c}\text { Número } \\
\text { do } \\
\text { galho }\end{array}$ & $\begin{array}{c}\text { Número } \\
\text { de } \\
\text { frutos }\end{array}$ & $\mathrm{PE}$ & PPN & PPA & $\begin{array}{l}\text { Estimativa } \\
\text { do } n^{\circ} \text { de } \\
\text { frutos (PE) }\end{array}$ & $\begin{array}{l}\text { Estimativa } \\
\text { do } n^{\circ} \text { de } \\
\text { frutos (PPN) }\end{array}$ & $\begin{array}{l}\text { Estimativa } \\
\text { do } n^{\circ} \text { de } \\
\text { frutos (PPA) }\end{array}$ \\
\hline 1 & 40 & 1.37 & $1 / 12$ & 0,0312 & 1480 & 480 & 1280 \\
\hline 2 & 34 & $1 / 37$ & $1 / 12$ & 0,0488 & 1258 & 408 & 697 \\
\hline 3 & 18 & $1 / 37$ & $1 / 48$ & 0,0241 & 666 & 864 & 747 \\
\hline 4 & 41 & $1 / 37$ & $1 / 48$ & 0,0455 & 1517 & 1968 & 900 \\
\hline 5 & 20 & $1 / 37$ & $1 / 48$ & 0,0182 & 740 & 960 & 1102 \\
\hline 6 & 13 & $1 / 37$ & $1 / 48$ & 0,0182 & 481 & 624 & 716 \\
\hline 7 & 46 & $1 / 37$ & $1 / 48$ & 0,0266 & 1702 & 2208 & 1731 \\
\hline 8 & 21 & $1 / 37$ & $1 / 96$ & 0,0139 & 777 & 2016 & 1506 \\
\hline 9 & 20 & $1 / 37$ & $1 / 192$ & 0,0177 & 740 & 3840 & 1127 \\
\hline 10 & 19 & $1 / 37$ & $1 / 192$ & 0,0114 & 703 & 3648 & 1673 \\
\hline 11 & 19 & $1 / 37$ & $1 / 72$ & 0,0134 & 703 & 1368 & 1422 \\
\hline 12 & 16 & $1 / 37$ & $1 / 144$ & 0,0102 & 592 & 2304 & 1566 \\
\hline 13 & 28 & $1 / 37$ & $1 / 144$ & 0,0160 & 1036 & 4032 & 1753 \\
\hline 14 & 14 & $1 / 37$ & $1 / 288$ & 0,0116 & 518 & 4032 & 1204 \\
\hline 15 & 24 & $1 / 37$ & $1 / 288$ & 0,0092 & 888 & 6912 & 2612 \\
\hline 16 & 15 & $1 / 37$ & $1 / 144$ & 0,0093 & 555 & 2160 & 1622 \\
\hline 17 & 10 & $1 / 37$ & $1 / 18$ & 0,0227 & 370 & 180 & 440 \\
\hline 18 & 16 & $1 / 37$ & $1 / 18$ & 0,0376 & 592 & 288 & 426 \\
\hline 19 & 41 & $1 / 37$ & $1 / 18$ & 0,1141 & 1517 & 738 & 359 \\
\hline 20 & 17 & $1 / 37$ & $1 / 36$ & 0,0485 & 629 & 612 & 350 \\
\hline 21 & 10 & $1 / 37$ & $1 / 144$ & 0,0252 & 370 & 1440 & 397 \\
\hline 22 & 13 & $1 / 37$ & $1 / 144$ & 0,0252 & 481 & 1872 & 517 \\
\hline 23 & 23 & $1 / 37$ & $1 / 72$ & 0,0283 & 851 & 1656 & 812 \\
\hline 24 & 12 & $1 / 37$ & $1 / 18$ & 0,0350 & 444 & 216 & 343 \\
\hline 25 & 10 & $1 / 37$ & $1 / 18$ & 0,0350 & 370 & 180 & 286 \\
\hline 26 & 18 & $1 / 37$ & $1 / 9$ & 0,0283 & 666 & 162 & 635 \\
\hline 27 & 13 & $1 / 37$ & $1 / 36$ & 0,0168 & 481 & 468 & 775 \\
\hline 28 & 23 & $1 / 37$ & $1 / 36$ & 0,0414 & 851 & 828 & 555 \\
\hline 29 & 14 & $1 / 37$ & $1 / 36$ & 0,0334 & 518 & 504 & 419 \\
\hline 30 & 11 & $1 / 37$ & $1 / 36$ & 0,0334 & 407 & 396 & 329 \\
\hline 31 & 23 & $1 / 37$ & $1 / 36$ & 0,0238 & 851 & 828 & 966 \\
\hline 32 & 25 & $1 / 37$ & $1 / 72$ & 0,0277 & 925 & 1800 & 903 \\
\hline 33 & 14 & $1 / 37$ & $1 / 72$ & 0,0146 & 518 & 1008 & 956 \\
\hline 34 & 11 & $1 / 37$ & $1 / 54$ & 0,0161 & 407 & 594 & 684 \\
\hline 35 & 14 & $1 / 37$ & $1 / 54$ & 0,0251 & 518 & 756 & 557 \\
\hline 36 & 23 & $1 / 37$ & $1 / 108$ & 0,0278 & 851 & 2484 & 828 \\
\hline 37 & 18 & $1 / 37$ & $1 / 108$ & 0,0147 & 666 & 1944 & 1224 \\
\hline TOTAIS & 747 & 1 & 1 & 1.0000 & & & \\
\hline \multicolumn{5}{|c|}{ VARIANCIA } & 123868.0000 & 680035,0000 & 201580,5072 \\
\hline \multicolumn{5}{|c|}{ MEDIA } & 747.00 & 1534.54 & 930.28 \\
\hline \multicolumn{5}{|l|}{$\overline{C . V .(\%)}$} & 47.11 & 53.74 & $\$ 8.26$ \\
\hline
\end{tabular}


Tabela 87 - Mínimo de $10 \mathrm{~cm}$ de circunferência e 20 frutos/galho, árvore 18.

\begin{tabular}{|c|c|c|c|c|c|c|c|}
\hline $\begin{array}{l}\text { Número } \\
\text { do } \\
\text { galho }\end{array}$ & $\begin{array}{c}\text { Número } \\
\text { de } \\
\text { frutos }\end{array}$ & $\mathrm{PE}$ & PPN & PPA & $\begin{array}{l}\text { Estimativa } \\
\text { do } n^{\circ} \text { de } \\
\text { frutos (PE) }\end{array}$ & $\begin{array}{c}\text { Estimativa } \\
\text { do } \mathrm{n}^{\circ} \text { de } \\
\text { frutr: }(\mathrm{PPN})\end{array}$ & $\begin{array}{l}\text { Estimativa } \\
\text { do } n^{\circ} \text { de } \\
\text { frutos }(\mathrm{PPA}) \\
\end{array}$ \\
\hline 1 & 85 & $1 / 16$ & $1 / 6$ & 0,0801 & 1360 & 510 & 1062 \\
\hline 2 & 62 & $1 / 16$ & $1 / 24$ & 0,0696 & 992 & 1488 & 891 \\
\hline 3 & 36 & $1 / 16$ & $1 / 24$ & 0,0363 & 576 & 864 & 991 \\
\hline 4 & 46 & $1 / 16$ & $1 / 48$ & 0.0266 & 736 & 2208 & 1731 \\
\hline 5 & 71 & $1 / 16$ & $1 / 48$ & 0,0430 & 1136 & 3408 & 1649 \\
\hline 6 & 63 & $1 / 16$ & $1 / 48$ & 0.0324 & 1008 & 3024 & 1944 \\
\hline 7 & 53 & $1 / 16$ & $1 / 48$ & 0,0372 & 848 & 2544 & 1425 \\
\hline 8 & 28 & $1 / 16$ & $1 / 9$ & 0,0603 & 448 & 252 & 464 \\
\hline 9 & 41 & $1 / 16$ & $1 / 18$ & 0,1141 & 656 & 738 & 359 \\
\hline 10 & 72 & $1 / 16$ & $1 / 18$ & 0.1272 & 1152 & 1296 & 566 \\
\hline 11 & 22 & $1 / 16$ & $1 / 9$ & 0,0700 & 352 & 198 & 314 \\
\hline 12 & 42 & $1 / 16$ & $1 / 12$ & 0,0642 & 672 & 504 & 655 \\
\hline 13 & 32 & $1 / 16$ & $1 / 12$ & 0,0737 & 512 & 384 & 434 \\
\hline 14 & 62 & $1 / 16$ & $1 / 12$ & 0,0730 & 992 & 744 & 850 \\
\hline 15 & 25 & $1 / 16$ & $1 / 24$ & 0,0343 & 400 & 600 & 728 \\
\hline 16 & 42 & $1 / 16$ & $1 / 24$ & 0,0580 & 672 & 1008 & 724 \\
\hline TOTAIS & 782 & 1 & 1 & 1.0000 & & & \\
\hline \multicolumn{5}{|c|}{ VARIÂNCIA } & 85421.0000 & 497649,0000 & 184093.6680 \\
\hline \multicolumn{5}{|c|}{ MÉDIA } & 782,00 & 1235.63 & 924,19 \\
\hline \multicolumn{5}{|l|}{ C.V. $(\%)$} & 37,37 & 57.09 & 46.43 \\
\hline
\end{tabular}

Tabela 88 - Mínimo de $15 \mathrm{~cm}$ de circunferência e 30 frutos/galho, árvore 18 .

\begin{tabular}{|c|c|c|c|c|c|c|c|}
\hline $\begin{array}{l}\text { Número } \\
\text { do } \\
\text { galho }\end{array}$ & $\begin{array}{l}\text { Número } \\
\text { de } \\
\text { frutos }\end{array}$ & PE & PPN & PPA & $\begin{array}{l}\text { Estimativa } \\
\text { do } n^{\circ} \text { de } \\
\text { frutos (PE) }\end{array}$ & $\begin{array}{c}\text { Estimativa } \\
\text { do } n^{\circ} \text { de } \\
\text { frutos (PPN) }\end{array}$ & $\begin{array}{l}\text { Estimativa } \\
\text { do } n^{\circ} \text { de } \\
\text { frutos (PPA) } \\
\end{array}$ \\
\hline 1 & 85 & $1 / 8$ & $1 / 6$ & 0,0801 & 680 & 510 & 1062 \\
\hline 2 & 98 & $1 / 8$ & $1 / 18$ & 0.0817 & 784 & 1764 & 1199 \\
\hline 3 & 117 & $1 / 8$ & $1 / 18$ & 0,0817 & 936 & 2106 & 1432 \\
\hline 4 & 116 & $1 / 8$ & $1 / 18$ & 0,0817 & 928 & 2088 & 1419 \\
\hline 5 & 181 & $1 / 8$ & $1 / 3$ & 0,3716 & 1448 & 543 & 487 \\
\hline 6 & 92 & $1 / 8$ & $1 / 6$ & 0,1378 & 736 & 552 & 667 \\
\hline 7 & 62 & $1 / 8$ & $1 / 12$ & 0,0730 & 496 & 744 & 850 \\
\hline 8 & 67 & $1 / 8$ & $1 / 12$ & 0.0924 & 536 & 804 & 725 \\
\hline TOTAIS & 818 & 1 & 1 & 1.0000 & & & \\
\hline VARIÁNCIA & & & & & 79157,0000 & 284796,0000 & 121690,7173 \\
\hline MÉDIA & & & & & 818.00 & 1138.88 & 980.22 \\
\hline C.V. $(\%)$ & & & & & 34.39 & 46.86 & 35.59 \\
\hline
\end{tabular}


Tabela 89 - Mínimo de $20 \mathrm{~cm}$ de circunferência e 40 frutos/galho, árvore 18.

\begin{tabular}{|c|c|c|c|c|c|c|c|}
\hline $\begin{array}{l}\text { Número } \\
\text { do } \\
\text { galho }\end{array}$ & $\begin{array}{c}\text { Número } \\
\text { de } \\
\text { frutos }\end{array}$ & PE & PPN & PPA & $\begin{array}{l}\text { Estimativa } \\
\text { do } n^{\circ} \text { de } \\
\text { frutos }(\text { ' } E)\end{array}$ & $\begin{array}{l}\text { Estimativa } \\
\text { do } n^{\circ} \text { de } \\
\text { frutos }(\mathrm{PPN})\end{array}$ & $\begin{array}{l}\text { Estimativa } \\
\text { do } n^{\circ} \text { de } \\
\text { frutos (PPA) }\end{array}$ \\
\hline 1 & 416 & $1 / 4$ & $1 / 3$ & 0,3252 & 1664 & 1248 & 1279 \\
\hline 2 & 181 & $1 / 4$ & $1 / 3$ & 0,3716 & 724 & 543 & 487 \\
\hline 3 & 92 & $1 / 4$ & $1 / 6$ & 0,1378 & 368 & 552 & 667 \\
\hline 4 & 134 & $1 / 4$ & $1 / 6$ & 0.1653 & 536 & 804 & 810 \\
\hline TOTAIS & 823 & 1 & 1 & 1.0000 & & & \\
\hline VARIÁNCIA & & & & & 251619,0000 & 98642.0000 & 112970,4302 \\
\hline MEDIA & & & & & 823,00 & 786,75 & 811,04 \\
\hline C.V. $(\%)$ & & & & & 60.95 & 39.92 & 41,44 \\
\hline
\end{tabular}

Tabela 90 - Árvore 19.

\begin{tabular}{|c|c|c|c|c|c|c|c|}
\hline $\begin{array}{c}\text { Número } \\
\text { do } \\
\text { galho }\end{array}$ & $\begin{array}{c}\text { Número } \\
\text { de } \\
\text { frutos }\end{array}$ & $P E$ & PPN & PPA & $\begin{array}{l}\text { Estimativa } \\
\text { do } n^{\circ} \text { de } \\
\text { frutos (PE) }\end{array}$ & $\begin{array}{l}\text { Estimativa } \\
\text { do } n^{\circ} \text { de } \\
\text { frutos (PPN) }\end{array}$ & $\begin{array}{l}\text { Estimativa } \\
\text { do } \mathrm{n}^{\circ} \mathrm{de} \\
\text { frutos (PPA) }\end{array}$ \\
\hline 1 & 7 & $1 / 50$ & $1 / 12$ & 0,0162 & 350 & 84 & 431 \\
\hline 2 & 14 & $1 / 50$ & $1 / 48$ & 0,0218 & 700 & 672 & 642 \\
\hline 3 & 16 & $1 / 50$ & $1 / 48$ & 0,0314 & 800 & 768 & 509 \\
\hline 4 & 6 & $1 / 50$ & $1 / 24$ & 0,0118 & 300 & 144 & 509 \\
\hline 5 & 7 & $1 / 50$ & $1 / 24$ & 0,0221 & 350 & 168 & 316 \\
\hline 6 & 8 & $1 / 50$ & $1 / 72$ & 0.0093 & 400 & 576 & 863 \\
\hline 7 & 6 & $1 / 50$ & $1 / 72$ & 0,0064 & 300 & 432 & 932 \\
\hline 8 & 4 & $1 / 50$ & $1 / 72$ & 0,0064 & 200 & 288 & 622 \\
\hline 9 & 12 & $1 / 50$ & $1 / 24$ & 0,0217 & 600 & 288 & 552 \\
\hline 10 & 19 & $1 / 50$ & $1 / 144$ & 0,0566 & 950 & 2736 & 336 \\
\hline 11 & 26 & $1 / 50$ & $1 / 144$ & 0,0196 & 1300 & 3744 & 1328 \\
\hline 12 & 5 & $1 / 50$ & $1 / 144$ & 0,0159 & 250 & 720 & 315 \\
\hline 13 & 14 & $1 / 50$ & $1 / 96$ & 0,0400 & 700 & 1344 & 350 \\
\hline 14 & 4 & $1 / 50$ & $1 / 96$ & 0.0100 & 200 & 384 & 400 \\
\hline 15 & 19 & $1 / 50$ & $1 / 18$ & 0,0212 & 950 & 342 & 895 \\
\hline 16 & 11 & $1 / 50$ & $1 / 18$ & 0,0172 & 550 & 198 & 640 \\
\hline 17 & 11 & $1 / 50$ & $1 / 36$ & 0,0147 & 550 & 396 & 746 \\
\hline 18 & 10 & $1 / 50$ & $1 / 72$ & 0,0147 & 500 & 720 & 678 \\
\hline 19 & 17 & $1 / 50$ & $1 / 144$ & 0,0238 & 850 & 2448 & 713 \\
\hline 20 & 12 & $1 / 50$ & $1 / 144$ & 0,0280 & 600 & 1728 & 429 \\
\hline 21 & 4 & $1 / 50$ & $1 / 18$ & 0,0090 & 200 & 72 & 443 \\
\hline 22 & 7 & $1 / 50$ & $1 / 27$ & 0,0118 & 350 & 189 & 595 \\
\hline 23 & 9 & $1 / 50$ & $1 / 54$ & 0,0326 & 450 & 486 & 276 \\
\hline 24 & 13 & $1 / 50$ & $1 / 108$ & 0.0195 & 650 & 1404 & 668 \\
\hline 25 & 18 & $1 / 50$ & $1 / 108$ & 0,0315 & 900 & 1944 & 571 \\
\hline 26 & 10 & $1 / 50$ & $1 / 108$ & 0.0189 & 500 & 1080 & 529 \\
\hline 27 & 16 & $1 / 50$ & $1 / 108$ & 0,0161 & 800 & 1728 & 993 \\
\hline 28 & 18 & $1 / 50$ & $1 / 108$ & 0,0234 & 900 & 1944 & 769 \\
\hline
\end{tabular}


Tabela 90 - Árvore 19 (continuação).

\begin{tabular}{|c|c|c|c|c|c|c|c|}
\hline $\begin{array}{l}\text { Número } \\
\text { do } \\
\text { galho }\end{array}$ & $\begin{array}{c}\text { Número } \\
\text { de } \\
\text { frutos }\end{array}$ & $\mathrm{PE}$ & PPN & PPA & $\begin{array}{c}\text { Estimativa } \\
\text { do } n^{\circ} \text { de } \\
\text { frutos (PE) }\end{array}$ & $\begin{array}{c}\text { Estimativa } \\
\text { do } n^{\circ} \text { de } \\
\text { frutos (PPN) }\end{array}$ & $\begin{array}{l}\text { Estimativa } \\
\text { do } n^{\circ} \text { de } \\
\text { frutos (PPA) } \\
\end{array}$ \\
\hline 29 & 23 & $1 / 50$ & $1 / 216$ & 0,0345 & 1150 & 4968 & 666 \\
\hline 30 & 23 & $1 / 50$ & $1 / 216$ & 0,0209 & 1150 & 4968 & 1101 \\
\hline 31 & 12 & $1 / 50$ & $1 / 24$ & 0,0321 & 600 & 288 & 374 \\
\hline 32 & 29 & $1 / 50$ & $1 / 24$ & 0,0448 & 1450 & 696 & 647 \\
\hline 33 & 11 & $1 / 50$ & $1 / 24$ & 0,0152 & 550 & 264 & 723 \\
\hline 34 & 16 & $1 / 50$ & $1 / 96$ & 0,0222 & 800 & 1536 & 720 \\
\hline 35 & 9 & $1 / 50$ & $1 / 96$ & 0,0163 & 450 & 864 & 552 \\
\hline 36 & 10 & $1 / 50$ & $1 / 192$ & 0,0096 & 500 & 1920 & 1038 \\
\hline 37 & 9 & $1 / 50$ & $1 / 192$ & 0,0096 & 450 & 1728 & 934 \\
\hline 38 & 10 & $1 / 50$ & $1 / 96$ & 0,0193 & 500 & 960 & 519 \\
\hline 39 & 17 & $1 / 50$ & $1 / 12$ & 0,0181 & 850 & 204 & 939 \\
\hline 40 & 21 & $1 / 50$ & $1 / 192$ & 0,0255 & 1050 & 4032 & 825 \\
\hline 41 & 16 & $1 / 50$ & $1 / 1536$ & 0,0126 & 800 & 24576 & 1273 \\
\hline 42 & 6 & $1 / 50$ & $1 / 1536$ & 0,0087 & 300 & 9216 & 688 \\
\hline 43 & 7 & $1 / 50$ & $1 / 768$ & 0,0213 & 350 & 5376 & 329 \\
\hline 44 & 10 & $1 / 50$ & $1 / 768$ & 0.0042 & 500 & 7680 & 2356 \\
\hline 45 & 15 & $1 / 50$ & $1 / 768$ & 0,0170 & 750 & 11520 & 884 \\
\hline 46 & 14 & $1 / 50$ & $1 / 96$ & 0,0149 & 700 & 1344 & 937 \\
\hline 47 & 8 & $1 / 50$ & $1 / 96$ & 0,0200 & 400 & 768 & 399 \\
\hline 48 & 26 & $1 / 50$ & $1 / 192$ & 0,0208 & 1300 & 4992 & 1253 \\
\hline 49 & 24 & $1 / 50$ & $1 / 192$ & 0,0149 & 1200 & 4608 & 1615 \\
\hline 50 & 11 & $1 / 50$ & $1 / 24$ & 0,0256 & 550 & 264 & 430 \\
\hline TOTAIS & 650 & 1 & 1 & 1,0000 & & & \\
\hline \multicolumn{5}{|c|}{ VARIÂNCIA } & 80017,5200 & 1397691,9167 & 93390,9327 \\
\hline \multicolumn{5}{|c|}{ MEDIA } & 650,00 & 2395,98 & 725,05 \\
\hline \multicolumn{5}{|l|}{ C.V. $(\%)$} & 43,52 & 49,34 & 42,15 \\
\hline
\end{tabular}


Tabela 91 - Mínimo de $7 \mathrm{~cm}$ de circunferência e 10 frutos/galho. árvore 19.

\begin{tabular}{|c|c|c|c|c|c|c|c|}
\hline $\begin{array}{l}\text { Número } \\
\text { do } \\
\text { galho }\end{array}$ & $\begin{array}{c}\text { Número } \\
\text { de } \\
\text { frutos }\end{array}$ & $\mathrm{PE}$ & PPN & PPA & $\begin{array}{l}\text { Estimativa } \\
\text { do } n^{\circ} \text { de } \\
\text { frutos (PE) }\end{array}$ & $\begin{array}{l}\text { Estimativa } \\
\text { do } n^{\circ} \text { de } \\
\text { frutos (PPN) }\end{array}$ & $\begin{array}{l}\text { Estimativa } \\
\text { do } n^{\circ} \text { de } \\
\text { frutos (PPA) }\end{array}$ \\
\hline 1 & 47 & $1 / 33$ & $1 / 6$ & 0,0812 & 1551 & 282 & 578 \\
\hline 2 & 25 & $1 / 33$ & $1 / 12$ & 0,0443 & 825 & 300 & 565 \\
\hline 3 & 12 & $1 / 33$ & $1 / 24$ & 0,0217 & 396 & 288 & 552 \\
\hline 4 & 19 & $1 / 33$ & $1 / 96$ & 0,0684 & 627 & 1824 & 278 \\
\hline 5 & 31 & $1 / 33$ & $1 / 96$ & 0,0237 & 1023 & 2976 & 1310 \\
\hline 6 & 18 & $1 / 33$ & $1 / 48$ & 0,0500 & 594 & 864 & 360 \\
\hline 7 & 19 & $1 / 33$ & $1 / 18$ & 0,0212 & 627 & 342 & 895 \\
\hline 8 & 11 & $1 / 33$ & $1 / 18$ & 0,0172 & 363 & 198 & 640 \\
\hline 9 & 11 & $1 / 33$ & $1 / 18$ & 0.0164 & 363 & 198 & 671 \\
\hline 10 & 10 & $1 / 33$ & $1 / 36$ & 0,0164 & 330 & 360 & 610 \\
\hline 11 & 17 & $1 / 33$ & $1 / 72$ & 0,0265 & 561 & 1224 & 642 \\
\hline 12 & 12 & $1 / 33$ & $1 / 72$ & 0,0311 & 396 & 864 & 386 \\
\hline 13 & 13 & $1 / 33$ & $1 / 36$ & 0,0338 & 429 & 468 & 384 \\
\hline 14 & 18 & $1 / 33$ & $1 / 36$ & 0,0548 & 594 & 648 & 328 \\
\hline 15 & 10 & $1 / 33$ & $1 / 72$ & 0,0200 & 330 & 720 & 499 \\
\hline 16 & 16 & $1 / 33$ & $1 / 72$ & 0,0171 & 528 & 1152 & 937 \\
\hline 17 & 18 & $1 / 33$ & $1 / 72$ & 0,0248 & 594 & 1296 & 726 \\
\hline 18 & 23 & $1 / 33$ & $1 / 144$ & 0,0366 & 759 & 3312 & 629 \\
\hline 19 & 23 & $1 / 33$ & $1 / 144$ & 0,0221 & 759 & 3312 & 1039 \\
\hline 20 & 12 & $1 / 33$ & $1 / 24$ & 0,0321 & 396 & 288 & 374 \\
\hline 21 & 29 & $1 / 33$ & $1 / 24$ & 0.0448 & 957 & 696 & 647 \\
\hline 22 & 11 & $1 / 33$ & $1 / 24$ & 0,0152 & 363 & 264 & 723 \\
\hline 23 & 25 & $1 / 33$ & $1 / 48$ & 0.0385 & 825 & 1200 & 649 \\
\hline 24 & 19 & $1 / 33$ & $1 / 96$ & 0,0193 & 627 & 1824 & 986 \\
\hline 25 & 10 & $1 / 33$ & $1 / 96$ & 0.0193 & 330 & 960 & 519 \\
\hline 26 & 17 & $1 / 33$ & $1 / 12$ & 0,0181 & 561 & 204 & 939 \\
\hline 27 & 21 & $1 / 33$ & $1 / 192$ & 0,0255 & 693 & 4032 & 825 \\
\hline 28 & 31 & $1 / 33$ & $1 / 384$ & 0,0426 & 1023 & 11904 & 728 \\
\hline 29 & 27 & $1 / 33$ & $1 / 384$ & 0,0212 & 891 & 10368 & 1272 \\
\hline 30 & 14 & $1 / 33$ & $1 / 96$ & 0,0149 & 462 & 1344 & 937 \\
\hline 31 & 26 & $1 / 33$ & $1 / 96$ & 0,0324 & 858 & 2496 & 802 \\
\hline 32 & 24 & $1 / 33$ & $1 / 96$ & 0,0232 & 792 & 2304 & 1034 \\
\hline 33 & 11 & $1 / 33$ & $1 / 24$ & 0.0256 & 363 & 264 & 430 \\
\hline TOTAIS & 630 & 1 & 1 & 1.0000 & & & \\
\hline \multicolumn{5}{|c|}{ VARIÂNCIA } & 49264,8788 & 990644,8333 & 64999,3198 \\
\hline \multicolumn{5}{|c|}{ MEDIA } & 630.00 & 1781.09 & 693,80 \\
\hline \multicolumn{5}{|l|}{ C.V. $(\%)$} & 35,23 & 55,88 & 36,75 \\
\hline
\end{tabular}


Tabela 92 - Mínimo de $10 \mathrm{~cm}$ de circunferência e 20 frutos/galho, árvore 19.

\begin{tabular}{|c|c|c|c|c|c|c|c|}
\hline $\begin{array}{l}\text { Número } \\
\text { do } \\
\text { galho }\end{array}$ & $\begin{array}{l}\text { Número } \\
\text { de } \\
\text { frutos }\end{array}$ & $\mathrm{PE}$ & PPN & PPA & $\begin{array}{l}\text { Estimativa } \\
\text { do } n^{\circ} \text { de } \\
\text { frutos }(\mathrm{PE})\end{array}$ & $\begin{array}{l}\text { Estimativa } \\
\text { do } n^{\circ} \text { de } \\
\text { frutos ( }(\mathrm{PN})\end{array}$ & $\begin{array}{l}\text { Estimativa } \\
\text { do } n^{\circ} \text { de } \\
\text { frutos (PPA) }\end{array}$ \\
\hline 1 & 47 & $1 / 17$ & $1 / 6$ & 0,0812 & 799 & 282 & 578 \\
\hline 2 & 25 & $1 / 17$ & $1 / 12$ & 0,0443 & 425 & 300 & 565 \\
\hline 3 & 80 & $1 / 17$ & $1 / 12$ & 0,1637 & 1360 & 960 & 489 \\
\hline 4 & 30 & $1 / 17$ & $1 / 9$ & 0,0384 & 510 & 270 & 781 \\
\hline 5 & 59 & $1 / 17$ & $1 / 9$ & 0,0904 & 1003 & 531 & 653 \\
\hline 6 & 47 & $1 / 17$ & $1 / 18$ & 0.0886 & 799 & 846 & 530 \\
\hline 7 & 26 & $1 / 17$ & $1 / 36$ & 0,0371 & 442 & 936 & 700 \\
\hline 8 & 23 & $1 / 17$ & $1 / 72$ & 0,0520 & 391 & 1656 & 442 \\
\hline 9 & 23 & $1 / 17$ & $1 / 72$ & 0,0315 & 391 & 1656 & 731 \\
\hline 10 & 46 & $1 / 17$ & $1 / 12$ & 0.0769 & 782 & 552 & 598 \\
\hline 11 & 25 & $1 / 17$ & $1 / 24$ & 0,0461 & 425 & 600 & 542 \\
\hline 12 & 29 & $1 / 17$ & $1 / 24$ & 0,0461 & 493 & 696 & 629 \\
\hline 13 & 21 & $1 / 17$ & $1 / 24$ & 0,0378 & 357 & 504 & 555 \\
\hline 14 & 31 & $1 / 17$ & $1 / 48$ & 0,0633 & 527 & 1488 & 490 \\
\hline 15 & 27 & $1 / 17$ & $1 / 48$ & 0,0315 & 459 & 1296 & 856 \\
\hline 16 & 26 & $1 / 17$ & $1 / 24$ & 0,0413 & 442 & 624 & 630 \\
\hline 17 & 24 & $1 / 17$ & $1 / 24$ & 0,0296 & 408 & 576 & 812 \\
\hline TOTAIS & 589 & 1 & 1 & 1.0000 & & & \\
\hline VARIÁNCIA & & & & & 76092,1176 & 94239,8333 & 16951,3336 \\
\hline MEDIA & & & & & 589.00 & 810.18 & 622.34 \\
\hline C.V. $(\%)$ & & & & & 46.83 & 37.89 & 20.92 \\
\hline
\end{tabular}

Tabela 93 - Mínimo de $15 \mathrm{~cm}$ de circunferência e 30 frutos/galho, árvore 19.

\begin{tabular}{|c|c|c|c|c|c|c|c|}
\hline $\begin{array}{l}\text { Número } \\
\text { do } \\
\text { galho }\end{array}$ & $\begin{array}{c}\text { Número } \\
\text { de } \\
\text { frutos }\end{array}$ & $P E$ & PPN & PPA & $\begin{array}{l}\text { Estimativa } \\
\text { do } n^{0} \text { de } \\
\text { frutos }(P E)\end{array}$ & $\begin{array}{l}\text { Estimativa } \\
\text { do } \mathrm{n}^{\circ} \mathrm{de} \\
\text { frutos (PPN) }\end{array}$ & $\begin{array}{l}\text { Estimativa } \\
\text { do } n^{\circ} \text { de } \\
\text { frutos (PPA) }\end{array}$ \\
\hline 1 & 47 & $1 / 10$ & $1 / 6$ & 0,0812 & 470 & 282 & 578 \\
\hline 2 & 105 & $1 / 10$ & $1 / 6$ & 0,2080 & 1050 & 630 & 505 \\
\hline 3 & 30 & $1 / 10$ & $1 / 9$ & 0,0384 & 300 & 270 & 781 \\
\hline 4 & 59 & $1 / 10$ & $1 / 9$ & 0.0904 & 590 & 531 & 653 \\
\hline 5 & 47 & $1 / 10$ & $1 / 18$ & 0,0886 & 470 & 846 & 530 \\
\hline 6 & 90 & $1 / 10$ & $1 / 18$ & 0,1206 & 900 & 1620 & 746 \\
\hline 7 & 46 & $1 / 10$ & $1 / 12$ & 0.0769 & 460 & 552 & 598 \\
\hline 8 & 70 & $1 / 10$ & $1 / 12$ & 0,0923 & 700 & 840 & 759 \\
\hline 9 & 93 & $1 / 10$ & $1 / 12$ & 0,1327 & 930 & 1116 & 701 \\
\hline 10 & 58 & $1 / 10$ & $1 / 12$ & 0.0708 & 580 & 696 & 819 \\
\hline TOTAIS & 645 & 1 & 1 & 1.0000 & & & \\
\hline VARIANCIA & & & & & 50168,1000 & 92021,8333 & 11529,3875 \\
\hline MÉDIA & & & & & 645.00 & 738,30 & 666.95 \\
\hline C.V. $(\%)$ & & & & & 34.73 & 41.09 & 16.10 \\
\hline
\end{tabular}


Tabela 94 - Minimo de $20 \mathrm{~cm}$ de circunferência e 40 frutos/galho, árvore 19.

\begin{tabular}{|c|c|c|c|c|c|c|c|}
\hline $\begin{array}{l}\text { Número } \\
\text { do } \\
\text { gall }\end{array}$ & $\begin{array}{c}\text { Número } \\
\text { de } \\
\text { frutos }\end{array}$ & PE & PPN & PPA & $\begin{array}{l}\text { Estimativa } \\
\text { do } n^{\circ} \text { de } \\
\text { frutos (PE) }\end{array}$ & $\begin{array}{l}\text { Estimativa } \\
\text { do } n^{\circ} \text { de } \\
\text { f itos (PPN) }\end{array}$ & $\begin{array}{l}\text { Estimativa } \\
\text { do } n^{\circ} \text { de } \\
\text { frutos (PPA) }\end{array}$ \\
\hline 1 & 47 & $1 / 9$ & $1 / 6$ & 0.0812 & 423 & 282 & 578 \\
\hline 2 & 105 & $1 / 9$ & $1 / 6$ & 0,2080 & 945 & 630 & 505 \\
\hline 3 & 89 & $1 / 9$ & $1 / 6$ & 0,1020 & 801 & 534 & 873 \\
\hline 4 & 47 & $1 / 9$ & $1 / 12$ & 0.1000 & 423 & 564 & 470 \\
\hline 5 & 90 & $1 / 9$ & $1 / 12$ & 0,1361 & 810 & 1080 & 661 \\
\hline 6 & 46 & $1 / 9$ & $1 / 12$ & 0,0769 & 414 & 552 & 598 \\
\hline 7 & 70 & $1 / 9$ & $1 / 12$ & 0,0923 & 630 & 840 & 759 \\
\hline 8 & 93 & $1 / 9$ & $1 / 12$ & 0,1327 & 837 & 1116 & 701 \\
\hline 9 & 58 & $1 / 9$ & $1 / 12$ & 0.0708 & 522 & 696 & 819 \\
\hline TOTAIS & 645 & 1 & 1 & 1.0000 & & & \\
\hline VARIÂNCIA & & & & & 32251,5556 & 38264,8333 & 16813,4939 \\
\hline MÉDIA & & & & & 645.00 & 699.33 & 662,65 \\
\hline C.V. $(\%)$ & & & & & 27.84 & 27.97 & 19.57 \\
\hline
\end{tabular}

Tabela 95 - Mínimo de $25 \mathrm{~cm}$ de circunferência e 50 frutos/galho, árvore 19.

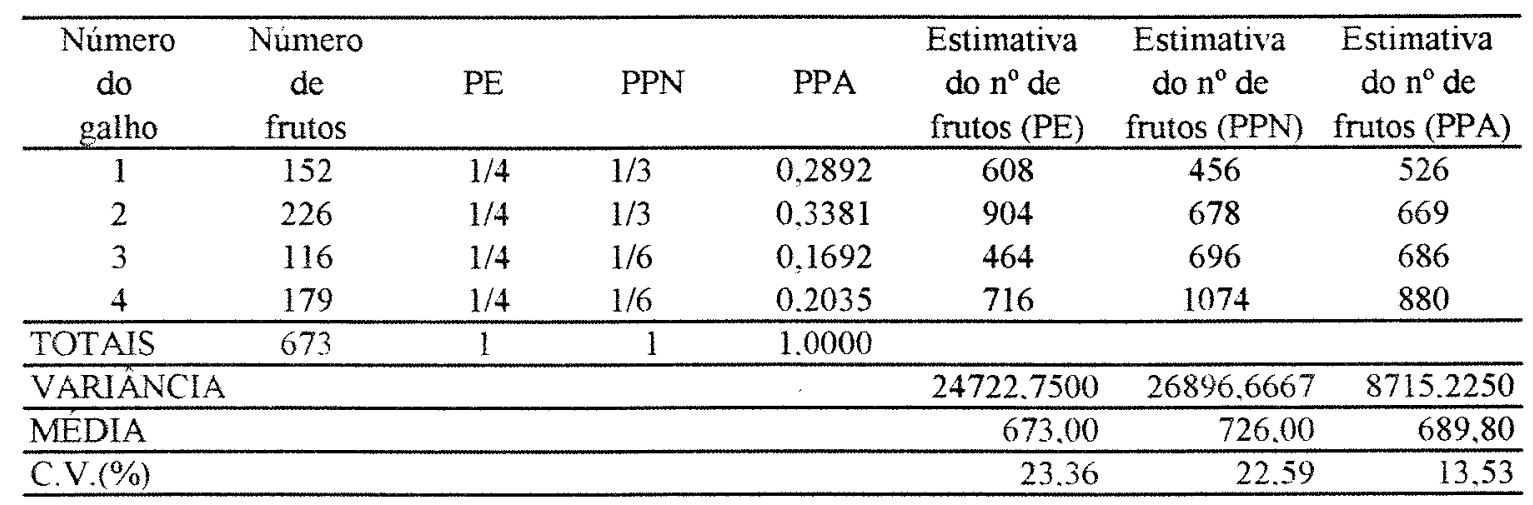


Tabela 96 - Arvore 20.

\begin{tabular}{|c|c|c|c|c|c|c|c|}
\hline $\begin{array}{l}\text { Numero } \\
\text { do } \\
\text { galho }\end{array}$ & $\begin{array}{l}\text { Número } \\
\text { de } \\
\text { frutos }\end{array}$ & $\mathrm{PE}$ & PPN & PPA & $\begin{array}{l}\text { Estimativa } \\
\text { do } n^{\circ} \text { de } \\
\text { frutos (PE) }\end{array}$ & $\begin{array}{l}\text { Estimativa } \\
\text { do } n^{\circ} \text { de } \\
\text { frutos (PPN) }\end{array}$ & $\begin{array}{l}\text { Estimativa } \\
\text { do } n^{\circ} \mathrm{de} \\
\text { frutos (PPA) }\end{array}$ \\
\hline 1 & 28 & $1 / 44$ & $1 / 9$ & 0,1135 & 1232 & 252 & 247 \\
\hline 2 & 19 & $1 / 44$ & $1 / 36$ & 0,0600 & 836 & 684 & 317 \\
\hline 3 & 9 & $1 / 44$ & $1 / 36$ & 0.0374 & 396 & 324 & 241 \\
\hline 4 & 14 & $1 / 44$ & $1 / 72$ & 0,0285 & 616 & 1008 & 492 \\
\hline 5 & 11 & $1 / 44$ & $1 / 72$ & 0,0198 & 484 & 792 & 586 \\
\hline 6 & 6 & $1 / 44$ & $1 / 36$ & 0.0271 & 264 & 216 & 221 \\
\hline 7 & 17 & $1 / 44$ & $1 / 18$ & 0.0533 & 748 & 306 & 319 \\
\hline 8 & 8 & $1 / 44$ & $1 / 144$ & 0,0085 & 352 & 1152 & 941 \\
\hline 9 & 7 & $1 / 44$ & $1 / 144$ & 0,0151 & 308 & 1008 & 463 \\
\hline 10 & 9 & $1 / 44$ & $1 / 72$ & 0,0281 & 396 & 648 & 320 \\
\hline 11 & 15 & $1 / 44$ & $1 / 36$ & 0,0409 & 660 & 540 & 367 \\
\hline 12 & 11 & $1 / 44$ & $1 / 6$ & 0.0423 & 484 & 66 & 260 \\
\hline 13 & 12 & $1 / 44$ & $1 / 6$ & 0,0423 & 528 & 72 & 284 \\
\hline 14 & 9 & $1 / 44$ & $1 / 12$ & 0,0390 & 396 & 108 & 231 \\
\hline 15 & 6 & $1 / 44$ & $1 / 24$ & 0,0152 & 264 & 144 & 394 \\
\hline 16 & 9 & $1 / 44$ & $1 / 24$ & 0,0238 & 396 & 216 & 379 \\
\hline 17 & 6 & $1 / 44$ & $1 / 96$ & 0,0220 & 264 & 576 & 273 \\
\hline 18 & 7 & $1 / 44$ & $1 / 96$ & 0,0141 & 308 & 672 & 498 \\
\hline 19 & 5 & $1 / 44$ & $1 / 48$ & 0,0125 & 220 & 240 & 401 \\
\hline 20 & 12 & $1 / 44$ & $1 / 192$ & 0,0217 & 528 & 2304 & 554 \\
\hline 21 & 7 & $1 / 44$ & $1 / 192$ & 0,0189 & 308 & 1344 & 371 \\
\hline 22 & 18 & $1 / 44$ & $1 / 96$ & 0,0445 & 792 & 1728 & 404 \\
\hline 23 & 8 & $1 / 44$ & $1 / 384$ & 0.0116 & 352 & 3072 & 690 \\
\hline 24 & 13 & $1 / 44$ & $1 / 384$ & 0.0140 & 572 & 4992 & 926 \\
\hline 25 & 11 & $1 / 44$ & $1 / 192$ & 0,0196 & 484 & 2112 & 560 \\
\hline 26 & 6 & $1 / 44$ & $1 / 192$ & 0,0080 & 264 & 1152 & 755 \\
\hline 27 & 18 & $1 / 44$ & $1 / 192$ & 0,0263 & 792 & 3456 & 685 \\
\hline 28 & 4 & $1 / 44$ & $1 / 48$ & 0.0049 & 176 & 192 & 810 \\
\hline 29 & 12 & $1 / 44$ & $1 / 96$ & 0.0248 & 528 & 1152 & 485 \\
\hline 30 & 10 & $1 / 44$ & $1 / 192$ & 0.0124 & 440 & 1920 & 808 \\
\hline 31 & 10 & $1 / 44$ & $1 / 192$ & 0.0124 & 440 & 1920 & 808 \\
\hline 32 & 13 & $1 / 44$ & $1 / 576$ & 0,0154 & 572 & 7488 & 845 \\
\hline 33 & 8 & $1 / 44$ & $1 / 1152$ & 0,0124 & 352 & 9216 & 644 \\
\hline 34 & 11 & $1 / 44$ & $1 / 1152$ & 0,0103 & 484 & 12672 & 1072 \\
\hline 35 & 7 & $1 / 44$ & $1 / 288$ & 0,0095 & 308 & 2016 & 736 \\
\hline 36 & 12 & $1 / 44$ & $1 / 576$ & 0,0087 & 528 & 6912 & 1380 \\
\hline 37 & 6 & $1 / 44$ & $1 / 576$ & 0.0069 & 264 & 3456 & 873 \\
\hline 38 & 11 & $1 / 44$ & $1 / 288$ & 0,0104 & 484 & 3168 & 1055 \\
\hline 39 & 14 & $1 / 44$ & $1 / 1152$ & 0,0066 & 616 & 16128 & 2113 \\
\hline 40 & 8 & $1 / 44$ & $1 / 1152$ & 0,0051 & 352 & 9216 & 1577 \\
\hline 41 & 14 & $1 / 44$ & $1 / 576$ & 0,0078 & 616 & 8064 & 1788 \\
\hline 42 & 8 & $1 / 44$ & $1 / 288$ & 0.0042 & 352 & 2304 & 1923 \\
\hline 43 & 6 & $1 / 44$ & $1 / 144$ & 0,0208 & 264 & 864 & 288 \\
\hline 44 & 6 & $1 / 44$ & $1 / 72$ & 0.0198 & 264 & 432 & 303 \\
\hline TOTAIS & 461 & 1 & 1 & 1.0000 & & & \\
\hline \multicolumn{5}{|c|}{ VARIANCIA } & 28629.272 & $108+143.5556$ & 91976.7227 \\
\hline \multicolumn{5}{|c|}{ MEDIA } & 461.0 & 2643.27 & 674.03 \\
\hline \multicolumn{5}{|l|}{$\mathrm{C} .(\%(\%)$} & 36.7 & 39.39 & 44.99 \\
\hline
\end{tabular}


Tabela 97 - Mínimo de $7 \mathrm{~cm}$ de circunferência e 10 frutos/galho, árvore 20 .

\begin{tabular}{|c|c|c|c|c|c|c|c|}
\hline $\begin{array}{l}\text { Número } \\
\text { do } \\
\text { galho }\end{array}$ & $\begin{array}{c}\text { Número } \\
\text { de } \\
\text { frutos }\end{array}$ & $\mathrm{PE}$ & PPN & PPA & $\begin{array}{l}\text { Estimativa } \\
\text { do } \mathrm{n}^{\circ} \text { de } \\
\text { frutos }(\mathrm{PE})\end{array}$ & $\begin{array}{l}\text { Estimativa } \\
\text { do } \mathrm{n}^{\circ} \text { de } \\
\text { frutos (PPN) }\end{array}$ & $\begin{array}{l}\text { Estimativa } \\
\text { do } n^{\circ} \text { de } \\
\text { frutos (PPA) }\end{array}$ \\
\hline 1 & 28 & $1 / 25$ & $1 / 9$ & 0,1135 & 854 & 448 & 976 \\
\hline 2 & 28 & $1 / 25$ & $1 / 18$ & 0,0973 & 488 & 512 & 430 \\
\hline 3 & 14 & $1 / 25$ & $1 / 36$ & 0,0445 & 350 & 504 & 315 \\
\hline 4 & 11 & $1 / 25$ & $1 / 36$ & 0,0309 & 275 & 396 & 356 \\
\hline 5 & 17 & $1 / 25$ & $1 / 18$ & 0,0533 & 425 & 306 & 319 \\
\hline 6 & 27 & $1 / 25$ & $1 / 36$ & 0,0517 & 675 & 972 & 522 \\
\hline 7 & 15 & $1 / 25$ & $1 / 36$ & 0,0409 & 375 & 540 & 367 \\
\hline 8 & 11 & $1 / 25$ & $1 / 6$ & 0,0423 & 275 & 66 & 260 \\
\hline 9 & 12 & $1 / 25$ & $1 / 6$ & 0,0423 & 300 & 72 & 284 \\
\hline 10 & 25 & $1 / 25$ & $1 / 6$ & 0,0780 & 625 & 150 & 321 \\
\hline 11 & 19 & $1 / 25$ & $1 / 24$ & 0,0485 & 475 & 456 & 392 \\
\hline 12 & 19 & $1 / 25$ & $1 / 96$ & 0,0406 & 475 & 1824 & 468 \\
\hline 13 & 18 & $1 / 25$ & $1 / 96$ & 0,0445 & 450 & 1728 & 404 \\
\hline 14 & 24 & $1 / 25$ & $1 / 192$ & 0,0256 & 600 & 4608 & 936 \\
\hline 15 & 11 & $1 / 25$ & $1 / 192$ & 0,0196 & 275 & 2112 & 560 \\
\hline 16 & 24 & $1 / 25$ & $1 / 96$ & 0,0342 & 600 & 2304 & 701 \\
\hline 17 & 12 & $1 / 25$ & $1 / 48$ & 0,0272 & 300 & 576 & 441 \\
\hline 18 & 10 & $1 / 25$ & $1 / 96$ & 0,0118 & 250 & 960 & 847 \\
\hline 19 & 10 & $1 / 25$ & $1 / 96$ & 0,0154 & 250 & 960 & 648 \\
\hline 20 & 13 & $1 / 25$ & $1 / 192$ & 0,0224 & 325 & 2496 & 579 \\
\hline 21 & 19 & $1 / 25$ & $1 / 192$ & 0,0331 & 475 & 3648 & 574 \\
\hline 22 & 18 & $1 / 25$ & $1 / 192$ & 0.0182 & 450 & 3456 & 990 \\
\hline 23 & 11 & $1 / 25$ & $1 / 192$ & 0,0122 & 275 & 2112 & 904 \\
\hline 24 & 22 & $1 / 25$ & $1 / 96$ & 0,0311 & 550 & 2112 & 707 \\
\hline 25 & 14 & $1 / 25$ & $1 / 96$ & 0,0208 & 350 & 1344 & 672 \\
\hline TOTAIS & 432 & 1 & 1 & 1.0000 & & & \\
\hline VARIÁNCIA & & & & & 25107,8400 & 430933.5556 & 33946,7312 \\
\hline MEDDIA & & & & & 429,68 & 1386.48 & 558,96 \\
\hline C.V. $(\%)$ & & & & & 36,88 & 47,35 & 32,96 \\
\hline
\end{tabular}


Tabela 98 - Mínimo de $10 \mathrm{~cm}$ de circunferência e 20 frutos/galho, árvore 20.

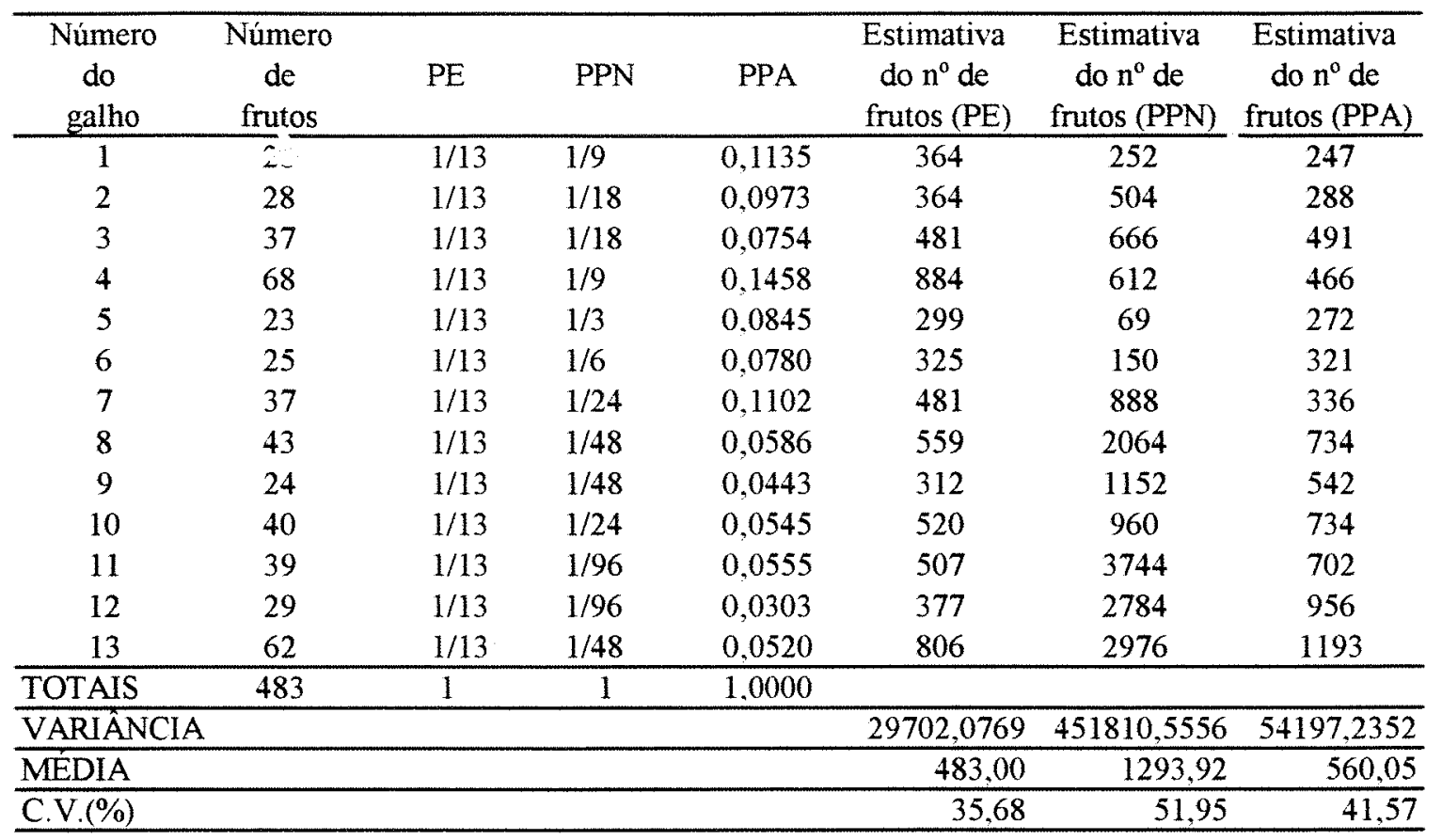

Tabela 99 - Mínimo de $15 \mathrm{~cm}$ de circunferência e 30 frutos/galho, árvore 20.

\begin{tabular}{|c|c|c|c|c|c|c|c|}
\hline $\begin{array}{l}\text { Número } \\
\text { do } \\
\text { galho }\end{array}$ & $\begin{array}{l}\text { Número } \\
\text { de } \\
\text { frutos }\end{array}$ & PE & PPN & PPA & $\begin{array}{l}\text { Estimativa } \\
\text { do } n^{\circ} \text { de } \\
\text { frutos }(\mathrm{PE})\end{array}$ & $\begin{array}{l}\text { Estimativa } \\
\text { do } \mathrm{n}^{\circ} \text { de } \\
\text { frutos (PPN) }\end{array}$ & $\begin{array}{l}\text { Estimativa } \\
\text { do } n^{\circ} \text { de } \\
\text { frutos (PPA) }\end{array}$ \\
\hline 1 & 28 & $1 / 9$ & $1 / 6$ & 0,1240 & 252 & 168 & 226 \\
\hline 2 & 65 & $1 / 9$ & $1 / 6$ & 0,1887 & 585 & 390 & 345 \\
\hline 3 & 68 & $1 / 9$ & $1 / 6$ & 0,1593 & 612 & 408 & 427 \\
\hline 4 & 37 & $1 / 9$ & $1 / 8$ & 0,1435 & 333 & 296 & 258 \\
\hline 5 & 67 & $1 / 9$ & $1 / 8$ & 0,1341 & 603 & 536 & 500 \\
\hline 6 & 40 & $1 / 9$ & $1 / 8$ & 0,0709 & 360 & 320 & 564 \\
\hline 7 & 39 & $1 / 9$ & $1 / 32$ & 0,0723 & 351 & 1248 & 539 \\
\hline 8 & 29 & $1 / 9$ & $1 / 32$ & 0,0395 & 261 & 928 & 734 \\
\hline 9 & 62 & $1 / 9$ & $1 / 16$ & 0.0677 & 558 & 992 & 916 \\
\hline TOTAIS & 435 & 1 & 1 & 1,0000 & & & \\
\hline VARIÂNCIA & & & & & 17992,5556 & 51221,3333 & 28229,0799 \\
\hline MEDDIA & & & & & 435.00 & 587.33 & 500,85 \\
\hline C.V. $(\%)$ & & & & & 30.84 & 38,53 & 33,55 \\
\hline
\end{tabular}


Tabela 100 - Mínimo de $20 \mathrm{~cm}$ de circunferência e 40 frutos/galho, árvore 20.

\begin{tabular}{|c|c|c|c|c|c|c|c|}
\hline $\begin{array}{l}\text { Número } \\
\text { do } \\
\text { galho }\end{array}$ & $\begin{array}{l}\text { Número } \\
\text { de } \\
\text { frutos }\end{array}$ & PE & PPN & PPA & $\begin{array}{l}\text { Estimativa } \\
\text { do } \mathrm{n}^{\circ} \mathrm{de} \\
\text { frutos }(\mathrm{PE})\end{array}$ & $\begin{array}{l}\text { Estimativa } \\
\text { do } n^{\circ} \text { de } \\
\text { frutos (PPN) }\end{array}$ & $\begin{array}{l}\text { Estimativa } \\
\text { do } \mathrm{n}^{\circ} \mathrm{de} \\
\text { frutos (PPA) }\end{array}$ \\
\hline 1 & 93 & $1 / 6$ & $1 / 4$ & 0,2559 & 558 & 372 & 363 \\
\hline 2 & 68 & $1 / 6$ & $1 / 4$ & 0.2161 & 408 & 272 & 315 \\
\hline 3 & 123 & $1 / 6$ & $1 / 4$ & 0.2775 & 738 & 492 & 443 \\
\hline 4 & 40 & $1 / 6$ & $1 / 8$ & 0,0709 & 240 & 320 & 564 \\
\hline 5 & 68 & $1 / 6$ & $1 / 16$ & 0,1119 & 408 & 1088 & 608 \\
\hline 6 & 62 & $1 / 6$ & $1 / 16$ & 0,0677 & 372 & 992 & 916 \\
\hline TOTAIS & 454 & 1 & 1 & 1.0000 & & & \\
\hline VARIÂNCIA & & & & & 26485,3333 & 53859.0000 & 21675,0444 \\
\hline MEDIA & & & & & 454,00 & 589.33 & 534,87 \\
\hline C.V. $(\%)$ & & & & & 35,85 & 39,38 & 27,53 \\
\hline
\end{tabular}

Tabela 101 - Mínimo de $25 \mathrm{~cm}$ de circunferência e 50 frutos/galho, árvore 20 .

\begin{tabular}{|c|c|c|c|c|c|c|c|}
\hline $\begin{array}{l}\text { Número } \\
\text { do } \\
\text { galho }\end{array}$ & $\begin{array}{l}\text { Número } \\
\text { de } \\
\text { frutos }\end{array}$ & $\mathrm{PE}$ & PPN & PPA & $\begin{array}{l}\text { Estimativa } \\
\text { do } n^{\circ} \text { de } \\
\text { frutos (PE) }\end{array}$ & $\begin{array}{l}\text { Estimativa } \\
\text { do } n^{\circ} \text { de } \\
\text { frutos (PPN) }\end{array}$ & $\begin{array}{l}\text { Estimativa } \\
\text { do } n^{\circ} \text { de } \\
\text { frutos (PPA) }\end{array}$ \\
\hline 1 & 93 & $1 / 4$ & $1 / 4$ & 0,2559 & 372 & 372 & 363 \\
\hline 2 & 68 & $1 / 4$ & $1 / 4$ & 0,2161 & 272 & 272 & 315 \\
\hline 3 & 123 & $1 / 4$ & $1 / 4$ & 0,2775 & 492 & 492 & 443 \\
\hline 4 & 170 & $1 / 4$ & $1 / 4$ & 0.2505 & 680 & 680 & 679 \\
\hline TOTAIS & 454 & 1 & 1 & 1,0000 & & & \\
\hline VARIÂNCIA & & & & & 21171,0000 & 21171,0000 & 16362,2790 \\
\hline MEDIA & & & & & 454,00 & 454,00 & 450,00 \\
\hline C.V. $(\%)$ & & & & & 32,05 & 32,05 & 28,43 \\
\hline
\end{tabular}

Tabela 102 - Árvore 21.

\begin{tabular}{ccclcccc}
\hline $\begin{array}{c}\text { Número } \\
\text { do } \\
\text { galho }\end{array}$ & $\begin{array}{c}\text { Número } \\
\text { de } \\
\text { frutos }\end{array}$ & PE & PPN & PPA & $\begin{array}{c}\text { Estimativa } \\
\text { do } n^{\circ} \text { de } \\
\text { frutos (PE) }\end{array}$ & $\begin{array}{c}\text { Estimativa } \\
\text { do } n^{\circ} \text { de } \\
\text { frutos (PPN) }\end{array}$ & $\begin{array}{c}\text { Estimativa } \\
\text { do } n^{\circ} \text { de } \\
\text { frutos (PPA) }\end{array}$ \\
\hline 1 & 13 & $1 / 57$ & $1 / 72$ & 0,0181 & 741 & 936 & 717 \\
2 & 21 & $1 / 57$ & $1 / 576$ & 0,0183 & 1197 & 12096 & 1147 \\
3 & 6 & $1 / 57$ & $1 / 576$ & 0,0046 & 342 & 3456 & 1311 \\
4 & 10 & $1 / 57$ & $1 / 288$ & 0,0121 & 570 & 2880 & 826 \\
5 & 6 & $1 / 57$ & $1 / 144$ & 0,0114 & 342 & 864 & 525 \\
6 & 16 & $1 / 57$ & $1 / 72$ & 0,0224 & 912 & 1152 & 714 \\
7 & 15 & $1 / 57$ & $1 / 72$ & 0,0224 & 855 & 1080 & 669 \\
8 & 7 & $1 / 57$ & $1 / 36$ & 0,0085 & 399 & 252 & 822 \\
9 & 6 & $1 / 57$ & $1 / 36$ & 0,0141 & 342 & 216 & 426 \\
10 & 4 & $1 / 57$ & $1 / 9$ & 0,0397 & 228 & 36 & 101 \\
11 & 52 & $1 / 57$ & $1 / 216$ & 0,0359 & 2964 & 11232 & 1447
\end{tabular}


Tabela 102 - Árvore 21 (continuação).

\begin{tabular}{|c|c|c|c|c|c|c|c|}
\hline $\begin{array}{l}\text { Número } \\
\text { do } \\
\text { galho } \\
\end{array}$ & $\begin{array}{c}\text { Número } \\
\text { de } \\
\text { frutos } \\
\end{array}$ & PE & PPN & PPA & $\begin{array}{l}\text { Estimativa } \\
\text { do } n^{\circ} \mathrm{de} \\
\text { frutos }(\mathrm{PE})\end{array}$ & $\begin{array}{c}\text { Estimativa } \\
\text { do } n^{\circ} \text { de } \\
\text { frutos (PPN) }\end{array}$ & $\begin{array}{l}\text { Estimativa } \\
\text { do } n^{\circ} \text { de } \\
\text { fruios (PPA) }\end{array}$ \\
\hline 12 & 15 & $1 / 57$ & $1 / 216$ & 0,0187 & 855 & 3240 & -800 \\
\hline 13 & 5 & $1 / 57$ & $1 / 108$ & 0.0197 & 285 & 540 & 254 \\
\hline 14 & 12 & $1 / 57$ & $1 / 54$ & 0,0360 & 684 & 648 & 333 \\
\hline 15 & 5 & $1 / 57$ & $1 / 108$ & 0,0091 & 285 & 540 & 550 \\
\hline 16 & 5 & $1 / 57$ & $1 / 108$ & 0,0142 & 285 & 540 & 352 \\
\hline 17 & 12 & $1 / 57$ & $1 / 216$ & 0,0133 & 684 & 2592 & 902 \\
\hline 18 & 6 & $1 / 57$ & $1 / 216$ & 0.0065 & 342 & 1296 & 921 \\
\hline 19 & 7 & $1 / 57$ & $1 / 648$ & 0,0096 & 399 & 4536 & 729 \\
\hline 20 & 31 & $1 / 57$ & $1 / 648$ & 0,0150 & 1767 & 20088 & 2068 \\
\hline 21 & 6 & $1 / 57$ & $1 / 648$ & 0,0121 & 342 & 3888 & 494 \\
\hline 22 & 18 & $1 / 57$ & $1 / 216$ & 0,0163 & 1026 & 3888 & 1103 \\
\hline 23 & 14 & $1 / 57$ & $1 / 54$ & 0,0279 & 798 & 756 & 502 \\
\hline 24 & 13 & $1 / 57$ & $1 / 54$ & 0,0315 & 741 & 702 & 413 \\
\hline 25 & 14 & $1 / 57$ & $1 / 96$ & 0,0158 & 798 & 1344 & 888 \\
\hline 26 & 12 & $1 / 57$ & $1 / 768$ & 0,0080 & 684 & 9216 & 1507 \\
\hline 27 & 16 & $1 / 57$ & $1 / 768$ & 0,0108 & 912 & 12288 & 1476 \\
\hline 28 & 8 & $1 / 57$ & $1 / 768$ & 0,0098 & 456 & 6144 & 812 \\
\hline 29 & 8 & $1 / 57$ & $1 / 768$ & 0,0060 & 456 & 6144 & 1343 \\
\hline 30 & 8 & $1 / 57$ & $1 / 192$ & 0,0110 & 456 & 1536 & 731 \\
\hline 31 & 12 & $1 / 57$ & $1 / 48$ & 0,0168 & 684 & 576 & 713 \\
\hline 32 & 8 & $1 / 57$ & $1 / 48$ & 0.0149 & 456 & 384 & 537 \\
\hline 33 & 14 & 157 & $1 / 96$ & 0,0219 & 798 & 1344 & 638 \\
\hline 34 & 8 & 857 & $1 / 768$ & 0,0065 & 456 & 6144 & 1232 \\
\hline 35 & 14 & 3.57 & $1 / 768$ & 0,0065 & 798 & 10752 & 2156 \\
\hline 36 & 15 & $1 / 57$ & $1 / 1152$ & 0,0063 & 855 & 17280 & 2373 \\
\hline 37 & 7 & $1 / 57$ & $1 / 1152$ & 0,0076 & 399 & 8064 & 915 \\
\hline 38 & 13 & $1 / 57$ & $1 / 1152$ & 0,0063 & 741 & 14976 & 2057 \\
\hline 39 & 12 & $1 / 57$ & $1 / 192$ & 0,0139 & 684 & 2304 & 861 \\
\hline 40 & 10 & $1 / 57$ & $1 / 24$ & 0.0452 & 570 & 240 & 221 \\
\hline 41 & 8 & $1 / 57$ & $1 / 24$ & 0.0289 & 456 & 192 & 277 \\
\hline 42 & 12 & $1 / 57$ & $1 / 48$ & 0,0255 & 684 & 576 & 471 \\
\hline 43 & 12 & $1 / 57$ & $1 / 48$ & 0,0122 & 684 & 576 & 983 \\
\hline 44 & 15 & $1 / 57$ & $1 / 96$ & 0,0193 & 855 & 1440 & 777 \\
\hline 45 & 19 & $1 / 57$ & $1 / 96$ & 0.0193 & 1083 & 1824 & 984 \\
\hline 46 & 16 & $1 / 57$ & $1 / 144$ & 0,0156 & 912 & 2304 & 1025 \\
\hline 47 & 12 & $1 / 57$ & $1 / 576$ & 0.0067 & 684 & 6912 & 1778 \\
\hline 48 & 9 & $1 / 57$ & $1 / 576$ & 0,0067 & 513 & 5184 & 1333 \\
\hline 49 & 17 & $1 / 57$ & $1 / 288$ & 0.0171 & 969 & 4896 & 995 \\
\hline 50 & 9 & $1 / 57$ & $1 / 288$ & 0,0099 & 513 & 2592 & 907 \\
\hline
\end{tabular}


Tabela 102 - Árvore 21 (continuação).

\begin{tabular}{|c|c|c|c|c|c|c|c|}
\hline $\begin{array}{c}\text { Número } \\
\text { do } \\
\text { galho }\end{array}$ & $\begin{array}{l}\text { Número } \\
\text { de } \\
\text { frutos }\end{array}$ & PE & PPN & PPA & $\begin{array}{l}\text { Estimativa } \\
\text { do } n^{\circ} \text { de } \\
\text { frutos (PE) }\end{array}$ & $\begin{array}{l}\text { Estimativa } \\
\text { do } n^{\circ} \mathrm{de} \\
\text { frutos (PPN) }\end{array}$ & $\begin{array}{l}\text { Estimativa } \\
\text { do } n^{\circ} \text { de } \\
\text { frutos (PPA) }\end{array}$ \\
\hline 51 & 11 & $1 / 57$ & $1 / 288$ & 0,0126 & 627 & 3168 & 876 \\
\hline 52 & 11 & $1 / 57$ & $1 / 12$ & 0,0272 & 627 & 132 & 404 \\
\hline 53 & 7 & $1 / 57$ & $1 / 12$ & 0,0305 & 399 & 84 & 230 \\
\hline 54 & 6 & $1 / 57$ & $1 / 12$ & 0,0305 & 342 & 72 & 197 \\
\hline 55 & 11 & $1 / 57$ & $1 / 24$ & 0,0228 & 627 & 264 & 483 \\
\hline 56 & 14 & $1 / 57$ & $1 / 24$ & 0.0431 & 798 & 336 & 325 \\
\hline 57 & 8 & $1 / 57$ & $1 / 12$ & 0,0272 & 456 & 96 & 294 \\
\hline TOTAIS & 681 & 1 & 1 & 1,0000 & & & \\
\hline \multicolumn{5}{|c|}{ VARIANCIA } & \multicolumn{3}{|c|}{$170311,00002949190,0000214610,5828$} \\
\hline \multicolumn{5}{|c|}{ MEDIA } & 681,00 & 3628,74 & 858,37 \\
\hline \multicolumn{5}{|l|}{ C.V. $(\%)$} & 60,60 & 47,33 & 53,97 \\
\hline
\end{tabular}

Tabela 103 - Mínimo de $7 \mathrm{~cm}$ de circunferência e 10 frutos/galho, árvore 21 .

\begin{tabular}{|c|c|c|c|c|c|c|c|}
\hline $\begin{array}{l}\text { Número } \\
\text { do } \\
\text { galho }\end{array}$ & $\begin{array}{l}\text { Número } \\
\text { de } \\
\text { frutos }\end{array}$ & $P E$ & PPN & PPA & $\begin{array}{l}\text { Estimativa } \\
\text { do } n^{0} \text { de } \\
\text { frutos }(\mathrm{PE})\end{array}$ & $\begin{array}{l}\text { Estimativa } \\
\text { do } n^{\circ} \text { de } \\
\text { frutos (PPN) }\end{array}$ & $\begin{array}{l}\text { Estimativa } \\
\text { do } n^{\circ} \text { de } \\
\text { frutos (PPA) }\end{array}$ \\
\hline 1 & 13 & $1 / 37$ & $1 / 48$ & 0,0199 & 481 & 624 & 652 \\
\hline 2 & 27 & $1 / 37$ & $1 / 96$ & 0,0334 & 999 & 2592 & 809 \\
\hline 3 & 10 & $1 / 37$ & $1 / 96$ & 0,0177 & 370 & 960 & 566 \\
\hline 4 & 16 & $1 / 37$ & $1 / 48$ & 0,0247 & 592 & 768 & 649 \\
\hline 5 & 15 & $1 / 37$ & $1 / 48$ & 0,0247 & 555 & 720 & 608 \\
\hline 6 & 13 & $1 / 37$ & $1 / 12$ & 0,0249 & 481 & 156 & 523 \\
\hline 7 & 52 & $1 / 37$ & $1 / 72$ & 0,0538 & 1924 & 3744 & 967 \\
\hline 8 & 15 & $1 / 37$ & $1 / 72$ & 0,0280 & 555 & 1080 & 535 \\
\hline 9 & 12 & $1 / 37$ & $1 / 36$ & 0,0396 & 444 & 432 & 303 \\
\hline 10 & 10 & $1 / 37$ & $1 / 36$ & 0,0256 & 370 & 360 & 391 \\
\hline 11 & 18 & $1 / 37$ & $1 / 72$ & 0,0218 & 666 & 1296 & 826 \\
\hline 12 & 45 & $1 / 37$ & $1 / 144$ & 0,0404 & 1665 & 6480 & 1114 \\
\hline 13 & 18 & $1 / 37$ & $1 / 144$ & 0,0180 & 666 & 2592 & 1003 \\
\hline 14 & 14 & $1 / 37$ & $1 / 36$ & 0,0307 & 518 & 504 & 457 \\
\hline 15 & 13 & $1 / 37$ & $1 / 36$ & 0,0346 & 481 & 468 & 376 \\
\hline 16 & 14 & $1 / 37$ & $1 / 96$ & 0,0158 & 518 & 1344 & 888 \\
\hline 17 & 32 & $1 / 37$ & $1 / 192$ & 0,0248 & 1184 & 6144 & 1293 \\
\hline 18 & 16 & $1 / 37$ & $1 / 192$ & 0,0208 & 592 & 3072 & 769 \\
\hline 19 & 12 & $1 / 37$ & $1 / 48$ & 0,0168 & 444 & 576 & 713 \\
\hline 20 & 14 & $1 / 37$ & $1 / 48$ & 0,0267 & 518 & 672 & 525 \\
\hline 21 & 23 & $1 / 37$ & $1 / 192$ & 0,0158 & 851 & 4416 & 1457 \\
\hline 22 & 15 & $1 / 37$ & $1 / 384$ & 0,0123 & 555 & 5760 & 1217 \\
\hline 23 & 20 & $1 / 37$ & $1 / 384$ & 0,0123 & 740 & 7680 & 1622 \\
\hline 24 & 12 & $1 / 37$ & $1 / 96$ & 0,0169 & 444 & 1152 & 709 \\
\hline 25 & 22 & $1 / 37$ & $1 / 12$ & 0,0741 & 814 & 264 & 297 \\
\hline
\end{tabular}


Tabela 103 - Minimo de $7 \mathrm{~cm}$ de circunferência e 10 frutos/galho, árvore 21 (continuação).

\begin{tabular}{|c|c|c|c|c|c|c|c|}
\hline $\begin{array}{l}\text { Número } \\
\text { do } \\
\text { galho } \\
\end{array}$ & $\begin{array}{c}\text { Número } \\
\text { de } \\
\text { frutos }\end{array}$ & $\mathrm{PE}$ & PPN & PPA & $\begin{array}{l}\text { Estimativa } \\
\text { do } n^{\circ} \text { de } \\
\text { frutos (PE) }\end{array}$ & $\begin{array}{c}\text { Estimativa } \\
\text { do } \mathrm{n}^{\circ} \text { de } \\
\text { frutos (PPN) }\end{array}$ & $\begin{array}{l}\text { Estimativa } \\
\text { do } n^{\circ} \text { de } \\
\text { frutos (PPA) } \\
\end{array}$ \\
\hline 26 & 12 & $1 / 37$ & $1 / 48$ & 0,0255 & 444 & 576 & 471 \\
\hline 27 & 12 & $1 / 37$ & $1 / 48$ & 0,0122 & 444 & 576 & 983 \\
\hline 28 & 15 & $1 / 37$ & $1 / 96$ & 0,0193 & 555 & 1440 & 777 \\
\hline 29 & 19 & $1 / 37$ & $1 / 96$ & 0,0193 & 703 & 1824 & 984 \\
\hline 30 & 16 & $1 / 37$ & $1 / 144$ & 0,0156 & 592 & 2304 & 1025 \\
\hline 31 & 21 & $1 / 37$ & $1 / 288$ & 0,0135 & 777 & 6048 & 1556 \\
\hline 32 & 17 & $1 / 37$ & $1 / 288$ & 0,0171 & 629 & 4896 & 995 \\
\hline 33 & 20 & $1 / 37$ & $1 / 144$ & 0,0225 & 740 & 2880 & 890 \\
\hline 34 & 11 & $1 / 37$ & $1 / 12$ & 0,0272 & 407 & 132 & 404 \\
\hline 35 & 13 & $1 / 37$ & $1 / 6$ & 0,0610 & 481 & 78 & 213 \\
\hline 36 & 11 & $1 / 37$ & $1 / 12$ & 0,0322 & 407 & 132 & 342 \\
\hline 37 & 14 & $1 / 37$ & $1 / 12$ & 0,0608 & 518 & 168 & 230 \\
\hline TOTAIS & 652 & 1 & 1 & 1.0000 & & & \\
\hline \multicolumn{5}{|c|}{ VARIÂNCIA } & 112628,0000 & 1312998.0000 & 132131,7188 \\
\hline \multicolumn{5}{|c|}{ MEDIA } & 652.00 & 2024,59 & 760,46 \\
\hline \multicolumn{5}{|l|}{ C.V. $(\%)$} & 51,47 & 56,60 & 47,80 \\
\hline
\end{tabular}

Tabela 104 - Mínimo de $10 \mathrm{~cm}$ de circunferência e 20 frutos/galho, árvore 21 .

\begin{tabular}{|c|c|c|c|c|c|c|c|}
\hline $\begin{array}{l}\text { Número } \\
\text { do } \\
\text { galho }\end{array}$ & $\begin{array}{c}\text { Número } \\
\text { de } \\
\text { frutos }\end{array}$ & $\mathrm{PE}$ & PPN & PPA & $\begin{array}{l}\text { Estimativa } \\
\text { do } n^{\circ} \text { de } \\
\text { frutos (PE) }\end{array}$ & $\begin{array}{l}\text { Estimativa } \\
\text { do } n^{\circ} \text { de } \\
\text { frutos (PPN) }\end{array}$ & $\begin{array}{l}\text { Estimativa } \\
\text { do } n^{\circ} \text { de } \\
\text { frutos (PPA) }\end{array}$ \\
\hline 1 & 56 & $1 / 14$ & $1 / 12$ & 0,0857 & 784 & 672 & 654 \\
\hline 2 & 42 & $1 / 14$ & $1 / 12$ & 0,0595 & 588 & 504 & 706 \\
\hline 3 & 84 & $1 / 14$ & $1 / 18$ & 0.1214 & 1176 & 1512 & 692 \\
\hline 4 & 99 & $1 / 14$ & $1 / 18$ & 0,1057 & 1386 & 1782 & 936 \\
\hline 5 & 27 & $1 / 14$ & $1 / 18$ & 0,0653 & 378 & 486 & 414 \\
\hline 6 & 88 & $1 / 14$ & $1 / 24$ & 0,0782 & 1232 & 2112 & 1126 \\
\hline 7 & 23 & $1 / 14$ & $1 / 48$ & 0,0328 & 322 & 1104 & 701 \\
\hline 8 & 35 & $1 / 14$ & $1 / 48$ & 0,0512 & 490 & 1680 & 683 \\
\hline 9 & 22 & $1 / 14$ & $1 / 12$ & 0,0741 & 308 & 264 & 297 \\
\hline 10 & 24 & $1 / 14$ & $1 / 12$ & 0,0447 & 336 & 288 & 536 \\
\hline 11 & 34 & $1 / 14$ & $1 / 24$ & 0,0459 & 476 & 816 & 741 \\
\hline 12 & 54 & $1 / 14$ & $1 / 48$ & 0,0470 & 756 & 2592 & 1149 \\
\hline 13 & 20 & $1 / 14$ & $1 / 48$ & 0,0345 & 280 & 960 & 579 \\
\hline 14 & 58 & $1 / 14$ & $1 / 3$ & 0,1540 & 812 & 174 & 377 \\
\hline TOTAIS & 666 & 1 & 1 & 1.0000 & & & \\
\hline \multicolumn{5}{|c|}{ VARIÂNCIA } & 134240,0000 & 417040,0000 & 69332.5197 \\
\hline \multicolumn{5}{|c|}{ MEDIA } & 666.00 & 1067,57 & 685,04 \\
\hline \multicolumn{5}{|l|}{ C.V. $(\%)$} & 55.01 & 60,49 & 38,44 \\
\hline
\end{tabular}


Tabela 105 - Mínimo de $15 \mathrm{~cm}$ de circunferência e 30 frutos/galho, árvore 21 .

\begin{tabular}{|c|c|c|c|c|c|c|c|}
\hline $\begin{array}{l}\text { Número } \\
\text { do } \\
\text { gallo }\end{array}$ & $\begin{array}{c}\text { Numero } \\
\text { de } \\
\text { frutos }\end{array}$ & $P E$ & PPN & PPA & $\begin{array}{l}\text { Estimativa } \\
\text { do } n^{\circ} \text { de } \\
\text { frutos }(\mathrm{PE})\end{array}$ & $\begin{array}{l}\text { Estimativa } \\
\text { do } n^{\circ} \text { de } \\
\text { frutos (PPN) }\end{array}$ & $\begin{array}{l}\text { Estimativa } \\
\text { do } n^{\circ} \text { de } \\
\text { frutos }(\mathrm{PPA})\end{array}$ \\
\hline 1 & 56 & $1 / 10$ & $1 / 12$ & 0,0857 & 560 & 672 & 654 \\
\hline 2 & 42 & $1 / 10$ & $1 / 12$ & 0.0595 & 420 & 504 & 706 \\
\hline 3 & 8.4 & $1 / 10$ & $1 / 18$ & 0,1214 & 840 & 1512 & 692 \\
\hline 4 & 99 & $1 / 10$ & $1 / 18$ & 0,1057 & 990 & 1782 & 936 \\
\hline 5 & 27 & $1 / 10$ & $1 / 18$ & 0,0653 & 270 & 486 & 414 \\
\hline 6 & 88 & $1 / 10$ & $1 / 12$ & 0,1138 & 880 & 1056 & 773 \\
\hline 7 & 95 & $1 / 10$ & $1 / 12$ & 0,1224 & 950 & 1140 & 776 \\
\hline 8 & 34 & $1 / 10$ & $1 / 12$ & 0,0620 & 340 & 408 & 549 \\
\hline 9 & 77 & $1 / 10$ & $1 / 12$ & 0,1102 & 770 & 924 & 699 \\
\hline 10 & 58 & $1 / 10$ & $1 / 3$ & 0.1540 & 580 & 174 & 377 \\
\hline TOTAIS & 660 & 1 & 1 & 1.0000 & & & \\
\hline VARIANNCIA & & & & & 67840.0000 & 242488.0000 & 35085.5026 \\
\hline MEDIA & & & & & 660,00 & 865.80 & 657.45 \\
\hline C.V. $(\%)$ & & & & & 39.46 & 56.88 & 28.49 \\
\hline
\end{tabular}

Tabela 106 - Minimo de $20 \mathrm{~cm}$ de circunferência e 40 frutos/galho, árvore 21.

\begin{tabular}{|c|c|c|c|c|c|c|c|}
\hline $\begin{array}{l}\text { Número } \\
\text { do } \\
\text { galho }\end{array}$ & $\begin{array}{c}\text { Numero } \\
\text { de } \\
\text { frutos }\end{array}$ & $\mathrm{PE}$ & PPN & PPA & $\begin{array}{l}\text { Estimativa } \\
\text { do } n^{\circ} \text { de } \\
\text { frutos (PE) }\end{array}$ & $\begin{array}{l}\text { Estimativa } \\
\text { do } n^{\circ} \text { de } \\
\text { frutos (PPN) }\end{array}$ & $\begin{array}{l}\text { Estimativa } \\
\text { do } n^{\circ} \text { de } \\
\text { frutos (PPA) }\end{array}$ \\
\hline $\mathrm{N}^{\circ}$ do galho & $\mathrm{N}^{\circ}$ de frutos & $\mathrm{PE}$ & PPN & PPA & $\begin{array}{c}\text { Estimativa } X \\
\text { (PE) }\end{array}$ & $\begin{array}{l}\text { Estintativa } \mathrm{X} \\
\text { (PPN) }\end{array}$ & $\begin{array}{c}\text { Estimativa } \mathrm{X} \\
\text { (PP } \mathrm{A})\end{array}$ \\
\hline l & 120 & $1 / 7$ & $1 / 6$ & 0.1452 & 840 & 720 & 827 \\
\hline 2 & 84 & $1 / 7$ & $1 / 12$ & 0,1563 & 588 & 1008 & 537 \\
\hline 3 & 126 & $1 / 7$ & $1 / 12$ & 0.1361 & 882 & 1512 & 925 \\
\hline 4 & 88 & $1 / 7$ & $1 / 12$ & 0.1138 & 616 & 1056 & 773 \\
\hline 5 & 95 & $1 / 7$ & $1 / 12$ & 0.1224 & 665 & 1140 & 776 \\
\hline 6 & 147 & $1 / 7$ & $1 / 6$ & 0.1722 & 1029 & 882 & 854 \\
\hline 7 & 58 & $1 / 7$ & $1 / 3$ & 0.1540 & 406 & 174 & 377 \\
\hline TOTAIS & 718 & 1 & 1 & 1.0000 & & & \\
\hline VARIANCI & & & & & 38478.0000 & 187518,0000 & 35030.4274 \\
\hline MEDIA & & & & & 718.00 & 927.43 & 724.17 \\
\hline C.V. $(\%)$ & & & & & 27.32 & 46.69 & 25.85 \\
\hline
\end{tabular}

